\title{
Innovation in car mobility : coevolution of demand and supply under sustainability pressures
}

Citation for published version (APA):

Dijk, M. (2010). Innovation in car mobility : coevolution of demand and supply under sustainability pressures. [Doctoral Thesis, Maastricht University]. Universitaire Pers Maastricht. https://doi.org/10.26481/dis.20100923md

Document status and date:

Published: 01/01/2010

DOI:

10.26481/dis.20100923md

Document Version:

Publisher's PDF, also known as Version of record

\section{Please check the document version of this publication:}

- A submitted manuscript is the version of the article upon submission and before peer-review. There can be important differences between the submitted version and the official published version of record.

People interested in the research are advised to contact the author for the final version of the publication, or visit the DOI to the publisher's website.

- The final author version and the galley proof are versions of the publication after peer review.

- The final published version features the final layout of the paper including the volume, issue and page numbers.

Link to publication

\footnotetext{
General rights rights.

- You may freely distribute the URL identifying the publication in the public portal. please follow below link for the End User Agreement:

www.umlib.nl/taverne-license

Take down policy

If you believe that this document breaches copyright please contact us at:

repository@maastrichtuniversity.nl

providing details and we will investigate your claim.
}

Copyright and moral rights for the publications made accessible in the public portal are retained by the authors and/or other copyright owners and it is a condition of accessing publications that users recognise and abide by the legal requirements associated with these

- Users may download and print one copy of any publication from the public portal for the purpose of private study or research.

- You may not further distribute the material or use it for any profit-making activity or commercial gain

If the publication is distributed under the terms of Article $25 \mathrm{fa}$ of the Dutch Copyright Act, indicated by the "Taverne" license above, 


\section{Innovation in Car Mobility}

Co-evolution of demand and supply under sustainability pressures

Marc Dijk 
This PhD research was carried out at the International Centre for Integrated assessment and Sustainable development (ICIS), Maastricht University

(C) Copyright Marc Dijk, Maastricht 2010

Druk: Datawyse / Universitaire Pers Maastricht

Omslag advies: Paulien Dijk

ISBN 9789052789705 


\section{Innovation in Car Mobility}

Co-evolution of demand and supply under sustainability pressures

PROEFSCHRIFT

ter verkrijging van de graad van doctor

aan de Universiteit Maastricht

op gezag van de Rector Magnificus,

Prof. mr. G.P.M.F. Mols

volgens het besluit van het College van Decanen,

in het openbaar te verdedigen

op donderdag 23 september 2010 om 16:00 uur

door Marc Martijn Dijk

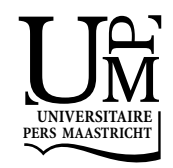




\section{Promotor}

Prof. dr. R. Kemp

\section{Beoordelingscommissie}

Prof. dr. P. Martens (voorzitter)

Prof. dr. ir. W. Bijker

Prof. dr. K. Frenken (Technische Universiteit Eindhoven)

Prof. dr. R. Madlener (Rheinisch-Westfaelische Technische Hochschule Aachen)

\section{This PhD research was supported by:}

The Dutch Knowledge Network on System Innovation (KSI). 


\section{Contents}

1 Introduction and research questions ...................................10

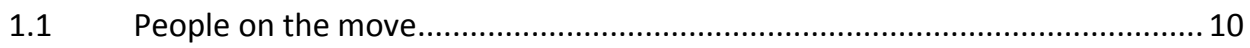

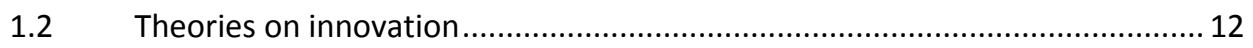

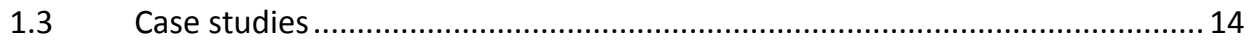

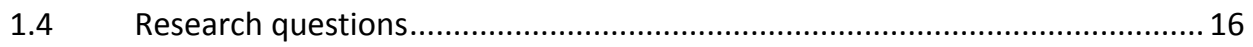

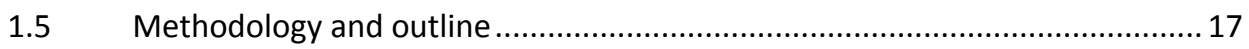

2 Theorizing innovation .................................................20

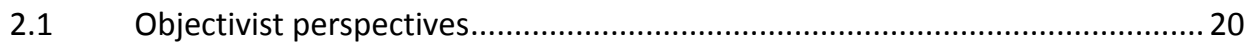

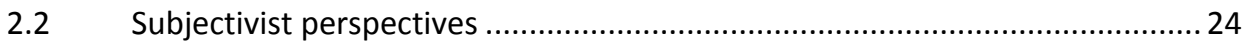

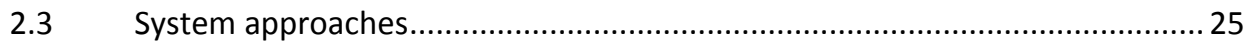

2.4 A framework with co-evolution of demand and supply ................................... 28

3 Methodology ............................................................... 34

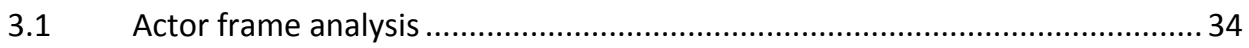

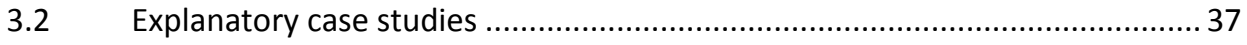

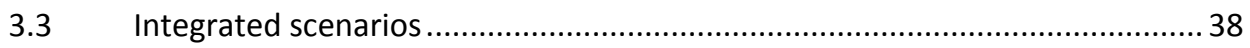

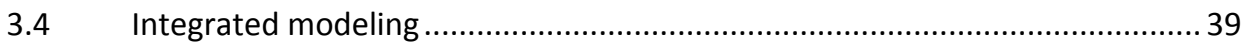

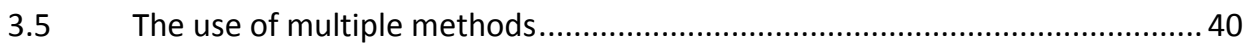

Part I: Analysis of recent history

$4 \quad$ Technological framing by car consumers ................................44

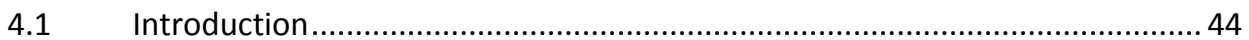

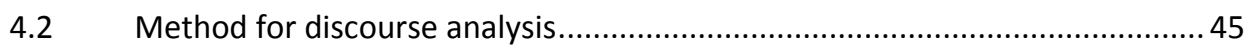

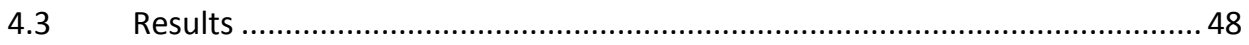

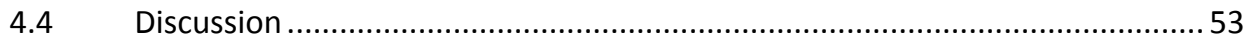

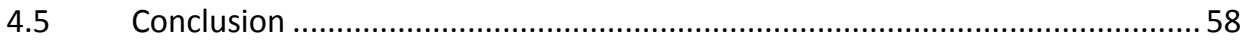

$5 \quad$ Technological framing by car firms ......................................62

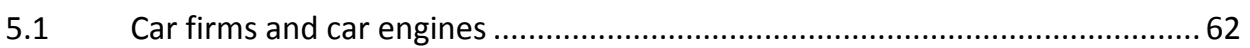

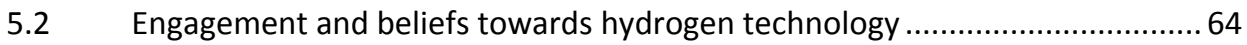

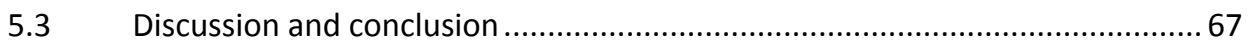


6 Emergence of (hybrid-) electric vehicles..................................70

6.1 Introduction ............................................................................................ 70

6.2 Evolution of engine technologies .............................................................. 71

6.3 Shifts in stakeholder perspectives ............................................................... 74

6.4 Co-evolution of demand and supply through feedback mechanisms ............... 85

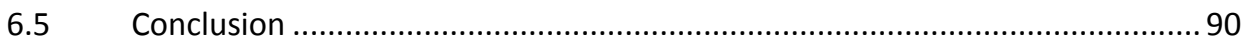

$7 \quad$ Policy framing of Park-and-Ride............................................99

$7.1 \quad$ Trends in parking policy.............................................................................9

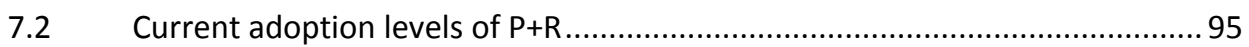

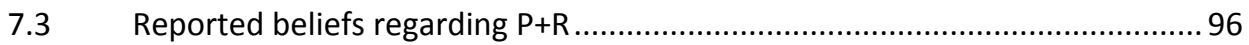

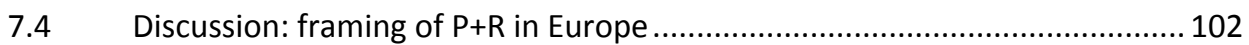

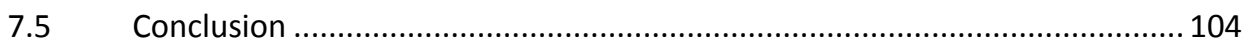

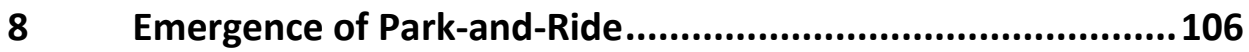

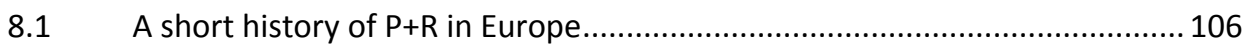

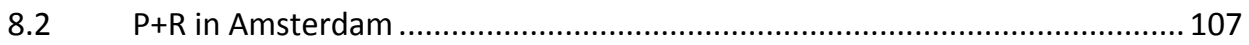

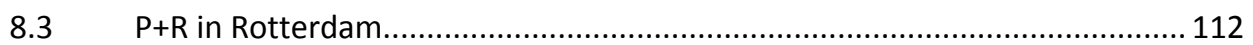

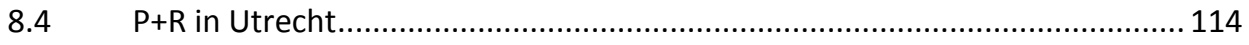

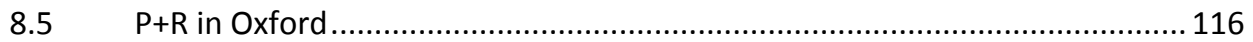

$8.6 \quad P+R$ in York

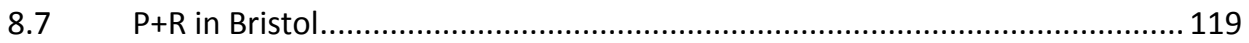

8.8 Co-evolution of demand and supply for parking ........................................ 120

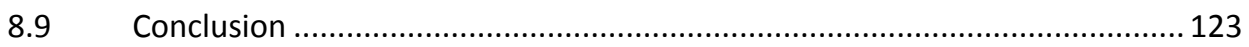

Part II: Future exploration

9 Scenarios of co-evolutionary trajectories...............................126

9.1 From epidemic modelling towards a co-evolutionary approach.................... 126

9.2 A formal model of car engine innovation ................................................... 128

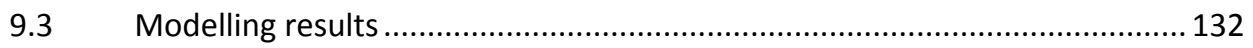

9.4 Scenarios for electric engine cars and diesel cars ....................................... 135

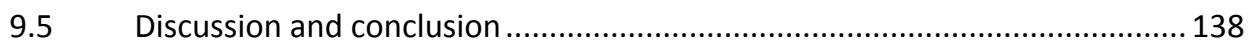

10 Policy options for sustainable car mobility............................142

10.1 Policy for green innovation: from static to evolutionary instruments ........... 142

10.2 Policy options for mitigating (total) $\mathrm{CO}_{2}$ emissions of car use...................... 145

10.3 Policy options for mitigating urban car use and parking ............................... 150

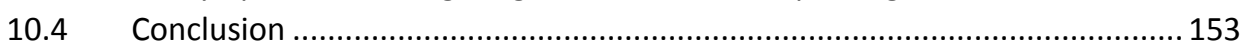




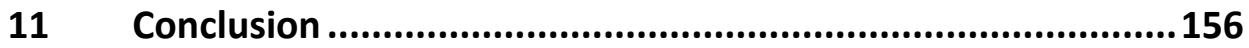

11.1 Question 1: How to combine SCOT and evolutionary economics? ................. 156

11.2 Question 2: Is a co-evolutionary approach reasonable and relevant for studying the emergence of $(H) E V s$ and $P+R$ ?

11.3 Question 3: Can we measure user frames and social connotations of innovations and incorporate the results in computer simulations and in historic-analytical analyses of socio-technical change?

11.4 Question 4: Does the incorporation of competing technologies in a diffusion model lead to different results?

11.5 Question 5: What is the value of a co-evolutionary conceptualization of innovation dynamics for policy?.

References

Appendix A: Method of analysis of stories

Appendix B: Definition of attributes.

Appendix C: Example of all HEV stories in 1996 ........................................ 177

Appendix D: Analysis of engine choice ............................................... 178

Appendix E: Stakeholder consultation ................................................... 180

Appendix F: Questionnaires ............................................................. 186

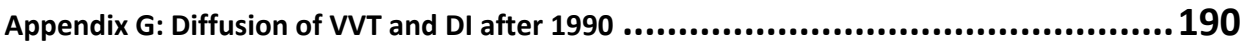

Appendix $\mathrm{H}$ : Individual firm strategic activities .......................................... 191

Appendix I: Statistical Details ...................................................... 193

Appendix J: Model description ......................................................... 196

Appendix K: Model analysis ............................................................... 202

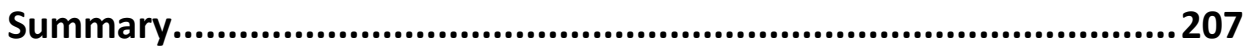

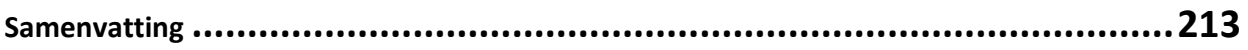

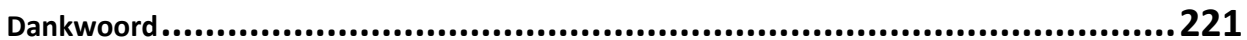

About the author ........................................................................ 222 


\section{Parts of this thesis appeared or are submitted as journal articles:}

\section{Chapter 2 is published as:}

Dijk, M. and Kemp, R. (2010), 'A framework for product market innovation paths-emergence of hybrid vehicles as an example', Int. J. Automotive Technology and Management, Vol. 10, No. 1 , p.56-76

\section{Chapter 5 is published as:}

Dijk, M. and Montalvo, C. (2009) 'Ultra low emission vehicle development: a study on the drivers for car firms and the implications for sustainable development policy', Int. J. Automotive Technology and Management, Vol. 9, No. 2, p.191-208.

\section{Chapter 6 is published as:}

Dijk, M. and Masaru, Y. (2010), 'The emergence of hybrid-electric cars: innovation path creation through co-evolution of supply and demand, Technological Forecasting \& Social Change (2010, in press; available online)

Chapter 4 is submitted to:

Technology in Society, as 'Technological frames of car engines', Dijk M.

Chapter 7 is submitted to:

Journal of Transport Geography, as 'Policy frames of Park-and-Ride in Europe', Dijk, M. and Montalvo, C.

Chapter 8 is submitted to:

Environmental and Planning A, as 'Emergence of Park and Ride in the Netherlands and the UK', by Dijk, M. and Parkhurst, G.

Chapter 9 is submitted to:

Journal of Evolutionary Economics, as 'Incorporating social context and co-evolution in an innovation diffusion model - with an application to cleaner vehicles', by Dijk, M., Kemp, R. and Valkering $\mathrm{P}$. 
Chapter 1

INTRODUCTION AND RESEARCH QUESTIONS 


\section{Introduction and research questions}

\subsection{People ON THE MOVE}

In the last 20 to 30 years people have travelled more often and further. Worldwide, more people have obtained access to car and air transport, and road traffic movements have grown strongly. In Europe, total passenger road kilometres doubled since 1980 (see Figure 1.1). The significant rise of traffic of people was enabled for a great part by the rise of (real) income levels per capita. Since 1980, EU economies expanded by $80 \%$ (OECD, 2006). Furthermore, the decline of the average size of European households has stimulated passenger transport, since it demands more individual transport. In 1970, for example, there were 5.5 million single-person households in Germany; in 1994, there were 12.7 million (+130\%). In the same period the population grew only $5 \%$ (SBD, 2009).

Movement of people has not only grown in distance, but also gained in ease and safety. In the Netherlands, the number of people that died in road traffic accidents in 2004 was a quarter of those in1972 (see Figure 1.2). Improvements in technology and infrastructure have enhanced the comfort of travelling. Available time for leisure trips has also increased. All in all, most people have enjoyed greater freedom to travel, entailing great merits for many.

However, alongside these gains in freedom to travel there are some clear drawbacks. Societies, in particular urban areas, have been burdened with severe impact from transport activities. Congestion, harmful emissions, traffic accidents, noise, scarcity of fossil fuels, fragmentation of landscape, scarcity of space and even social alienation have been identified as problems associated with contemporary mobility systems (Adams, 2005). The principal problem arising from traffic congestion, for instance, is the time and costs lost by transport users. Further, congestion contributes to local air pollution which damages human health. Many of the substances emitted have been linked to health problems ranging from minor irritation to carcinogenic qualities (WHO, 1999). Figure 1.3 illustrates that congestion in urban areas is growing. Figure 1.4 shows that emission of greenhouse gases from road transport has steadily grown as well. The emission of PM and NOx has decreased, though locally they are still above critical levels.

Policymakers at local, national and international levels have been challenged firmly to deal with these negative effects of mobility. Mobility issues are multi-faceted, since they include social, economic, ecological as well as technological aspects. Policy concerns are typically interconnected and cross several policy fields. Societal stakeholders have conflicting perceptions of the problem, whereas gains and burdens of transport activities are distributed unevenly over various societal groups.

Transport policies have been partially successful in the last 20 to 30 years. The increase of safety levels and decrease of polluting gases (such as particulate matter, nitrogen oxides, as seen in Figure 1.2) can be attributed directly to transport-related policies. However, some effects have remained critical or have even grown. Congestion levels and greenhouse gas emissions are the main examples of this. It raises the question how policies concerning these two issues can be improved.

The outcomes of transport policies are often difficult to understand, let alone predict, and possibly they can be enhanced by deeper understanding of recent transport sectoral dynamics ${ }^{1}$.

\footnotetext{
${ }^{1}$ Clearly, this is not the only way to enhance policy outcomes.
} 


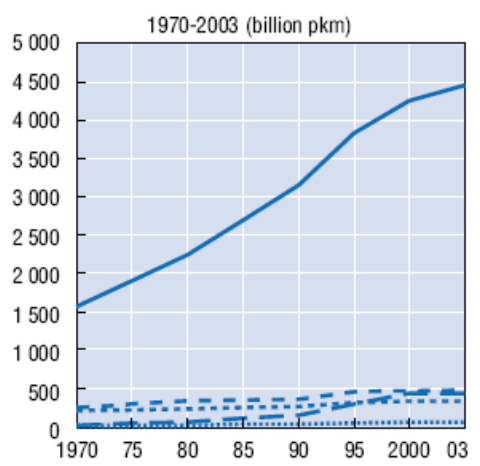

Figure 1.1: Passenger transport trends by modes in the EU, 1970-2003 (passenger-km) (Source: OECD 2006).

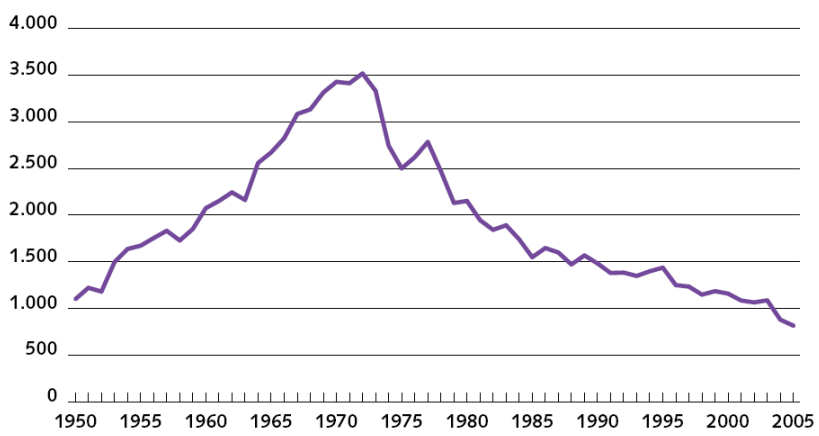

Figure 1.2: Traffic casualties in The Netherlands, 19502005 (Source: MVW, 2006)

\section{Hours of Delay}

per Traveler

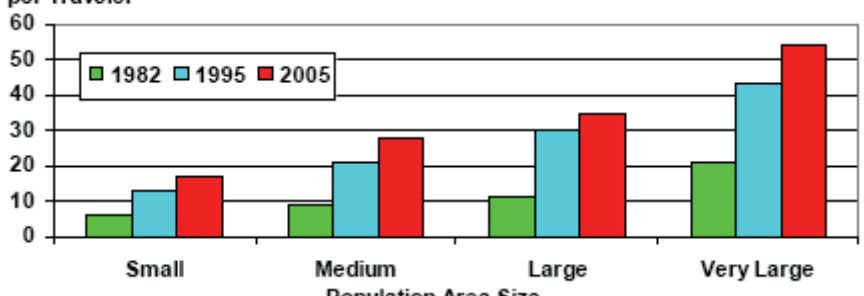

Figure 1.3: Congestion levels in U.S. cities (source: Schrank and Lomax, 2007).

Comparing congestion patterns across countries and regions is not easy, since indicators and assumptions used are often fairly diverse. The general pattern in Europe and North America is nevertheless that congestion in urban areas is growing Small $=$ less than $500,000 \quad$ Large $=1$ million to 3 million Medium $=\mathbf{5 0 0 , 0 0 0}$ to 1 million Very Large $=$ more than 3 million (OECD, 2007).

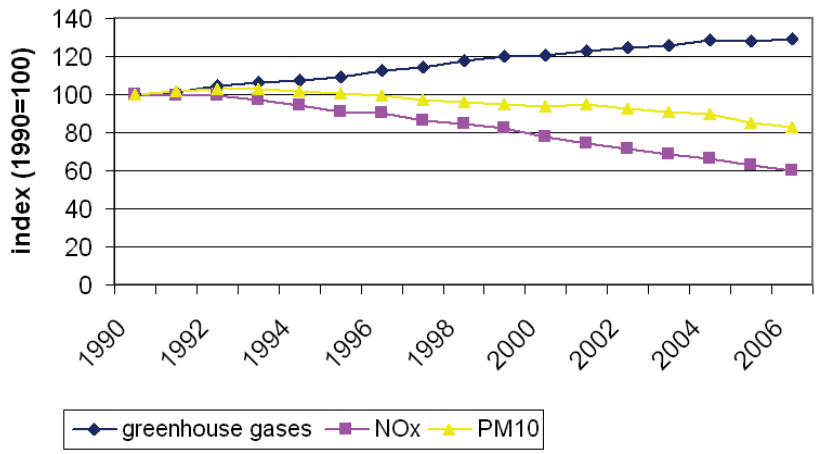

Figure 1.4: Emissions from (European) road transport are declining, except for greenhouse gases (source: Eurostat). PM10 refers to particles of 10 micrometers or less. While greenhouse gases contribute to climate change, particulates and NOX have a significant impact on human health. 
With sectoral dynamics we mean the nature of change and innovation of important (passenger) transport practices in the last fifteen years. Understanding these dynamics facilitates influencing the dynamics towards policy aims.

In this thesis we therefore study the innovation of a few important practices and technologies. We address questions such as how new (supposedly cleaner) technologies, for instance hybridelectric vehicles, emerged. How did travel behaviour of urban commuters change? What has been the role and impact of regulation? Transport technologies and practices exist in numerous forms and modalities, ranging from international air transport, to public transport bikes in your neighbourhood. Some changes take place at a rapid pace, some slow. We chose to focus on two cases in particular: one transport technology (car engine technology), and one mobility practice (Park-and-Ride facilities, abbreviated as $P+R$ ). $P+R$ is a service provided by a city to motorists who can park their vehicle at the edge of a city (centre) and continue their journey by means of public transport. The two cases may play a prominent role in the mitigation of greenhouse gas emissions and congestion levels, respectively. The cases have their own distinct dynamics, one with a strong technological component, and the other with a strong social-behavioural and (local) policy component. We analyze these developments longitudinally, in a time-span of about fifteen years, in order to be more sensitive to the intrinsic patterns of change in the cases (compared to 'one-shot' case studies).

In summary, studying the emergence of novel technologies and practices aims to contribute to a deeper understanding of the dynamics of recent innovation in car engines and urban car use (what happened and why?), in order to advance theories of innovation. In addition to such a theoretical contribution, the analysis hints at the effectiveness of regulation and policies. This delivers a second contribution: providing transport policy practitioners with systematic insights in their sector to improve policy making.

\subsection{THEORIES ON INNOVATION}

Innovation refers to the emergence of new products, processes or practices. Studies in various scientific fields have addressed emergence of new technology and innovation. Broadly there are two strands of literature. The first and oldest strand consists of innovation scholars from economics and related fields. In this strand Joseph Schumpeter (1883-1950) is one of the founding fathers, who referred to innovations as product and service innovations, technological innovations, process innovations, organizational and managerial innovations, conceptual and institutional innovations. Schumpeter (1934) bequeathed us with a scheme of technological change consisting of invention - the first practical demonstration of an idea; to innovation - the first commercial application of an invention to the market; to diffusion - the spread of the innovation into the market. His concept of innovation as creative destruction of established practices suggests that firms search for innovation to provide them with temporary market power, eroding the profits and position of established firms. His work is often labelled as evolutionary although he himself was opposed the use of this label.

From the early 1980s onwards, a new wave of economists revitalized evolutionary theorizing of innovation (Nelson and Winter, Dosi, Saviotti, Metcalfe, Bessant). This strand of literature has moved beyond the simple linear model, and regards innovation as a process of matching technical possibilities to market opportunities, involving multiple interactions and types of learning. Authors typically view innovators as proposing - and bringing into reality - solutions to problems, creating technological variety. Of the possible options that emerge, some get selected to the exclusion of others. Agents are boundedly rational, operating in a changing competitive landscape, with uncertain outcomes. 
Evolutionary models have given less thought to the role of the social context (or embeddings) of technology, e.g. social institutions and demand structures. After 1990 more authors have been hinting at a co-evolutionary approach, which seeks to include dynamics of institutions in particular (e.g. Nelson 1994). However, as Saviotti (2005) notices, these dynamics are still poorly understood.

A second strand of innovation literature originates from sociology and history of technology ${ }^{2}$. From the 1980s onwards, authors in this strand have emphasized the social context in which technology is created and used (Bijker, Hughes, Pinch, Latour). A key concept is social construction of technology (SCOT), where 'technology' is viewed not as an objective entity (as in economic and technical studies), but rather described 'through the eyes of social groups'. These authors demonstrated how various social interpretations of technology drive trigger directions of technological development.

However, both strands of literature likely provide only partial answers of how and why innovation of such a multi-faceted issue as car mobility takes place. Economic (co-) evolutionary innovation studies based on the assumption of an objective innovation neglect the various social meanings a technology or product may have to different people. The social dynamics during technological change are overlooked. SCOT literature on the other hand neglects technoeconomic characteristics of the innovation (such as prices, research investment levels) and scale and learning mechanisms. Since the second half of the 1990s some authors have sought integration of the two strands, dealing with the limits of both. Rip and Kemp (1998) elaborated the co-evolution of 'the social' and 'the technical', analysing the emergence, transformation and decay of socio-technical systems. Their 'multi-level' model of innovation distinguishes between the macro level of the socio-technical landscape, the meso level regime, and the micro level niche. Geels (2005) worked out the key idea that radical innovations come about through interactions between processes at these three levels. That is: the breakthrough from niche to regime level occurs gradually, as a new technology 'branches' or 'penetrates' different application domains, before entering mainstream markets. These studies have highlighted more than previous studies the patterns in which established technologies are sometimes abandoned and overthrown by emerging niches.

Whilst appreciating this contribution, a number of scholars have also pointed to drawbacks of these studies and the MLP. Shove and Walker (2007) critically appraised studies in this field, finding they are typically distanced, even voyeuristic, making few claims about how individuals and organisations can [or] might (. . .) act to affect the processes in question ( . . ) p.764). Genus and Coles (2008) have suggested, amongst other things, that the model undervalues the role of agency (p.1440), i.e. focuses more on interaction patterns of actors, whilst neglecting their intentions. They also find a tendency to focus on 'winning' technologies (p.1444). Others suggested that the studies have been less explicit on the mechanisms or key processes that drive the patterns of change of the niche and regime (Negro 2007). Interactions between niche and regime are claimed to be important, yet the interactions are not specified in term of feedback processes. In summary, the MLP has put less emphasis on stakeholder perspectives and their role in key processes of niche and regime interaction. Consequently, studies of the MLP have been less sensitive for the variety of possible innovation paths, other than the 'winning' or prevailing transition in a specific case.

In this thesis we elaborate a co-evolutionary approach to innovation, building upon the integrating bridge of evolutionary economics and sociology of technology, initiated by Rip, Kemp and Geels. We develop a micro-macro model (more familiar to the economic tradition), thus

\footnotetext{
${ }^{2}$ Though this strand hardly uses the term innovation, but instead technology, artifact or technology in development.
} 
deviating from the three-levelled niche, regime and landscape model. At the micro level, the innovation is described through the eyes of stakeholders, whereas at macro level aggregated indicators such as total sales and prices are incorporated. We hold (groups of) actors as the basic element of analysis, stepping into their shoes, mapping their mental framing and attitudes. A frame is the way in which the innovation is described or interpreted by an actor. Further, in this thesis we extend the notion of feedback effects through scale and learning with the effect of consumer taste formation, including social connotation. We discuss the advantages and disadvantages of this approach for the notion of co-evolution. We aim to contribute to evolutionary economic co-evolutionary studies (in the neo-Schumpeterian tradition), as well as to co-evolutionary approaches in the broader field of innovation studies.

\subsection{CASE STUDIES}

The two cases we address, innovation of car engines and of urban car parking, are interesting for a co-evolutionary approach, since in both cases the introduction of new 'hardware' (technology and/or infrastructure) goes together with adaptations of 'software' (soft things such as stakeholder perspectives and institutional factors). Moreover, both innovations emerge in a sector with an established dominant design or socio-technical regime (Kemp et al., 1998), and the novelties interact with that regime, with possible transformative impacts.

The car engine sector has been dominated by internal combustion (IC) technology for more than a century now. The engines constructed by Otto, Daimler and Benz in the 1880s have been greatly improved since then, though they are in principle surprisingly similar to today's engines. We refer to the ICE regime as the social grammar around the dominant technology, ICE, such as market structure, user perspectives and practices (reflecting their preferences and endorsed social connotations), producer skills, capabilities and perspective, regulations, and supporting institutions. In addition to established gasoline and diesel IC engines, electric vehicles have (re-) emerged as a market niche in the 1990s. For suppliers, full electric vehicles require a considerable extension of their technology competences and skills, since the character of electric components significantly differs from the IC ones. For users too, driving an electric vehicle means a drastic reduction of vehicle autonomy (compared to ICE) and another way of refuelling. An alternative refuelling infrastructure would be required to support the wider use of these vehicles. Regarding these differences in the social and institutional context, electrical vehicles can be identified as a niche outside the ICE regime.

As an intermediate solution, hybrid-electric vehicles have emerged on the market after 1997. They combine an IC engine with an electric engine. Vehicle autonomy and refuelling are similar as to ICEs. For suppliers, hybrid-electric vehicles require a significant extension of their technology competences and skills, as in the case of electric vehicles. Hybrids are typically more expensive than ICEs, but have a higher fuel economy. Various owners see their vehicle as 'socially responsible', as 'the right vehicle for society'. In the context of increasing oil prices, stricter emission regulation and rising environmental concerns this type of vehicle has gained market shares of a few percentages in Japan, the United States and various European countries. In a longer time frame, the co-existence of the emerging electric and hybrid-electric niche and the dominant ICE regime can be mapped out as follows. Figure 1.5 draws a typology based on two dimensions. The first dimension is the level of the change. It refers to the rate at which suppliers refine their skills and competences on a technology or the rate to which user perspectives or regulatory settings adapt. Change may be fast or slow. The second dimension of the typology is the location of (the majority of) the change. This may be located inside the regime or outer-regime. So, niches may develop inside (or close to) the dominant regime, or outside (further away). 


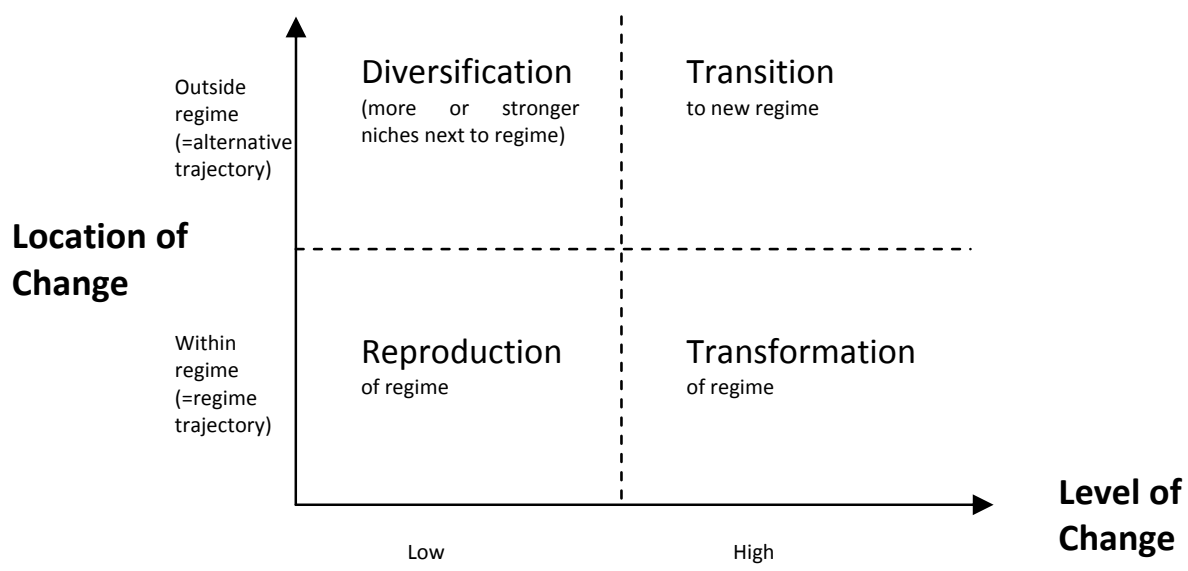

Figure 1.5: Typology of innovation trajectories (combining notions of Abernathy \& Clark (1985) and Geels and Kemp (2007).

The typology helps to see that, in general, the emergence of hybrid-electric and electric vehicles may follow four scenarios. First, change can be strong and located within the ICE regime (bottom, right). This delivers 'transformation' of the regime, and redirection of the trajectory. The established technology, ICE, is gradually substituted with a new one (e.g. low-emission ICEs or mild hybrid-electrics). The user practices and institutions however are here sustained.

Second, change can be strong and located at the outer-regime electrical niche (top-right). Here, transition or switch to a new trajectory occurs. The new technology, e.g. full-electric vehicles, may lead to adaptation of user practices, for example to another way of refuelling, reduction of the average length of the trips, and to combining car trips with public transportation. New infrastructures for electric refuelling will be built, whereas petrol stations deteriorate. New suppliers may enter the market. The dominant momentum switches from the regime trajectory to the former (outer-regime) niche trajectory, which then speeds up non-linearly.

Thirdly, change can be slow and located within the regime (bottom, left). Some incremental innovation takes place in the regime, cumulatively shaping a trajectory of slow refinement of ICE technology. Mostly, there is 'reproduction' of existing actor perspectives, practices and technologies of the regime.

Fourth, change may be slow and located mainly outside the regime, as alternative to the dominant design (top, left). Here, diversification takes place, since the regime stays in place, but co-exiting niches become slightly stronger.

In this thesis we will study the actual trajectories of (hybrid-)electric engine technologies. The research questions in this case study will be summarized in the next section.

In our second case, urban car parking, we find a new practice, $P+R$, emerging in the context of a dominant practice: parking in the city centre. One way to define the regime, i.e. the social grammar around the dominant practice, is by using a typology of vehicle ownership and (urban) vehicle use, see Figure 1.6. The typology presents the entire field of urban passenger mobility. Vehicles may be owned individually or by an organization, and may be driven individually or involve collective use. In the upper-left quadrant we find the practice in which a vast majority of travellers is involved: private car use with parking at the destination. This practice is possible through an enabling infrastructure of on-street parking spaces as well as off-street parking garages, operated by both private and public organizations. We denote the dominant urban car parking regime as the practice of parking in the city centre as such, including the perspectives of 
corresponding motorists, and the perspectives and arrangements of private and public organizations who supply parking spaces. In the bottom-right quadrant we find collective use of publicly owned vehicles, i.e. public transportation. In most urban areas this is a second but smaller regime, enabled by a network of buses, trams, metro and or trains.

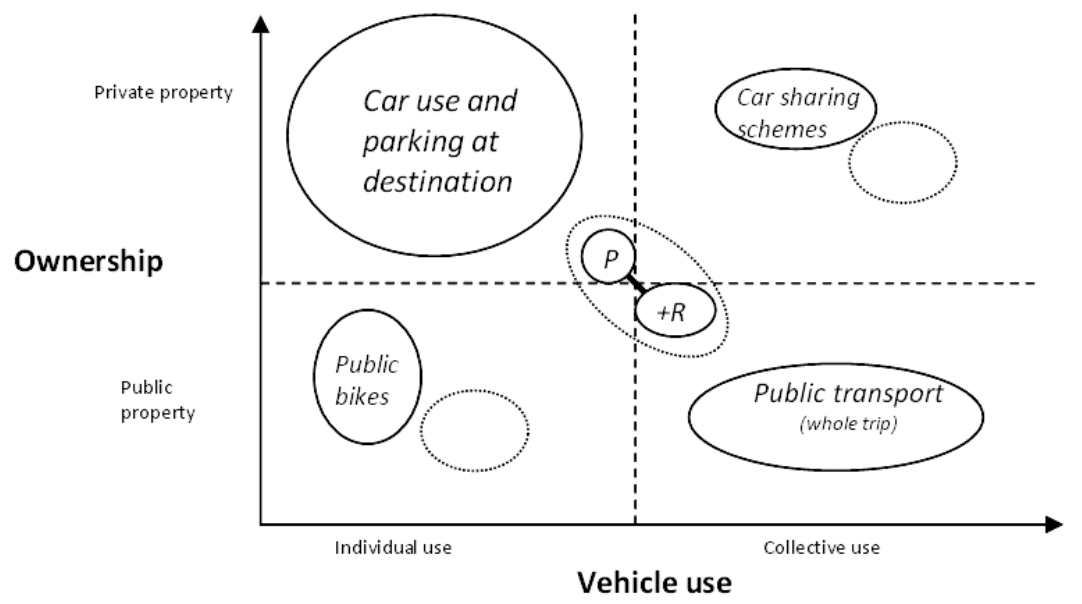

Figure 1.6: Typology of urban passenger mobility (adapted from Orsato (2009))

In this context $\mathrm{P}+\mathrm{R}$ is introduced in many cities as a facility to accommodate intermodal travel. The sites offer parking of the privately owned car, and transfer to either public collective transport (buses, metro etc.) or public bikes. Travellers opting for $P+R$ must change their perspective of their car. They must leave an idea behind of the car as the machine that takes them anywhere they want. They must embrace a significant symbolic-cultural change which reframes the car as a means to access public transport, rather than a door-to-door personal transport mode. Therefore, $\mathrm{P}+\mathrm{R}$ can be identified as a niche in urban passenger transport, outside the dominant regime of parking in the city centre. Both niche and regime co-exist within a context of one market for urban parking. Finally, as in the first case study, this case is interesting for a second reason. The $P+R$ niche may become a 'working' configuration that shapes and reshapes the regime, potentially overthrowing the regime of high central parking intensity.

In this thesis we will study the actual innovation trajectories of $P+R$ in European cities. We specify the research questions in the two case studies in the next section.

\subsection{RESEARCH QUESTIONS}

The focus of this thesis can be summarized in the following research questions:

1. How to combine the objectivist approach of evolutionary economics, with its attention to prices and markets, with the constructivist approach of SCOT (social construction of technology), with its attention to frames and actor groups?

2. Is a co-evolutionary approach a reasonable and relevant approach to study the emergence of $(H) E V s$ and $P+R$, regarding:
a. the diffusion dynamics it highlights?
b. what it learns about path dependence and path creation (i.e. niche-regime dynamics)? 
c. the incorporation of both aggregate and agent-based elements so as to give a microunderpinning of macro patterns with feedback loops from macro to micro?

3. Can we measure user frames and social connotations of innovations and incorporate the results in computer simulations and in historic-analytical analyses of socio-technical change?

4. Does the incorporation of competing technologies in a diffusion model lead to different results?

5. What is the value of a co-evolutionary conceptualization of innovation dynamics for policy? Does it lead to different policy implications than the economic welfare perspective and those of the innovation system perspective?

Obviously, questions 1 and 2 relate to the theoretic side of this thesis, while questions 3 and 4 relates to the methodology, and question 5 to the policy side.

\subsection{Methodology AND OUTLINE}

In chapter 2 we address the state of the art of theories on innovation. We discuss some gaps in the literature, some of which are our research questions. We provide initial answers (hypotheses) to some of these questions in the form of a conceptual (co-evolutionary) framework. This framework is applied in the remainder of the thesis, and appraised in the concluding chapter. Chapter 3 goes into the research methodologies we apply.

In chapter 4 to 10 we make two successive steps: historic-analytic approaches to the cases (what has happened?), and future exploration (what could happen?). In the first step the recent (15year) history in car engine technology and $P+R$ is described in terms of the conceptual framework. A special focus is put on mental frames of actor groups and shifts therein. The frames of car consumers are studied longitudinally; frames and attitudes of car firms are analyzed. Policy frames of local governments are studied with regard to $P+R$.

The second step is future exploration. In chapter 9 we develop scenarios, supported by a simulation approach. Informed by the data of recent developments in the case study, we formalize actor frames and attitudes, and make assumptions on the decision processes. This delivers a simulation analysis of the interplay of demand and supply, modelling various possible trajectories. Two scenarios for the future of (hybrid-)electric vehicles are developed and discussed.

The second step (what could happen?) includes a policy discussion in chapter 10. After taking account of the analysis in the forgoing chapters, we explore effective ways for policymakers to stimulate cleaner car engines and use of $P+R$ in cities.

Chapter 11 draws conclusions on our five research questions and discusses the merits and drawbacks of our approach.

In this thesis historical explanatory case studies are combined with building future scenarios. Discourse analysis, quantitative modelling, as well as statistical analyses are brought together in this study. 

Chapter 2

THEORIZING INNOVATION 


\section{Theorizing innovation}

In this chapter we review the state-of-the art of innovation theories. Our review seeks which theories are most applicable for analyzing innovation in (car) mobility technologies and practices, such as emergence of hybrid-electric vehicles, and emergence of Park-and-Ride $(P+R)$. We distinguish between objectivist, subjectivist, and system perspectives. We denote subjectivist $^{3}$ perspectives as approaches that describe innovations through the eyes of members of social groups. The interpretations of these individuals and organizations are thus a basic element in the analysis. In other words: the actor-technology relation is key. Objectivist ${ }^{4}$ approaches on the other hand, focus on the more objective characteristics of technology, for instance trends in efficiency rates, processor speed, prices and sales levels (i.e. diffusion rates). Difference in interpretation of one technology between different social groups is typically neglected. A third type of approaches, system approaches, seeks to integrate elements of the previous two in one framework $^{5}$. The three types of approaches to innovation that we distinguish leave however a number of relevant issues unresolved. Section 2.4 presents a framework, complementing to the system approaches, for studying some of these issues.

\subsection{OBJECTIVIST PERSPECTIVES}

\section{Economic studies}

As introduced in chapter one, the Austrian economist Joseph Schumpeter (1883-1950) is regarded a founding father of innovation theories, explaining why firms search for innovation. He described innovation as a shift in production function (of a firm, an industry or an entire country), that may be due to technical progress in a narrow sense - that is, product or process innovation - or the opening up of a new market, the acquisition of a new source of raw materials, or a structural reorganization of an industry (Schumpeter, 1935). His concept is unusually broad and dynamic for an economist by considering product and process technology aspects together with industry and market aspects. The (neo-) classical school, by contrast, treats innovation essentially as an investment problem faced by rent-seeking agents. According to the neo-classical view, if the costs of innovation (the costs of research and development, marketing and so on) match the benefits in terms of expected benefits for the innovator, an investment of money and effort will be made. In the footsteps of Schumpeter, especially in the last quarter of the $20^{\text {th }}$ century, a new wave of economists revitalized evolutionary theorizing of innovation, also considering the broader institutional context. This strand of innovation theory provides the basis for explaining why technology is so highly patterned and why it exhibits so much stability. Abernathy and Utterback (1978), in their book Patterns of industrial innovation, distinguish three phases in the emergence and development of a technology. In the first phase, when the technology emerges, product innovation is intense, and product variety widens. In the second, transitional phase competition between products (or regulatory standards) takes place, competing for a dominant design. The emergence of this opens way to standardisation and mass

\footnotetext{
${ }^{3}$ Subjectivism is a philosophical tenet that accords primacy to subjective experience as fundamental of all measure and law. In an extreme form, it may hold that the nature and existence of every object depends solely on someone's subjective awareness of it. It is also referred to as interpretivism.

${ }^{4}$ Objectivism is the belief that reality is mind-independent. It is synonymous to philosophical realism.

${ }^{5}$ Note that the subjectivist-objectivist grouping of approaches is not always easy. Some concepts that I label as 'objectivist' may even include 'subject' characteristics. Still, when they neglect characterizing the subjectinnovation relation (cf. Emirbayer 1997), we affirm they are not subjectivist.
} 
production. The third phase is that of a mature technology, where innovation continues but only gradually. Following this line of enquiry, Freeman and Perez (1988) studied cycles in technological development and economic returns, pointing to a cyclical pattern of incremental versus radical innovation. The first refers to a phase of continuous gradual improvement of many products, processes and services. By contrast, at discontinuous events the gradual process is punctuated by radical innovation, often involving a combined product, process and organizational innovation. Between such (rare) discontinuous events, technologies and systems exhibit a great amount of stability. As a simple illustration of a mature technology one may compare a car engine in 1950 with one produced in 2000, and see how remarkably similar they are.

One of the explanations for this great amount of stability of established technologies is that innovators (i.e. firms or engineers) are constrained in what they know and what they believe is possible. Nelson and Winter (1982) stressed that these bounds of engineers and designers stem from shared socio-cognitive models of problems and possible solutions, directing the search, research and development process. Extending this idea, Giovanni Dosi proposed that innovators operated within a 'technological paradigm'. The choice of technical problems worth solving and the approaches used to solve them tend to restrict proposed solutions along particular avenues. Cumulatively, a technological trajectory is set out that provides incremental innovation rather than radical.

Following the same line of thought, Brian Arthur and Paul David developed models to study technological competition between competing designs. Their case studies and models have illustrated how an initial advantage of the existing path is self-reinforced through processes of increasing returns to adoption as a result of scale and learning or network effects. This is the notion of path dependency that is now widely acknowledged among scholars in technical change.

Business scholars have addressed innovation from an entrepreneurial perspective. These studies are mostly centered on finding effective firm strategies for successful innovation. Authors have argued that, apart from Research and Development (R\&D) expenditures, some firms become persistent innovators due to dynamic economies of scale and learning by doing. Economies of scale may be utilized by any size firm expanding its scale of operation. It entails the fall of average cost per unit as scale is increased. Typically, benefits stem from purchasing, management and marketing. Economies of scale are also derived partially from learning by doing. This is the learning associated with accumulative production of a given item, improving the producers' skills, subsequently reducing production time and cost. Some authors in this field distinguish between technological and organizational capabilities, and have stressed the role of organizational learning (Leonard-Barton, 1992; 1995; Von Hippel and Tyre, 1995). Others have hinted at the importance of consumer involvement. Apart from direct consumer involvement in product development, firms learn from the market how much commercial potential a technology has. They learn about consumer preferences and how they evolve. The critical role of these user/producer interactions has been pointed out by Lundvall (1988) and Von Hippel (1988). Firms learn especially from emerging market niches with new technologies, from their own customers but also from customers of competitors. It will shape their business strategy and reevaluate their current technological competences. The lessons will also guide future R\&D investments toward better market application of technologies.

In their application evolutionary models have been focussing on firms and industries and on process innovations related to production efficiency. They have given less thought to the role of the social context (or embeddings), e.g. social institutions and demand structures. After 1990, more authors have been hinting at a co-evolutionary approach, which seeks to include such institutions in particular. Norgaard (1984) was the first to use the concept of co-evolution explicitly in a socio-economic context. He proposes to understand societal change or development as a co-evolutionary process, i.e. co-evolution between cultural systems (where he means: 
social organisation, knowledge, technology, values) and ecological systems. Norgaards explanation of change goes beyond 'interactive determinism', hence is different from cause and effect thinking. The terms 'to co-evolve' and 'co-evolution' that he uses, refer to an ongoing positive feedback between components of evolving systems. He explains how 'positive feedback' tears a system away from its (old) equilibrium (but may reach a new one, out of multi possible ones). Negative feedback tends to bring a system back in its equilibrium. Though negative feedback models are convenient for understanding and design, the natural and social processes and their interactions that we observe do not lead to equilibrium conditions (Norgaard, 1994, p.82). Coevolutionary models of systems on the other hand, he notes, can readily be thought of as providing their own change from within, or endogenously.

Nelson (1994) worked out the life-cycle of technology (Abernathy and Utterback, 1978) in terms of co-evolution of industry structure and supporting institutions with the technology. Nelson questions the universality of this original story. It will fit better for industries where the product is a 'system', and where customers have similar demands. For industries where consumer needs are divergent and specialized (such as the pharmaceutical industry) it is less likely applicable. Nelson also points to a third component to the co-evolution of technology and industry structure: supporting institutions. He argues they are not simply an outcome of the prevailing technology, but co-evolve with the technology and industry structure. Examples are industry associations and quality standards.

Other scholars have provides case-specific applications of a co-evolutionary approach. Rosenkopf and Tushman (1998) provide a case-study application on co-evolution of networks of communities of practitioners and technology in the flight simulation industry. They work out how inter-organizational networks and communities socially construct technological change; in turn, technological outcomes determine the evolution of organizations and communities. Rosenkopf \& Tushman develop a set of propositions on the emergence, growth and reformation of "cooperative technical organizations" (СTO) networks, and explore how the evolution of these networks both shapes and is constrained by technological outcomes in the flight simulation industry. They argue that varying levels of technological uncertainty between eras of ferment (high uncertainty) and eras of incremental change (low uncertainty) engender fundamentally different modes of network evolution: social construction during eras of ferment, and technological determinism during eras of incremental change. More than previous studies, this study identifies specific mechanisms than constitute the co-evolution (of CTO's and technology).

Jacobides and Winter (2005) provide a framework on capabilities co-evolving with transaction cost, to understand how firms make choices with respect to vertical scope. This is done through the identification of the specific evolutionary mechanisms that determine vertical scope over time. They identify four key evolutionary mechanisms, which explain how capabilities affect scope, and how scope affects capability.

Van den Bergh and Stagl (2003) propose a framework for studying the co-evolution between economic behaviour and institutions. They examine the interaction between social institutions and the behaviour of individuals and groups. They discuss mechanisms of how institutions influence, enable or constrain behaviour of individuals, and mechanisms of how interaction among individuals influences institutions: altruism, co-operation, individuals forming groups, etc. They conclude that, if one aims to formalize the entire set of two way interactions between individuals and institutions, then a multi-layered structure is required, and this would go beyond simple evolutionary game models.

Windrum and Birchenhall (2005) present a formal multi-agent model that explicitly includes consumers in addition to firms. In their model the nature and direction of technological innovation is determined by the interaction of heterogeneous consumer preferences and heterogeneous firm knowledge bases at the micro level. Since the two populations exercise a 
strong selective force for each other one can speak of a co-evolution between consumers and firms. Conceptually, the article resembles an argument of Saviotti $(2005, p .19)$ to address coevolution of demand and supply: Demand is created gradually as an innovation diffuses and as various forms of learning take place, both on the consumer and of the producer side. These forms of learning are mutual (...). Thus we can say that demand and supply co-evolve during the life cycle of a technology (...), which means that their institutions co-evolve.

In summary, co-evolutionary approaches in economics are employed increasingly, mostly to include the role of institutions in technological development. Our short overview confirms that co-evolution is useful as a framework to single out a small number of components of a complex innovation system in order to study their interacting evolution, since it gives us an analytically more tractable problem. Notions and mechanisms from various research fields can be drawn in and integrated. Many of the contributors above have done this. Nevertheless, as Saviotti (2005) notices, the current understanding of co-evolving institutions and technologies is still poor. The notion of co-evolution is defined rather loosely in most publications. It tends to be used for any two or more variables that are partly dependent on each other; as a new term for all interaction phenomena. Van den Bergh et al. (2006) have provided a stricter definition, referring to coevolution as processes where two variation and selection processes, comprising two or more populations or systems, interact or mutual interfere. This definition we follow in this thesis. We further stress that without explicating the processes or mechanisms that constitute co-evolution in a specific case, the term becomes merely a synonym to interaction or co-dynamics (where codynamics are simple dynamic changes reciprocally occurring between two or more identified systems). So, a co-evolutionary approach is (more) reasonable when it is explicit about the key processes underlying the coevolving components.

\section{Innovation diffusion studies}

One field that includes objectivist approaches to innovation is innovation diffusion studies. It has its origin in social geography (Sauer, Hägerstrand), and was later adopted in marketing studies. The focus in most diffusion studies is on aggregate patterns, which are often found to be Sshaped. Rogers (1983) mentions five characteristics of an innovation that help to explain their difference in rate of adoption curves: (1) relative advantage, (2) compatibility, (3) complexity, (4) triability, and (5) observability. He offers a typology of adopters based on when they adopt but does not offer a dynamic model of innovation diffusion in terms of endogenous and exogenous mechanisms.

For explaining S-shaped diffusion patterns there are two models. The most well-known and widely applied model is the epidemic model pioneered by Bass (1969). It builds on the premise that what limits the speed of usage is the lack of information available about the new technology, how to use it and what it does. Information diffusion is governed by social contacts and marketing. Epidemic models have been widely applied in curve-fitting exercises (Bass, 1986; Mahajan et al., 1990). Supply factors and changes in the environment are typically neglected, or incorporated in a crude way. Mahajan et al. (1990) identify nine crude assumptions, three of which are:

- Total market potential of a new product (= final number of adopters) stays constant in time.

- Diffusion of an innovation is independent of all other innovations.

- The nature of an innovation does not change over time

Although Mahajan et al. and others (for example Lee et al., 2006) mention studies that overcome several assumptions, the models remain one sided in explaining the driving forces of innovation diffusion processes (still spread of information). Other relevant feedback effects, such as progressive improvement of the product (affecting adopter attitudes), remain neglected. The second type of models explaining S-shaped diffusion patterns incorporate some micro theory. These models are referred to as rational choice models, or threshold models. They are 
typical economic models in which any actor is expected to adopt an innovation the moment it becomes economic to do so. Supply aspects such as the techno-economic characteristics of an innovation can be incorporated in this type of model (as being done in Ireland and Stoneman, 1982). The model is mostly applied to the diffusion of production technologies, often using size as critical variate (David, 1969; Davies, 1979). Bigger companies are expected to adopt earlier because of economies of scale advantages or available capabilities. Bonus (1973) applies a threshold analysis to the diffusion of household durables (cameras, TV sets, and automobiles), using income as the critical stimulus.

Both types of diffusion models are widely and successfully applied to simple as well as to complex technologies, but learning as well as social and institutional aspects are typically poorly integrated. The social embedding of technologies has been addressed more profound by subjectivist approaches, to which we turn now.

\subsection{SUBJECTIVIST PERSPECTIVES}

\section{Science, Technology and Society (STS) Studies}

Sociology of technological change came of age in the 1980s, mostly in reaction to the linear model of innovation (dating back to Schumpeter), referred to as technological determinism. Scholars in this field objected to the assumption of new generations of technology succeeding each other in a linear sequence from ideas and inventions of technicians, to development and design, to market implementation (Smith and Marx, 1994), finally shaping society. By contrast, Science, Technology and Society (STS) studies, as this field is usually referred to, emphasize the role of societal actors in technical development. Within STS, different approaches have been taken. The Social Construction of Technology (SCOT) takes a constructivist approach, where the innovation is not described as an objective entity, but rather through the eyes of members of social groups (e.g. Bijker et al., 1987; Bijker, 1995). Such groups may be producers, policymakers or users, but also categories like men, women, or businessmen. Different social groups may interpret an artefact differently, e.g. what they like about it, what meaning they attach to it, what they experience as problems, what they regard as possible solutions. Hence, the artefact has interpretative flexibility, and various technological frames may exist for one and the same technological hardware. Bijker recognizes a technological frame as structuring the interactions among members of a social group, similar to Kuhn's paradigm (Kuhn, 1962). Individual actors will have a certain degree of inclusion in the 'frame'. High inclusion means that an actor acts, interacts, and thinks to a great degree in terms of that frame. Since development of technological artefacts is often triggered by problems that relevant actors experience with it, perceptions of social groups are essential for understanding the development of a technology, scholars of SCOT argue.

Other authors have elaborated on these notions. Oudshoorn and Pinch (2003) stress that formation of the social frame (or script) of novel products should be understood as a process involving users as well as designers. Designers are important by shaping the initial forms, functions and meanings of objects. Users, by their different ways of interpreting, using and talking about technologies, further contribute to their social shaping, including the attribution of symbolic meanings to the product. This is part of what some call the domestication process of a

\footnotetext{
6 The concept of 'technological frame' of a social group has some similarity with 'technological paradigm' (Dosi, 1982, p.152): a "model" and a "pattern" of solution of selected technological problems, based on selected principles derived from natural sciences and on selected material technologies. Both concepts denote socio-cognitive characteristics of actors towards a technology.
} 
product into daily life (Lie and Sørensen, 1996). In the field of marketing the symbolic meaning or value that goods and services hold is well established too (e.g. Douglas and Isherwood, 1979), though there it is more distinct from the functional value. In both fields the symbolic value is as a social connotation or meaning attributed to the product, and consumers will have a certain degree of inclusion in such a social construct. It may be positive or negative (even at the same time, for different groups of consumers), thus adding value in the eyes of a consumer, or decreasing it. The Sport Utility Vehicle (SUV) for instance, has for a large group of car drivers symbolic associations of ultimate status, power and freedom, as its user is able to control a powerful machine, and is capable of crossing any terrain. For others, by contrast, SUVs are exponents of decadence, of spilling of petrol, and of insolence, which makes them in the Netherlands facetiously called PC-Hooft tractor (after the posh P.C. Hooftstreet in Amsterdam). Obviously, social meaning or connotation is multidimensional, fluid, and therefore often hard to pin down.

There are more approaches within STS, though we will not address them all thoroughly here. Most notably among them is Actor Network Theory (ANT), which highlights the importance of linkages between actors and artefacts. The combination of actor and network means that there are no actors without networks. Artefacts do not work unless they are placed in a wider configuration that works (Rip and Kemp 1998). A third approach in STS, known as Large Technical Systems theory (LTS, Hughes, 1983) is a socio-technical mode of analysis, approaching the technological artefact as one component in a system with a variety of other components, such as the supporting infrastructure, related technologies, user groups, producers, legislation, etc. In general, studies in STS have elaborated how new technologies and technological systems come about and function, but devote less attention to how established technologies and practices are sometimes abandoned or radically transformed.

The merit of these subjectivist approaches is at least twofold. First, authors demonstrated how various social interpretations of technology drive various directions of technological development. Therefore, technology should not be viewed as a sole objective entity (as in economic and technical studies), but rather be described 'through the eyes of social groups'.

Secondly, the subjectivist approach has convincingly stressed that the 'burden' of history in the emergence of novelty is not the only force. By strategic choices of agents, entrepreneurs, users or policymakers may stimulate creation of new paths (Garud and Karnoe, 2001; 2003). Rather than being passive observers in a stream of events, entrepreneurs, users and policymakers are able to reflect and act pro-actively towards a certain goal; a goal that may go against dominant social conventions.

\subsection{SYSTEM APPROACHES}

In system approaches to innovation linkages between elements are central. Since an element may be social as well as non-social, these approaches can be regarded as an attempt to integrate a balanced share of subjectivist and objectivist elements into one framework. Note that 'system' does not refer to the technology here, but to the strong links between various elements, with weaker links to elements outside the system. Since many elements are social groups, this approach is close to a social network approaches. Studies using system approaches have demonstrated that innovation is not an individual but a collective endeavour, emerging from interaction of multiple actors. Though the ample attention for social groups suggests a fair subjectivist inclination, still most of the studies lean towards the objectivist approach, neglecting the variety of interpretations within one social group (such as users). 


\section{System approach to radical innovation or 'transition'}

Whereas until the middle of the 1990s most innovation studies had been centred on incremental innovation and lock-in, since then system approaches addressing radical innovation have increasingly appeared. In this approach the emergence, transformation and decay of sociotechnical systems is analyzed as co-evolution of 'the social' and 'the technical'. Rip and Kemp's (1998) 'multi-level' perspective (MLP) of innovation distinguishes between the macro level of the socio-technical landscape, the meso level regime, and the micro level niche. The sociotechnical regime at the meso level is an extended version of Nelson and Winter's (1982) technological regime, and is defined here as the meta-coordination of a number of coexisting regimes, such as the technological regime, user and market regime, socio-cultural regime, and policy regime. Different regimes have relative autonomy on the one hand, but are interdependent on the other (Kemp et al., 2001 p.277).

Technological niches are micro level spaces where radical novelties emerge. While initially unstable and weak, they act as 'incubation rooms', protecting novelties against mainstream market selection (Kemp et al., 1998; Schot, 1998). The socio-technical landscape forms an exogenous environment beyond the direct influence of niche and regime actors. Examples are macro-economic and macro-political environments and developments.

Geels (2005) worked out the key idea that radical innovations come about through interactions between processes at these three levels: (a) niche-innovations build up internal momentum, through learning processes, price/performance improvements, and support from powerful groups, (b) changes at the landscape level create pressure on the regime and (c) destabilisation of the regime creates windows of opportunity for niche-innovations. Various retrospective analyzes of the rise and fall of selected socio-technical systems have been developed, such as 'from sail to steam ships', 'from horse to car', 'from coal to gas' (Correlje and Verbong, 2004; Geels, 2005). These MLP studies have highlighted more than previous studies the patterns in which established technologies are sometimes abandoned and overthrown by emerging niches. They have enriched the understanding of interaction of two technologies, or niche-regime (or regime-regime) dynamics for that matter. Raven en Verbong (2007) have worked out interaction of two socio-technical regimes in the Dutch energy sector, building upon notions of Pistorius and Utterback (1997). These studies suggest that, in addition to pure competition, two technologies may have a symbiotic or predator/prey relationship. Raven en Verbong distinguish a spill-over relation, which is a special case of symbiosis (commensalism), and also integration, when previously separated regimes become one. The authors find that in practice the different types of relationships are not exclusive and can occur simultaneously or sequentially.

In a similar line of enquiry Geels (2005) describes fit-stretch patterns as a type of niche-regime dynamics. Geels found that the social framing of new niche technologies is initially very close to the social framing of the regime technology. Early cars, for instance, were called 'horseless carriages'. Perceptions gradually changed as people gained more hands-on experience with the technology. From a 'fit' with the horse-based regime, the framing of cars progressively 'stretched', and a unique frame emerged.

\section{Innovation systems}

In the innovation literature different types of innovation systems are discerned where each type focuses on a specific aspect, depending on one's unit of analysis. In the national innovation systems approach, it is the country that is the unit of analysis, influencing the technology choice and learning processes (Freeman, 1987; Lundvall, 1992; Nelson, 1992). Then there is the regional innovation systems approach within a country, where cultural variables, such as social networks, are important (Saxenian, 1991). The sectoral innovation system focuses on the firms that are active in the innovative activities of a sector (Breschi and Malerba, 1997). These approaches 
regard innovation as a learning process, which contains the interaction of the development of a technology with the system in which the technology is embedded. Most analyses of innovation systems are quasi-static: they explain the social structure, and the related performance of the innovation system. However, less emphasis is put on the dynamic processes (e.g. how technology changes in time in the system).

A fourth related approach, technological innovation systems, puts more focus on a specific technology, and on how relevant actors and institutions contribute - in one way or another, directly or indirectly, intentionally or not - to the emergence or production of innovation (Hekkert et al., 2006). TIS studies analyze a technological innovation in a sector by referring to systemic features, including actors, institutions, (sometimes) technologies and most importantly, interrelations between them (Carlsson et al., 2002). A TIS is defined as a dynamic network of agents interacting in a specific economic/ industrial area under a particular institutional infrastructure and involved in the generation, diffusion, and utilization of technology (Carlsson and Stankiewicz, 1991, p.93). These studies have described how an initially small scale, emerging technology passes through a formative stage, before reaching a market environment. A TIS may accelerate the development of the technology greatly. The scholars conceptualize underlying build-up processes in terms of system functions, or key activities. These involve: entrepreneurial activities, knowledge development, knowledge diffusion, guidance of the search, market formation, resource mobilization, and support from advocacy coalitions (Hekkert et al., 2007). The studies have contributed detailed analyses of how acceleration through a TIS may occur. The concept is less clear why some TISs are successful whereas others are not. In other words: it remains unresolved when or under what conditions this accelerating build-up is likely to occur. The reason of this deficiency may be that the concept focuses more on the niche (TIS) development, and neglects how this niche interacts with the established regime. There is little attention to how users appreciate the niche product vis-à-vis other products and their mental perspective (framing).

Both studies of systems in transition and studies of TIS have left a few relevant issues unresolved. They both typically stay away from the precise perceptions of members of social groups. This underexposure of this part of agency obscures the (socio-practical) alternatives that individuals and organizations perceive, and consequently the potential of various directions of innovation. Shove and Walker (2007) find MLP studies are typically distanced, even voyeuristic, making few claims about how individuals and organisations can [or] might (...) act to affect the processes in question (. . . ) p.764). Genus and Coles (2008) have suggested, amongst other things, that the model undervalues the role of agency (p.1440), i.e. focuses more on interaction patterns of actors, whilst neglecting their intentions. They also find a tendency to focus on 'winning' technologies (p.1444). Others suggested that the studies have been less explicit on the mechanisms or key processes that drive the patterns of change of the niche and regime (Negro, 2007). Whereas interactions between niche and regime are claimed to be important, yet the interactions are not specified in term of feedback processes. As we saw earlier, the same holds for the TIS approach. In summary, both system approaches have put less emphasis on stakeholder perspectives and their role in key processes of niche and regime interaction.

In the next section we develop a framework that addresses these two issues. As suggested by Genus and Coles (2008), we increase the input from constructivist approaches, more precisely from the social construction of technology (SCOT). We present a two-layered, co-evolutionary framework, where the micro level incorporates subjectivist elements, by mapping the perspectives of individuals and organizations and describing the innovation trough the eyes of these key stakeholders. Further the macro level addresses aggregated, objectified indicators, such as prices and total sales levels. By addressing feedback mechanisms between and within the layers, we try and identify the key processes that constitute the niche-regime dynamics, delivering path dependent and path creating inclinations of a sector at the same time. 


\subsection{A FRAMEWORK WITH CO-EVOLUTION OF DEMAND AND SUPPLY}

In our framework we consider demand and supply as two populations of attributes that coevolve (Saviotti, 2005; Windrum and Birchenhall, 2005; Safarzynska and Van den Bergh, 2010). When we speak of demand and supply we thus mean the demand side and supply side. On the supply side, suppliers are creating technological variety. Of the possible options that emerge, some are selected on the market to the exclusion of others. On the demand side we have heterogeneous people of different income and lifestyles, equipped with preferences, beliefs and ways of thinking.

Market price is important, but certainly not the whole story behind supply and demand. Markets are socially embedded (Rip and Kemp, 1998) and products are socially constructed (Bijker, 1995). Underlying supply and demand we find socio-economic actors, with ways of interpreting, expectations, capabilities, habits, etc. We therefore consider demand as more than actual sales, as including consumer attitudes towards various options. Supply is more than actual production, and involves capabilities, business opportunity, and future expectations towards the various options. The heterogeneity in potential adopters creates a variety of demand. In our scheme, there is present demand and future anticipated demand. Under influence of the latter, suppliers make decisions (select foci) about investment in research and development. By proposing solutions to problems, suppliers are viewed as creating technological variety (see Figure 2.1).

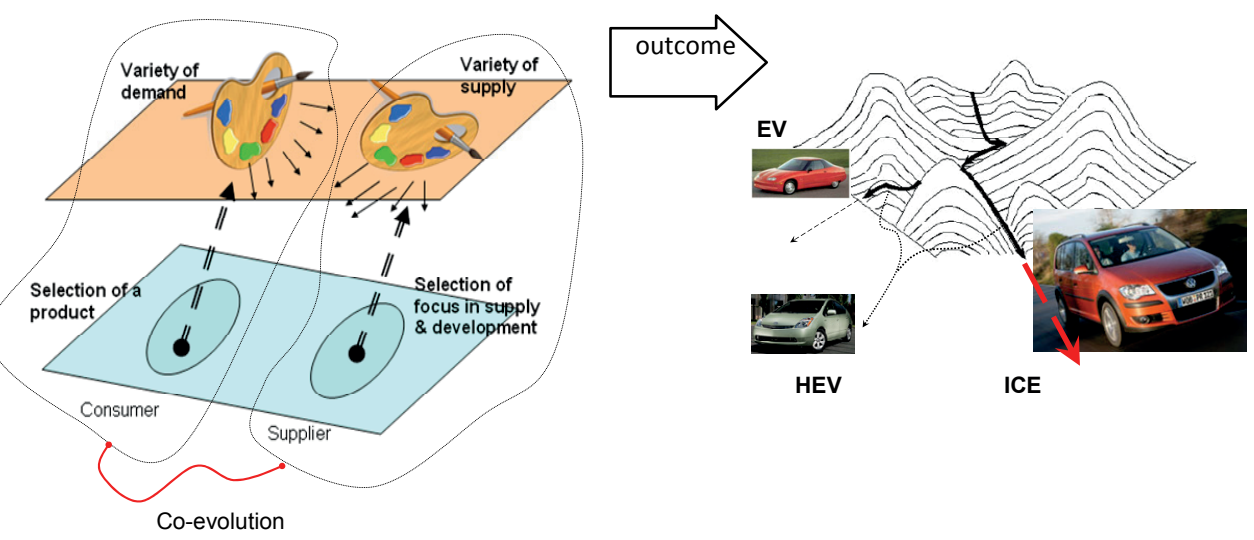

Figure 2.1: Trajectories as an outcome of co-evolution of demand and supply. Regime trajectory may co-exist with niche trajectory(s). A trajectory has its own level of momentum.

In our scheme we distinguish a micro level where the innovation is described through the eyes of actors (consumers and suppliers), and a macro level where aggregate indicators of the innovation are considered. We suggest that this micro-macro framework is instrumental to highlight both actor perspectives, and address dynamics between the layers (as we clarify below). As noted in the previous section, these two issues, actor perspectives and feedback mechanisms, are what we want to highlight in comparison to the MLP and the TIS approach. The social context in which technology is created and used is not stable, but undergoing change due to the introduction of novelty and due to institutional and material adaptations that go with it (Rip and Kemp, 1998). Both at the supplier and at the consumer side various forms of learning take place. These forms of learning are interrelated, in the sense that at the very beginning suppliers have to inform consumers about the innovation, but then suppliers themselves gradually learn how to evaluate demand as an innovation diffuses. Learning entails the 
availability of new skills and knowledge, new social connotations, changing future expectations, new supplier-user relationships, and changes in the regulatory framework. Consumers, by their different ways of interpreting, using and talking about technologies, further contribute to their social shaping. This is part of what some call the domestication process of product into daily life (Lie and Sorensen 1996). Thus, both the technological hardware and the relevant social context change in a complex process with strong evolutionary traits.

The process of co-evolution is thus socially enacted, but not planned by actors. In the case of vehicle engines, for example, the following actors are involved: car manufacturers, engine component suppliers, car users, car repair shops, sales persons, journalists, university researchers and teachers, banks, venture capitalists, shareholders, and policy makers. It is impossible to include all actors in a behavioural model of innovation diffusion. For the purposes of our framework, we include three types of actors at the micro level: consumers of the innovation (in the example: buyers of new cars), suppliers of the innovation (car manufacturers) and policy makers (regulators of the sector and sponsors of research and green products). In our scheme regulation adapts over time, but is not co-evolving in the same sense as demand and supply. Instead, we regard policymakers, and the regulation they impose, as a force that shapes the coevolution of supply and demand.

The actual behaviour of all actors translates into macro patterns, such as total sales of the various options, prices, technological progression of various options. These macro level indicators in return influence the individual agents at the actor level: it is a circular (micromacro) process (see Figure 2.2a).
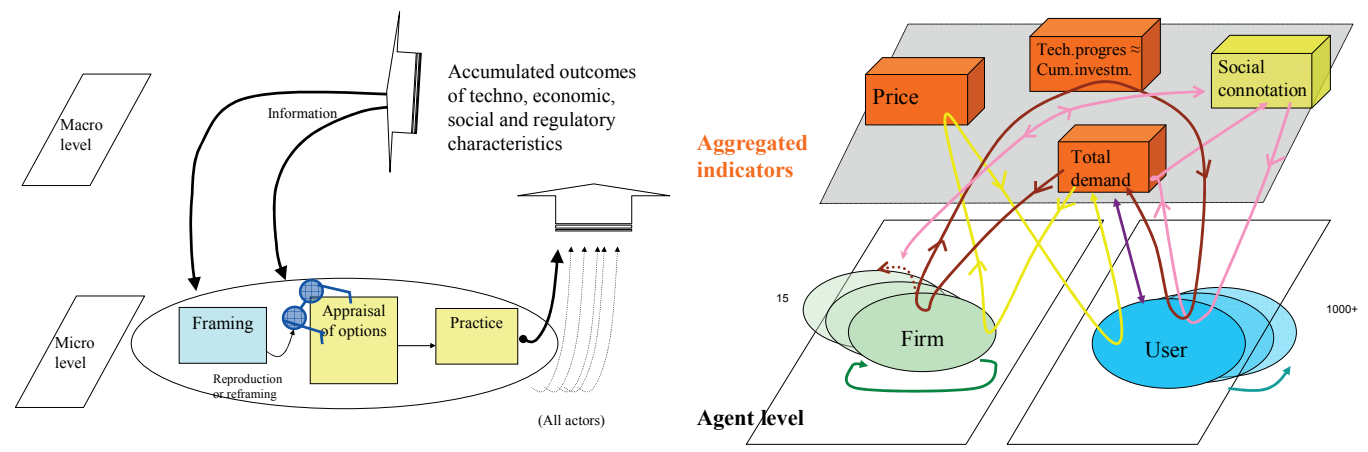

Figure 2.2: (a) Innovation as a circular process involving two layers, where (b) various feedback mechanisms may be identified.

The studies of innovation we reviewed in sections 2.1 to 2.3 have identified various feedback mechanisms during the emergence of a product market or industry. Between the micro- and macro-level we distinguish (see Figure 2.2b):

- Increasing returns to scale: cost per unit fall as firms take advantage of economies of scale, allowing them to profitably sell products at lower prices, which stimulates sales and further scale economies (See Figure $2.2 \mathrm{~b}$ yellow)

- Learning about the market: growing sales lead to better knowledge about the heterogeneity of demand (who prospective buyers are, their willingness to pay for specific features, what is valued and less valued); knowledge which may be used for R\&D and new product offer- 
ings, which will give rise to refined products and more targeted marketing effort; consumers learn which products they appreciate most that, which will stimulate its sales (See Figure 2.2b brown)

- Social construction of meaning: products obtain a social meaning, which will differ across groups; products may become more or less desirable because of this. The dynamics may stimulate sales (in case of positive stories and connotation) or discourage them (in case of negative stories and meanings) (See Figure $2.2 \mathrm{~b}$ pink)

- Network effects: increases in usage lead to direct increases in value (as in the case of the telephone) (See Figure 2.2b purple); increased usage of the product may also spawn the production of complementary goods such as fuelling stations and assets such as skills which increase the value of the original product; in the case of competing technologies the one with the greatest installed base and compatibility with existing systems has an advantage over the other.

Alongside these micro-macro processes, there are also micro-micro feedback loops:

- Learning-by-doing: production experiences leads to improved skills and helps to discover cost-efficiencies in production, allowing manufacturers to reduce prices and increase sales and production (see Figure $2.2 \mathrm{~b}$ green).

- Imitation of use: potential adopters have a tendency to imitate peers (taste formation) (see Figure $2.2 \mathrm{~b}$ blue) (at the supply side, producers may also imitate successful features of competitor products).

The velocity of the loops differs. Some loops are more rapid, such as falling prices in the course of a few years, or the improvement of technological quality of new options. Other loops are slow or discontinuously changing, such as those involving social factors.

In our framework, actor groups have a mental perspective or frame. A frame is the way in which the innovation is described or interpreted by an actor. The framing metaphor can be understood as a window or spectacles (worn by the actor group) that filters the total amount of information in a first impression (what it is about and what it important for them), and focuses attention on key elements and aspects within ${ }^{7}$.

Using the example of an alternative engine, say electric propulsion, the user may perceive this as either a green engine, or just another engine, possibly an exciting new engine or something he finds hard to label (he or she may not give it any thought). For manufacturers, the engine may be perceived as a something that is of interest to their customers or to new customers, as something for which a clear or uncertain market is anticipated. For producers the profitability of an engine (the business case) is likely to be an essential component of the frame. Policy makers on the other hand may see the engine as a solution for air pollution problems or as something that is interesting from an employment point of view (new jobs).

Frames are devices for interpretation by accentuating certain attributes of the car (engine): maximum speed, power or fuel use, etc. It is well established that goods and service hold symbolic as well as functional value (Douglas and Isherwood, 1979). So, besides functional attributes, there is an attribute of social connotation, symbolic meaning. The populations of (prospective) users and firms are heterogeneous: users and firms are very different in terms of individual characteristics (such as preferences and technological capabilities). The frames are consciously or unconsciously applied by firms, consumers and policy makers when they deal with various opportunities and problems of vehicles.

\footnotetext{
${ }^{7}$ Since our definition of frame is limited to the mental perspective of an actor group, it slightly differs from Bijker's (1995) technological frame, which includes the actions and interactions of the actors of the group.
} 
With this novel framework we analyse both the emergence of (hybrid-)electric engines and $P+R$ in a changing social context as a dynamic process of co-evolution of demand and supply, mediated by feedback loops. 

Chapter 3

METHODOLOGY 


\section{Methodology}

We apply a number of research methods to investigate and appreciate the framework presented in section 2.4. The most prominent ones applied can be put under four headings: actor frame analysis, explanatory case study, integrated scenarios, and integrated modelling. Below we concisely describe what the method is, and how we applied it. The final section addresses the rationale for combining methods in one study.

\subsection{ACTOR FRAME ANALYSIS}

In support and as input to the explanatory case study, we analyze frames of actor groups (in chapter 4, 5 and 7). As denoted in chapter 2, a frame is the evaluative structure in which the innovation is described or interpreted by actors. More precise, it is the manifestation of (relevant) beliefs, perception and appreciation around the innovation. Since Immanuel Kant published his 'Critique to Pure Reason' by 1781 , social scientists have been stressing the limited cognitive capacities of man. Due to the diversity and versatility of reality, humans perceive only some aspects or elements of an observed part of reality at once. Originating from philosophy, social psychological research has devoted extensive attention to the notion of attitudes, which can be regarded as 'simplifiers' used for the evaluation of objects and situations: they prevent one to appraise things over and over again (Fazio, 1989). In the same line of enquiry, the framing metaphor should be understood as a window or pair of spectacles that filters the total amount of information in the impression, and focuses attention on key elements and aspects within. Thus, framing involves processes of inclusion and exclusion as well as emphasis. In general, this is not a conscious process, but something that happens unconsciously in the course of communicative processes. Entman (1993) summarizes the essence of framing processes as follows: Framing involves selection and salience. To frame is to select some aspects of perceived reality and make them more salient in the communicating text. We follow this definition here.

In social issues frames are everywhere. All stakeholders have their own perspective. In fact, an actor 'wears' a whole range of spectacles, for various situations or objects. Policymakers also make sense of reality through framing, both of the variety of problems they are confronted with, as well as various possible solutions strategies. Schön and Rein (Schon and Rein, 1994, p.26) provide a useful definition of policy framing as the process through which:

Things are selected for attention and named in such a way as to fit the frame constructed for the situation. They select for attention a few salient features and relations from what would otherwise be an overwhelmingly complex reality. They give these elements a coherent organization, and they describe what is wrong with the present situation in such a way as to set the direction for its future transformation ... It is typical of diagnostic-prescriptive stories such as these that they execute the normative leap in such a way as to make it seem graceful, compelling, even obvious.

A frame is thus a perspective from which an amorphous, ill-defined, problematic situation can be made sense of and acted upon. For the sake of our study the question raises how to analyze actor frames in practical cases. Though frame analysis has a long history in political sciences (Rein and Schon, 1977; Schon and Rein, 1994) and communication sciences (lyengar, 1991; Reese et al., 2001), currently no fully fledged, standard methodology exists to analyse frames (König, 2008). In this thesis we apply two distinct methods to analyze actor frames.

The first method (applied in chapter 4) is discourse analysis to track attributes in frames. It examines what attributes are used to describe the innovation, and how these attributes are appreciated. The frame concept underlying this method is referred to as attribute framing 
(Hallahan, 1999). It highlights how some characteristics of objects are accentuated, whereas others are neglected, thus (consciously or unconsciously) biasing processing of information in terms of focal attributes. For example, take a simple data-stick. The frame of a data-stick may have a structure of various attributes (or categories): the memory size (512kB), the color (white), the physical size (small /thin), the (non-) existence of a hook nail, to hang it around a necklace (included), the price $(\$ 15,-)$, the production cost $(\$ 10,-)$, the level of sales (1 million a year), etc. By implicitly attaching weights to various attributes, different groups of actors interpret the same product differently: they attach different meaning and value to it. The set of weights that an actor group applies in evaluating adoption or investment we call the frame or category structure. In addition, a consumer may appreciate each attribute to higher or lower extent. He or she may find a storage capacity of $512 \mathrm{kB}$ too low, be fond of the white color and the small shape, and find the hook nail irrelevant. An electronics supplier may focus on the price, production cost and expected sales levels, and draw his conclusions on his business opportunity. In other words, a frame has two parts: a category-structure (which may include a hierarchy between the categories), and category or attribute appraisal (see Figure 3.1).

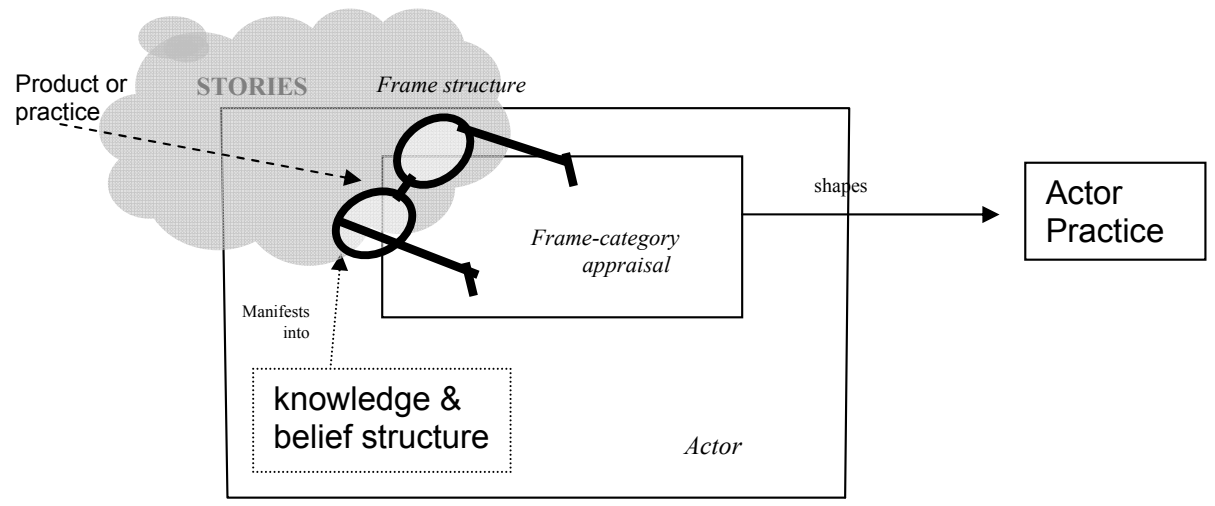

Figure 3.1: Stories carry the cognitive frame-structure and appraisal of innovations by market actors. These frames are the manifestation of knowledge and belief systems.

In chapter four we trace attribute framing from stories in both contemporary newspapers, as well historic ones. Accordingly, this method allows studying frames longitudinally.

The second way to study frames (applied in chapter 5 and 7) is a survey to analyze belief systems of actors. This social-psychological approach regards knowledge and belief systems as the underlying basis of the actor frame. In other words: knowledge and beliefs become manifest in the frame.

In order to assess belief-systems of users, producers, or policymakers who consider adopting, developing or regulating an innovation, the empirical survey approach developed by Montalvo (Montalvo, 2002; 2006) is employed (see Figure 3.2).

This approach is based on a simple behavioural theory designed to understand human social behaviour on the basis of the underlying intentions, attitudes, subjective norms and behavioural control. Though Montalvo's approach was designed to study behaviour rather than frames, we suppose both are anticipated by belief systems. For our study we developed a questionnaire that could identify the various beliefs (and their salience) of car firms and city governments with respect to car engines and $P+R$ respectively. By including elements of the established technology or practice in the survey, we determine the (dis)favour with the innovation as opposed to conventional options. 
The measurement of belief systems is difficult (Malim and Birch, 1998), since they are not directly observable. On the one hand there is little doubt that holding a particular belief is linked to a particular sort of practices or behaviour. On the other hand this relation is far from clear: specific behaviour may contradict a general attitude. To counter this drawback, we should track belief systems for specific behaviours (a choice, an action), in which actors are in a 'reasonable' state-of-mind.

Montalvo's model suggests that the innovative activities executed in an organisation are reflected in its relevant decision-makers' willingness to innovate, which in turn is determined by three domains in their belief-system: their (1) attitude towards innovation, (2) their perceived social pressures to innovate and (3) their perceived control over the innovation process.

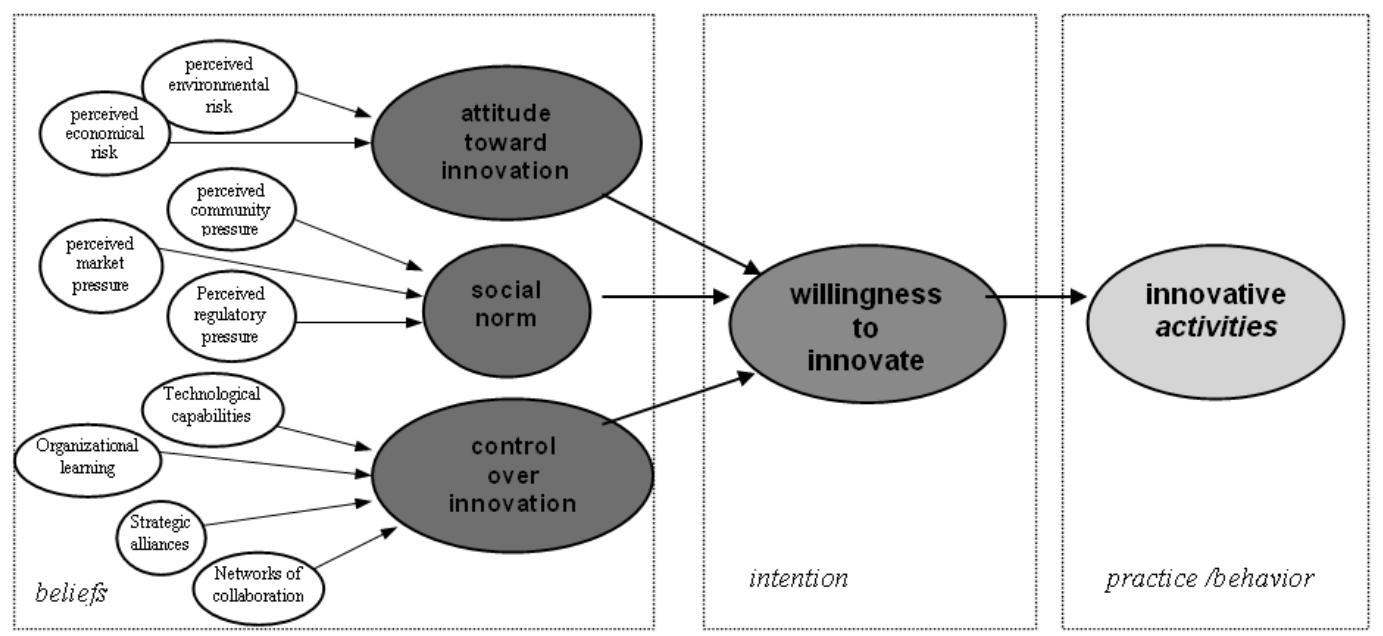

Figure 3.2: Schematic illustration of Montalvo's behavioural model (2002)

The attitude towards innovation is an indicator of the degree to which relevant decision-makers like or dislike (i.e. form positive or negative associations with) the expected direct outcomes of their engagement in innovative activities. Typically these outcomes refer to expected economic benefits and losses for the innovative entrepreneur and, in the case of an engagement in cleaner technology, also the positive effect of the latter on the environment. Therefore, as the main determinants of the entrepreneurs' perceived attitude toward engaging in the new technology or practice, the model distinguishes between:

- $\quad$ perceived Economic Risk/ Opportunity (ER)

- $\quad$ perceived Environmental Risk (EV)

In contrast to attitude, perceived social pressure refers to the positive or negative normative connotations associated with an engagement in the technology. In particular, the model distinguishes:

- the Regulatory Pressure (RP), referring to the perceived stringency of environmental regulations and standards,

- $\quad$ the Market Pressure (MP), arising from the perceived attitude of consumers and competitors concerning the technology, and

- the perceived Community Pressure (CP) from stakeholder groups in the community constituting the social environment of the innovating firm. 
The third category of determinants refers to the entrepreneurial decision-maker's perceived control of the innovation process. This part of the belief system essentially comprises:

- the perceived Technical Capabilities (TC) allowing a company to use technological opportunities offered by the market

- the company's perceived capability to engage in Organizational Learning (OL)

- $\quad$ perceived capabilities to form Strategic Alliances (AL) with customers or suppliers

- perceived capabilities to use Collaboration Networks (NW) with research institutions in order to outsource the acquisition of knowledge needed for the innovation process.

These nine items are potentially salient underlying beliefs to the willingness to develop the innovation. For our study we developed a survey questionnaire to identity the various beliefs of car firms with respects to low emission engines (chapter 5 ), as well as one for city governments with respect to $P+R$ (chapter 7 ). By correlating the actual engagement with stated beliefs, using statistical techniques, we gather insight on the salience of various beliefs ${ }^{8}$.

\subsection{EXPLANATORY CASE STUDIES}

Explanatory case studies are suitable for applying pre-defined frameworks on a new case, testing causalities and explanatory value (Yin, 1994). They can tell rich stories in terms of dynamics and interacting processes. They address the 'how' and 'why' questions. Since our study seeks understanding in recent innovation dynamics of car mobility, this is thus a valuable method. Explanatory case studies differ from exploratory studies, since in the latter type fieldwork and data collection may be undertaken prior to definition of the research questions and hypotheses. Case studies can be designed in various ways, most significantly it may be single instead of multiple, and holistic or embedded. This thesis uses a multiple and embedded case studies method. Multiple, since we address two cases. Two case studies have advantage over one, since comparisons and contrasts can be made, which may lead to refinement of the framework. The method is also embedded, since the analysis uses various levels and units of analysis. The embedded case study approach allows for a multiplicity of methods that may be applied at the various levels or sub-units.

For our two cases, the emergence of hybrid-electric vehicles and the emergence of Park-andRide $(P+R)$, chapter six and eight provide rich descriptions of how and why these innovations were developed and adopted, using the notions and processes of the framework. We do this level by level: first we describe innovation in terms of technological progress and diffusion of sales or use (i.e. at an aggregate level). We address price trends, trends in social connotation and regulation in place or put in place. These are aggregate patterns and here we leave out the role of individual actors. As a second step we examine the role of stakeholders (firms, consumers, and regulators) in the evolution of the innovation. We address actor perspectives, attitudes and behaviors. Finally, we examine interactions and feedbacks between the two layers.

By means of our two cases, we critically appraise the two-layered framework with co-evolution of demand and supply. The two cases have their own distinct dynamics, one with a strong technological component, the other with a stronger social-behavioral and (local) policy component. We study these developments longitudinally, in a time-span of about fifteen years,

\footnotetext{
${ }^{8}$ It was practically not possible to include the various alternative innovation options (such as for car engines gasoline and diesel technology, hybrid-electric and natural gas). Therefore we work under the (rather strong) assumption that beliefs and willingness of the innovation we investigate can be studied independent of beliefs and opportunities around alternatives. For $P+R$ nevertheless, a range of alternative transport (parking) policy options were included, providing opportunity to compare innovation options more directly.
} 
in order to be more sensitive to the intrinsic patterns of change (compared to 'one-shot' or 'cross sectional' case studies).

\subsection{INTEGRATED SCENARIOS}

In chapter 9 we develop integrated future scenarios for the diffusion of cleaner car engines, supported by a simulation model. Integrated scenarios are structured descriptions of possible futures (Rothman, 2006). They are not images of the future, but movies of the future: a sequence of events that could lead to a certain final image (Rotmans, 2001a). More precise they are denoted as descriptions of journeys to possible futures that reflect different assumptions about how current trends will unfold, how critical uncertainties will play out, and what new factors will come into play (UNEP, 2002). They should be plausible but simplified descriptions.

Scenarios are not developed to predict the future. Scenario analysis is rather a tool that is used to deal with uncertainties, making various assumptions about trends of main drivers explicit. Thinking about what may happen in the future provides a means to share our understanding about particular sectors, and our concerns to it. Potential future problems may come into focus. Analysing 'what if ... ??' questions may help to identify choices and make decisions, for example regarding policy interventions. Scenarios are usually developed in sets, where each scenario explores the implications of different assumptions of key drivers or mechanisms.

Scenarios have been developed in broadly two ways. They can be made by a small group of scientific experts (expert scenario analysis) or involve a large group of stakeholders (participative scenario analysis). In both cases, the development process may be supported by a formal model. If that is the case, the results are likely quantitative scenarios. If not, scenarios are typically narratives (qualitative). Qualitative and quantitative representations should be seen as complementary (Rothman 2006). Qualitative scenarios can explore relationships and trends for which few or no numerical data are available. They can easily incorporate human motivations, values and behavior. Alternatively, quantitative scenarios can provide (an impression of) greater rigor, precision, and consistency. Their assumptions are explicit and their conclusions can be traced back to the assumptions. The effects of changed assumptions can easily be checked, pointing to important uncertainties.

Combining qualitative and quantitative input can make a scenario more consistent and robust (Notten, 2005). A quantitative scenario might be enriched with the use of qualitative information. Likewise, a qualitative scenario might be tested for plausibility through the quantification of information, if possible.

Our scenarios analysis in Chapter 9 involves a qualitative and a quantitative element. The development of the two scenarios is supported by a formal model. There were no stakeholders directly involved in the process. Since we focus on the role of social construction of connotation in the progress of technological trajectories there, we examine two assumptions on the strength of this mechanism. As a result we present two scenarios for new car sales diffusion: one scenario in which the sales of (hybrid-) electric vehicles increase significantly and one in which the share of diesel engines is able to remain dominant. The scenarios are more than descriptions of the output of the model, since they are enriched with 'educated' guesses. They are narrative scenarios, constituting the dynamics suggested in the two model runs. 


\section{$3.4 \quad$ INTEGRATED MODELING}

The notion 'model' has many meanings. It is both used for photo models like Claudia Schiffer, for miniaturized objects, for conceptual frameworks, as well as for mathematical models and computer simulations of complex systems. Within the natural and the economic sciences, models usually refer to mathematical formalizations of (parts of) real world systems (Jager, 2000). This is how we will use the term in this thesis. An example is the mathematic formulation of the relation between economic growth and emissions. Formal models are worthwhile in scientific research, since their outcomes can be compared to observations in the real world. This makes models testable, in the sense that outcomes of two different formal descriptions can be judged on which is better in describing a real world process.

In general, integrated (simulation) models try and describe quantitatively as much as possible the cause-effect relationship of a phenomenon, and the cross-linkages between different contextual processes, including feedbacks (Martens, 2006). Feedback processes can amplify or dampen key-indicators in the system, therefore being the most significant mechanisms in a system. An example of a simple (positive) feedback is: if more people adopt an innovation, unit cost and prices will decrease, which will trigger more people to adopt. Even a simplified but integrated model can provide useful insight in the principle dynamics of complex issues or sectors. They are used to structure information, and help to become sensitive for significant interactions. Causal relations are explicitly specified and results can be analytically traced. However, any attempt to fully represent a complex issue with its numerous linkages and interlinkages with other issues is doomed to fail. They are never intended as 'truth machines', perfectly replicating real life systems and predicting the future. Integrated models complement rather than replace approaches of detailed models and case studies that cover only some parts of complex phenomena.

Integrated models have sought to integrate non-human dynamics (e.g. in ecological, or technical systems) with social dynamics (Valkering, 2009). One of the first examples is the global change model TARGETS (Rotmans and Vries, 1997). The model combines the global dynamics in different sectors (energy, water, food etc.) with various management perspectives or styles. The authors apply a systems dynamics approach, which is well-suited for incorporating quantitative, equation-based relations between indicators. However, this approach is less suitable for incorporating the social and psychological richness of actors. Several scholars (Janssen and Vries, 1998; Moss et al., 2001; Van der Veen and Rotmans, 2001) have proposed to extend the integrated framework with Agent-Based Modelling (ABM). ABM can be considered as an umbrella term for various agent-based modelling approaches (Agent-based modelling, Agentbased social simulation, Multi-agent-based simulation, Multi-agent simulation (see Hare and Deadman, 2004), in which social entities are represented as computer agents acting upon their social and natural environments. The main merit of this type of models is that they simulate how assumptions at a micro-level (e.g. how an agent behaves, how they interact) emerge to macro phenomena over time, due to interactions of an heterogeneous set of agents. The agent-based method is useful for combining data from subjectivist methods (i.e. from studies on actor frames) with those of objectivistic studies (e.g. learning- and scale mechanisms).

In chapter 9 we develop a simulation model which formalises our conceptual framework for the case of car engine innovation. The two-layered, agent-based approach allows a microunderpinning of macro patterns, incorporating feedback loops from macro to micro. We examine the diffusion and development of refined internal combustion engine vehicles and the diffusion and development of (hybrid) electric vehicles. We formalize actor frames and attitude formation, based on empirics of chapter 6 . We discuss the dynamic process as constituting coevolution of demand and supply of products, especially how improvement in functionality interacts with formation of social connotation of an innovation. 


\subsection{THE USE OF MULTIPLE METHODS}

Combining various methods in one study is not new. In a few scientific fields a practice of combining methods has emerged. Most notable is the field of Integrated Assessment. Integrative studies have branched off from environmental studies in search for integration of nonhuman dynamics (e.g. in ecological or technical systems) with social dynamics. Two groups of methods are distinguished: analytical methods and participatory methods (Van Asselt, 2000). Rotmans (2001b) addresses the notion of integration in these studies, (implicitly) touching upon the combination of subjective knowledge elements (referred to as 'the value-laden information provided by societal actors') and objectified knowledge elements (referred to as 'scientific facts'). In his view, the latter should be provided by scientists, whereas the first should be provided by societal stakeholders. Subsequently, the actor perspectives and findings from analytic methods should come together in an active dialogue (Rotmans, 2001, p.22), which may or may not lead to shared and or integrated perspectives. Hence, he views integration as a dialogue or participatory process. Methodological approaches on combining methods are, however, relatively immature. Mingers and Brocklesby (1997) provide clues to the delicate question on how to select a set of methods. They map out twelve aspects of the phenomenon that need to be addressed by the methods applied. Roe (1998) argues that the various methods need to be orthogonal (i.e. very different) in order to be used in the triangulation procedure. Triangulation (of results) has been proposed in this context as a notion to seek validation of data and results by combining a range of methods, sources or analysts. One principal tenet of triangulation is that the object of analysis should remain the same for all instruments of analysis (Roe, 1998). De Ridder et al. (2007) suggest a chronology for application of various methods in an integrative study. He suggests that participatory tools are more appropriate in the first phase of the study, the problem analysis, to elucidate views of the various stakeholders, explicate knowledge and values within the problem, and ideas about solutions to alleviate the problem. In subsequent phases (i.e. identification and analysis of various options), when the focus has crystallized, analytic tools are more appropriate. The paper is not explicit on how results from different tools should be combined. Grosskurth (2008) acknowledges that no general panacea can be developed for this. He argues to balance an equal share of analytical input form desk studies and subjective participatory input in an integrative study, and he refers to two exemplary studies: VISIONS (Van Asselt et al., 2005), and Quest (Tansey et al., 2002).

Combining methods has a few advantages. The simultaneous use of various methods can improve the quality and adequacy of a study considerably (Rotmans 2001), and conclusions are usually more convincing if they are based on several different sources of information (Yin 1994). It enables the analysis and interpretation of impacts of a wide range of issues, policy options and strategies. Combining different methods can compensate for one-sidedness. In complex issues, one method easily results in only partial explanation of a phenomenon, as in the blind men and the elephant tale (as observed in Kemp and Pontoglio (2008).

Combining methods has difficulties too. Combination of outcomes and knowledge elements is difficult to validate scientifically. There is no unifying theory that indicates how this analytical process of integration should happen, despite that the term triangulation is increasingly used. Difficulties of triangulation typically include that it is time consuming and requires a variety of skills of the researcher. A more fundamental difficulty is to ensure that the different methods applied will not have a similar bias. In other words, the various methods need to be orthogonal (i.e. very different) in order to be used in the triangulation procedure (Roe 1998). Ironically, precisely this requirement makes integration or comparison of the results of different methods difficult. Another fundamental issue is that various methods may stem from different paradigms, and therefore possibly incommensurable. Mingers and Brocklesby (1997) suggest such problems 
are not insurmountable ${ }^{9}$. Nevertheless, the authors do not address the important question how sensitive the meta-analysis is to the set of methods selected.

Considering these advantages and limitations, combination of various methods is not always a good idea. It is a labour intensive process that should only be undertaken if it is really necessary for the subject or problem at hand. Grosskurth (2008) suggests that multi-methodology is appropriate in cases were the research subject or problem is characterized by complexity, ambiguity, subjectivity, and normativity (p.26). For our cases on sustainability issues in car mobility these characteristics seem to apply. As we noted earlier mobility issues are multifaceted, since they include social, economic, ecological as well as technological aspects. Policy concerns are typically interconnected and cross several policy fields. Societal stakeholders have conflicting perceptions of the problem, whereas gains and burdens of transport activities are distributed unevenly over various societal groups.

\footnotetext{
${ }^{9}$ They find that the work of Giddens (1984) and Bhaskar (1994) present an ontological perspective that can subsume the objective-subjective dichotomy.
} 

Chapter 4

TECHNOLOGICAL FRAMING BY CAR CONSUMERS 


\section{Technological framing by car consumers}

In this chapter we analyze technological frames of car consumers towards car engines. We map the frames by studying the stories that are told about the engines. The central question is: how do consumers frame different types of engines (diesel, hybrid-electric, full-electric), and how have frames shifted between 1990 and 2005? Section 2 describes how we analyze frames from stories through a method for discourse analysis. In section 3 we present data on car engine market stories from national newspapers in the Netherlands. Section 4 discusses patterns in the data and section five answers our central questions and draws conclusions.

\section{$4.1 \quad$ INTRODUCTION}

Consumers use stories to understand new products, to determine their value to them (Feick and Price, 1987). Through interpersonal communication or media reports people spread marketplace information, and this influences evaluations and choices (Arndt, 1967). Stories carry the framing and appraisal of innovations by market actors. As such, stories are important to understand the evolution and success of product markets (Rosa and Spanjol, 2005). From a cognitive science perspective, market stories help to generate the 'knowledge structures' that enable market actors to reconcile current experiences and behaviours with pre-existing beliefs. By doing so, stories shape future behaviours (ibid. pg. 199).

Although several studies have analyzed user perspectives on automobiles in general (Heath and Scott, 1998; Steg et al., 2001), hardly any examined perceptions of car engines specifically. Most notably is one study reporting that a majority of HEV owners saw their vehicle projecting images that were linked to larger values as social awareness, responsibility and concern for others (Heffner et al., 2005), and another study finding that 31 percent of HEV buyers said they purchased an HEV because the vehicle 'makes a statement about me' (CNW, 2006). Steg et al. (Steg et al., 2001) find that for car buyers symbolic value plays a significant role next to functional characteristics, but the question how people frame their vehicles' propulsion technology remains unresolved. Another study analyzed the relative importance of fuel economy, next to other consumer car preferences (Mytelka, 2008). The author argues that the oil price shocks of the 1970 s seem to have marked the early 1980 s preference structure with its emphasis on fuel economy, whereas five years later, fuel economy was of least important to consumers, whereas price and reliability had become the prime concern.

Business consultants from Maritz-research studied (stated) changes of consumer habits due to rising fuel prices (in France, Germany and the UK, in 2006, with responses of 1240 new vehicle owners). On the statement 'I think about buying, or have bought, a vehicle with a more economical engine', $57 \%$ agrees mildly or strongly, while only $23 \%$ disagrees mildly or strongly. Based on these figures they conclude that a major share of European drivers is changing their car purchase considerations, due to rising fuel prices. How familiar are people with new propulsion systems? In the same research Maritz found $20 \%$ is very familiar with hybrid-electric petrol engines, $34 \%$ somewhat familiar, $39 \%$ has heard of the technology, and $8 \%$ is not at all familiar. Full electric vehicles are somewhat less well-known: $9 \%$ very familiar, $35 \%$ somewhat familiar, $48 \%$ has heard of the technology, and $8 \%$ is not at all familiar. Of all alternative engine technologies, hybrids are best known.

Though insightful, these studies have not clarified how consumers multifariously frame different types of engines (diesel, hybrid-electric, full-electric), and how those frames have shifted between 1990 and 2005. This is what we focus on here. 
Frames become manifest in stories. As stated in chapter 3, currently no coherent methodology exists for frame analysis. Rather, frame analyses are a number of related, even though sometimes partially incompatible methods for the analysis of discourses (Scheufele, 1999). Since car engines are objects, we acknowledge that attribute framing is a useful method for analyzing frames in this chapter. This method tracks the accentuation of some characteristics of objects, and the neglect of others. Accordingly, it highlights the (conscious or unconscious) bias of information procession in terms of focal attributes (see chapter 3 ).

Rosa and Spanjol (2005) discuss ways to analyze market narratives or stories. Although they do not explicitly link the concept of stories with frames, they do provide a number of applicable aspects of these stories told by market actors. Main aspects they touch upon are:

- complexity of the story - this is the number of attributes that (market) actors use to describe competing product models.

- ordinality in the story - this is the extent to which market actors use 'ordered categories' (where a category is ordered when it can be presented on a rated scale, more or less precise).

- Subjective-evaluative centrality of the story - this is the proportion of attributes that is subjectively evaluated (in contrast to valence-neutral observations).

Whereas complexity is driven partly by the product's technical features, ordinality and precision are variable properties of cognitive object attributes in (shared) knowledge structures of market actors (Scott et al., 1979). Market actors are defined as:

. . buyers, sellers, and others who interact in market arenas (Rosa and Spanjol 2005, pg. 199). Narratives of market actors are not restricted to consumers' word of mouth: ... but include stories 'circulated by producers and cultural intermediaries such as the media and advertisers'. This suggests that in any product market, market actors can include consumers, producers, retailers and intermediaries, media, government agencies, and other organizations. Moreover, stories that actors tell in social settings are not independent but rather interdependent (Weick, 1995). Market actors tell stories to one another, directly or indirectly, and they collectively shape one another's thinking (ibid.).

Rosa and Spanjol expect differences in stories between new emergent product markets and mature markets, where innovation is only incremental. In accordance with Bijker's notion of interpretative flexibility (before closure), they state:

In the case of new products, there is a general lack of experience among market actors, and the initial goals or benefits that new products can or should fulfil are unclear. In turn, the lack of experience requires sense making and evaluation of all product attributes and features, which contributes to conflicting market stories because of the diverse needs and approaches of the people who experience the products and share stories (ibid. pg. 200).

Similar to the notion of decreasing interpretative flexibility in the process of closure, they make the following propositions:

- Market conversations in the early stages of market development are likely to include more product attributes (i.e. higher complexity).

- Ordinality is likely to increase when a market develops.

- Evaluative centrality in market stories increases as a product market develops.

In addition to an analysis of the structure of the stories around the innovation, we contend that these notions allow identification of the appraisal of (attributes of) an innovation. Rosa and Spanjol acknowledge that market stories contain both objective descriptions next to subjective evaluative statements: appraisal. When statements around an attribute contain a subjective evaluation, an analysis can apply different scales. For each attribute an investigator can 
determine whether the innovation is described as large improvement, improvement, comparable, decline or large decline with respect to the existing technology, product or practice. When an objective-descriptive statement of an attribute is made, the appraisal can not be identified. (See Appendix A for more details on this methodology.)

As an example of the way we analyze a newspaper article (story), see for example this story on an HEV in 2005:

Triggered by high oil prices, the Toyota Prius, a fuel-efficient hybrid sells like hot cakes in the United States. Not the tank-like Hummer but the modest Prius is the status symbol. (...)

Both cars are popular in the U.S., but last year the Prius was the winner. For the Prius, Car of the Year in 2004, there is a waiting list. (...)

The Prius runs almost 1 liter per $30 \mathrm{~km}$ by combining petrol with electricity and is affordable: from 16 thousand euro. Compare that to the Hummer. They run at best 1 per $10 \mathrm{~km}$ and the cheapest version costs 40 thousand euro. That Arnold Schwarzenegger has eight ones is fun, but is no longer a guarantee for success. ( . ..)

Apparently, the desire for the status symbol was so great that the average waiting period of two months was insurmountable. Toyota has announced that the monthly production this year will rise from 10 thousand to 15 thousand vehicles, but still there will be a waiting list, predicts the company.

Hollywood plays a roll in the success. In his latest film Be Cool John Travolta drives around in a Prius. "No, it is not fast, but if you are important, they wait on you", Travolta notes, and casts a loving look at the Prius. (...) Moreover, motorists have nothing but good things to say about their Prius. The magazine Consumer Reports writes that at present they are the most satisfied car owners. (...)

(Source: De Volkskrant (April 20th 2005, (C PCM Uitgevers), under the title: Toyota's flagship displaces the tough Hummer: Environment-conscious Americans to choose the hybrid car Prius, especially now John Travolta drives it in his new film.)

We recognize six attributes in this account, see table 4.1. For example the author refers to the fuel efficiency of the engine, evaluating it simply as 'fuel efficient', without using ordered categories. Table 4.1 lists the other five attributes. We label non- (or less) functional adjectives or adverbs before (or behind or around) 'engine'; e.g. sportive, modern, revolutionairy, powerful, super or boring - engine, as social connotation or symbolic-affective attribute. See Appendix $\mathrm{B}$ for a complete list of the attributes we recognized in the set of accounts in all the years, as well as how we defined them.

Table 4.1: Attributes of an HEV story

\begin{tabular}{|l|l|l|}
\hline Phrases used & Attribute & Evaluation \\
\hline fuel-efficient & Fuel efficiency & Neutral (0) \\
\hline $\begin{array}{l}\text { hybrid, combining petrol } \\
\text { with electricity }\end{array}$ & Engine structure & Not evaluated (-) \\
\hline $\begin{array}{l}\text { modest, status symbol (2x), } \\
\text { winner, nothing but good } \\
\text { things to say }\end{array}$ & Social connotation & Large improvement (+2) \\
\hline 1 liter per $30 \mathrm{~km}$ & Fuel use & Improvement (+1) \\
\hline $\begin{array}{l}\text { affordable: from } 16 \\
\text { thousand euro }\end{array}$ & Price & Neutral (0) \\
\hline not fast & Performance & Decline (-1) \\
\hline
\end{tabular}

When, subsequently, the analyses of all stories (of an engine) in one year are accumulated, we acquire insight in the yearly averages of discourse on an engine. Such an analysis, for example in the discourse on the hybrid-electric engine in 1996, reveals that engine structure is the most 
frequent mentioned attribute ${ }^{10}$ : in seven of seven accounts. Environmental impact is second, with six out of seven. Further, the analysis showed that none of the accounts was based on actual user or producer hands-on experience of the storyteller. In $50 \%$ of the cases that an attribute was mentioned, it was subjectively evaluated. Overall appraisal of the innovation was +16. (We refer to Appendix A (method) and C (HEV 1996) for more details on this.)

We studied market stories of one mature car engine (diesel, incremental innovation) and two emerging markets (electric and hybrid-electric engines). In the first half of the 1990s an innovated version of an ICE, the direct injected diesel engine, came to market in the Netherlands. In those same years, cars with electrical engines were introduced by Fiat (1992) and Peugeot-Citroen (1995). By 2000, hybrid-electric vehicles came to market in the Netherlands, first introduced by Toyota.

We chose to analyze articles in large national Dutch newspapers: Telegraaf, Volkskrant, NRC, Trouw, AD, and Het Parool. Together they count for nearly two million copies a day, in a country of around 16 million people. The subscribers of these papers are from all corners of the political spectrum, and all levels of social-economic status. It makes sense to study market stories in newspapers, since:

The interdependence of market stories is evident when individual consumer' sense making has sufficient volume and momentum to be carried over into popular press. For example, it is common for commercial publications to echo consumers' viewpoints at large. In turn, the in-print affirmation of consumers' viewpoints can amplify the influence of these particular market stories (Rosa and Spanjol 2005; pg. 199).

We chose four moments in time (see Table 4.2):

- $\quad$ beginning of the 90 s (the first accounts of the innovations)

- halfway the 90s (we chose the year 1996, in which new regulation in California took effect)

- the year 2000

- the year 2005

We found roughly 500 articles in the four periods. After closer examination, it showed that around 180 contained stories on the new engines (while others just mentioned them).

Table 4.2: Number of (stories in) newspaper articles on car engines. Data before 1996 does not include articles of the Telegraaf.

\begin{tabular}{|l|r|r|r|r|r|r|r|r|r|r|r|r|r|r|r|r|}
\hline & 1990 & 91 & 92 & 93 & 94 & 95 & 96 & 97 & 98 & 99 & 0 & 1 & 2 & 3 & 4 & 5 \\
\hline Direct injected diesel & 1 & 2 & 0 & 5 & & & 10 & & & & 29 & & & & 39 \\
\hline Electric car & 6 & 5 & & & & & 20 & & & & 7 & & & & 3 \\
\hline Hybrid-electric car & 0 & 0 & 1 & 6 & & & 7 & & & & 22 & & & & & 41 \\
\hline Total & 7 & 2 & & & & & 37 & & & & 58 & & & & & 83 \\
\hline
\end{tabular}

We now turn to the results of the analysis of the complete set of around 180 articles that appeared in the newspapers in the four periods (thus not a sample).

\footnotetext{
${ }^{10}$ We contend that the number of times that an attribute is mentioned is an indication of the importance of an attribute for the market.
} 


\subsection{RESULTS}

Our analysis of the stories delivered the following results of the frames of the diesel engine, hybrid-electric engine and electric engine respectively.

\section{Direct Injected (DI) diesel engine (1990-93, 1996, 2000 and 2005)}

Table 4.3: key indicators from yearly discourses on direct injected diesel engines

\begin{tabular}{|l|c|c|c|c|c|c|}
\hline DI Diesel & \# accounts & $\begin{array}{c}\text { Complexity } \\
\text { (+average) }\end{array}$ & ordinality & appraisal & $\begin{array}{c}\text { Subject.- } \\
\text { evaluated }\end{array}$ & $\begin{array}{c}\text { \% user } \\
\text { experience }\end{array}$ \\
\hline $1990-93$ & First 7 & $11(2.7)$ & $82 \%$ & +7 & $63 \%$ & $29 \%$ \\
\hline 1996 & 10 & $16(8.2)$ & $88 \%$ & +28 & $49 \%$ & $60 \%$ \\
\hline 2000 & 29 & $19(6.5)$ & $89 \%$ & +75 & $66 \%$ & $86 \%$ \\
\hline 2005 & 39 & $19(6.7)$ & $89 \%$ & +46 & $41 \%$ & $67 \%$ \\
\hline
\end{tabular}

For DI-diesel we found various remarkable things:

- Complexity: the total number of attributes used to describe a DI diesel engine was 11 in 1990-93, 16 in 1996, and 19 by 2000 and 2005 (see Table 4.3). The number increases in time: a diesel engine stayed a complex product, but due to technological innovation even wooed increasing attention (= increasing number of stories) and focus on characteristics. Examples of new attributes are tax and drivability.

- The average number of attributes used in one account initially increased from 2.7 in 1990/93, to 8.2 in 1996, then decreasing to 6.5 in 2000, and 6.7 by 2005 (see table 4.3). It seems as if in the beginning of the 1990s this innovation was not of much interest to tell long stories about. Stories were very short. Only when more improved versions (with DI technology) had come to the market (by 1996), they were described in more detail, with often reports on test drives. The decrease (of the average number of attributes) after 1996 is a slight confirmation of Rosa and Spanjol's proposition of decreasing complexity in the course of market development.

- The most mentioned attributes in 1990-93 are engine volume and fuel efficiency/use $e^{12}$ (though both only 43\%), all others are even lower. By 1996 engine volume and fuel efficiency are both mentioned in $100 \%$ of the accounts, and engine capacity and acceleration were 90 and $80 \%$ respectively (see Figure 4.1). By 2000 engine volume is $86 \%$, and engine capacity and torque are both $83 \%$. By 2005 engine capacity is mentioned most (97\%), while engine volume is still very important (87\%). Acceleration is third with $77 \%$. We conclude that engine volume and engine capacity are two attributes that have become a stable part of the frame of DI diesel, appearing in at least 83\% of accounts since 1996.

\footnotetext{
${ }^{11}$ This is the \% of accounts that are based on user experience (test drives etc.) or production experience (after market launch).

${ }^{12}$ In the remainder of the analysis fuel efficiency and fuel use are united as one attribute.
} 


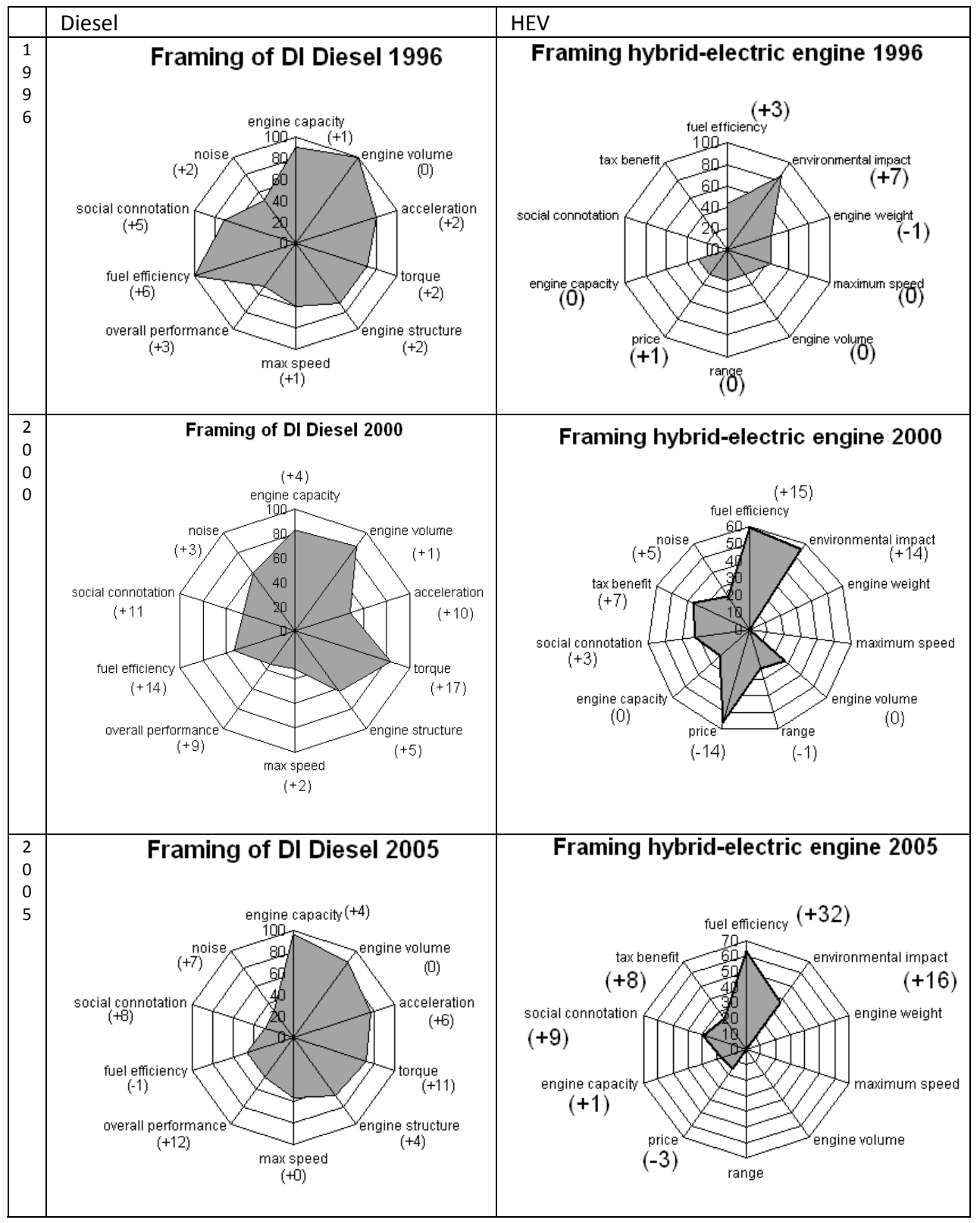

Figure 4.1: Technological frames for direct injected diesels and for hybrid-electric engines in 1996, 2000 and 2005: the spider diagrams indicate the attention for attributes in those years, whereas the outer values indicate the appraisal score of that feature. For example, in 2005 engine capacity is mentioned in 97\% of the accounts and on balance this attribute was evaluated as +4 , which means there were two account in which it was seen an improvement (+1) and in one as a large improvement (+2); in the other accounts the attribute was not evaluated. 
- Environmental impact was mentioned in $20 \%$ of the accounts in $1996,3 \%$ in 2000 , and $10 \%$ in 2005. It therefore was a very minor attribute. Environmental concerns are apparently little associated with discussing new diesel engines.

- Looking to the type of accounts, by 1996 accounts have a higher proportion of 'experiences' with the innovation (60\% compared to $29 \%$ in 1990), all from the user (see Table 4.3). By 1990 there were mainly 'announcements' of research or products. By $2000,86 \%$ of accounts were based on user or producer experiences, and by $200567 \%$. Hence it stayed high.

- If 'total appraisal' of the DI diesel engine is quantified, it shows a jump form +7 in 1990-93 to +28 in 1996, and +75 in 2000 (see Table 4.3). Certainly this value is not very accurate, but it does indicate that the DI diesel engine was appraised very positively by market actors around 1996 and especially $2000^{13}$. (There are various articles headed 'super diesel'.) In 2005 it stayed high.

- Ordinality of the DI diesel is high: it slightly increases from $82 \%$ in $1990 / 93$ to $88 \%$ in 1996 , to $89 \%$ in 2000 , to $89 \%$ in 2005 . Rosa and Spanjol's proposition that ordinality increases when a market develops is slightly confirmed here. The increase is modest, just as the incremental innovation.

- The percentage of subjectively-evaluated attributes fluctuates from $63 \%$ in $1990-93$, to $49 \%$ in 1996 , to $66 \%$ in 2000 , to $41 \%$ in 2005 . With Rosa and Spanjol we would expect this percentage to increase over time, due to an increase of assessments of the product. This proposition is clearly not confirmed here.

\section{$\operatorname{HEV}(1992 / 93,1996,2000$, and 2005}

Table 4.4: key indicators from yearly discourses on hybrid-electric vehicles

\begin{tabular}{|l|l|l|l|l|l|l|}
\hline HEV & $\begin{array}{l}\# \\
\text { accounts }\end{array}$ & $\begin{array}{l}\text { Complexity } \\
\text { (+ average) }\end{array}$ & $\begin{array}{l}\text { ordinal- } \\
\text { ity }\end{array}$ & appraisal & $\begin{array}{l}\text { Subject.- } \\
\text { evaluated }\end{array}$ & $\begin{array}{l}\text { \% user } \\
\text { experience }\end{array}$ \\
\hline $1992-93$ & First 7 & $14(4.0)$ & $93 \%$ & +10 & $57 \%$ & $0 \%$ \\
\hline 1996 & 7 & $19(6.0)$ & $79 \%$ & +16 & $50 \%$ & $0 \%$ \\
\hline 2000 & 22 & $33(6.5)$ & $88 \%$ & +16 & $75 \%$ & $41 \%$ \\
\hline 2005 & 41 & $28(3.9)$ & $89 \%$ & +80 & $66 \%$ & $15 \%$ \\
\hline
\end{tabular}

For HEV we found:

- Complexity: the total number of attributes used to describe a HEV was 14 in 1992-93, 19 in 1996, 33 by 2000 and 28 by 2005 (see Table 4.4). 2000 is the year of market launch. A HEV was and is a very complex product. The increase up to 2000 seems due to an increasing focus on a very complex product.

- The average number of attributes per account increased from 4.0 in $1992 / 93$, to 6.0 in 1996 , to 6.5 in 2000 . By 2005 it had decreased to 3.9 per account. Like with complexity, the increase (up to 2000) seems due to an increasing focus on a very complex product. Since this is prior to market launch, the shared knowledge around HEV was still fairly low, so accounts could not built onto existing knowledge. By 2005 we see a sharp decrease of the average number of indicators in an account. I believe this is due to a growth in the shared knowledge of the product. This partly confirms Rosa and Spanjol's proposition of a decreasing complexity during market development.

\footnotetext{
${ }^{13}$ This statement generalizes over all accounts, which therefore loses the conflict of stories. In section 4.4 we will discuss conflicting stories or frames.
} 
- The most mentioned attribute in $1992-93$ is engine structure (100\%): all accounts mention the combination of the electric engine with the ICE, to indicate what a HEV is. Environmental impact and fuel efficiency are 43\%, all others are lower. By 1996 engine structure is still $100 \%$, followed by environmental impact ( $86 \%$ ), see Figure 1. Engine weight and maximum speed, and fuel efficiency were less prominent (each 43\%). By 2000 engine structure was still highest with $77 \%$, followed by fuel efficiency (59\%), price (55\%), and environmental impact (55\%). By 2005, engine structure was still highest (88\%), followed by fuel efficiency (63\%), and environmental impact (37\%). Price dropped sharply to $15 \%$. In conclusion: in the mid-nineties engine structure and environmental impact were main attributes, while around 2005 this had become engine structure and fuel efficiency. This may well have to do with increasing fuel prices in the early 2000s, and also with a consumer tendency to focus on individual benefits, instead of common goods (such as air quality).

- Looking to the type of accounts, in 1990 and 1996 accounts are not based on user or production experiences. Only by 2000 , when the Toyota Prius is launched (in autumn) 'experiences' are observed, already in $41 \%$ of the accounts, all from the user. Increase of this number is expected after 2000. By 2005 this number had decreased however to $15 \%$ (even in absolute terms: 6 accounts in contrast to 9 in 2005). This seems to be the case because very few hybrid models have been launched after 2000 in general, and especially in 2005. By contrast, other types of accounts increased, such as 'sector observations and/or future expectations' (34\%), and policy announcement or discussion (22\%). In conclusion, hybrid engines receive increasingly attention, though this is less related to actual increase of product models and user experience.

- If 'total appraisal' of the HEV is quantified, it shows a steady increase from +10 in 1992-93 to +16 in $1996,+16$ in 2000 , to +80 by 2005 (see Table 4.4). Certainly this value is not very accurate, but it does indicate that the appraisal of HEV were slightly positive by 2000 , and very high by 2005 . We should be cautious with conclusions however, since the level of actual experiences with the innovation is fairly low by 2005 . To become more conclusive, we examined the appraisal of the (8 accounts of) user and producer experiences in 2005 . We found an appraisal of +20 . (Relative to DI Diesel this is low, since that scored +46 by 2005 , with $67 \%$ user accounts.) Further we observe two conflicting stories: user experiences are fairly positive about HEV $(+21)$, while the two producer accounts are indifferent or slightly negative about it $(-1)$.

- Ordinality fluctuates from $93 \%$ in $1992-93$ to $79 \%$ in 1996 , to $88 \%$ in 2000 , to $89 \%$ by 2005 (see Table 4.4). It is fair to say it is roughly $80-90 \%$. This is comparable to DI Diesel.

- The percentage of 'subjectively-evaluated' attributes varied from $57 \%$ in $1992-93$, to $50 \%$ in 1996 , to $75 \%$ in 2000 , to $66 \%$ in 2005 . With Rosa and Spanjol we would expect this percentage to increase over time, due to an increase of assessment of the product. With regard to the drop after 2000, the proposition is not confirmed here.

Electrical vehicle: 1990/91, 1996, 2000, and 2005

Table 4.5: key indicators from yearly discourses on electric vehicles

\begin{tabular}{|l|l|l|l|l|l|l|}
\hline EV & $\begin{array}{l}\# \\
\text { accounts }\end{array}$ & $\begin{array}{l}\text { Complexity } \\
\text { (+ average) }\end{array}$ & ordinality & appraisal & $\begin{array}{l}\text { Subject.- } \\
\text { evaluated }\end{array}$ & $\begin{array}{l}\text { \% user } \\
\text { experience }\end{array}$ \\
\hline $\begin{array}{l}1990- \\
91\end{array}$ & First 7 & $18(5.4)$ & $78 \%$ & -3 & $63 \%$ & $14 \%$ \\
\hline 1996 & 20 & $22(4.5)$ & $86 \%$ & -31 & $52 \%$ & $35 \%$ \\
\hline 2000 & 7 & $19(5.9)$ & $89 \%$ & -12 & $73 \%$ & $71 \%$ \\
\hline 2005 & 2 & $13(8)$ & $77 \%$ & -5 & $56 \%$ & $50 \%$ \\
\hline
\end{tabular}


For EV we found the following remarkable things:

- Complexity, i.e. the total number of attributes used to describe an EV, was 18 in 1990, 22 in 1996, 19 by 2000, and 13 by 2005 (see Table 4.5). Apparently an electric car engine was and stayed a complex product for several years, with many aspect and elements to refer to. Only by 2005 it was framed slightly simpler, which may result from the low number of accounts (only two). It is difficult to test Rosa and Spanjol's proposition of a decreasing level of complexity, since the market for EVs didn't develop.

- Three most mentioned attributes are in 1990: range (71\%), environmental impact (71\%), and maximum speed (57\%). Whereas in 1996 these are range $(75 \%)$, price $(55 \%)$, and engine structure (50\%), the first two being negatively evaluated. Environmental impact dropped in the course of time, to $35 \%$ of the accounts by 1996 , while being appraised positively. By 2000 there is only one attribute mentioned in more than $50 \%$ of the accounts: range (71\%). This attribute is evaluated very negatively. By 2005 three attributes are used in all (of the two) accounts: range, refuel-time, and way of refuelling. None of them is evaluated positively.

- A number of attributes had disappeared by 1996 (compared to 1990), four new attributes came in use (refuel locations, production cost, dirty weather speed, size, operation cost). These relate to the use of the product. They were all four appraised with a decline or a large decline in satisfaction compared to contemporary cars.

- Looking to the type of accounts, by 1996 accounts have a higher proportion of 'experiences' with the innovation ( $35 \%$ compared to $14 \%$ in 1990), both from the user and the producer side. By 1990 there were mainly 'announcements' of products or user experiments. By $2000,71 \%$ of accounts were based on user or producer experiences. By 2005 reports of experiences was one of two.

- If 'total appraisal' of EV is quantified, it shows a drop from minus 3 in 1990 to minus 31 in 1996, minus 12 in 2000, and minus 5 in 2005. Certainly this value is not very accurate, but it does indicate roughly what the appraisal of the innovation is. In 1996 and 2000 there is clearly a general feeling that the innovation has more disadvantages than advantages. The same holds for 2005.

- Ordinality slightly increases from $78 \%$ in 1990 to $86 \%$ in 1996, to $89 \%$ in 2000 , and then dropping to $77 \%$ in 2005 , see Table 4.5 . It is fair to say it is roughly $80-90 \%$. Rosa and Spanjol's proposition that ordinality increases when a market develops is difficult to test here, since a market for EV did not really develop.

- The percentage of subjectively-evaluated attributes varies from $63 \%$ in 1990 , to $52 \%$ in 1996 , to $73 \%$ in 2000 , and $56 \%$ in 2005 . With Rosa and Spanjol we would expect this percentage to increase over time, due to an increase of assessments of the product. The decrease between 1990 and 1996 is surprising, since some user experiments are done in this period. Maybe the percentage of 1990 is relatively high, because of high expectations around $\mathrm{EV}$, possibly wishful thinking. This brings market actors to positive appraisals, which are not based on actual experiences. 


\subsection{DISCUSSION}

\section{Little attention for new engines}

The six national newspapers in the Netherlands published 180 stories on car engine innovations in the four periods we studied. Regarding the total number of newspaper issues during those periods, the attention for new car engines is not so high. Total yearly issues for the newspapers exceed 310. Given the 40 to 80 engine innovation stories, we find one account in every 20 to 30 days in each newspaper. So, new car engines get not so much attention, probably on the assumption that large parts of the general public are likely not really interested in the precise technology below the bonnet.

\section{Growing attention for new engines}

We found that attention for new engine technology is growing after 1996: from about 40 stories a year in 1996 to about 60 by 2000 to more than 80 a year by 2005 (see Table 4.2).

\section{Most attention for unconventional engines}

We observed that there is relatively more attention in newspapers for unconventional innovations than for incremental innovations. In 1996 twenty articles (or sections) were explicitly on the electric vehicle, while only ten were on the direct injected diesel. Still, only the latter was successful as a product market with regard to sales levels and investments of firms. Similarly, the largest share of articles in 2005 was on HEV, while new diesel engines were far more sold that year. Apparently, newspaper has a favor for what is most new.

\section{Hypes around unconventional engines}

Attention for one of the unconventional engines, the electric engine, fluctuates strongly: from 6 in 1990 to 20 in 1996, to 7 in 2000, to 3 in 2005. This suggests a hype-disappointment cycle. Gartner consultancy (see Geels 2005) has described this as a typical cyclical pattern of some new technologies, consisting of a phase of self-reinforcing boost of expectations, followed by peak of the hype, and finally a sharp trough of disillusionment. After the backlash the enthusiasm may recover. Electric engines have gained renewed attention after 2005, mostly due to a new generation of batteries, but this is outside the boundaries of this analysis.

For the hybrid-electric engine we do not find such a cyclical pattern. Attention for these engines shows a steady growth from 7 in 1996 to 22 in 2000 to 41 in 2005.

\section{An engine is complex}

The newspaper articles reflect that an engine is a complex product! In each period of a year, at least more than ten attributes are used to describe the innovation. The first newspaper account about a test drive of the Toyota Prius applied fourteen attributes to describe the engine-related aspects of the vehicle, and over the whole year attributes used to portray an HEV added up to thirty three. It is unlikely that laymen can handle this complexity. Probably many will loose interest in the precise engine, unless one is a 'car-enthusiast'. This relates to the first conclusion.

\section{Hybrid frames shift more than diesel}

For direct injected diesel engines, we found that engine capacity and volume are two attributes that have become a stable part of the frame of DI diesel, appearing in at least $83 \%$ of accounts since 1996. Other persistent prominent attributes are acceleration, torque, maximum speed, engine structure and fuel efficiency. We conclude that between 1996 and 2005 the shift in diesel framing was only slight (both in structure and in appraisal), see also in Figure 4.2 (which is a reprint of part of Figure 4.1). 
Framing of DI Diesel 2000

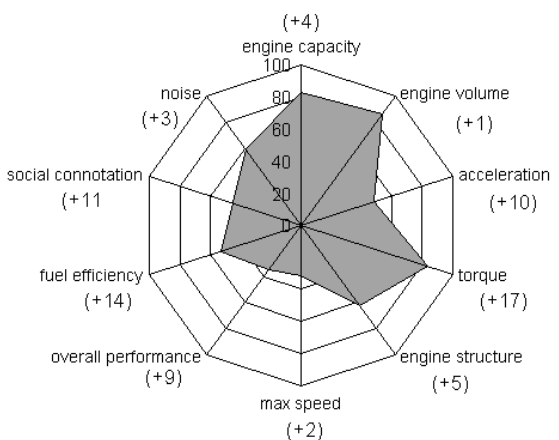

Framing of DI Diesel 2005

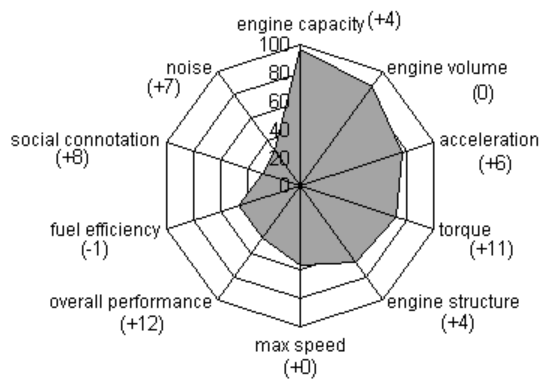

Figure 4.2: Technological frames for direct injected diesels in 2000 and 2005: the spider diagram indicates the attention for attributes; the outer values indicate the appraisal score of that feature.

The drop in appraisal for fuel efficiency is the only notable change. It fell from +14 in 2000 to -1 in 2005. This may be because users got accustomed to the relatively high fuel efficiency of the DI diesel engine, and found it normal by 2005.

For HEV on the other hand, there has been quite a shift in the frames between 2000 and 2005, which is shown in Figure 4.3 (which is a reprint of part of Figure 4.1).

\section{Framing hybrid-electric engine 2000}

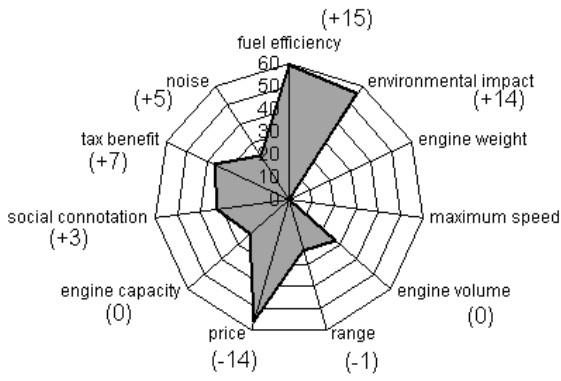

\section{Framing hybrid-electric engine 2005}

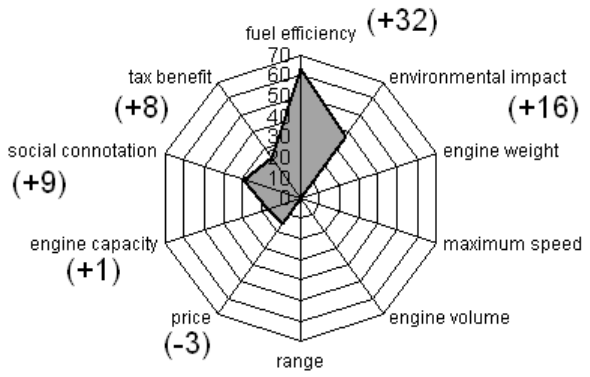

Figure 4.3: Technological frames for HEV in 2000 and 2005: the spider diagram indicates the attention for attributes; the outer values indicate the appraisal score of that feature.

Most remarkable is the decrease in emphasis of environmental impact: from $86 \%$ (1996) to 55\% (2000) to $37 \%$ (2005), simultaneously to an increase on fuel efficiency: $43 \%$ (1996) to 59\% (2000) to $63 \%$ (2005). This may well have to do with increasing fuel prices in the early 2000 s, and also with a consumer tendency to focus on individual benefits, instead of common goods (such as air quality). Further, price of the engine is evaluated negatively by $2005(-3)$, though in 2000 this was much worse (-14). This is probably due to fiscal support for HEV and/or high gasoline prices. All in all framing of HEV changed quite substantially, and took place mainly prior to the diffusion process: in 2005 the percentage of HEV in new car sales was only $0.5 \%$. Apparently the frame was fairly flexible by that time; more than the more mature diesel market. These observations confirm Bijkers' (1995) notion of increasing obduracy in the process of closure. Diesel technology is an established technology (more than 100 years old), and indeed we find that frames of diesel 
engines are fairly stable. This is probably since consensus emerged among different relevant social groups about the dominant meaning of the artefact. Hybrid-electric and electric technologies on the other hand are new for the market, and therefore their framing is still fairly fluid. Another difference of HEV with diesel in this respect is that it has less prominent attributes: where diesel had three attributes higher than $80 \%$, and another three around $60 \%$, HEV has only one higher than $60 \%$, and another two $55 \%$ or lower.

\section{Little environmental concern in diesel frame}

Engine capacity and volume are two attributes that have become a stable part of the frame of DI diesel, appearing in at least $83 \%$ of accounts since 1996. Further, environmental impact was mentioned in $20 \%$ of the accounts in $1996,3 \%$ in 2000 , and $10 \%$ in 2005 . It therefore was a very minor attribute. Environmental concerns are apparently little associated with discussing new diesel engines throughout the whole period.

\section{Social connotation plays a role}

We found that social connotation is not the most important attribute in technological frames of car engines, but that it does play a role. Steg et al. (2001) have studies the relative importance of social symbolic attributes of cars (not car engines) next to functional attributes. This had been hardly tested and validated by empirical research before. Through a social-psychological method they find that both functional and symbolic-affective attributes are significant in the attractiveness of the car. They do not specify which one of the two is most important. Through our discourse analysis we found that for car engines prices and functional performance attributes are most important, but that social meaning does play a role too. We mapped the development of social connotation of the improved diesel engine. In a significant share of the accounts social connotative attributes are attached to the engine (45\% in $2000,28 \%$ in 2005$)$, which is stable and positive, varying from 'super-diesel', to 'delicious' and 'brand-new'. Highest appraisal occurred around 2000; by 2005 the enthusiasm had slightly tempered.

The development of social connotation of electric and especially hybrid-electric vehicles shows some remarkable dynamics. In the mid-1990s we find that attention for EVs was fairly high: 20 accounts, which is double the amount of direct injected diesels in that year. Social connotation was however underdeveloped: only in $15 \%$ of the accounts we could recognize it, in quite neutral statements. Most accounts were summing up technical characteristics. Around 2000 attention for EVs had collapsed, and social connotation had not developed. Meanwhile, attention for HEVs had grown considerably, up to 22 accounts by 2000. Social connotative attributes already appeared in one third of the accounts. They were mostly positive (with adjectives such as 'high-tech', 'environmental friendly', 'modern'), some were neutral, and one was negative. By 2005 attention had mounted up to 41 accounts, even more than direct injected diesels in that year. Reference to social connotation appeared in about a third of the accounts, and its mainly positive appraisal had caught up with direct injected diesel. Since our findings are based on all stories in national newspapers, they are difficult to compare to a survey of American HEV consumers, which finds that 31 percent of HEV buyers said they purchased an HEV because the vehicle 'makes a statement about me' (Heffner et al., 2007). It slightly suggests that social connotation is more important for American than for Dutch buyers.

In our study twenty-two percent of the accounts of HEV in 2005 were directly part of a policy discussion, and either announcing tax (or parking) discounts for hybrids, or pleading for it. This indicates the dominant social climate of praise for hybrids, and how it was easily adopted in political pleas. Apart from influencing consumers, it thus also pushed political support for tax discounts on HEVs in many countries. 


\section{Phases in shifting frames}

Two phases can be distinguished in the technological framing during market development of an innovation (product): before market launch and after. Before launch we observe a low level of hands-on user (or producer) experience in the stories, only experiments. We found typically positive attitudes and expectations, enthusiasm for what is seen as progress, and some marketing language. After product launch hands-on user (and producer) experience increase, and from that moment on appraisals start to relate to the actual (adoption, sales) behavior. We observe the appraisal of an unsuccessful product, EV, sharply decreasing after launch (from -3 in 1990 to -31 in 1996, see Table 4.5), which will be surprising for an observer without practical experience with the technology. Appraisal of a successful product, such as direct injected diesel, increased after launch (from +7 in 1992 to +28 in 1996). The product market subsequently further unfolded. The trend for HEV is right in the middle of these two more extreme scenarios: it was +10 by $1992,+17$ by 1996 and +16 by 2000 .

The indication of two phases explicates that 'stories' told and heard by market actors are not the whole story. Hands-on experience is another. As soon as people have actual experiences with the product, their original stories and frames may well be overruled. Flashy catchy testimonies can make people enthusiastic, but actual experience will re-balance their attitudes. Most car drivers have fairly stable preferences and expectations regarding car driving (drivability, maximum speed, acceleration, range, safety, comfort level etc.). They can for instance be told that $120 \mathrm{~km}$ of range is enough for most of their trips, such as with an EV, but if they experience this as an increased threat of ending up with no electricity half away a trip, their enthusiasm crumples.

This analysis suggests that the notion of the hype-disappointment cycle (Geels 2005) can be further developed by incorporating the market evolution of the product. We find that the market launch of a product is a critical moment in the appreciation and attention for the product. The twist of the trend line of product expectations or appraisal, either upward or downward, is an important indication of the success of the new product market.

\section{How is HEV appreciated in 2005, relative to DI Diesel?}

If 'total appraisal' of the HEV is scored (see Appendix A), it shows fluctuation from +10 in 199293 to +17 in $1996,+16$ in 2000 , to +80 by 2005 (see Table 4.4). Though this value is not perfectly accurate, it does indicate that the appraisal of HEV where fairly high by 2000 , and very high by 2005. It may seem that hybrid is appraised higher than DI diesel by 2005 ( +80 versus +46$)$, but the low level of user experiences of the story tellers in the hybrid accounts $(15 \%)$ is affecting the comparison. To become more conclusive, we examined the appraisal of the ( 8 accounts of) user and producer experiences, and we found an appraisal of +20 . Relative to DI Diesel this is lower, since that scored +35 on the sole user accounts by 2005 .

\section{Conflicting (sub) frames in the technological frames}

Both for electric and hybrid-electric vehicles we found dissimilarities of stories between producers and consumers: the first being mostly pessimistic about the innovation, and the latter mostly positive. For example in 2005: user experiences are fairly positive about HEV $(+21)$, while producer accounts are indifferent or slightly negative about it $(-1)$. Car firms evaluate new products on the basis of their business opportunity (profitability), which usually means a mass production and sales basis (Lehna, 2004). For EV and HEV most producers did not perceive bright outlooks (or said so for strategic reasons given their economic interest in non-electric vehicles).

Within the group of consumers there are likely various sub-frames too, relating to various consumer groups. Since our discourse analysis is less suited to find sub-frames, we analyzed actual sales ('revealed preferences'), and performed semi-structured interviews with car salesmen. Customers of new vehicles can choose their preferred type (and size) of engine out of 
a range of alternatives (usually between two to six). We analyzed the outcomes of such consumer choices for the $30^{\text {th }}$ highest volume car types in The Netherlands, in total more than 200.000 choices (in a year), between 2003 and 2008 (see Appendix D for more details on this analysis). We found three types of (engine) consumer groups. A first group, consisting of (on average) 30 to $35 \%$ of consumers, chose the cheapest engine. The cheapest engine tends to be lightest, and this results in relatively high fuel economy (for its class). A second, largest share of customers is willing to pay (a few thousands of euro) more for a stronger engine (with lower fuel economy): this is the case in 60 to $70 \%$ of the consumers. Customers have different reasons for this: typically to drive more convenient on the highway, or because they like sporty driving, for status, or to use a caravan. Few customers are willing to pay (a few thousand euro) more for a cleaner engine: if such an option is available it was only $5 \%$ or less; often such an option is not

Table 4.6: Size and characteristics of consumer sub-frames..

\begin{tabular}{|l|l|l|l|l|l|}
\hline Consumer sub-frame & Size & Weights \\
\hline & & Functionality & $\begin{array}{l}\text { Social } \\
\text { Connotation }\end{array}$ & $\begin{array}{l}\text { Price } \\
15\end{array}$ & $\begin{array}{l}\text { Environmental } \\
\text { Impact }\end{array}$ \\
\hline 1: 'penny-pinchers' & $35 \%$ & 0.30 & 0.20 & 0.45 & 0.05 \\
\hline 2: 'power for convenience' & $60 \%$ & 0.50 & 0.20 & 0.30 & 0 \\
\hline 3: 'green' & $5 \%$ & 0.05 & 0.20 & 0.30 & 0.45 \\
\hline
\end{tabular}

\section{Consumer Frame 1: Pennypinchers Consumer Frame 2: Convenience}
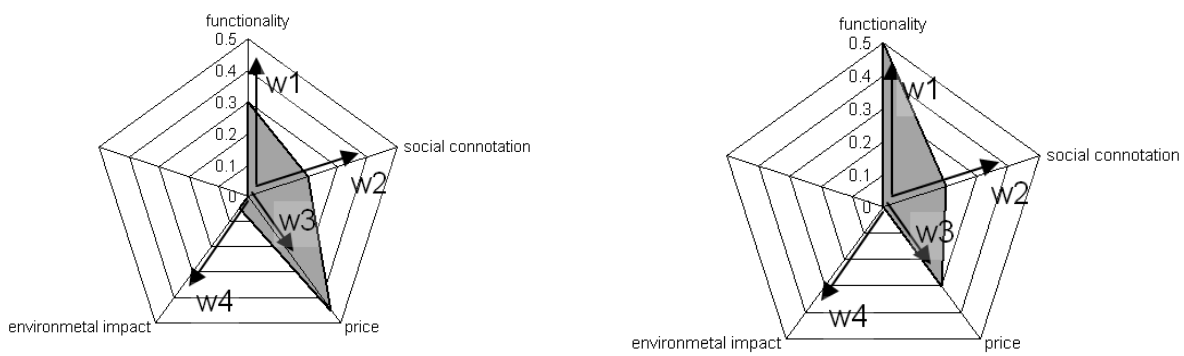

\section{Consumer Frame 3: Green}

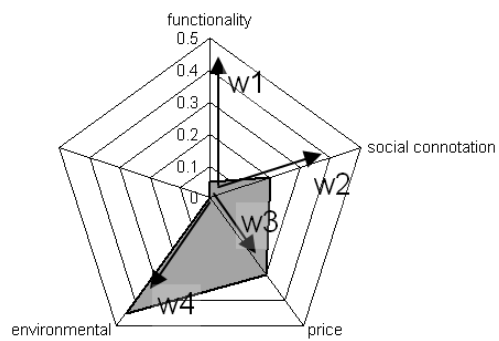

Figure 4.3: Consumer sub-frames; Table 4.6 visualized.

available $^{16}$. Adding up these 'green' ICE consumers with hybrid-electric drivers (and LPG drivers), makes the estimated share of 'green consumers' in the whole population around 2 or $3 \%$. We

\footnotetext{
${ }^{14}$ Functionality includes engine capacity, acceleration, maximum speed, etc.

${ }^{15}$ Price includes purchase price and operational cost (which relates to fuel efficiency)
} 
found no evidence that this group is growing: hybrid sales stabilized at 2800 in 2005, 2006 and 2007, being about $0.5 \%$ market share; LPG did not grow either.)

In order to get a flavour of the three sub-groups, we combine the discourse analysis with the revealed preferences, and sketch three subgroups or sub-frames, within the aggregated market frames of Figure 4.2 and 4.3. Table 4.6 shows how we sketch these three groups with their distinct balance of attention for functionality, social connotation, price, and environmental impact. Individual consumers will be inclined to one of these three sub-frames. The rationale here is that when the three user groups (frames) are merged, accounting their sizes, they should deliver the (aggregate and averaged) socio-technical frame, such as in figure 4.2 and 4.3. Clearly, this is not a perfectly sound method, but valuable as a first estimate for consumer sub-groups.

\subsection{CONCLUSION}

Consumers use stories to understand new products, to determine their value to them. Prior to hands-on experience from product trials and observation of other users, stories are the only way people learn about a product. By analyzing stories on different types of car engines over the course of 15 years, we found evidence how consumers frame different engines differently:

- framing of conventional diesel engines has been fairly stable between 1996 and 2005, despite progressive technological innovation. Main attributes were engine capacity (number of $\mathrm{kW}$ ), engine volume (number of liters) and torque (amount of force, in Nm). Environmental impact is rarely referred to.

- framing of hybrid-electric engines shifted much more than frames of diesel engines. Remarkable is the decrease in emphasis of environmental impact: from 86\% (1996) to 55\% (2000) to $37 \%$ (2005), simultaneously to an increase on fuel efficiency: $43 \%$ (1996) to $59 \%$ (2000) to $63 \%$ (2005). Price of the engine is evaluated negatively by $2005(-3)$, though in 2000 this was much worse $(-14)$.

- framing of electric vehicles has also been less stable. Only range is a persistently salient attribute, evaluated negatively. Others, like price and refuel time, are slightly less persistent and or salient.

By 2005 , overall appraisal scores of the various engines were -1 for $\mathrm{EV},+20$ for $\mathrm{HEV}$, and +35 for DI Diesel, where only consumers with user experience are taken into account.

We draw four final conclusions from our analysis. First, framing of the established technology (conventional diesel engines) is more obdurate than that of an unconventional engine. This corresponds with Bijker's (1995) notion of stabilization towards a dominant frame in the course of market development of an artefact, or in other words: high obduracy after closure.

Second, two phases can be distinguished in the technological framing during market development of an innovation (product): before market launch and after. As soon as people have actual experiences with the product, their original stories and frames may well be overruled. This conclusion suggests that the notion of the hype-disappointment cycle (Geels 2005) can be further developed by incorporating the market evolution of the product. We find that the market launch of a product is a critical moment in the appreciation and attention for the product.

\footnotetext{
${ }^{16}$ Here, engines are meant that are specifically engineered for high fuel economy, without compromising on power. An example is the 3 -liter engine from Audi/Volkswagen, which can make $100 \mathrm{~km}$ on 3 liter petrol. These engines are more expensive. Not all manufacturers offer these high efficiency engines. After 2007 more versions have appeared on the market (e.g. Volkswagen Bluemotion).
} 
Third, social connotation plays a role in technological frames of car engines. This resembles the conclusion that Steg et al. (2001) found for the car as a whole. We found that for car engines social connotation is not the most important attribute, rather prices and functional performance attribute are more important. For car engines social meaning does play a role though. Apart from influencing consumers, we found that it also affects policy discussions political support of tax measures.

Fourth and finally, we found some evidence for sub-frames among consumers. Supported by an analysis of actual sales in the Netherlands, we provided hints that three sub-groups can be distinguished in the total population of consumers of new cars: for the first group (in size about $35 \%)$ price is the most salient attribute. They are satisfied with the functionality of the cheapest engine. The second group (about $60 \%$ ) is willing to pay more for a stronger engine. Customers have different reasons for this: typically to drive more convenient on the highway, or because they like sporty driving, for status, or to use a caravan. Finally a small third group is willing to pay more for a cleaner engine. This group is not larger than 2 or $3 \%$. There is little evidence that it is growing. 

Chapter 5

TECHNOLOGICAL FRAMING BY CAR FIRMS 


\section{Technological framing by car firms}

In this chapter we analyze technological frames of car firms towards development of Ultra Low Emission Vehicles (ULEV). We examine the framing of firms by studying their belief systems and actual engagement. The central question is: Which underlying beliefs significantly drive the engagement in the development of ULEV technology? A second question concerns whether we can map out diversity between firms. We thus 'step into the shoes' of the car firms and analyse their social, business, technological and environmental considerations. In order to achieve enough focus, we will focus on hydrogen vehicle technology ${ }^{17}$ as an example of an ULEV. Scholars, industry strategists as well as policy makers acknowledge hydrogen as an important future energy carrier for transportation (Hekkert and Van den Hoed, 2004).

In section 5.1 we first introduce how car firms view car engines in general. We then present results of our survey to identify present-day beliefs of global car firms towards development of hydrogen propulsion technology (section 5.2). In section 5.3 we discuss the outcomes, also in the light of additional semi-structured interviews. We address the relation of actor beliefs and actor framing, offering a conclusion at the end.

\subsection{CAR FIRMS AND CAR ENGINES}

A glance at the product range in today's car showrooms shows a strong commitment of all mainstream vehicle manufacturers to conventional Internal Combustion (IC) gasoline and diesel technology. These types of engines have been built and refined for more than 100 years now (Cowan and Hulten 1996). After 1990, alternative ways of propelling vehicles have been presented by various car firms: full electric and hydrogen, as well as hybrid-electric models. In general, these three alternatives have received much less (research and development) attention than the dominant IC engine. Hybrid-electric engines have yet been incorporated in most car manufacturers' research efforts now, at least to some extent. Most firms consider them important on the short or medium term (Teske and Chanaron 2007). From an environmental perspective, they should be considered neither a minor nor a major innovation, decreasing harmful emissions (from driving) by $10 \%$ to $20 \%$ (Lave and MacLean, 2002). Next to hybridelectric systems, more radical alternatives had been presented earlier on. There are full electric vehicles, which were (re)introduced in the 1990s and there are hydrogen vehicles, introduced around 2000. These latter two types of vehicles are examples of Ultra Low Emission Vehicles (ULEVs). They emit extremely low levels of harmful gases compared to existing diesel and gasoline vehicles. California's Air Resources Board defines a ULEV as a vehicle that emits $50 \%$ less pollution emissions than the average for new cars released in that model year. In this chapter, we follow that definition, and include $\mathrm{CO}_{2}$ as a harmful gas in the examined emissions ${ }^{18}$.

Car firms are confronted with a range of uncertainties around car engines. What are the future expectations of various alternative technologies? How strict will future emission legislation be? How should one enhance technological capabilities around alternative technologies: collaborate with suppliers, build strategic alliances with competitors or perform corporate Research and Development (R\&D)? How much money should one invest in alternative technologies? When is

\footnotetext{
${ }^{17}$ When the term 'hydrogen engines' is used in this chapter, two types of engines are meant: Fuel Cell vehicles (FCs) as well as ICE with hydrogen as fuel. For the survey in section 5.2 we have only included hydrogen fuel cells though.

${ }^{18}$ Obviously, emissions during the production of the fuel should be incorporated in the computation.
} 
the market ready for product launches? Is there a 'business case'? When are prototypes good enough to be launched? These are all questions without straightforward answers to firms.

How do car firms then deal with alternative propulsion technologies? Inter-firm competition in the R\&D on new engine technologies is intense (Molot, 2008). There is major competition over gasoline and diesel technology, as well as hybrid-electric and hydrogen vehicles. The high cost for this type of research and the search for competitive advantage sometimes push car firms into strategic alliances with each other, as well as with suppliers. For cleaner technologies, several partnerships have emerged, often partly government-sponsored (such as California's Fuel Cell Partnership). Although research consortia are important in the initial stages of research on new and costly technologies, inter-firm competition for first-mover advantages imposes limits on the extent of corporate cooperation around R\&D.

In this chapter we focus on firm framing towards hydrogen engine technologies, as an example of an ULEV. Most of the major (top five) auto assemblers are working to produce hydrogen vehicles and are doing so in their home countries, generally at sites close to their head offices. Daimler's Fuel Cell (FC) R\&D is based in Germany; those of Ford and GM are in the USA, and Toyota's base is in Japan. GM, which began cooperation with the US Department of Energy on alternative fuels in 1989-1990, was the first assembler to begin research on hydrogen vehicles. GM has invested considerable resources over a long period of time in the search for a viable Fuel Cell Vehicle (FCV) and has alliances with a number of companies, such as Dow Chemical. In recent years, some demonstration projects with fleets of consumer vehicles have been launched in Washington, California and Berlin, amongst others, where both GM and Daimler are participating. Toyota and Honda are also investing quite substantially in R\&D around FCVs ${ }^{19}$ (Van den Hoed, 2005; Molot, 2008).

Some companies regard hybrid technology as an important transition step on an indefinite time path to FCVs. Toyota expects that assemblers that master hybrids will have significant cost and learning advantage over competitors when commercialising FCs (Molot, 2008).

Again, because of the significant first-mover advantage (that will accrue to the assembler that first produces a reliable and reasonably priced FCV), it is not surprising that assemblers undertake this kind of leading-edge research in-house. In describing the 'strict partitioning' between research undertaken in-house and that conducted in research partnerships, one expert used the term "firewall" (Avadikyan and Larrue, 2003). Disruptive technologies are, by definition, uncertain. Despite the huge amount invested in R\&D to develop FCVs, a number of uncertainties around cost, infrastructure, hydrogen production and storage remain.

How strong is the dedication of firms to hydrogen technology development? Are firms investing to make way for market introduction as soon as possible? Or are firms slightly engaging as a minimal insurance to not miss the boat when it departs? These latter matters have stayed unresolved. In the next section we describe the hydrogen technology through the eyes of car firms, and analyze their technological frames.

\footnotetext{
${ }^{19}$ Until 2000 Daimler/Chrysler has invested approximately \$1 billion on FCVs. By 2004, an estimated \$6-10 billions has been spent by the auto industry alone to research and develop FCVs.
} 


\subsection{ENGAGEMENT AND BELIEFS TOWARDS HYDROGEN TECHNOLOGY}

This section presents responses of seven global car firms ${ }^{20}$ towards hydrogen technology, which were contacted in 2005. Though the absolute number of this set is not high, the seven firms do represent a significant share of the (around 12) major global car manufacturers. The majority of the respondents were at senior engineering level (see Appendix E). Therefore, we can be confident that respondents were sufficiently knowledgeable about the firm's strategy on hydrogen. (The questionnaire is printed below in Appendix F.)

We assume these people to have voiced the vision of their organization. Regarding the seniority of most respondents and the way we have asked the question ('for your organisation') this is plausible. Nevertheless, the response may be biased for two reasons. Apart from the personal bias (from their position or personal opinion), there may be strategic PR considerations involved that intend to put the firms in a more positive light. At this point it is very difficult to assess to what extent this has played a role for the respondents, but we will need to take this into account when interpreting the response. Therefore, we will discuss the results of the questionnaire survey in the light of two additional interviews (90 minutes, semi-structured, see Appendix E). The combination of the questionnaires and interviews gives sufficient confidence to draw some conclusions from this analysis.

\subsubsection{Engagement in developing a hydrogen vehicle}

The extent to which a firm is 'engaged in development of hydrogen propulsion' was a key question asked at the beginning and end of the questionnaire (scale of $1-5$, ranging from 'not at all, very little, little, moderately, to extensively). From the response at the beginning of the questionnaire we find that the mean value for the seven respondents was 4.3 (for present engagement) and 4.3 (for future engagement). In other words, the perceived present engagement is slightly above 'moderate'. Further we find that firms do not intend to increase their development efforts for the hydrogen car.

In order to test the stability of the respondents the same question was posed again at the end of the questionnaire. Now we find that the engagement in hydrogen vehicle development is 2.5 (present) and 3.2 (future) on average, much lower than the 4.3 that was found (for both) earlier. It is remarkable that the difference between the scores and the beginning and the end is so great. We suspect that responses at the end of the questionnaire are less biases by possible PR considerations that one may have had in mind at the start of the questionnaire, and also because respondents have activated their knowledge on the firms considerations in the course of all the questions (completing the questionnaire took about 20 minutes). Finally, with regard to the responses during the interviews at two car manufacturers, we were told that hydrogen technology was only a minor area of development for them and for most of the firms in the sector, and therefore we assume that the mean value of 2.5 is most accurate, suggesting that firms are little engaged in hydrogen vehicle development.

The distribution of values over the respondents gives an indication on how the mean value was delivered; see Figure 5.1. The distribution of engagement over the car manufacturers shows that the largest share of firms in the dataset (i.e. four of seven) regards their engagement as 'little'. One firm chooses 'moderately' and two choose 'not at all' (whereas one did not respond to this question at the end).

\footnotetext{
${ }^{20}$ These are: Daimler/Chrysler, Honda, Nissan, Renault, Peugeot, Saab and Audi.
} 


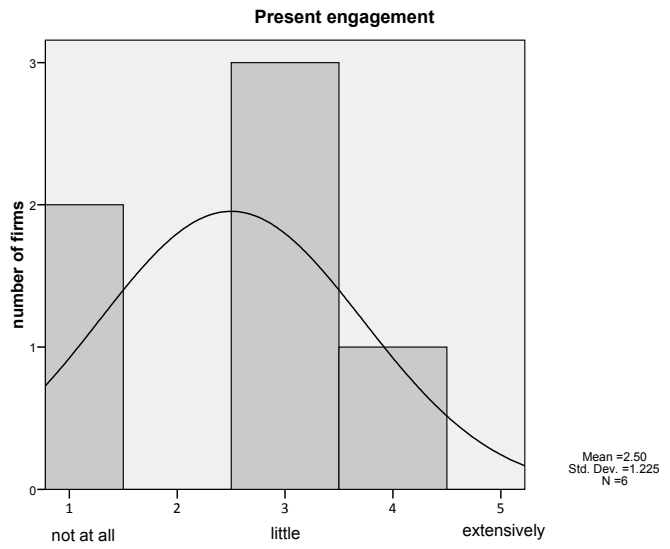

Figure 5.1: Distribution of present engagement in hydrogen vehicle development over the respondents

\subsubsection{Potential drivers of engagement}

Following the social-psychological model of Montalvo (2002, 2006, see chapter 3), we consider nine potentially salient underlying beliefs to the engagement levels, grouped in three categories. These are: perceived Environmental Risk (EV) and Economic Risk/Opportunity (ER), both components of attitude toward innovation; perceived Community Pressure (CP), Market Pressure (MP), and Regulatory Pressure (RP), all components of perceived social pressures to innovate; perceived Technological Capabilities (TC), Organisational Learning (OL), strategic alliances (AL) and Collaboration Networks (NW), all components of perceived control over the innovation process.

By each of the seven respondents, these nine items were scored in the questionnaire (scale of $1-7)^{21}$ : Table 5.1 shows the mean values.

Table 5.1: The mean values of beliefs to the hydrogen vehicle

\begin{tabular}{ll}
\hline item & mean \\
\hline Perceived Environmental Risk & 2.9 \\
Perceived Economic Risk & 2.4 \\
Perceived Market Pressure & 2.4 \\
Perceived Community Pressure & 2.6 \\
Perceived Regulatory Pressure & 2.3 \\
Perceived Technological Capabilities & 3.3 \\
Perceived Organizational Learning Cap's & 3.3 \\
Perceived Strategic Alliance Capabilities & 4.4 \\
Perceived Networks of collaboration Cap's & 4.6 \\
\hline
\end{tabular}

${ }^{21}$ Or more precisely: 1 = very unlikely/not at all, $2=$ fairly unlikely, $3=$ slightly unlikely, $4=$ uncertain, $5=$ slightly likely, 6 = fairly likely, 7 = very/extensively likely. 
The low values for the salient beliefs that we observed in Table 5.1 are consistent with the low mean value of the present 'willingness' for the firms (3.9) that we found (see above). Here, we find that the 'attitude' towards the innovation process is slightly negative:

- The economic consequences of developing hydrogen vehicles are perceived to 'slightly likely' bring losses (2.4).

- The environmental risks of the current car models (i.e., Internal Combustion Engines (ICE)) is perceived to be slightly low (2.9).

The pressure from the social environment to develop hydrogen vehicles is not perceived as high by car firms:

- $\quad \mathrm{MP}, \mathrm{CP}$ and RP are perceived to be low: between 2.3 and 2.6. These are not likely to press the firms towards the development of hydrogen vehicle technology in the short run (one to two years).

The perceived capacity to perform the development of hydrogen vehicles is perceived as weak:

- TC and OL capabilities are 3.3 on average, where 3 means slightly low and 4 means uncertain. AL and NW are about one unit higher (4.4 and 4.6, respectively), that is, between uncertain and slightly easy.

Since the variance of the scores is quite high, a sole conclusion on the mean values is somewhat risky. Therefore, in addition, we will examine the answers of the seven companies separately (where actual engagement is scored on a scale of 1-5, whereas beliefs are score on scale 1-7):

- Firm 1 is presently little engaged in hydrogen (3) and has few plans for the next 5 to 10 years (3). It is uncertain about the economic consequences of engagement (4). EV is perceived as very low (1). Social pressures are perceived to be very low $(1,2$ and 2$)$. Its own TC around hydrogen is perceived as weak (2), but OL, AL or NW capabilities are uncertain or slightly strong (5). Conclusion: firm 1 has little ambition for hydrogen and is most optimistic about its NW capabilities (slightly strong).

- $\quad$ Firm 2 is hardly engaged in hydrogen (1), and it has few plans for the future (3). It would mean big losses for the firm (7). The EV of the current models is uncertain (4). Social pressures are low (2, 1 and 1). Capabilities are very weak (TC: 3 ; others, 1, 2 and 2). Conclusion: firm 2 is hardly engaged in hydrogen vehicle development for two possibly related reasons: its current capabilities around hydrogen vehicles are perceived to be weak and engagement will currently only mean great losses.

- $\quad$ Firm 3 is also hardly engaged in hydrogen vehicle development (1), and has no plans for the future (1). It perceives the economic consequences as very negative $(6$, moderated losses). The EV of the current models is slightly small. Social pressures are small $(2,1,1)$. The TC and $\mathrm{OL}$ around hydrogen are perceived to be very low (both 1). However, the capabilities to form AL and NW are seen as slightly and fairly high (6 and 5). Conclusion: similar to firm 2, firm 3 is very unwilling to engage in hydrogen vehicle development for two probably related reasons: its current capabilities around hydrogen are very small and engagement will currently bring moderated losses to them. Firm 3 seems to trust external knowledge sources at the moment.

- Firm 4 is moderately engaged (4) and has moderate plans (4). Still, it expects moderate losses from the current engagement. The environmental effects are uncertain. Social pressures are uncertain $(3,4,4)$. TC and OL are seen as slightly strong (5), just as AL and NW (5 and 6). Conclusion: firm 4 is fairly engaged and it believes to be (slightly) capable to engage in hydrogen vehicles.

- Firm 5 is currently little engaged with hydrogen (3), but has moderate plans for the future (4). Economic opportunities are currently seen as very negative (7). Social pressures are perceived to be very low $(1,1,1)$. Technological capabilities are low $(2)$, but the capabilities 
to build alliance and benefit from networks are slightly and fairly good ( 5 and 6). Conclusion: firm 5 is currently little engaged in hydrogen, but is confident about its network.

- Firm 6 is presently little engaged in hydrogen (3) and has some plans for the future (4). It is uncertain about all pressures (4), except for environmental risk, which is seen as slightly low (3). Conclusion: firm 6 is uncertain about hydrogen (or at least not outspoken about it).

- Firm 7 did not respond to the question on engagement at the end of the questionnaire, but the response to that question at the beginning suggests they are moderately engaged (4). It sees minimal economic losses (5). The environmental risk of the current models is perceived to be quite low (2). Social pressures are uncertain (all 4). TC and OL are perceived to be uncertain; only forming alliances are perceived to be slightly easy. Conclusion: this company is optimistic, most likely due to confidence in alliances, and expectation of some economic returns.

Three conclusions can be drawn from these discussions.

- Conclusion 1: we find three subgroups in the population of firms:

$\circ \quad$ Subgroup 1: these firms are somewhat engaged hydrogen (firms 1, 5 and 6).

- Subgroup 2: these firms are hardly engaged (firms 2 and 3), probably due to two related reasons: their current capabilities around hydrogen vehicles are perceived to be weak and engagement will currently only mean great or moderate losses.

- Subgroup 3: these firms are moderately engaged (firms 4 and 7). In one case, this is because of its slightly strong capabilities; the other seems to have high confidence in alliances. Both acknowledge current losses, but these are apparently seen as necessary investments.

- Conclusion 2: the (perceived) level of technological capabilities TC and organisational learning capabilities (OL) seems to have a high correlation with the engagement level. The two non-engaging companies have weak capabilities and one of the two optimistic companies has high capabilities (for the other firm, the response value is missing). From the three companies of little engagement, two are uncertain about their capabilities.

- Conclusion 3: five out of seven firms see their capabilities for AL and NW (i.e., attaining the required knowledge from outside) as higher than their own current TC and OL. It looks like a fair majority of the firms choose to rely on external technological knowledge sources for their potential hydrogen vehicle development.

\subsection{DISCUSSION AND CONCLUSION}

What does this analysis of belief systems clarify on technological framing by car firms? As we described in chapter 3 , we suppose knowledge and beliefs become manifest in the frame. The specific hydrogen-related belief-structure of firms shapes their framing of hydrogen technology. This delivers a specific appraisal of the technology, which can be summarized as willingness (i.e. as behavioural intention). Subsequently, willingness will shape (though not determine) the firm's behaviour with respect to the technology (see Figure 5.2). 


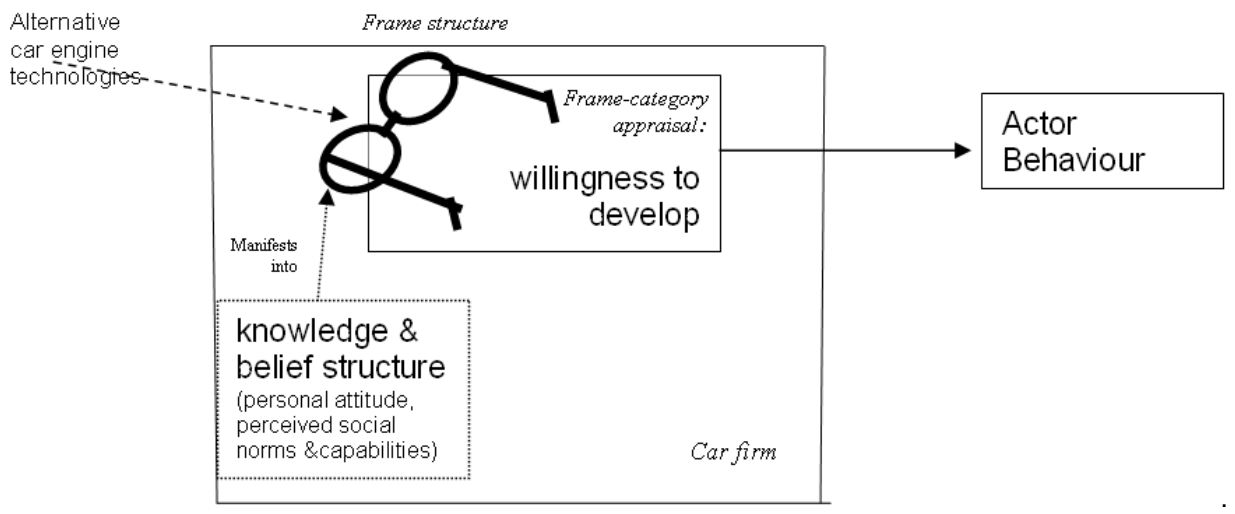

Figure 5.2: Relation between frame, willingness and belief-structure of a specific technology.

In this chapter we have correlated specific beliefs with specific engagement, namely regarding development of hydrogen technology by car firms. We have found differences in engagement levels, and we identified three subgroups. We found that these differences most strongly correlate to different levels of (perceived) technological and organizational capabilities. However, although firms diverge in the appraisal of hydrogen technology, neither from the questionnaires, nor from additional interviews (see Appendix E), we found evidence that framestructures of car firms towards hydrogen technology differ significantly, i.e. regarding the weights they attach to economic opportunity, environmental risk etc. All firms are part of the same global market, with fierce competition. All firms emphasize business opportunities, both immediate and future opportunities, when considering development of hydrogen technology. A main question for business is: do consumers expect and value cleaner engines (personal communication at Audi and Peugeot)? Secondary, their relative position regarding competitors is important. Further, social expectations and pressures for novel technologies, such as hydrogen, affect R\&D expenditures of firms to some extent, whereas emission regulation is a boundary condition that needs to be met.

The more detailed level of communication in the interviews suggested that there are two technological frames towards a technology, or two sub-frames: an $R \& D$ technology frame and a product launch technology frame. The R\&D frame evaluates the development of technology for future product launches. Execution of R\&D delivers engine prototypes, most importantly as concept cars, which may be shown at international motor shows, without the direct intention to be produced. This frame appraises the extent to which enhancing technological competences is important for the firm.

Secondly, the product launch technology frame relates to the technology on the near-future products. This frame appraises the extent to which new technology will be incorporated in new products. Each new car or engine is seen as a project with revenues and cost. Revenues are from expected sales, and costs are from product engineering and manufacturing. Each project (product) should achieve a certain return on investment in order to be approved. As long as production investments in a new product-technology have no profitable outlook, a firm will usually wait with launching the product.

None of the car firms consider launching hydrogen vehicles in the next 5 years. All firms perform $R \& D$ on hydrogen at least to some extent, though the amount significantly varies. Firms that consider themselves stronger engaged in hydrogen are those who perceive their technological and organisational competences as higher. 
Chapter 6

EMERGENCE OF (HYBRID-) ELECTRIC VEHICLES 


\section{Emergence of (hybrid-) electric vehicles}

In this chapter we analyze the emergence of (hybrid-) electric engines on the automobile market after 1990. We apply the two-layered model (see section 2.4) as an explanatory framework: we include agency through a micro layer where the innovation is described through the eyes of the members of stakeholder groups. Aggregate trends of niche, regime and (relevant) landscape are considered in the macro layer. We hypothesize that three stakeholder groups and four feedback mechanisms are key in the emergence of hybrid-electric engine technology and competition with ICE. We explicate the role of techno-economic mechanisms alongside social and regulatory mechanisms for the case of automotive engines, including social meaning of an engine. The coevolutionary analysis is novel in the integrated conception of actor perspectives, feedback effects and competition between products.

This chapter is structured as follows. In section 1 we review other studies on electric and hybridelectric vehicles. In sections 2 and 3 we sketch the technological evolution of the car engine after 1990. In section 2 we focus on aggregate patterns, while in sections 3 we address the perspectives of individual stakeholders (firms, consumers, and regulators). Section 4 integrates the previous sections into a co-evolutionary framework. Section 5 draws conclusions on our approach as well as on the car engine sector.

\section{$6.1 \quad$ INTRODUCTION}

Attention for hybrid-electric vehicles is booming. At a growing pace news magazines report on these partial electric drives. Consumers increasingly drive them, and car firms more and more explore them. Critics state that similar short-lived hypes appeared in the mid-1990s on electric vehicles and around 2000 on fuel cell vehicles, and they may be right. Still, today's momentum is distinctive in one important way: hybrid-electric engines have been sold 1.5 million times worldwide now. How could this happen in a sector that is typically risk-aversive and a classic example of 'lock-in' to a dominant technology?

Other researchers have studied this subject, but mostly with a narrower focus. Some focused only on firms, while ignoring consumers. Pilkington et al. (2002) for example explore patenting of electric vehicles activity as an indicator of its technological development. Oltra and Saint Jean (2009b) present a patent data analysis on diversity in firm strategies around various low emission engines. Hekkert and Van den Hoed (2004) analyze firm competition of hybrid technology versus fuel cells. By contrast, other researchers focused on consumers, whilst disregarding car firms. Haan et al. (2006) study why Swiss consumers like HEVs, and how they differ from ICE drivers. Gerard et al. (2006) do the same for US drivers. Few studies have an integrated character: incorporating consumers and firms, competition between technologies, and including technical, economic, social and regulatory aspects. Exceptions are Cowan and Hulten (1996), from the field of evolutionary economics, addressing possibilities to escape lockin, a move from gasoline toward electric vehicle development. They explained the domination of internal combustion (IC) technology in the automotive sector for more than a century now, fuelled by gasoline and diesel. Their analysis however ends in 1995 (excluding HEVs) and is less specific on firm and consumer perspectives. Another more integrated approach is Oltra and Saint Jean (2009a), who's sectoral system approach delivers a multi-faceted analysis of the automotive sector; but is restricted to France.

These studies have shown their value in explaining trends in consumer preferences, innovation at firm level (technological innovation, learning), and market and sector level (competition and 
diffusion), however, the conceptual approaches are less specific on the role of a changing social context and, accordingly, stakeholder perspectives. Popularity or social connotation of products, especially new emerging environmental products, may change alongside technological innovation. A chief example is hybrid-electric vehicles entering the car market since 1997. Many owners see their vehicle as 'socially responsible', as 'the right vehicle for society' (Heffner et al., 2006). Progression of such connotation will influence the further innovation and diffusion process of the technology, affecting both the consumer and the producer side. There are currently no theories in this field that incorporate this interaction of such social and technological aspects.

In this chapter we explicate the role of techno-economic mechanisms alongside social and regulatory mechanisms for the case of emergence of (hybrid-) electric engines on the automobile market. We see four key mechanisms, and three key actor groups. We present the new technology in the context of evolution of demand and supply of car engines, which results in a co-evolutionary analysis.

\subsection{EVOLUTION OF ENGINE TECHNOLOGIES}

In this section we sketch aggregate patterns of the technological evolution of the car engine after 1990. We examine innovation of both the ICE and electric engines, and address both technical aspects and diffusion of use.

\subsubsection{Internal combustion engine}

For more than a century now, vehicle engines are dominated by internal combustion (IC) technology. The engines constructed by Otto, Daimler and Benz in the 1880s have been greatly improved since then, though they are in principle surprisingly similar to today's engines.

After 1990, car firms continued to refine the internal combustion engines, especially with respect to performance and emissions. In Germany, fuel consumption of the fleet typically decreased 25\% from 1990 till 2003 (Daimler-Chrysler, 2003), while average horsepower of the engine highly increased ${ }^{22}$. Trends in the Netherlands were similar to Germany (see figure 6.1). Initially average fuel economy remained fairly constant there from 1990 until 1997. This was despite a trend of increasing average vehicle mass, and therefore only possible due to more efficient engines. After 1997 growth in engine fuel efficiency surpasses growth in vehicle mass, resulting in a decrease of average fuel use. The impressive rise in fuel efficiency was possibly through broader application of two new engine components in particular ${ }^{23}$ : direct injection and variable valve systems (Holt, 2005). These innovations comprise the following:

Fuel injection (FI) is a system for injecting fuel into an internal combustion engine. Prior to 1985, carburetors were the dominant device for this. Lack of injection accuracy causes a fair share of incomplete combustion, which forms the primary source engine emissions. Improved (i.e. electronic) fuel injection systems were increasingly applied (40\% market share in 1988, and nearly $100 \%$ by 1990 ) and reduced incomplete combustion. Direct injection (DI) systems can be seen as most recent generation of Fl.

\footnotetext{
${ }^{22}$ Note that these trends are influenced by the proportion of choice for smaller lighter vehicles and heavier vehicles. In the US for example there is such a preference for heavy vehicles that the fuel consumption did not decrease at all in that period.

${ }^{23}$ Other relevant innovations that were increasingly applied were turbo and intercooler for diesel engines, and multi-point injection systems for gasoline, and EGR.
} 
Variable valve timing (VVT) makes it possible to change the timing of some or all of the valves of an internal combustion engine during engine operation. Optimizing valve timing at all engine loads and speeds significantly improves engine efficiency, power, and exhaust emissions. Gasoline mileage improvements of up to $20 \%$ can be achieved with VVT (Dresner and Barkan, 2005).

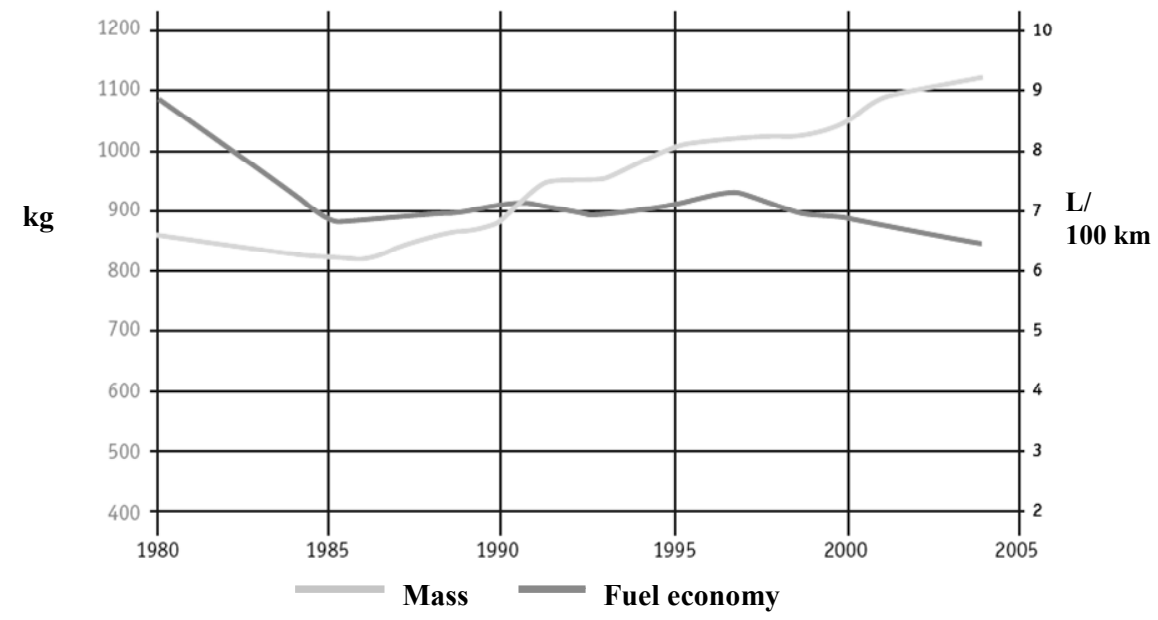

Figure 6.1: Trends of average car mass and fuel consumption of the Dutch vehicle fleet from 1980 till 2005 (source: Bovag-Rai (2005)).

Production and sales levels of VVT and DI rose considerably after 1990 (see graphs in Appendix $\mathrm{G})$. The diffusion of direct injection systems was fairly fast on the diesel market. Beise and Rennings (2005) show that, in Western Europe, the growth moved from $5 \%$ to $70 \%$ in only 8 years. By 2001 is had reached almost $80 \%$. Application on the gasoline market has been increasing as well after 2002 (reaching 13\% in Europe in 2007). Diffusion of variable valve systems was also considerable, though initially mainly among larger engines (greater than 2.0 liters). We found it has reached 40, 50 and 60\% in Western Europe, USA and Germany respectively.

\subsubsection{Electrical engines}

From the mid 1990s onwards, electrical engines (re-) emerged as alternative technology for propelling vehicles. First this was as pure electric vehicles (Battery Electric Vehicle, BEV); later as hybrid-electric vehicles (HEV). Electric battery vehicles consist of an electric engine that moves the wheels, a battery for energy storage, and an electronic engine controller. Up to 1996, the production and sales of electrical vehicles was dominated by small companies outside the car manufacturing industry, most notably the Danish City El. Sales were very low (only a few hundred per year). Around 1995 though, car manufacturers showed an increasing interest in marketing their electric vehicles (just prior to California's ZEV requirements for 1996). After a time of showing prototypes at automobile shows, they now started to launch production vehicles. Most car manufacturers favored electrifying existing models as an initial, low-cost 
strategy (Renault Clio, Peugeot 106, etc.). Around 2000 however, it was undeniable that BEVs were unsuccessful as a product market (see sales levels in the Netherlands in Table 6.1), mainly due to limited range, and a higher price relative to comparable IC vehicles. Not more than a few thousand were sold yearly between 1995 and 2000 worldwide.

Table 6.1: Sales of diesel cars (units), battery electric vehicles and hybrid electric vehicles in the Netherlands 1995-2006 (Sources: www.avere.org, www.bovag.nl, Beise and Rennings (2005))

\begin{tabular}{|l|l|l|l|l|}
\hline & BEV & HEV & DI Diesel & Non-DI Diesel \\
\hline $\mathbf{1 9 9 5}$ & & 0 & 8500 & 76500 \\
\hline $\mathbf{1 9 9 6}$ & 60 & 0 & 28800 & 61200 \\
\hline $\mathbf{1 9 9 7}$ & 10 & 0 & 33250 & 61750 \\
\hline $\mathbf{1 9 9 8}$ & 15 & 0 & 48000 & 52000 \\
\hline $\mathbf{1 9 9 9}$ & 13 & 0 & 66000 & 54000 \\
\hline $\mathbf{2 0 0 0}$ & 12 & 0 & 86400 & 33600 \\
\hline $\mathbf{2 0 0 1}$ & 0 & 50 & 93600 & 26400 \\
\hline $\mathbf{2 0 0 2}$ & 0 & 63 & 93500 & 16500 \\
\hline $\mathbf{2 0 0 3}$ & 25 & 17 & 92650 & 16350 \\
\hline $\mathbf{2 0 0 4}$ & 7 & 1062 & 102000 & 18000 \\
\hline $\mathbf{2 0 0 5}$ & 0 & 2800 & 104550 & 18450 \\
\hline $\mathbf{2 0 0 6}$ & 0 & 2800 & 116450 & 20550 \\
\hline
\end{tabular}

After 1997 a few car firms launched hybrid-electric versions (HEV). Hybrids have similar range as IC-vehicles. Toyota presented its Prius on the Japanese market in 1997, and Honda followed with the launch of its Insight in California in 1998. Prices were initially much higher than ICEs, but Toyota initially paid a premium of around $10 \%$ on each vehicle, to push down the price. It sold more than 15.000 HEVs annually in its first years. In 1999 Toyota's Prius was launched in California and later worldwide, followed by a $2^{\text {nd }}$ generation Prius in 2004. By 2002 worldwide cumulated HEV sales exceeded the 100.000 mark, by 20081.5 million. Market shares reached around $0.5 \%$ in the Netherlands in 2005 , rising to $2 \%$ in (first half of) 2008 . In the USA it was around $4 \%$ in USA in first half of 2008.

The trend in the annual sales of hybrid vehicles produced by Toyota is shown in Figure 6.2. By 2005 the overseas sales of Toyota's hybrid vehicle, mainly in the United States, had surpassed those in the domestic market. 


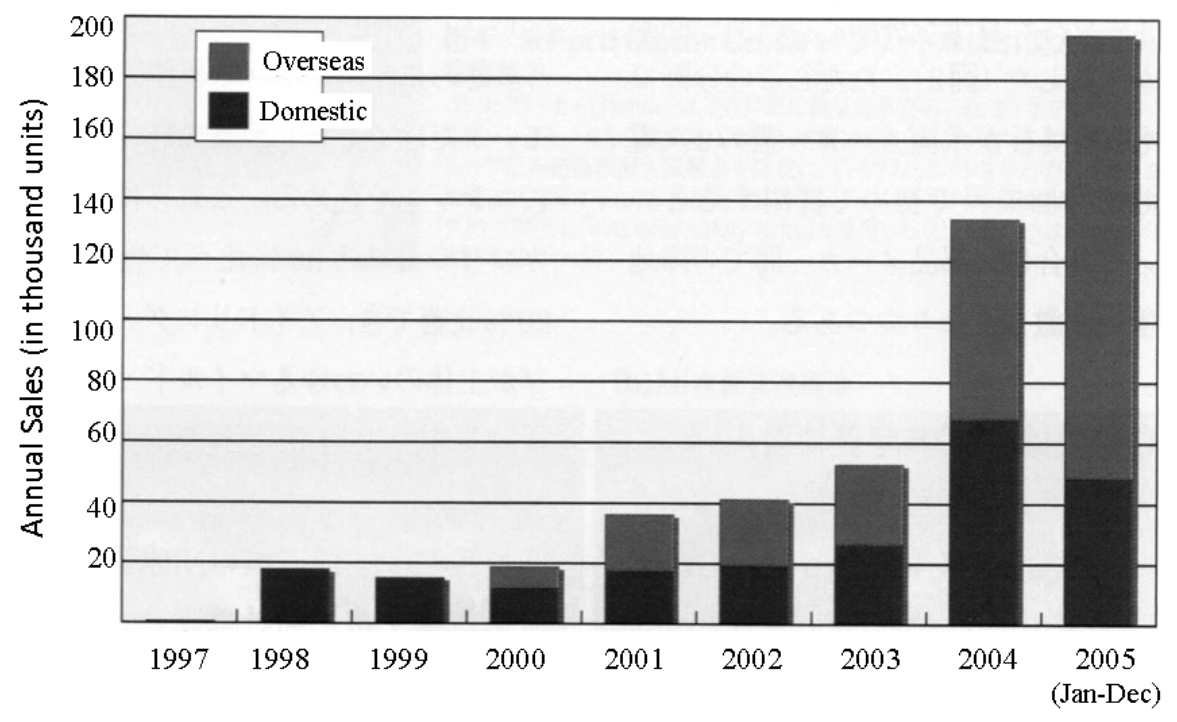

Year

Figure 6.2: Annual Sales of Toyota's Hybrid Vehicles (Source: Tanokura and Karishu, 2006).

\subsection{SHIFTS IN STAKEHOLDER PERSPECTIVES}

This section examines the role of stakeholders in the evolution of car engine technology after 1990. Whereas the previous section focused on aggregate patterns, we now address the innovation through the eyes of three stakeholders: users, producers and policymakers, and how they changed after 1990.

\subsubsection{User perspective}

Since we cannot address all car users in the world, we limit ourselves to discourse analysis of the Dutch car market, analysis of stated preferences on the US market, and analysis of actual sales in the Netherlands.

\section{User frames}

Though many studies are performed on the social perception of automobiles (see Steg et al., 2001; Heffner et al., 2007), few studies have examined perspectives on car engines specifically. It is not clear how people perceive the propulsion technology of their vehicle, and how they come to choosing the one or the other. Through the analysis of newspaper and their car magazine supplements (see chapter 4) we were able to determine what features obtained attention among potential users, and how such features were valued (as something positive or negative). Here we summarize the main findings for BEVs, HEVs and diesel engines successively. Our analysis disclosed that for BEVs in 1996 range was perceived a salient attribute (mentioned in $75 \%$ of the accounts), as well as price (55\%). Both range and prices were negatively appraised, which shows that markets actors were dissatisfied with both functionality and price. Environ- 
mental impact (only 35\%) had dropped in frequency in comparison to 1990, though it was positively appraised (assessment score of +5 ). The social connotation score of BEV was 0 by 1996, which means neutral. By 2000 there was only one salient attribute: range (71\%). This attribute was evaluated negatively (assessment score -5 ). Hence, perceived functionality was still low, and attention for BEV had decreased.

In 2000 Toyota's hybrid-electric Prius was launched in the Netherlands. Our analysis disclosed that for HEVs prominent attributes up until 2000 were fuel use (59\%), price (55\%), and environmental impact (55\%). By 2005, they were fuel use (63\%) and environmental impact (37\%). The higher price as a negative factor dropped in importance to $15 \%$. Fuel use being a positive factor was increasingly appraised: scoring +15 in 2000 and even +32 in 2005. The negative score for price dropped: from -14 in 2000 to -3 in 2005 . The score for social connotation rose from +3 in 2000 to +9 by 2005 . Our analysis of articles disclosed that hybrids were mostly associated with low fuel use, while remarks on performance were few. Acceleration, an aspect of performance, was mentioned in only $17 \%$ of the accounts and appraised as +5 in 2005 . This satisfaction was low in comparison to diesels.

For HEV, there has been a shift in the frames between 2000 and 2005, which is shown in Figure 6.3 (which is a reprint of part of Figure 4.1).

\section{Framing hybrid-electric engine 2000}

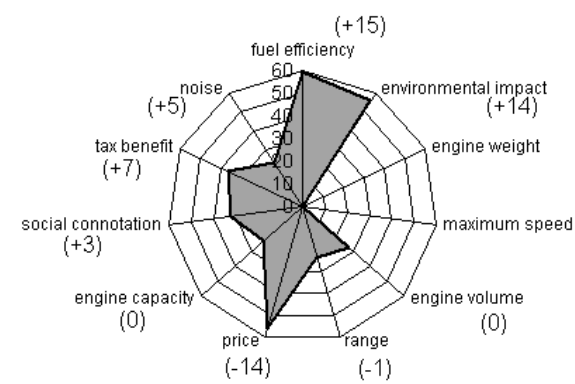

Framing hybrid-electric engine 2005

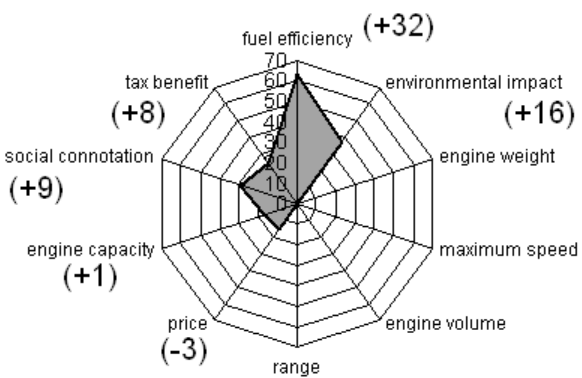

Figure 6.3: Frames for HEV in 2000 and 2005: the spider diagram indicates the attention for attributes; the outer values indicate the appraisal score of that feature.

Most remarkable is the decrease in emphasis of environmental impact (from 55\% to $37 \%$ ), simultaneously to a slight increase on fuel efficiency (59\% to 63\%). This may well have to do with increasing fuel prices in the early 2000s, and also with a consumer tendency to focus on individual benefits, instead of common goods (such as air quality). The change in frame for HEV was quite substantial, and took place mainly prior to the diffusion process: in 2005 the percentage of HEV in new car sales was only $0.5 \%$. Apparently the frame was fairly flexible by at that time. For BEV, by contrast, there was not a big change in frames (between 1996 and 2000): it was stable in its negative appraisal of range, price and refuel time.

We also examined frames of the diesel engine, which were increasingly equipped with direct injection systems (see section 6.2). Performance attributes, such as engine capacity ('horsepower'), acceleration and torque, got most attention. Innovations of diesel engines were well appreciated, both in terms of (perceived) functionality, as in the social connotation. Overall performance was appraised +9 in 2000 and +12 in 2005. Social connotation scored +11 in 2000 and +8 in 2005. Only price was dissatisfying for most people: -2 in 2000 and -7 in 2005 . 
Between 1996 and 2005 the shift in framing was only minor (both in structure and in appraisal), which is shown in Figure 6.4 (which is a reprint of part of Figure 4.1). The drop in appraisal for fuel efficiency is the only notable change. It may be because users got accustomed to the relatively high fuel efficiency of the DI diesel engine, and found it normal by 2005.

Framing of DI Diesel 2000

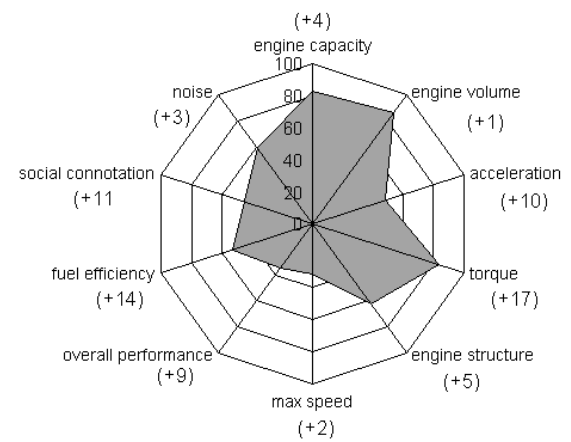

Framing of DI Diesel 2005

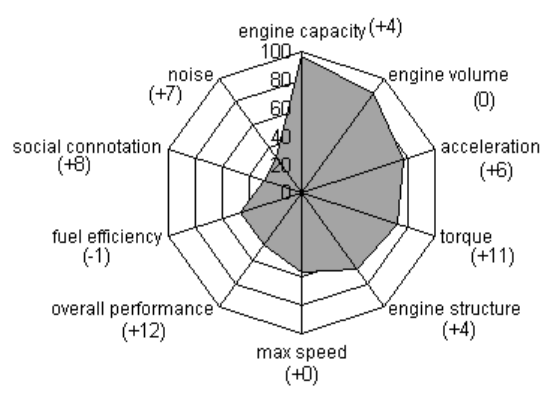

Figure 6.4: Frames for direct injected diesels in 2000 and 2005

The changes in frame-attribute appraisal reflect the technological innovations that occurred on the one side and changes in social perceptions on the other (emphasis on fuel economy, attention for climate change).

Apart from discourse analysis, one can also ask consumers about their preferences, and identify stated preferences. Mytelka (2008) presents a study on car preferences, not on car engines. It shows the relative importance of fuel economy, next to other consumer car preferences, see table 6.2. It shows that dependability ${ }^{24}$ has always been a prominent attribute for (US) consumers. Fuel economy fluctuates in importance, most likely due to fluctuations of the oil price. (Most notable is the decrease in importance of fuel economy between 2004 and 2005, since the fuel price rose between those years.)

Table 6.2: Trends in vehicle attributes (Adapted from Mytelka (2008) and Kubik (2006))

\begin{tabular}{|l|l|l|l|l|l|l|l|l|l|l|}
\hline & \multicolumn{7}{|l|}{ Trends in vehicle attribute preference USA } \\
\hline Attributes & $\mathbf{1 9 8 0}$ & $\mathbf{1 9 8 7}$ & & $\mathbf{1 9 9 6}$ & $\mathbf{2 0 0 1}$ & $\mathbf{2 0 0 4}$ & $\mathbf{2 0 0 5}$ \\
\hline Fuel economy & 42 & & 4 & & 7 & & 10 & 22 & 12 \\
\hline Dependability & 31 & & 44 & & 34 & & 29 & 26 & 33 \\
\hline Low price & 14 & & 31 & & 11 & & 8 & 10 & 6 \\
\hline Quality & 4 & & 8 & & 19 & & 22 & 19 & 20 \\
\hline Safety & 9 & 14 & & 29 & & 29 & 23 & 26 \\
\hline
\end{tabular}

Business consultants from Maritz-research studied change of consumer habits due to rising fuel prices (in France, Germany and the UK, in 2006, with responses of 1240 new vehicle owners). On the statement 'I think about buying, or have bought, a vehicle with a more economical engine', $57 \%$ agrees mildly or strongly, while only $23 \%$ disagrees mildly or strongly. Based on these

${ }^{24}$ That is: reliability 
figures they conclude that a major share of European drivers is changing their car purchase considerations, due to rising fuel prices. How familiar are people with new propulsion systems? In the same research Maritz found $20 \%$ is very familiar with hybrid-electric petrol engines, $34 \%$ somewhat familiar, $39 \%$ has heard of the technology, and $8 \%$ is not at all familiar. Full electric vehicle are somewhat less known: $9 \%$ very familiar, $35 \%$ somewhat familiar, $48 \%$ has heard of the technology, and $8 \%$ is not at all familiar. Of all new /alternative engine technologies, hybrids are most familiar. What engine do they consider for their next vehicle purchase? of the respondents, $24 \%$ considers or strongly considers electric, $47 \%$ for $L P G, 55 \%$ for petrol, $60 \%$ for hybrid-electric, and $72 \%$ for diesel.

In other words: hybrid-electric vehicles are considered more than petrol engines, if we believe what these people say. But what do they actually buy? That is the topic of the next sub-section.

\section{User Behaviour}

Customers of new vehicles can choose their preferred type (and size) of engine, out of a range of alternatives (usually between two to six). In chapter 4 we analyzed the outcomes of such consumer choices for the $30^{\text {th }}$ highest volume car types in The Netherlands, in total more than 220.000 choices (in a year). We found three types of (engine) consumer groups. A first group, consisting of 30 to $35 \%$ simply chooses the cheapest engine. The cheapest engine tends to be lightest, and this results in relatively high fuel economy (for its class). A second, largest share of customers is willing to pay a few thousands Euro more for a more powerful engine (with lower fuel economy): this is the case in 60 to $65 \%$ of the purchases. Customers have different reasons for this: typically because they like sporty driving, for status, to drive more comfortable on the highway, or to use a caravan. Few customers are willing to pay a few thousands Euro more for a cleaner engine: $5 \%$ or less. Often such an option is not available ${ }^{25}$. Adding up these 'green' ICE consumers with hybrid-electric drivers (and LPG drivers), makes the estimate share of 'green consumers' in the whole population around 2 to $5 \%$. We found no evidence that this group has grown between 2003 and 2007 in the Netherlands. These 'green' drivers make up the third segment, which is the smallest one.

\subsubsection{Policy perspective}

From the 1970s onwards, governments were increasingly confronted with insights in the severe health implications of vehicle emissions. Emission regulation at a European level was adopted around1985; in the USA and Japan already in the 1970s. This section examines government bodies regulating the car (engine) sector. For simplicity we will not address the framing of the emission issue here; the political discussions (what is the problem, what are alternative solutions? what is the 'best' solution?) and formation of majorities is a too complicated matter for the sake of this chapter. In this section we examine what the outcomes were, such as decided emission standards and subsidies on R\&D. In section 6.4 the impact of these regulations on the engine market and innovation process is addressed.

\section{European policy initiatives}

The regulation adopted in Europe in 1985 provided targets for around the year 1992. In addition, in the course of the 90s standards were defined in a series of EU directives staging the progressive introduction of increasingly stringent standards (see Figure 6.5). Emissions of NOX, HC,

\footnotetext{
${ }^{25}$ Here, engines are meant that are specifically engineered for high fuel economy, without compromising on power. An example is the 3-liter engine from Audi/Volkswagen, which can make $100 \mathrm{~km}$ on 3 liter petrol. These engines are more expensive. Not all manufacturers offer these high efficiency engines.
} 
carbon monoxide (CO), and particulate matter are regulated. Figure 6.5 shows how requirements for diesel cars evolved, as an example. Similar progressive standards were set for gasoline vehicles.

\section{NOx and PM emission standards for diesel cars}

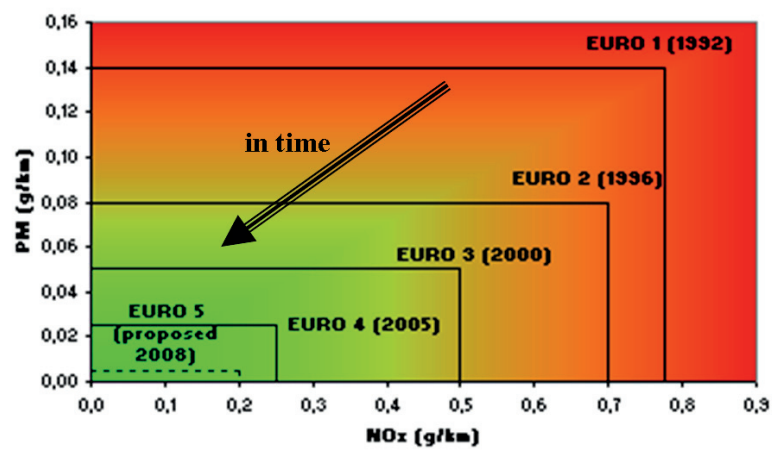

Figure 6.5: NOx and PM emission standards for diesel cars (1992-2005) (Source: Wikipedia, 2006).

The Euro-directives provided the industry with requirements on pollutants for 5 to 8 years ahead. This gave vehicle manufacturers a focus point for their engine development work. From the beginning of 1990s onwards, it became more and more apparent to policymakers that apart from polluting emissions, another type of vehicle emissions, $\mathrm{CO}_{2}$, needed limitation as well. The EU chose a different strategy on this: a voluntary covenant between the EU and the automotive industry $^{26}$. In 1998, after two years of negotiation, the EU signed agreements with the car manufacturer association of Europe (ACEA), Japan (JAMA) and Korea (KAMA), committing them to reaching $140 \mathrm{~g} / \mathrm{km}$ by 2008/2009, which is a 22\% reduction compared to 1995 .

In order to support these emission requirements, governments at EU and national levels have regularly provided funds for research \& development (R\&D) on cleaner engines. Also, to support this direction at the customer side, many national governments provided subsidies on the purchase of low emission vehicles, for example battery electric vehicles (mostly from the middle of the 1990s onwards). After 2000, many EU countries also implemented energy labelling schemes. These intend to provide information to the customer on the fuel efficiency of vehicles relative to other vehicles of the same (size) class.

\section{US policy initiatives}

Regulation in the USA was adopted in the middle of the 1970s, defining maximum Corporate Average Fleet Economy (CAFE) numbers. The CAFE program requires car manufacturers' fleets to meet specific average fuel economy levels (for a model year). The CAFE standards have been unchanged since 1996, requiring that the fleet averaged fuel economy of all passenger cars, sold by a car manufacturer in a specific year, exceeds 27.5 miles per gallon (while pickups, vans and SUV's must get an average of 20.7 m.p.g.). CAFE standards do not get progressively stricter over the years. Actually, the highest fuel average fleet fuel economy in the US was in 1987.

${ }^{26}$ Different legal proposals concerning the reduction of $\mathrm{CO}_{2}$ from vehicles were discussed (e.g. fiscal measures) from the beginning of the 1990s, but no agreement could be reached between the EU member states. This is why they came to a voluntary approach then. 
Apart from these law enforced regulations, a voluntary agreement in the USA became important in early 1998, the National Low Emissions Vehicle (NLEV) Program. It was triggered by developments in California in the early nineties (see below). Nine states and more or less all automotive manufacturers agreed stricter tailpipe standards in 1999, and nationally in 2001. These were more stringent than those in place by the EPA ${ }^{27}$. Further, the US government subsidized the US Advanced Battery Consortium, cooperation between GM, Ford and Chrysler, started in 1991. In the 10-year program the government spent 814 million, while the three firms spent 980 million dollar.

\section{California}

Some governments found the European and US federal (EPA) standards too weak. Initiated by severe health problems in the Los Angeles area, the California Air Resources Board (CARB) had ambition to set stricter standards. When it learned about novel electric vehicles in $1990^{28}$, it set new standards to trigger further development and sales of electric vehicles ${ }^{29}$. It adopted the ZEV Mandate in 1990, requiring that by 19982 percent of all new cars sold in California would be "zero emission". In the year 2000 all new cars sold had to be either "low emission", "ultra low emission" or "zero emission". Moreover, by $200375 \%$ had to be low emission vehicles (LEV), 15 $\%$ ultra low emission vehicles (ULEV) and $10 \%$ zero emission vehicles (ZEV). As Kemp (2005) notices, the ZEV Mandate was a significant piece of legislation, since California represents about $4 \%$ of the world market for cars and about $12 \%$ the US car market. The Mandate was relaxed however later on, most notably in 1996 when the 1998-2002 requirements were abolished, and in 1998 when ZEV credits could be earned through partial electric vehicles. By 1994, four additional states had adopted the California ZEV mandate (New York, Massachusetts, Vermont and Maine); eight more have joint the National Low Emissions Vehicle (NLEV) Program, approving stricter requirements than EPA. In section 6.4 the impact of these regulations on the engine market and innovation process is addressed.

\subsubsection{Firm perspective}

For manufacturers, a novel engine may be perceived in various ways: as something that is of interest to their current customers, to new customers, as a product for which there is a future market when further developed (but no immediate market), or as an engine for which the market prospects are highly unclear. For producers the profitability of an engine (the business case) is likely to be an essential component of the frame. This sub-section first addresses the framing of car firms, and then examines individual firm behaviour (strategies) on car engine developments after 1990.

\footnotetext{
${ }^{27}$ Automobile firms were eager to participate in this voluntary agreement, since it would prevent more states to adopt the ZEV-mandate. From the end on 1993 onwards they had been lobbying for this (see Burke, 2000, pg. 45).

${ }^{28}$ When GM presented the prototype at the January 1990 LA Auto Show, it made electric vehicle technology seem real and encouraged CARB to include EV's in the mandate it adopted in September of that year. This result was unforeseen by GM officials, see Hoogma et al. 2002).

${ }^{29}$ For a more detailed analysis on how this regulation came about, see Kemp (2005).
} 


\section{Firm frames}

In order to survive between competitors, vehicle manufacturers define a certain business strategy, which contains a technology strategy. Most important aim of vehicle manufacturers is developing vehicles that are attractive to the market, which means: attractive to the customer, on a mass production and sales basis. The business strategy defines the current and near-future product mix that should make the company profitable and competitive.

The technology strategy has two sides: an R\&D technology strategy and a product launch technology strategy. The R\&D strategy aims to develop technologies for future product launches. R\&D delivers engine prototypes, most importantly as concept cars, which may be shown at international motor shows, without the direct intention to be produced. R\&D budgets are typically 5 to $15 \%$ of total firm turnover.

The product launch technology strategy defines the technology on the near-future products. Each new car or engine is seen as a project with revenues and cost. Revenues are from expected sales, and costs are from product engineering and manufacturing. Each project (product) should achieve a certain return on investment in order to be approved. Production volume is important for the developing firm, in order to get beyond break-even point. As long as production investments in a new product-technology have no profitable outlook, a firm will wait with launching the product. On the other hand firms are eager to achieve first-mover advantage. This is the temporary monopoly advantage that will accrue to the assembler first producing a reasonably priced improved engine, attractive to consumers. Consumer preferences are therefore the most important driver of product launches; firms need to supply what potential users want, to generate revenues for recouping the costs made. Emission requirements are a boundary condition for product launches: new vehicles have to comply with the regulation.

\section{Firm behaviour}

Firms differ in their precise strength and weakness of capabilities for innovation (Prahalad and Hamel, 1990). In this section we examine typical behaviour of firms in the sector after 1990, while we also address individual firm strategies, both for ICE and for electric engines. To identify firm behaviour we consider patent data and new product launches ${ }^{30}$.

Patent data and new product launches reveals that most car manufacturers were involved in developing or adopting variable valve timing (VVT) and new fuel injection systems (after 1990 most notably direct injection (DI) systems). Comparing the patent figures of ICE after 1990 on the one hand and BEV and HEV on the other, reveals a striking difference: total patent numbers of BEVs and HEVs are much lower (Burke et al., 2000; Hannibal and Meyer, 2000; Pilkington et al., 2002; Berggren et al., 2009). In the 1990s progress and attention for IC engines was a factor 8-10 larger. Analyses of Oltra and Saint Jean (2009) on the French automotive industry confirm these figures: see investment figures of PSA in Figure 6.6 as an example. The authors also hint at a slightly increasing diversification of technological competences of most firms after 2000.

\footnotetext{
${ }^{30}$ We acknowledge the limitations of patent data as indicator of technological innovation (most notably that not all innovations are patented, see also Griliches (1990)). This section complements patent data with presented concept cars and actual market launches after 1990, which overcomes some of the drawbacks.
} 


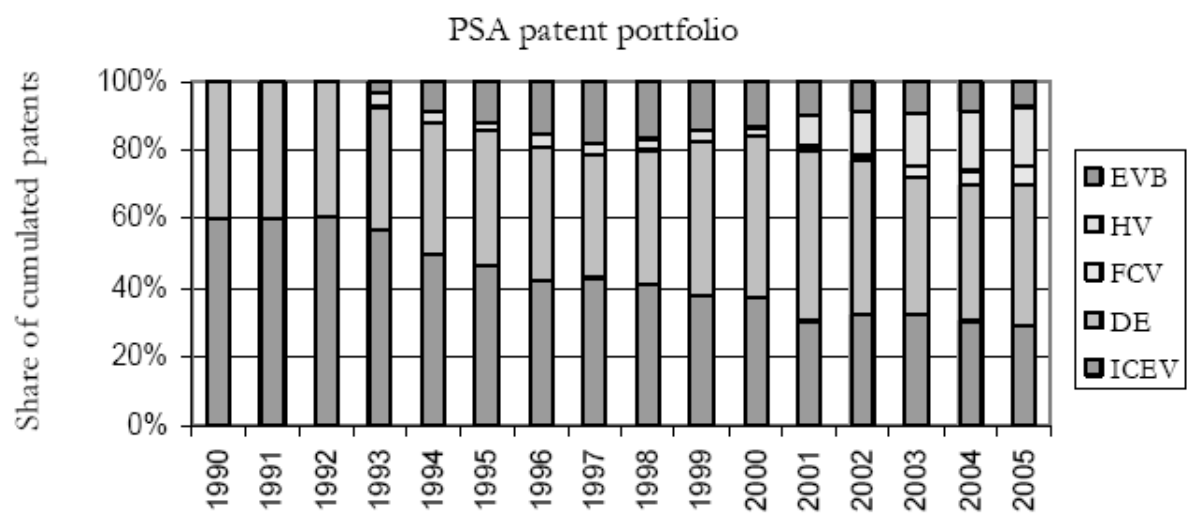

Publication date

Figure 6.6: PSA patent portfolio (Oltra and Saint Jean 2009), including battery-electric vehicle (EVB), hybrid-electric vehicle (HV), fuel cell vehicles (FVH), diesel engines (DV), and gasoline engines (ICEV).

The trends in Japanese patent applications for cleaner propulsion technologies by Toyota are given in Figure 6.7 (Yarime, Shiroyama, and Kuroki 2008). The green arrows indicate when revisions and modifications were made to California's ZEV regulation. It shows that patent applications of electric vehicles rose sharply in the early 1990s, triggered by ZEV, since Toyota relied heavily on the large US market for their exports (ibid.: 195). Quandt (1995) concludes that the ZEV requirement was largely responsible for the electric vehicle development programs run by almost every global automobile manufacturer at that time (1994). He reports that Toyota assigned 100 engineers in 1992 to a new division with the mission of developing a 1998-model BEV for the California market. Further, Cohen et al. (2009) reports that the project team of Toyota's hybrid-system (starting by the end of 1994/beginning of 1995), had intensive interactions with Toyota's Electric Vehicle Development Division - communication of their team leaders was called 'a catch-ball process'. The Toyota-Matsushita joint venture for battery development (starting in March 1995) for its hybrid system, was relatively easy since Matsushita was already a supplier for Toyota's electric vehicle development (Magnusson and Berggren, 2001). In other words, despite ZEV's failure to trigger BEV sales, it did have a lasting affect on technological capabilities of (some) firms. 


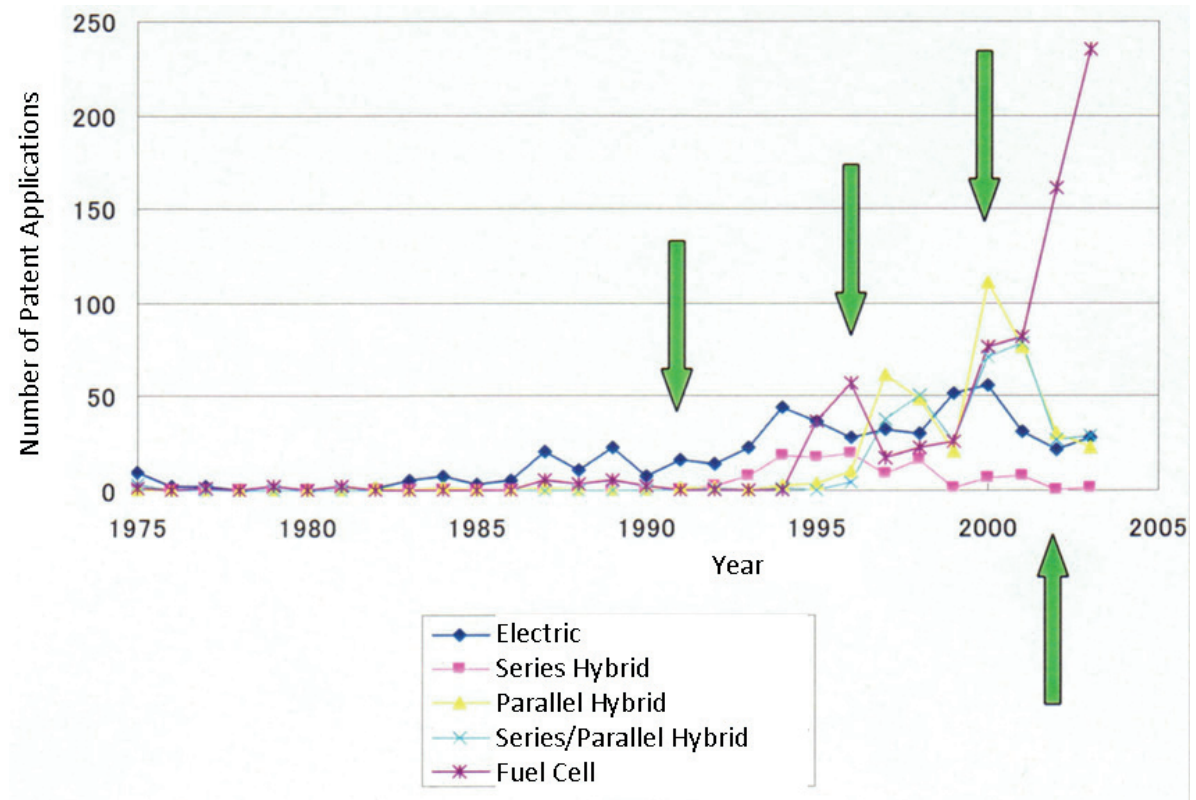

Figure 6.7: Patent Applications by Toyota on Clean Vehicles (Yarime et al., 2008).

Firms improved ICE performance after 1990, since they observed and expected most consumer satisfaction there. The technological refinements enabled vehicles to accelerate faster even though they became heavier (Fischetti, 2002). Most firms did not regard electrical propulsion as a profitable strategy to increase satisfaction of the majority of consumers. Some firms did explore the segment of green consumers with clean ICEs and electric engines, first with BEVs, later with HEVs. But these efforts suffocated after disappointing sales, and remained minor issues compared the incremental innovation of ICE engines. (Differences between firms are described below.)

Research on new car engines is a costly activity, which pushed various firms in research consortia (Molot, 2008), especially for hybrids and fuel cells. The research collaboration of GM, Daimler and BMW on hybrid technology is an example. These collaborative activities are however currently strictly separated from the leading edge research that is undertaken in-house, because of the significant first mover advantages.

R\&D work is executed on two different places in the industry: at vehicle manufacturers and at suppliers. Pilkington and Dyerson (2006) conclude that there is a clear difference between ICE and BEV here. Much of the research activity in BEVs occurred within the supplier network (especially in Japan) rather than exclusively in the mainstream carmakers themselves. They explain this to the need for more radically technology shift, required by the more radical change of regulation in California. This shift proved too great for them to make themselves, they argue. In contrast, the incremental innovation in IC engines could be met by existing capabilities and networks of firms. Nevertheless, diesel and gasoline innovations are also driven considerably from research at first tier suppliers, such as Bosch, Denso, Valeo and Delphi.

The Table 6.3 sketches individual firm strategic activities after 1990 (i.e. three firms are shown here, further nine in Appendix H). Descriptions are limited to main concept cars and launches. The examination of individual firm strategic activities shows that in the last 15 
Table 6.3: Chronologic overview of strategic car engine activities, limited to main launches and concept cars of ICE, BEV and HEV. Combination of various sources: www.answers.com, wikipedia.nl, wikipedia.en, Van den Hoed (2004), Cowan and Hulten (1996), Hannibal and Meyer (2000), Teske and Chanaron (2007). The table is an overview, and does not claim to be complete.

\begin{tabular}{|c|c|c|c|}
\hline Firm & ICE & $B E V$ & HEV \\
\hline GM & $\begin{array}{l}\text { Presentation concept of VVT } \\
\text { system in } 1995 \text { (dubbed Ecotec } \\
\text { engine), launch in } 1997 \text { for Opel } \\
\text { Corsa, with later updates (2000: } \\
\text { Double Continuous Variable Cam } \\
\text { Phasing, and 2003: Twinport), } \\
\text { which were gradually available in } \\
\text { more models. } \\
\text { Gasoline DI was presented in 2002, } \\
\text { but slowly adopted in three } \\
\text { engines (2004: Vectra /Signum; } \\
2005 \text { Opel Pontiac; 2007: Saturn } \\
\text { Sky). } \\
\text { DI diesel (called DTI) adopted in } \\
\text { 1996 (Omega, Astra in 98), } \\
\text { updated as CDTI in 2003. DI spread } \\
\text { soon over all diesel models. }\end{array}$ & $\begin{array}{l}\text { GM spent more than } \\
\text { \$1 billion developing } \\
\text { the EV1 (GM's } \\
\text { estimate). Only } 800 \\
\text { vehicles were leased } \\
\text { during a four-year } \\
\text { period. In } 1998 \text { the } \\
\text { last update of EV1 } \\
\text { was launched. After } \\
\text { relaxation of ZEV } \\
\text { mandate (1996) GM } \\
\text { shifted research } \\
\text { focus towards fuel } \\
\text { cell technology }\end{array}$ & $\begin{array}{l}\text { Until } 2004 \text { skeptical about } \\
\text { hybrids. In } 2006 \text { research } \\
\text { collaboration was established } \\
\text { with DC and BMW. } \\
\text { GM announced (in 2006) } \\
\text { launch of full hybrid system in } \\
\text { two SUVs (Tahoe, Yukon) for } \\
\text { late 2007; by late 2008 they } \\
\text { were limited available (with } \\
25 \% \text { better fuel economy, and } \\
\$ 2.500 \text { more expensive). }\end{array}$ \\
\hline Toyota & $\begin{array}{l}\text { Introduced VVT in the } 1992 \text { Corolla } \\
\text { GT-versions. Followed up by VVT-I } \\
\text { (1996), and VVTL-I (1998); } \\
\text { gradually launched in various } \\
\text { vehicles (Avensis 2000, Camry } \\
\text { 2001). } \\
\text { The same Avensis engine also } \\
\text { applied direct gasoline injection for } \\
\text { the first time. } \\
\text { Developed its own DI system, } \\
\text { common rail, in } 1995 \text { (D-4D), } \\
\text { adopted gradually to various } \\
\text { models. New generation of diesel } \\
\text { engine in } 2003 \text { (D-CAT). }\end{array}$ & $\begin{array}{l}\text { Launched electric } \\
\text { Toyota RAV4 by } \\
\text { 1996. Sold only a few } \\
\text { hundred annually. } \\
\text { Shift of R\&D focus } \\
\text { away from BEV in } \\
1996 \text { (relaxation of } \\
\text { ZEV), towards HEV } \\
\text { and fuel cells. }\end{array}$ & $\begin{array}{l}\text { Pioneered with HEV in } 1997 \text { in } \\
\text { Japan, } 2000 \text { in California. Sold } \\
\text { around } 15.000 \text { HEVs annually } \\
\text { in first years; by } 2002 \text { total } \\
\text { exceeds } 100.000 \text {. Estimated } \\
\text { losses on every vehicle sold up } \\
\text { to } 2002 \text { or } 2003 \text { of a few } \\
\text { thousand dollars. By } 2008 \\
\text { three models Toyota have } \\
\text { been launched outside Japan } \\
\text { (Prius, Highlander, Camry } \\
\text { 2006), and three of Lexus. } \\
\text { Total sales adding to } 1.5 \\
\text { million. }\end{array}$ \\
\hline$B M W$ & $\begin{array}{l}\text { Introduction of VVT (vanos, 1992), } \\
\text { with a second generation in 1998 } \\
\text { (double vanos). Third generation } \\
\text { (valvetronic) in } 2001 . \\
\text { BMW introduced GDI in } 2001 \text { (only } \\
\text { some models). New generations in } \\
2003 \text { and 2006. } \\
\text { Common rail diesel adopted in } \\
1998, \text { and became standard after } \\
2000 \text {. }\end{array}$ & $\begin{array}{l}\text { No EV concept cars } \\
\text { presented. One } \\
\text { technical paper on } \\
R \& D \text { on E1 made } \\
\text { public (1992). }\end{array}$ & $\begin{array}{l}\text { Until } 2004 \text { skeptical about } \\
\text { hybrids. In } 2006 \text { research } \\
\text { collaboration was established } \\
\text { with GM and D/C. No near } \\
\text { future plans for full hybrid } \\
\text { launches. They have } \\
\text { incorporated some electronic } \\
\text { assistance for increasing } \\
\text { efficiency of ICE. }\end{array}$ \\
\hline
\end{tabular}

years firms have strongly focused $R \& D$ and engineering on incrementally improving their ICE engines. Up to 1996 some attention was spend on BEV technology, obviously initiated by California ZEV mandate. In 1996, when the mandate was relaxed, most firms shifted to fuel cell technology, as a more promising alternative for BEV (even before BEV proved a market failure!). Exceptions were Toyota and Honda, shifting to both fuel cell and hybrid-electric technology. Toyota and Honda pioneered in launching hybrid vehicles, Ford followed (Ford Escape, 2006). 
Teske and Chanaron (2007), studying firm strategies towards HEV (by 2006), cluster the manufacturers in three groups: pro's, cautious pro's, and most reluctant. In group 1 they see Toyota, Honda, Ford, and GM. In group two they regard Hyundai, Kia, PSA, Nissan, D/C and BMW. In group three they hold Renault, VW/Audi and Fiat. The chronology of the commercialization of hybrid vehicles by major Japanese auto companies are shown in Table 6.4 (Yarime et al., 2008).

Table 6.4: Commercialization of Hybrid Vehicles by Japanese Auto Makers (Source: Toyota Motor Corporation, 2003; Tachimoto et al., 2005; Center for Electric Vehicles, 2006; Karishu and Tanokura, 2007).

\begin{tabular}{|c|c|c|c|c|}
\hline Auto Maker & Vehicle Name & Year & Hybrid Type & Hybrid System \\
\hline \multirow[t]{9}{*}{ Toyota } & Prius & 1997 & Parallel & $\begin{array}{l}\text { Toyota in-house } \\
\text { (THS) }\end{array}$ \\
\hline & Coaster Hybrid EV & 1997 & Series & Toyota in-house \\
\hline & Crown Mild Hybrid & 2001 & Parallel & $\begin{array}{l}\text { Toyota in-house } \\
\text { (THS-M) }\end{array}$ \\
\hline & Estima Hybrid & 2001 & Parallel & $\begin{array}{l}\text { Toyota in-house } \\
\text { (THS-C) }\end{array}$ \\
\hline & Alphard Hybrid & 2003 & Parallel & $\begin{array}{l}\text { Toyota in-house } \\
\text { (THS-C) }\end{array}$ \\
\hline & Prius & 2003 & Parallel & $\begin{array}{l}\text { Toyota in-house } \\
\text { (THS II) }\end{array}$ \\
\hline & $\begin{array}{l}\text { Harrier/Kluger } \\
\text { Hybrid }\end{array}$ & 2005 & Parallel & $\begin{array}{l}\text { Toyota in-house } \\
\text { (THS II) }\end{array}$ \\
\hline & Lexus & 2006 & Parallel & $\begin{array}{l}\text { Toyota in-house } \\
\text { (THS II) }\end{array}$ \\
\hline & Camry & 2006 & Parallel & $\begin{array}{l}\text { Toyota in-house } \\
\text { (THS II) }\end{array}$ \\
\hline \multirow[t]{2}{*}{ Nissan } & Tino Hybrid & 2000 & Parallel & Nissan in-house \\
\hline & Altima Hybrid & 2006 & Parallel & Toyota (THS II) \\
\hline \multirow[t]{3}{*}{ Honda } & Insight & 1999 & Parallel & $\begin{array}{l}\text { Honda in-house } \\
\text { (IMA) }\end{array}$ \\
\hline & Civic Hybrid & 2001 & Parallel & $\begin{array}{l}\text { Honda in-house } \\
\text { (IMA) }\end{array}$ \\
\hline & Accord Hybrid & 2004 & Parallel & $\begin{array}{l}\text { Honda in-house } \\
\text { (IMA) }\end{array}$ \\
\hline Mazda & Tribute Hybrid & 2004 & Parallel & Aisin AW (HD-10) \\
\hline
\end{tabular}




\subsection{CO-EVOLUTION OF DEMAND AND SUPPLY THROUGH FEEDBACK MECHANISMS}

This section integrates aggregate trends of demand and supply of car engines (section 6.2) with stakeholder perceptions and initiatives (section 6.3 ). Figure 6.8 below presents a timeline, with stakeholders (frames and behaviour) evolving at the micro level. Simultaneously, the accumulation of their practices leads to two distinct innovation trajectories at the macro level: ICE (section 6.4.1) and (hybrid-)electric engines (section 6.4.2). As an illustration we schematize developments chronologically, and visualize the feedback mechanisms on the two distinct innovation trajectories. One type of mechanism relates to techno-economic factors (learning and returns to scale), another to social factors (framing and social connotation). Regulations also influence these mechanisms. The development of the two-layered framework denote to coevolution of demand and supply in a broad sense, while the trends of total sales (demand) at the macro level and total products offered (supply) denote to co-evolution in a more narrow sense. Figure 6.8 illustrates that we have identified a strong ICE regime over the whole period after 1990: car firms supplied (practically solely) ICEs to meet demand for two large consumer groups: those seeking sufficient performance engines at the lowest price (segment 1), and those preferring more powerful engines at a slightly higher price (segment 2). We discuss the innovation path of the ICE regime according to various mechanisms that shape demand and supply below.

\subsubsection{ICE regime trajectory}

\section{Learning-about-the-market}

Learning-about-the-market was a significant mechanism in co-evolution of demand and supply for ICE engines (see figure 6.8). Firms learned which engines had the best business opportunity, and they learned how to shape the technology best for that opportunity. After 1990 technical capabilities for applying VVT (for gasoline) and DI (for diesel) in consumer vehicles grew at various firms, after pioneering launches of Honda in 1989 (VVT) and Fiat (DI) in 1987. Since emission regulation became increasingly stricter, firms found VVT an attractive option for more expensive, high performance side of the car market. DI was mainly applied in medium sized diesel vehicles: Fiat Croma and Audi 100. It was attractive for firms with large sales share of diesel engines, such as Fiat and VW/Audi. Around 1990, five out of 21 manufacturers had VVT systems in production vehicles, two had DI systems. These (launching) companies now learned from their own vehicles how VVT and DI could be best applied in high volume products. While some firms waited with application on production vehicles (typically because it was not profitable yet and not required yet for meeting regulation), they did advance on R\&D work: their technical capabilities on especially VVT grew. (Although for DI systems firms relied more on suppliers such as Bosch.) These efforts were based on expectations that, in time, VVT would be necessary for improving performance and emissions of IC engines. In 1992-94 the number of market applications doubled quickly. Firms learned that customers in this group were willing to pay extra for an engine (around a few thousands of euros) for increased performance. Manufacturers observed sales numbers that were large enough to earn back a major share of their R\&D investments. After 1997-98 many firms believed VVT to be profitable for medium priced models. It was now a means to both increase performance, but also to keep emissions within limits (i.e. standards). Finally, around 2000, almost all manufacturers applied VVT and DI systems in one or more engine models. After 2000, it further spread to more models. 


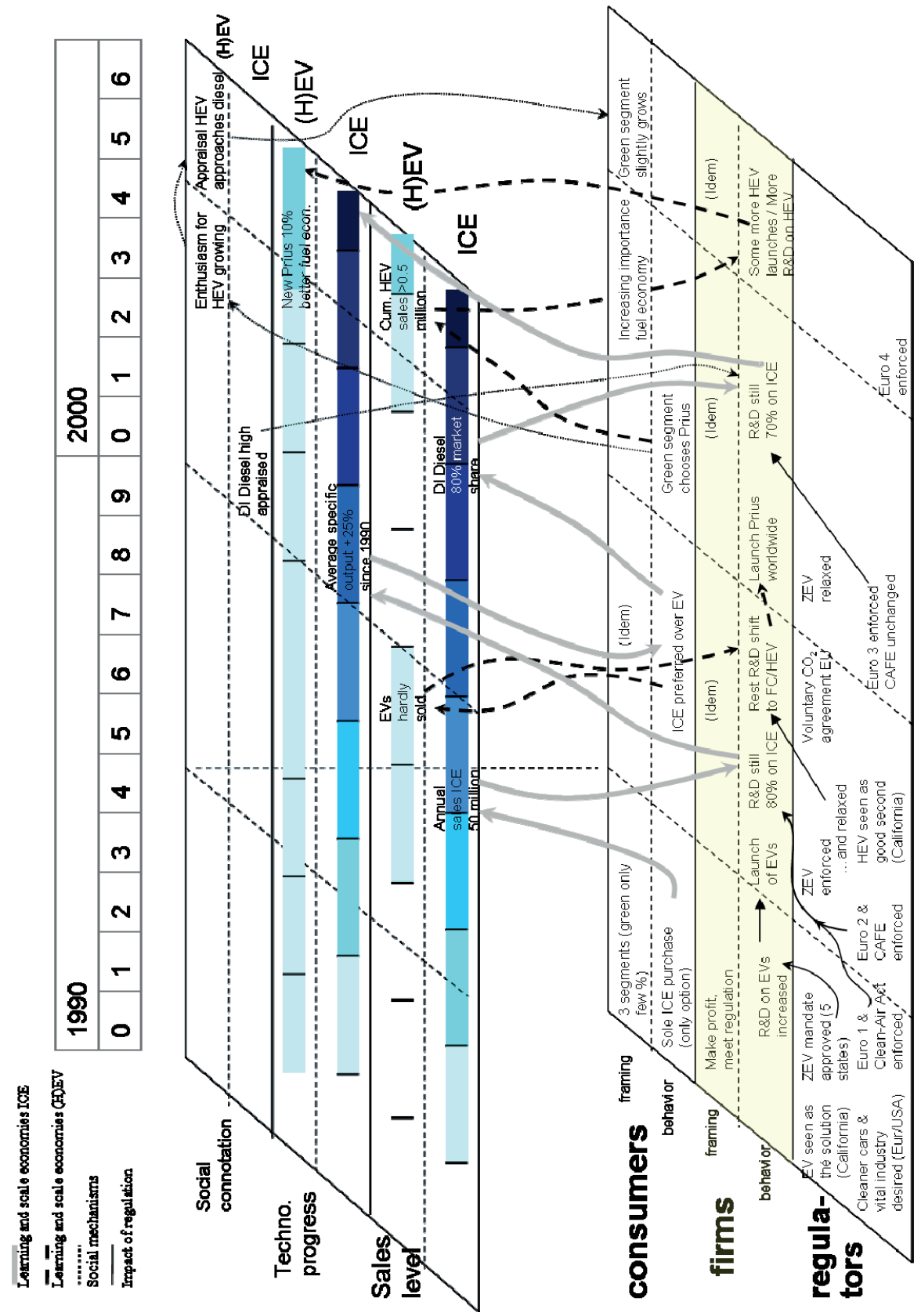

Figure 6.8: Schematization of co-evolution of demand and supply 


\section{Learning-by-doing}

Technological learning and application of VVT and DI improved the efficiency of ICEs substantially. Average specific output of vehicles (kW per liter) grew with 20 to $25 \%$ between 1990 and 2000 (DeCicco et al., 2001). From table 6.3 and Appendix $\mathrm{H}$ we surmise that firms employed three types of learning strategies for engine technology: (1) perform own R\&D, (2) collaborate in R\&D with competitors (e.g. Fiat, GM and PSA around 2000), and (3) temporarily license-in an engine from a competitor, to buy time and learn to make it yourself (e.g. PSA from Mitsubishi in 1999). A final strategy is to buy an engine sub-system from a supplier (such as Bosch, Delphi).

\section{Increasing returns to scale}

Increasing-returns-to-scale was also an important mechanism. For DI systems production levels grew steadily (see Appendix G), especially since various car firms shared the same component supplier. Common-rail, a new generation of DI around 1997, was developed at Fiat, but soon sold to Bosch. This was purposely to benefit from scale economies at this first tier supplier. Subsequently it became available for all firms. VVT systems, on the other hand, were mostly developed in-house at individual firms, resulting in smaller scale batches. It did result in a higher variety of VVT systems. This dissimilarity between VVT and DI may explain why the diffusion speed of DI was steeper than VVT. It reached nearly $100 \%$ in Europe by 2005 ; VVT by contrast reached about $40 \%$, see Appendix G).

\section{Social construction of connotation}

Our discourse analysis of the Dutch market (through national newspapers) reveals the development of social connotation of the improved diesel engine, between 1996 and 2005. Attention for the engine increased with its application: from 10 accounts in 1996, to 29 by 2000 and 39 in 2005. In a large share of the accounts a social connotation is attached to the engine $(45 \%$ in $2000,28 \%$ in 2005), which is stable and positive, varying from 'superb', to 'smooth' and 'pleasant'. Highest appraisal occurred around 2000; by 2005 the enthusiasm had slightly tempered.

\subsection{2 (H)EV - niche trajectory}

\section{Learning-from-the-market}

Learning-from-the-market of $(\mathrm{H}) \mathrm{EV}$ s only really started after 1995, when the first paying consumers started using the vehicles. Before 1995 BEVs were in an experimental and demonstration stadium. Manufacturers tested small batches of vehicles to study practical use. Most firms were pessimistic about the business opportunity of these vehicles on the short term. Some, most notably Renault and PSA, were more confident. The ZEV mandate required large firms to launch models in 1996. By 1997 and 1998 manufacturers learned that their gloomy expectations were right: BEV's were hardly sold. Most consumers were unhappy with low autonomy (kilometers per battery charge), maximum speed and high battery price.

In 1996 California relaxed the mandate, and became more enthusiastic for HEVs. This turn triggered most firms to shift R\&D focus away from BEV, towards fuel cells. Apart from PeugeotCitroen, no large manufacturer launched updates of BEVs after 1999. Although most firms focused mainly on fuel cells, Toyota and Honda studied hybrid-electric engines equally intensive. Contrasting all other car firms, Toyota launched its Prius by 1997, producing 1000 cars a month, a number which was soon doubled. Honda followed in 1998. Most firms stayed skeptical about hybrids until 2005, expecting they would only be suitable for a small market niche. Meanwhile Toyota and Honda's sales added up to more than half a million (by 2005). Other firms increased investments in hybrids after 2005; some started research collaborations. 


\section{Learning-by-doing}

Technical improvement of BEVs was meager. GM's EV1 model years 1996 and 1998 show a range extension from 55-95 miles to 75-150 miles. Maximum speed stayed constant at $80 \mathrm{mph}$. Toyota's RAV4 had similar max speed, and a similar range of 80-120 miles. A 1998 Citoen Berlingo had slightly lower performance: a range of $96 \mathrm{~km}$ and max speed of $95 \mathrm{~km} / \mathrm{h}$.

For hybrids, core of the technological challenge has been on the battery packs. Most hybrids use conventional nickel-hydride batteries. Specific output of these batteries ( $\mathrm{kWh}$ over $\mathrm{kg}$ ) has not improved much after 2000. Engineers have advanced though on trade-offs between total battery power (settling zero emission range and fuel economy) on the one hand and vehicle driving performance (acceleration, max speed) on the other. Progression on the battery life-time has also been achieved ${ }^{31}$.

Learning strategies that firms employed for electric and hybrid electric technology were similar as those for ICE technology. It varies from own R\&D, research collaboration with competitors (such as GM, D/C and BMW in 2005), to licensing-in engines or components from competitors (Ford licenses components from Toyota).

\section{Increasing returns to scale}

Scale benefits for BEVs were limited for two reasons. Total sales levels were only a few thousands a year, and also those sales were spread over more than 10 firms. There were no key suppliers (yet) who would supply batteries or electric engine systems to most car firms (as Bosch did for DI systems), so each supplier had limited batches. By 1993 prices of electric vehicles were more than double the price of their petrol counterparts (Cowan and Hulten, 1996). In 1995 the prices were 40-50 percent higher than the cheapest version of the equivalent gasoline makes (for Peugeot and Renault ${ }^{32}$ ), whereas in 1998 an electric Peugeot was $25-35 \%$ more expensive than its diesel or gasoline counterpart, respectively (Funk and Rabl, 1999). In 2005, the retail price of a Citroen Berlingo electric was still 30\% above the petrol one. Since the market launch of most of electric vehicles (by 1995), scale benefits have thus appeared to be limited: only about 10 to 20 percent in ten years.

For hybrids, the majority of the increased cost of the vehicle is associated with the batteries. Despite growing production levels the nickel-hydride batteries have remained expensive, mostly due to high nickel prices, which is one of the basic materials. Scale benefits have been stronger though than for BEVs, since almost all HEVs are produced by two firms only. Toyota and Honda will surely have benefitted from their increasing scale of production of HEVs.

\section{Social construction of connotation}

The development of social connotation of electric and especially hybrid-electric vehicles shows an interesting dynamic. In the 1990s we found that attention for BEVs was fairly high: 20 accounts, which is double the amount of direct injected diesels in that year. Social symbolic meaning was however underdeveloped: only in $15 \%$ of the accounts there was reference to it, in quite neutral statements. Most accounts were summing up technical characteristics. Around 2000 attention for BEVs had collapsed, and social connotation had not developed. Meanwhile, attention for HEVs had grown considerably, up to 22 accounts by 2000 . Social connotation already appeared in one third of the accounts. They were mostly positive (with adjectives such

\footnotetext{
${ }^{31}$ We disregard investments in Lithium-ion batteries here, though investments are estimated on one billion annually. This type of batteries promise great advancement in specific output, but are not acknowledged viable for automotive applications yet.

${ }^{32}$ These prices include a reduction of 5000 FRF in state aid and 1000 FRF in aid from EDF, the state owned supplier of electric energy.
} 
as 'high-tech', 'environmental friendly', 'modern'), some were neutral, and one was negative. By 2005 attention had mounted up to 41 accounts, even more than direct injected diesels in that year. Social connotation appeared in about a third of the accounts, and its mainly positive appraisal had caught up with direct injected diesel. This indicates the dominant social climate of praise for hybrids. Apart from influencing consumers, this also affected policy discussions. Twenty-two percent of the accounts were directly part of a policy discussion, containing pleads for tax (or parking) discounts for hybrids, and later also announcements of actual regulation. So, in the growing climate of praise for hybrids, politicians started to mention hybrid vehicles as a solution for environmental problems. In the Netherlands, as well as in many other European countries, this has lead to fiscal policies that give a preferential treatment to hybrid vehicles. This has affected sales levels of hybrids directly (for instance in the Netherlands HEV sales tripled in 2008 after new regulation for lease drivers, see also De Haan et al. (2007)). The indirect effects on technological development are less obvious. The number of hybrid models on the market in Europe is still limited (about four), but firms have launched more models with more fuel efficient gasoline and diesel engines. The slow growth of hybrid models may be because technological development takes time, holding up European and American firms to launch hybrid models. More likely, some firms believe than even despite social praise and fiscal incentives for hybrids, ICEs have still the largest short term potential for fuel efficiency gains and profits.

\subsubsection{Interaction of regime and niche}

Electric and hybrid-electric engines did not emerge in a vacuum: they emerged alongside existing dominant regime of gasoline and diesel technology. Innovation, progress and learning on electric technology took place alongside progress and learning on ICE technology. As acknowledged in chapter 2, innovation is usually inert on, or 'locked-in', an existing path (path dependency). For car engines we have encountered three sources of lock-in. One source from the production side: it is economically not very attractive to invest much in a new, still immature technology. Those will not lead to more revenues in the short term. Competition on the present market is fierce, and it is (relatively) more attractive and necessary to invest in incremental innovation of the existing technology. This yields a pattern in which car manufacturers continuously refine the dominant design in order to improve environmental performance of ICEs. Since Ward (1967) innovation scholars refer to this as the 'sailing-ship' effect.

We have found a second source of lock-in at the consumer side: about ninety-five percent of consumers were satisfied with the way ICEs performed. They comprised two major consumer groups: those seeking sufficient performance engines at the lowest price, and those preferring more powerful engines at a slightly higher price. The remainder of about $5 \%$ (i.e. those who prefer clean and fuel efficient engines and who are willing to pay slightly higher purchase price for this) is the current niche market for hybrid technologies. For most consumers however, IC technology performed as they expected, at a predictable cost. They favoured innovations of ICE over electric engines.

We discerned a third source of lock-in related to regulation. We found that the European Euro 1 to 5 regulations for example have mainly led to an impressive though incremental innovation trajectory of ICE, decreasing certain emissions step by step (see also Oltra and Saint Jean, 2009a). But they have not triggered radical innovations and escape from lock-in. (A similar effect of relatively weak environmental regulations on promoting incremental innovations, which has functioned to prolong the existing technological trajectory, is found in the chemical industry by Yarime (2007)). On the contrary we found that California's ZEV mandate did stimulate an escape from lock-in of the ICE trajectory, as we found in our analysis of the firm perspective (section 6.3.3) and is also found in other studies (Frenken et al., 2004; Van den Hoed, 2004). Until 1996 it 
put substantial pressure on firms to perform R\&D effort for alternative engines, enhancing technological competences on ULEV technologies (electric and fuel cells). After relaxation of the mandate in 1996, most firms relaxed efforts for radical innovations by putting them in a longer time-frame.

\section{Path creation}

Stimulated by California's regulation, Toyota had made considerable advancement in electric vehicle technology (Quandt, 1995; Yarime et al., 2008). While all manufactures where relieved with ZEV relaxation, and lobbied for further reduction, Toyota saw a business opportunity for its electric engine technology, in the form of a hybrid-electric vehicle (Magnusson and Berggren 2001). The Prius I (1997) was targeted at the 'green' niche in Japan, providing an extremely low fuel use (3.6 liter per $100 \mathrm{~km}$ ), while compromising on acceleration and maximum speed. When the Japanese niche was captured successfully, the crossing of the Pacific to California was undertaken. The Prius II was launched there in 2000, though with a renewed trade-off of electric power (increasing fuel use to 5.1 liters per $100 \mathrm{~km}$, but also increasing acceleration). This 'higher performance' Prius was received well in California, a state with a considerable amount of environmentally conscious consumers. By 2004 the (improved) Prius III was launched worldwide, and was received well in most countries by the green consumer segment. Total global sales provided Toyota with a considerable scale level, which probably made the hybrid venture profitable (by about 2005), though precise figures on this do not exist. Honda early followed Toyota in this endeavor, launching the Insight already by 1998. Other firms were reluctant, expecting hybrids to be worthwhile for a small niche of the market only. After 2005 firms were less certain on this, and increased R\&D attention for hybrids. The crucial question is whether and when hybrids will become attractive for consumers in segment two: those who seek sufficient performance at the lowest price. If fuel prices continue to rise, a point may be reached soon where the extra purchase cost of hybrids will be recovered by lower fuel cost. Since this segment comprises around $35 \%$ of the market, this would mean an enormous boost to hybrid technology sales. Secondly, if the social connotation of hybrids continues to grow, taking over the appreciation of cleaner and more fuel efficient ICEs, the amount of consumers that are willing to pay more for HEVs would grow. At the same time, policymakers would then favor hybrid technology over cleaner ICE technology, which could lead them to introduce policies give an extra stimulus for HEV sales.

Looking back to the period of 1997 to 2007, we observe that Toyota was successful in addressing the green consumer segment with hybrid technology, essentially triggering the creation and spur of the hybrid niche trajectory. Other companies have addressed this same low-emission vehicle segment from time to time, by launching both conventional IC technology (Golf eco-matic, 1993; Volkswagen Lupo 3 liter in 2000; Opel Corsa eco in 2002; Mercedes A160), and alternative propulsion systems (notably PSA with several electric models, Audi with Duo hybrid in 1997). However, firms withdrew these vehicles from the market, and reduced efforts towards this segment, since in each case sales were disappointing. Toyota's Prius was rolled out vigorously to the worldwide green segment and also appealed to a slightly broader set of consumer (including those who like high-tech devices), paving a way to the wider application of hybrid technology in other models.

\subsection{CONCLUSION}

In this chapter we describe and explain the emergence of electric engines in the automobile market after 1990. We addressed aggregate level outcomes, such as total sales and technological progress in the sector, both for ICE and for electric engine technology. Furthermore, we 
examined the perspectives of three key stakeholders: firms, consumers and regulators, and how they changed. Moreover, we worked our four feedback mechanisms which underlie the niche and regime dynamics.

We have identified a strong ICE regime over the whole period after 1990: car firms supplied (practically solely) ICEs to meet demand for two large consumer groups: those seeking sufficient performance engines at the lowest price, and those preferring more powerful engines at a slightly higher price. Starting with the pioneering launch of the Prius I (1997), Toyota was successful in addressing the green consumer segment around the globe with hybrid technology, creating and spurring the hybrid niche trajectory.

We can draw a few conclusions from the analysis. First, market niche trajectories need to pass a critical size in order to be viable. PSA was unable to reach a critical size of its electric vehicle activities, despite considerable investments and support from local and national governments (such as a large scale experiment in La Rochelle). The vehicles were broadly regarded as relatively expensive and impractical due to little autonomy. By contrast, first year sales of HEV were to the order of 10 times higher then first year sales of BEV: about 15.000 vehicles versus about 1.500. Hybrids were appreciated for high fuel economy, similarly practical as ICs and benefitted from the positive social connotation. Somewhere in between these two values may be the critical size for a one-year-old (green) market niche on the automobile market (under current fuel prices, subsidy regime etc.).

Second, environmental regulators have hoped for the radical (green) innovation of car engines, but their regulation has mostly stimulated incremental innovation of ICEs, enforcing the lock-in. California's ZEV mandate is an exception, indirectly stimulating R\&D on ULEVs.

Third, social pressure from civil society (via social connotation) influences the momentum of technology trajectories in a few ways, though mostly indirectly. Business and technology strategies of car firms are focused on consumers of new cars, not so much on citizens in general, and therefore R\&D budgets are only slightly influenced by social pressures. The degree of inclusion of consumers of new cars in the social connotations, their receptiveness for social pressures, is a more important factor: directly via their influence on actual sales, and indirectly by shaping R\&D budgets. Further, the influence of social pressure is indirect via a second route, through policy discussions leading to regulation, which will subsequently influence technological development. For hybrids the main regulatory instrument has been fiscal incentives for consumers, which have stimulated sales levels directly. The impact on technological development is less obvious though. The number of hybrid vehicles on the European market is still limited.

All in all, this chapter adds to our understanding of historic and contemporary innovation paths of car propulsion technology. The mechanisms we identified hint at the large complexities involved in the interaction of emerging niches with established regimes, which makes the predicting of the future paths impossible. The analysis has shown that the positive social connotation of the new technology, (H)EV, has counterbalanced techno-economic path dependencies, affecting both consumers, producers and, not the least, policymakers. For electric and hybrid-electric engines the latter group seems to be essential in order to gain further momentum in the future. 

Chapter 7

POLICY FRAMING OF PARK-AND-RIDE 


\section{Policy framing of Park-and-Ride}

In this chapter we analyse framing of Park and Ride within urban transport policies. In recent years Park and Ride $(P+R)$ facilities are increasingly introduced by local authorities as an alternative for or addition to parking supply in the city centre. In this chapter we present results of a questionnaire survey among 45 cities in Europe, based on a social-psychological method described in chapter 3.

This chapter is structured in four sections. It starts with an overview of trends in urban parking policies in the last three decades. In section 2 we present our findings on present engagement levels of $P+R$, whereas in section 3 we map out diversity in framing of $P+R$ throughout European cities by revealing current beliefs about $P+R$. Finally, we track the salient beliefs in framing of $P+R$. In section 4 we discuss our findings, whereas section 5 concludes.

\subsection{TRENDS IN PARKING POLICY}

In recent years Park and Ride $(P+R)$ facilities are increasingly developed by authorities as an alternative for or addition to parking supply in the city centre. $P+R$ is a service provided to motorists to park at the periphery of an urban area, where public transport operate to and from the city centre. Medium and large cities around Europe suffer from an increasing flow of cars every day, entailing severe traffic congestion (OECD, 2007). Local governments have been challenged to respond to growing road use and parking demand, but policies have been rather ambiguous on this point. On the one hand they have aimed at accommodating the growing number of cars, by increasing parking supply and road capacity; on the other hand cities have discouraged urban car use, improved public transport, and developed $P+R$ facilities.

The typical evolution of urban parking policy can be portrayed in seven phases (TCT, 2005):

1. No parking measures. This phase is sustainable until the level of parked cars has a negative impact on the attraction and quality of the area.

2. Parking regulation and control. This means that in some streets parking will become prohibited.

3. Time restrictions (free of charge). This results in more efficient use of available space from increased turnover of cars.

4. Paid parking. Parking tariffs become used as a key to control the use of parking spaces.

5. Resident parking schemes. An overflow of parkers to neighbouring areas (often residential) will require resident parking schemes.

6. $P+R$ facilities. These are developed as an alternative for or addition to parking supply in the city centre.

7. Mobility management. It comprises various activities to tune the combination of private and public transport in order to provide an acceptable mobility-chain for travellers.

This typical evolution parking policy is the outcome of an ongoing debate at local level on how to respond to growing parking demand. We find two ultimate response strategies for local governments:

- car-accommodating strategy or 'predict-and-provide' (Vigar, 2001): aiming to increase capacity of parking in the city centre (e.g. by parking garages), and creating sufficient road capacity to enable cars to those parking spaces in or near the centre. 
- car-limiting strategy ${ }^{33}$ : aiming to seriously limit car-parking in the city centre (by high prices of parking, and few parking garages in the city centre), and in parallel creating facilities to leave the car at or out of the ring of the centre, with the necessary public transport facilities (bus, train, tram, metro, bike) to reach the centre. The places to leave the car and transfer to public transport are (usually) called Park and Ride $(P+R)$ facilities.

The rationale behind urban parking policy is not at all evident ${ }^{34}$. In larger cities, typically rival policy frames appear: a frame where parking policy is a tool to attract customers and strive for parking accommodation, or alternatively, it is viewed as one of the few engineering tools to restrain traffic and congestion, in order to enhance quality of life in the urban area. In practice, parking policy tends to reflect a compromise between these frames, delivered through the twin instruments of regulations which limit who can park and for how long and pricing structures which may seek to favour parking 'acts' of different duration according to the perceived economic priority and need for equitable treatment that the regulatory authorities afford to different classes of motorist.

A third motivation, generally less forcefully articulated, is the raising of revenue for local authorities from charging for parking on the highway or through investment in off-street parking capacity. In most European countries, local authorities have high financial dependence on nationally-raised taxes allocated by the central governments, which retain a strong influence over how allocated funds are ultimately spent. In the context of this financial regime parking revenues offer the rare alternative of a significant revenue stream which can be allocated to transport or non-transport budgets against locally-determined motivations and justifications.

Scientific studies on Park and Ride are relatively scarce (see Bos, 2004 for review). They tend to focus on quantitative data around the factors influencing the use of $P+R$ sites (cf. Bos and Molin, 2006) or on effects of $P+R$ schemes on urban car use (cf. Parkhurst, 2000). To our knowledge no scholars have studied and compared how and why a large collection of European cities construes Park-and Ride.

\subsection{CURRENT ADOPTION LEVELS OF P+R}

We investigated current adoption levels of Park-and-Ride facilities in Europe. We asked local authority officers to mark their level of engagement in $\mathrm{P}+\mathrm{R}$ (where: $1=$ not at all, $2=$ very little, 3 $=$ little, $4=$ moderate, and $5=$ extensively). Figure 7.1 presents their responses (as marks) on a map of Europe. We find that $P+R$ is adopted fairly unevenly across Europe. Eleven cities (or $25 \%$ of our response group) are extensively engaged (marked as 5 in red on the map). Another quarter has little or very little employed $P+R$ (marked as yellow and blue, 3 to 1 ). Most cities $(45 \%)$ are moderately engaged (marked as orange 4 ). Two cities have no P+R development at all. Geographically, we find that cities in Northern-western Europe (especially UK and Germany) have higher adoption levels than cities in southern and eastern Europe. Stienstra (2004) also

\footnotetext{
${ }^{33}$ This is also called 'steering approach', as opposed to the previous 'car demand-following' approach.

${ }^{34}$ Since Adam Smith economists have regarded land invested in transport capacity as only indirectly contributing to welfare and to be reduced to an efficient minimum. Whilst extensively debated for road infrastructure, the often inefficient use of land for free or low cost parking and the wider external costs of providing parking at below market rate are less often recognised, with Shoup's work being the most important exception (e.g. Shoup 2005).
} 
found that parking policies in general are more advances in North-western Europe, diffusing to the east and south.

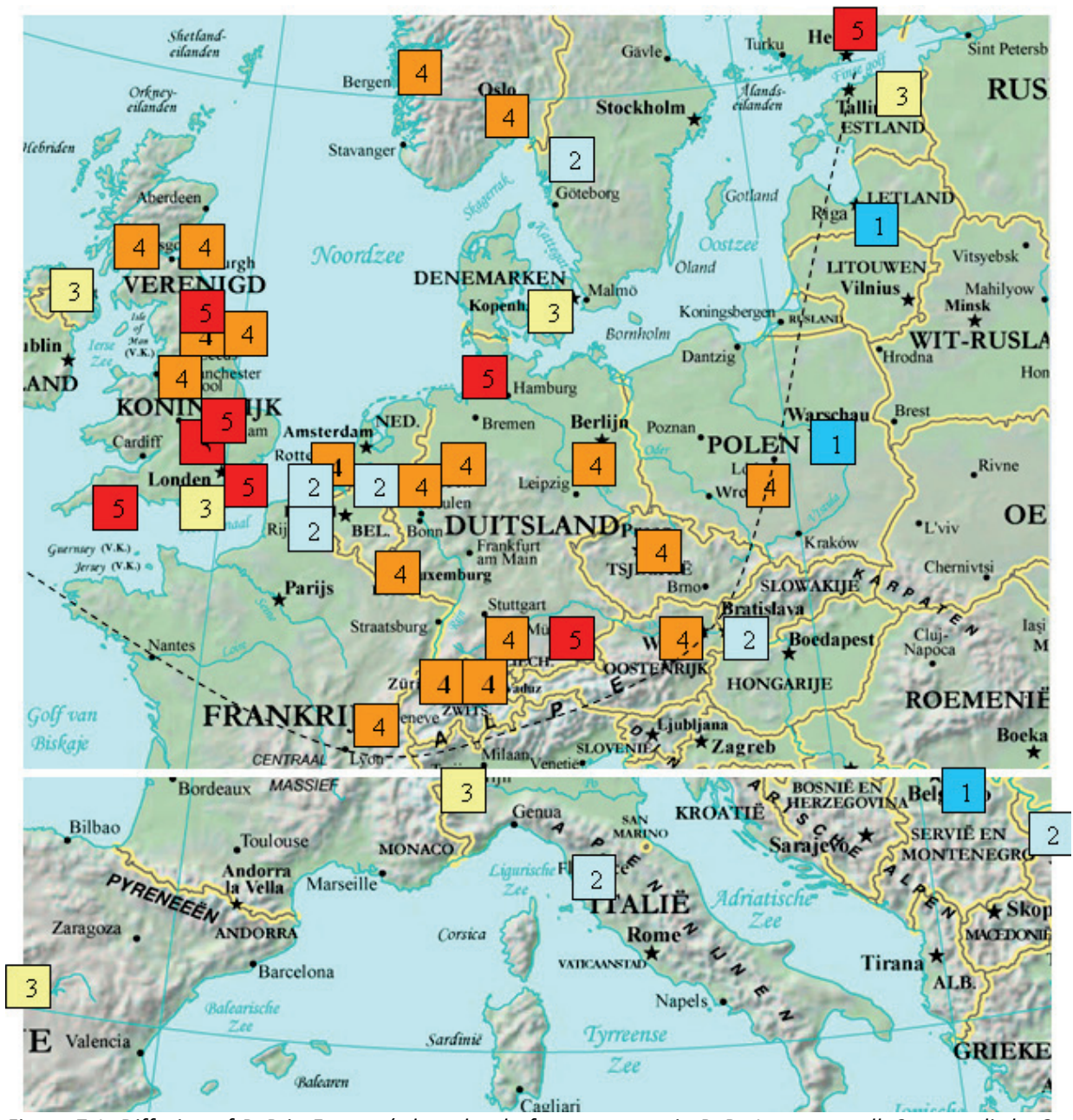

Figure 7.1: Diffusion of $P+R$ in Europe (where level of engagement in $P+R: 1=$ not at all, $2=$ very little, $3=$ little, $4=$ moderate, and $5=$ extensively)

Figure 7.1 raises the question why cities across Europe differ in their implementation of $P+R$. Why do local authority officers vary in their appreciation of $P+R$ ? In the following section we analyse framing of Park and Ride within urban transport policies in greater detail.

\subsection{REPORTED BELIEFS REGARDING P+R}

We provided statements and questions to the local transport policymakers in the 45 cities (see the questionnaire in Appendix F). The statements involve the most important elements of $P+R$ and parking policies in general, based on the analysis in section 7.1 and four semi-structured 
interviews with relevant local civil servants (see Appendix E). We can be confident that respondents were sufficiently knowledgeable about their city's parking policies and $P+R$ initiatives for two reasons. First, the city organizations helped in finding an appropriate person to complete the questionnaire after our request for information 'concerning barriers and drivers to the adoption of Park \& Ride facilities in your city' in the cover letter of the questionnaire. Second, from the respondents who indicated their position we find that a majority works at senior level in the traffic and transport department (team leader, head of a group).

We assume that respondents to have voiced the vision of their organization. In various statements in the questionnaire we use the phrase 'in our city', and there is no reason to presume that these transport professionals would not be able to indicate the field of influence around $P+R$ in their city, especially since many are at senior level. Nevertheless, the respondent's assessment of various pressures on the city government will be slightly coloured by the personal opinion on $\mathrm{P}+\mathrm{R}$ or position in the organization. In our analysis we neglect these personal biases, and assume that the respondent perfectly voiced the view of the city government and the considerations behind current policies. We realize that this is a fairly strong assumption.

\section{Current urban parking policies}

We evaluate five urban parking policy measures. We look at the following ones:

- Decreasing the number of vehicles in city centre (as a policy aim)

- Increasing the prices to park in the city-centre

- Expanding parking capacity in the city centre

- Expanding capacity of the roads to the centre

- Developing P+R facilities

Figure 7.2 to 7.7 present the distribution of response frequencies of the 45 cities to these statements. We found that cities aim to curtail car use: for virtually all cities 'decreasing car use in the city centre' is a policy aim 'to increase the quality of the city centre environment' (Figure 7.2). Only two cities slightly disagreed: Hamburg and Rotterdam. In these cities congestion and (car use contribution to) air quality are apparently no critical issues. Various measures are applied to support the policy aim to decrease car use. Most cities apply pricing: about $84 \%$ (Figure 7.3). In most cities the current parking price (by 2005) is less than 2 euro's per hour (Figure 7.4). Responses also show that most cities are not expanding parking in the city centre to solve parking problems: around $65 \%$ disagrees (Figure 7.5 ). On the contrary, around $20 \%$ slightly agrees they do use parking expansion. Further, we found that less that a quarter of the cities expand road capacity in order to solve congestion issues (Figure 7.6). For most cities, P+R facilities are one of the measures to decrease car-use in the city-centre: Notably 36 out of 45 cities apply $P+R$ as (at least one of the) measure(s) to decrease car use, which is $80 \%$ (Figure 7.7).

\section{Engagement level in $P+R$}

To what extent are these cities engaged in $P+R$ ? We evaluate:

- present engagement levels

- existing plans to future development

Figure 7.8 and 7.9 present the distribution of response frequencies of the 45 cities to these statements. We found that most cities are moderately engaged in P+R: $45 \%$ (see Figure 7.8 ). 
Fig. 7.2: Decreasing vehicles as policy

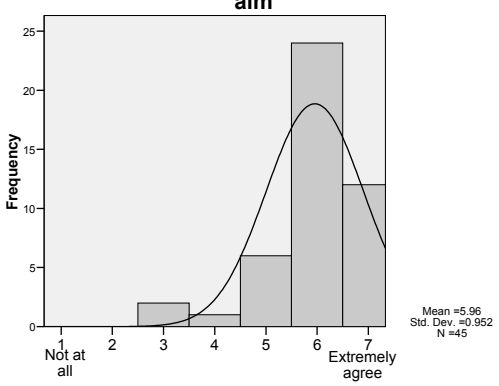

Fig. 7.4: Current parking price

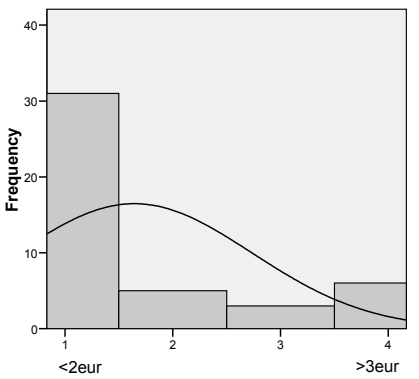

Fig. 7.6: Expanding road capacity

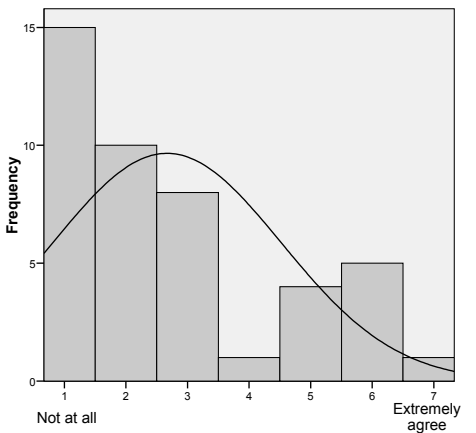

Fig. 7.8: Present engagement with $P+R$

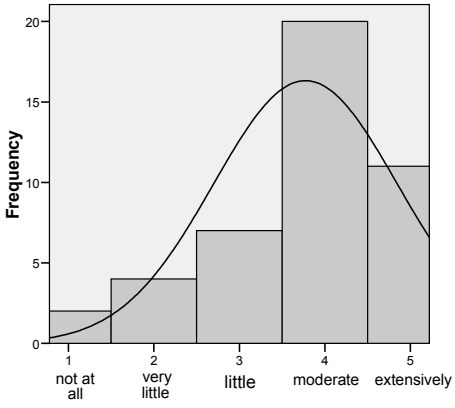

Fig. 7.3: Increasing parking prices

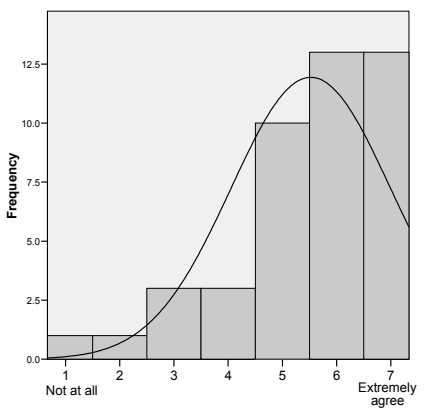

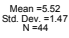

Fig. 7.5: Expanding parking capacity

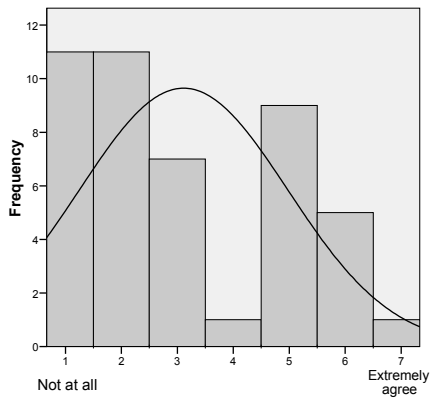

Mean $=3.11$
Std. Dev. $=1.861$
$\mathrm{~N}=45$

Fig. 7.7: $P+R$ as measure

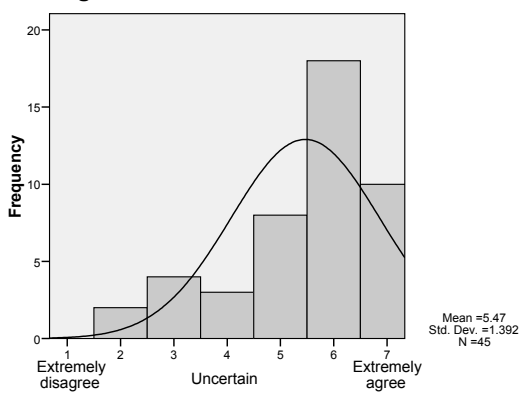

Fig. 7.9: Plans to develop $P+R$

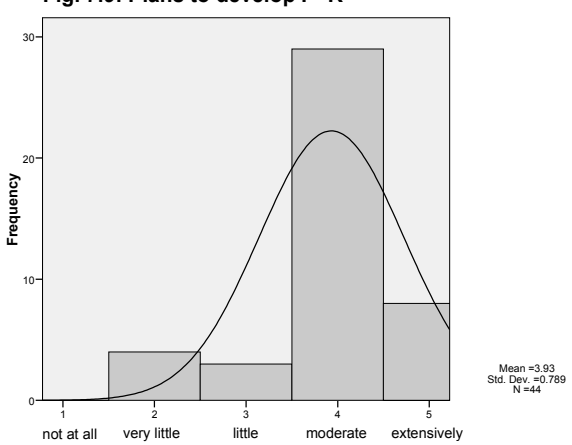


Eleven cities (or $25 \%$ ) are extensively engaged. Another quarter has little or very little employed $P+R$. Further, most cities have moderate plans to develop $P+R$ in the future (68\%, see Figure 7.9). Eight cities have extensive plans: Edinburg, Florence, Rotterdam, Helsinki, Oxford, Tallinn, Gent, and Genève. Four cities have very little plans: Luxemburg, Dortmund, Zurich, and Copenhagen.

\section{Nine potential drivers of engagement in $P+R$}

In this section we describe beliefs of city governments which may drive their engagement of $P+R$. We provided statements according to the nine items of the behavioural model (that we described in chapter 3 , section 3.1), and these are the perceived:

- environmental relevance of $P+R$ for the city

- economic implications of $P+R$ for the city

- demand for $\mathrm{P}+\mathrm{R}$ (from car drivers)

- $\quad$ pressure from the community (NGO's, stakeholder groups)

- (national or EU) regulatory pressures

- technological knowledge and capabilities

- organizational capabilities

- capabilities to form strategic alliances

- capabilities to establish networks of collaboration

Figure 7.10 to 7.18 presents the distribution of response frequencies to these statements. Most cities find that, regarding the environmental effects of car use for the city centre, that $P+R$ is relevant (66\%, see Figure 7.10). Notably, nine cities (20\%) disagree on this: Torino, Wolverhampton, Lodz, Gent, Vienna, Zürich, Dortmund, Munich, Warschau. They do not regard P+R as a relevant solution for decreasing environmental impacts in their city centre.

The economic implications of $P+R$ for the city, such as the economics attractiveness of the city centre (for shops and businesses), are found uncertain by about one third of the respondents (Figure 7.11). The largest share of cities associates $P+R$ with economic loss: $47 \%$. A minority experiences (moderate or minimal) economic benefits: $26 \%$. Two cities see great losses: Genève and Prague.

Perceived demand for $P+R$, i.e. market pressure to develop $P+R$ is polarized (Figure 7.12): $48 \%$ views it as high (mostly slightly high), whereas $43 \%$ as low (mostly slightly low). Thereof two cities see extremely low pressure (Oxford, Riga), and two cities see extremely high pressure (Plymouth, Edinburg).

Community pressure to develop $\mathrm{P}+\mathrm{R}$ (such as pressures from NGO's, representatives of shops and businesses, environmental organizations) (Figure 7.13) is regarded to be lower than market pressure on average: the mean is 3.23 compared to 4 for market pressure. $58 \%$ of the cities see it as weak, while $26 \%$ regard it as strong (mostly slightly strong). Cities that find it quite strong and extremely strong are Birmingham and Edinburg respectively.

Same as community pressure, pressure from national and EU authorities to develop $P+R$ is mostly regarded as low: $57 \%$ (Figure 7.14 ). Only $30 \%$ believes it is slightly high. The mean is comparable to community pressure: 3.16 . Cities that find it quite strong are Oslo, Helsinki and Rotterdam.

For a large majority of the cities technological capabilities (Figure 7.15) are no concern or barrier to develop P+R: $72 \%$ sees them as high. Only $12 \%$ considers them low (mostly slightly low); Torino as single quite low.

Similarly as for technological capabilities, a great majority (of $70 \%$ ) regards organizational capabilities for P+R (Figure 7.16) as high (mostly slightly and quite high). Most pessimistic is Dortmund (extremely low), whereas most optimistic are Genève and Plymouth (extremely high). 
Chapter 7
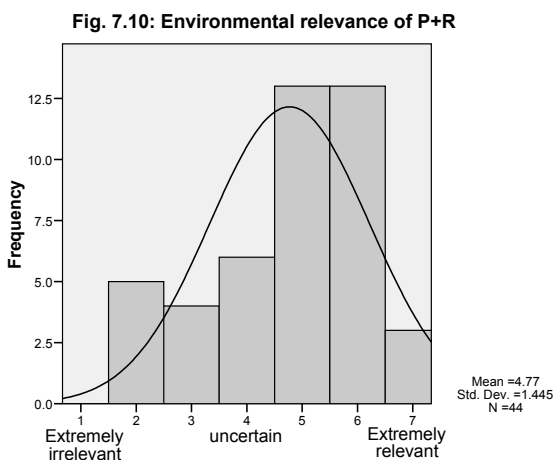

Fig. 7.12: Demand for $P+R$
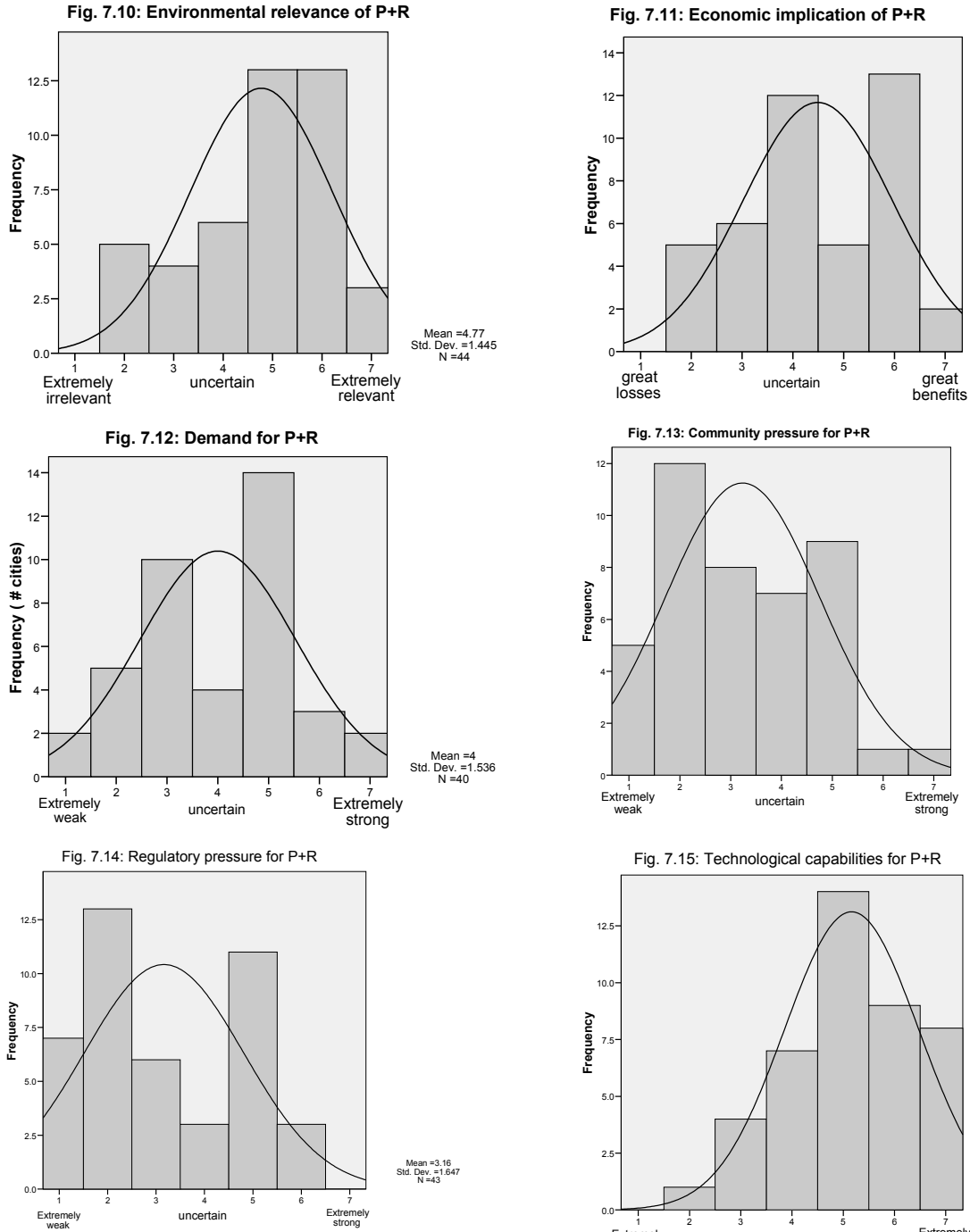

Mean $=4.49$
Std. Dev. $=1.47$
$N=43$

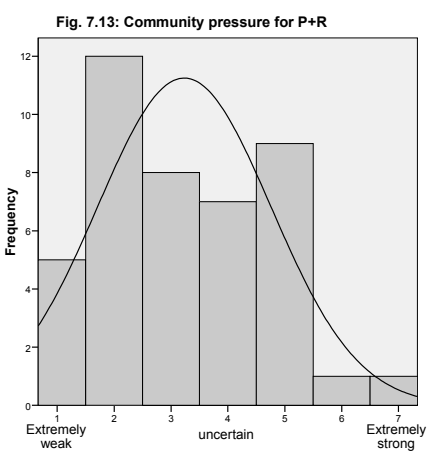

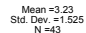

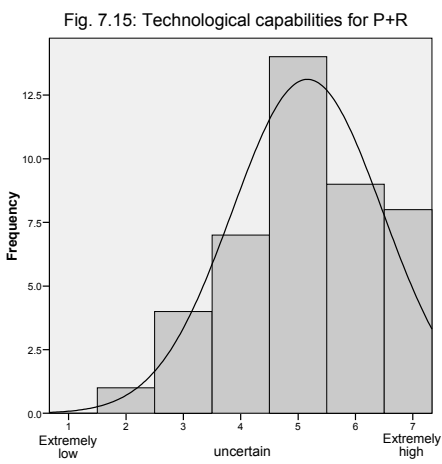

Mean $=5.16$
Stc. Dov $=1.1 .008$
$N=43$

Fig. 7.16: Learning capability for $P+R$

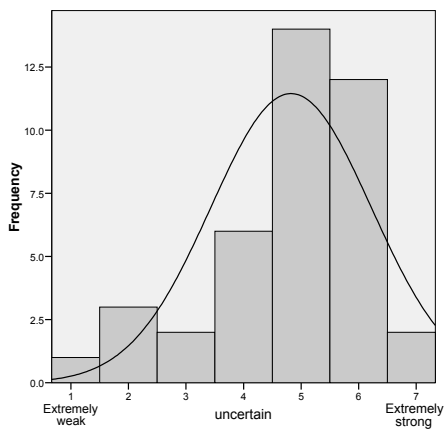

Mean $=4.82$
Std. Dev. $=1.394$
$\mathrm{~N}=40$

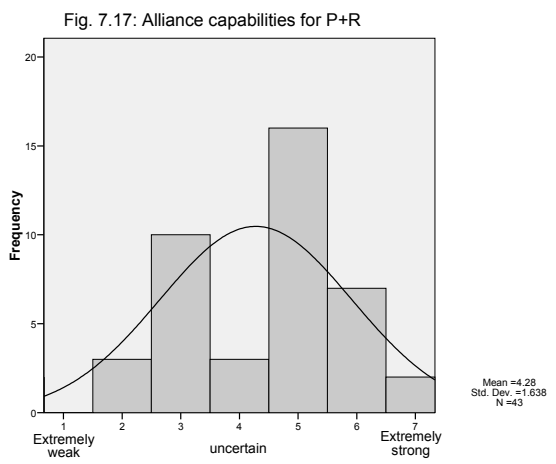




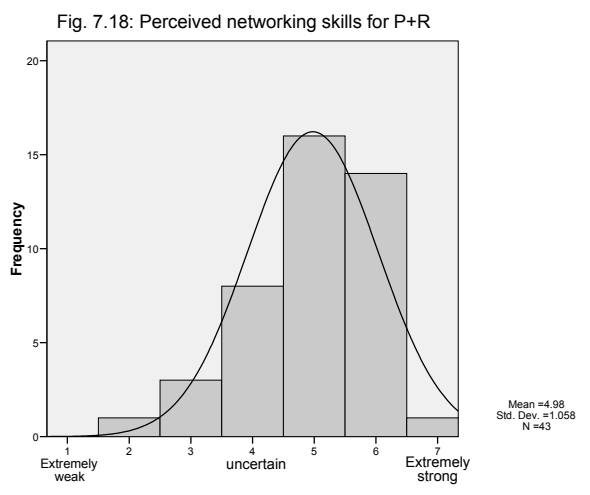

About $58 \%$ believes building of strategic alliances for $\mathrm{P}+\mathrm{R}$ (e.g. with private bus or rail companies) is easy (mostly slightly easy), see Figure 7.17. The number of cities that has concerns about this capability (13) is a bit higher than for the previous two statements. Three cities believe it's quite difficult: Lodz, Belfast, and Torino. Only four cities (about 9 percent) find that building networks of collaboration to acquire know-how for development is difficult (Torino, London, Rotterdam and Bratislava), see Figure 7.18.

\section{Alternatives to $P+R$}

We provided statements on the perceived effectiveness of $P+R$ and various alternatives. First we asked about their appreciation of $P+R$ as a policy measure. Subsequently we asked about (effectiveness of) alternatives to $P+R$.

1. Statement $A: P+R$-facilities would be a good measure of my city to decrease car-use in our city-centre

2. Statement B: 'Increasing the prices to park' would be a good measure of my city to decrease car-use in our city-centre

3. Statement C: The effectiveness of 'limiting or decreasing places to park in the city centre' as a measure to decrease car-use in our city-centre is.

4. Statement D: I believe that other available technologies / practices are more effective than $P+R$ (to increase environmental quality of the city centre)

Figure 19 to 22 present the distribution of response frequencies to these statements. A great majority believes $P+R$ to be a good measure to decrease car traffic in their city centre: $93 \%$ (Figure 7.19). The same holds for pricing of parking in the city centre ( $82 \%$, see figure 7.20$)$. The mean value here is 5.31, very close to the mean of the confidence in $P+R$ (5.33). 'Limiting parking capacity' is less regarded as an effective measure: in total $57 \%$ (see figure 7.21 ). About $36 \%$ finds it minimal effective. The mean is 4.53 .

Is $\mathrm{P}+\mathrm{R}$ the best measure to decrease car traffic? We asked whether other practices were regarded more effective than $P+R$. We found $61 \%$ of the cities agreeing with this statement, who thus believe that other measures are more effective than $P+R$ (Figure 7.22). About a quarter is uncertain. The mean value is 4.73 . Four cities (or $9 \%$ ) disagree and thus believe that $P+R$ is the most effective measure.

Finally, directly following on statement $D$ we posed an open question: Which measures are more effective than $P+R$ (to increase environmental quality of the city center)? Most cited were: better or more public transportation (54\%), promotion and facilities for bike use $(31 \%)$, road pricing or congestion charge (31\%). Finally four cities underlined the necessity of a package of measures (not just one solution like $P+R$ ), and the difficulty to see $P+R$ as sole measure. 

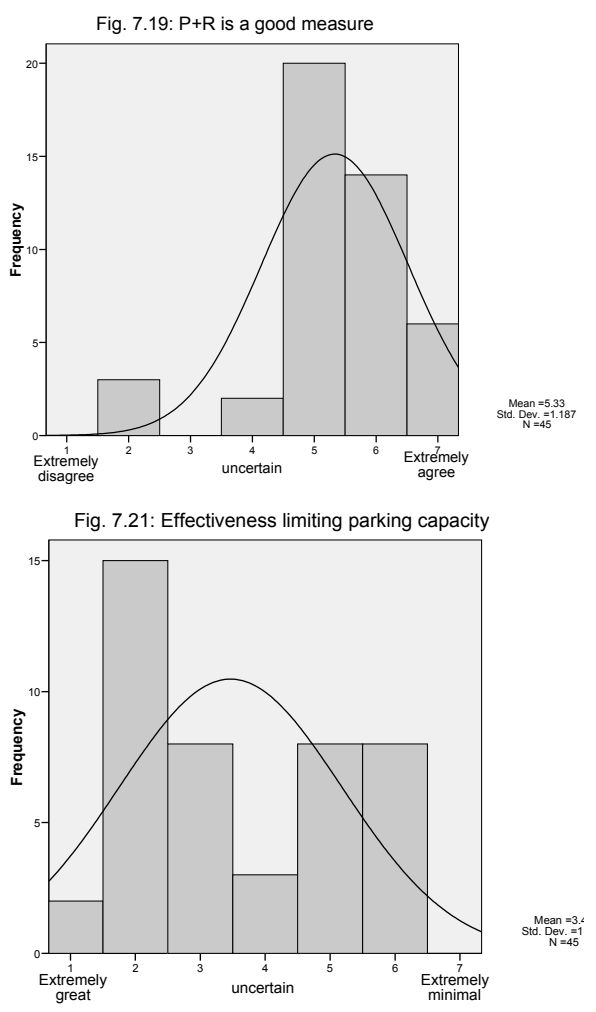

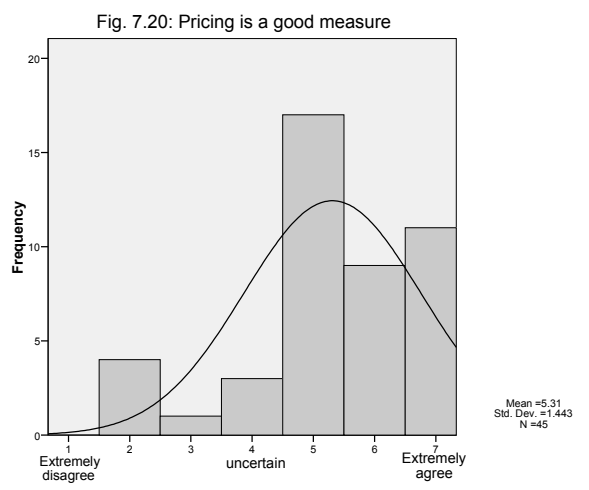

Fig. 7.22: Other ways more effective than $\mathrm{P}+\mathrm{R}$ ?

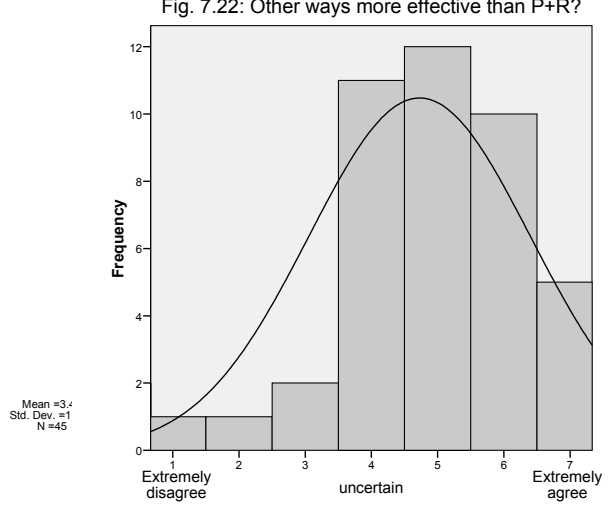

\subsection{DISCUSSION: FRAMING OF P+R IN EUROPE}

In this section we analyze the salience of the various beliefs regarding $P+R$ through a statistical analysis of beliefs and actual engagement in $P+R$.

\section{Validity of the behavioural model}

In order to confirm the validity of the behavioural model described in the methodology section, we analyse the validity of the hypothesis $\mathrm{H}$ :

$$
I \sim W=W(E V+E R+M P+C P+R P+T C+O L+N W+A L)
$$

Stating that perceived environmental effects (EV), economic implications (ER), market pressure (MP), community pressure (CP), regulatory pressure (RP), technological capability (TC), organisational learning (OL), strategic alliance formation ( $\mathrm{AL}$ ) and networks of collaboration (NW) consistently contribute to the firm's actual engagement (I) in the development or adoption of an innovation such as $\mathrm{P}+\mathrm{R}$, hypothesis $\mathrm{H}$ is represented by the following equation:

$$
I \sim W=w_{0}+w_{1} \mathrm{EV}+w_{2} \mathrm{ER}+w_{3} \mathrm{MP}+w_{4} \mathrm{CP}+w_{5} \mathrm{RP}+w_{6} \mathrm{TC}+w_{7} \mathrm{OL}+w_{8} \mathrm{NW}+w_{9} \mathrm{AL}
$$


In order to test this hypothesis, actual engagement $I$ is subjected to a (stepwise) linear regression on all variables. Through a backward procedure we examined various model combinations by removing insignificant variables from the model until we there were only significant ones left (see Appendix I). We found a good model fit (R square 0.383 ; adjusted R square of 0.328 ) for a model with three independent variables: market pressure, economic implication and organizational learning capabilities, see Table 7.1. The p-value for this model is below 0.01 and thus the null hypothesis can be rejected and, accordingly, hypothesis $\mathrm{H}$ is confirmed.

Table 7.1: Result of stepwise (backward) regression of actual engagement in Park+Ride and the corresponding beliefs regarding $P+R$ (final step; unstandardised coefficients; significance in parentheses)

\begin{tabular}{|l|l|}
\hline Variables & Actual engagement (I) \\
\hline & \\
\hline Constant (b) & $0.62 \pm 0.71(0.388)$ \\
\hline Market Pressure, MP & $0.23 \pm 0.094(0.019)$ \\
\hline Economic implications, ER & $0.23 \pm 0.095(0.020)$ \\
\hline Organizational Learning Capability, OL & $0.25 \pm 0.099(0.017)$ \\
\hline $\mathrm{R}^{2}$ (adjusted) & $0.383(0.328)$ \\
\hline
\end{tabular}

This set of three variables is found to make relevant contributions to the prediction of the organizations' engagement in Park-and-Ride. Attempts to include each of six other predictors as a fourth variable led to negligible increases in $R^{2}$, whereas the fourth variable was never significant (and in most case the three variables remained significant). The correlation matrices for the three variables all show correlations below 0.15 (see Appendix I), which indicates that multicollinearity is not a problem and, thus, the variables indeed measure different aspects of the willingness to engage.

\section{Salient beliefs}

Looking more closely at the variables, it becomes evident that the three variables have practically an equally important contribution (as measured by the size of the coefficient) to the willingness to develop $P+R$. The importance of Economic implications of $P+R$ for city governments is understandable for a few reasons. City authorities care about the effects of $P+R$ on the local economy, most notably on the attractiveness of the city centre for visitors of shops, services and businesses. The fear to put off visitors is likely part of the explanation for those responders perceiving negative effects, whereas those who expect positive effects find that loss of attractiveness in terms of parking is compensated through increased attractiveness of the inner-city in terms of safer and more liveable streets and squares. In many cities these potential effects lead to lively political debates, as Stienstra (2004) notes.

Beside economic implications through the effect of $P+R$ on attractiveness of the city centre, some responders may also have thought about the direct impact on the city's financial budget. It is quite difficult to develop and operate $P+R$ sites on a budget neutral basis. Cities therefore face yearly returning operational costs, in addition to investment cost of constructing the sites. Also, parking revenues from central locations make up a significant share of total local tax revenues, 
and cities may fear losing those revenues through introduction of $P+R$. The rather tight budget of city governments explains why this financial factor is of salient importance to them.

It is notable how diverse cities perceive these potential economic effects, as figure 12 shows. The largest share of cities P+R expects losses: $47 \%$, while a minority experiences (moderate or minimal) economic benefits: $26 \%$.

Market pressure is a second important contributor to willingness. We interpret market pressure as demand for $\mathrm{P}+\mathrm{R}$ from car motorists (since we asked for demand signals, see Appendix $\mathrm{F}$ ). Obviously, demand from car motorists is an important factor for the city's engagement in $P+R$ as it would not make sense to construct sites if they would not be used. The other way around it would make a lot of sense to construct sites if motorist would really like them. Experiences in other cities are important in this respect, since they are taken as examples of how much car motorist like $P+R$ and actually use it. Oxford's well functioning $P+R$ sites in the early 1990s (with car interception ratio of around $10 \%$ ) has stimulated other British cities to experiment with $P+R$. Even though physical infrastructures and cityscapes are very different, cities learn from each other.

Organizational learning is the third salient driver. This factor denotes the authorities' capabilities to organize $P+R$. Business innovation research suggests that organizational learning is a critical capacity for organizations aiming to innovate (Leonard-Barton, 1992; Lynn et al., 1998). Since innovation is typically surrounded by uncertainty, the absorptive capacity of new knowledge is key. For many cities $\mathrm{P}+\mathrm{R}$ is a relatively new initiative, and still in development. It is not very clear how the sites can be operated and managed most efficiently, and what impact on other parts of city government organization and financial effects are. In this stage it is therefore explicable that organizational learning capabilities are a significant driver to the development of $P+R$.

Obviously, our analysis does not suggest that the other six potential drivers of $P+R$ are irrelevant. Although they not turn out to be significant in the statistical analysis of the respondent group, they may well be important for specific cities. Also, the importance of drivers may vary in the course of the innovation process in a city (phases such as future planning and visioning, implementation, operation), and accordingly some factors may be only critical in a certain phase, which is something we would not easily disclose with our regression analysis.

\subsection{CONCLUSION}

This chapter offered three things to the literature on Park-and-Ride. First, we reported on present adoption levels of $P+R$ in Europe. The survey outcomes reveal that a quarter of the responding cities is extensively engaged with developing $P+R$, whereas another half is moderately engaged. Geographically, we found that cities in Northern-western Europe have higher engagement levels than cities in southern and Eastern Europe. Second, we map out diversity in framing of $\mathrm{P}+\mathrm{R}$ throughout European cities, by revealing current beliefs about $\mathrm{P}+\mathrm{R}$. We showed how diversified their interpretation of $\mathrm{P}+\mathrm{R}$ is. Linear regression analysis suggests that economic implications of $P+R$ for the city, perceived demand for $P+R$, and organisational learning capabilities are the salient drivers for city governments whether or not to engage in $P+R$ development, explaining almost $40 \%$ of the variance in their engagement levels in $P+R$. Thirdly, Park-and-Ride is certainly not the only transport policy initiative in town to improve accessibility and liveability of the city. Most cities apply combinations of measures. We found that $P+R$ is appreciated as part of such a package, but is not regarded the perfect one. Most cities regard $P+R$ as a 'plan $B^{\prime}$. 
Chapter 8

EMERGENCE OF PARK-AND-RIDE 


\section{Emergence of Park-and-Ride}

In this chapter we analyse the introduction of Park-and-Ride $(P+R)$ facilities in six cities across the Netherlands and the UK. We apply the two-layered model (see section 2.4) as an explanatory framework: we include agency through a micro layer where the innovation is described through the eyes of the members of stakeholder groups. Aggregate trends of both niche, regime and (relevant) landscape are considered in the macro layer. For our case of $P+R$, we find two types of stakeholders to be most relevant: travellers and the local government. Travellers constitute a demand for parking, while the city government is the initiator of a city's parking strategy. To a large extent it regulates the parking prices and amount of parking supply; both in the city centre, as well as at $\mathrm{P}+\mathrm{R}$ sites in more peripheral locations.

This chapter is structured as follows. Section 1 provides a general historic account of $P+R$ in Europe, as well as an account of major scientific studies to it. Sections 2 to 7 analyze urban parking developments in six cities in the Netherlands and the UK. They refer to relevant city government policy reports, complemented with information from various semi-structured interviews with civil servants (see Appendix E). Section 8 compares the six cases and analyzes whether the introduction of $P+R$ has stimulated transition towards low traffic city centres. Section 9 concludes.

\subsection{A SHORT HISTORY OF P+R IN EUROPE}

The concept of $P+R$ is not very new. The early birth of the $P+R$ concept was by 1932 , when Bernard Mees, a Dutchman, published a book on possible ways to solve congestion problems: "Verkeersvraagstukken voor de grote stad"(CROW, 2004). Subsequently, it was picked up in the 1950s in the USA, where the first P+R sites were built (MU-Consult, 2000). The United Kingdom followed suit and started to develop the first experimental $P+R$ sites in various English cities in the 1960s: Oxford and Leicester were the first ones. Even though, as Cairns (1997) states, those first schemes were considered a failure. The first permanent UK schemes began in Nottingham (1970) and Oxford (1973), joined by a handful of other, mostly historic, towns by 1990. After 1990, however, the possibility of financial support from central government, followed by national policy endorsement, encouraged many other towns to initiate schemes (Parkhurst and Richardson, 2002). Other (European) countries followed the example and by now $P+R$ schemes can be found in a majority of European countries.

Park and Ride facilities have emerged in many cities as one of the initiatives to mitigate the impacts of urban mobility to the city population. Motorists who park their vehicle at the edge of a city (centre) and continue their journey by means of public transport, will in principle lower road and parking intensity in the city centre. Some studies have confirmed that P+R-facilities can promote the use of public transport, relieve urban traffic congestion and reduce the level of carborne exhaust in city centres (Pickett et al 1999). Other studies hinted at possible counter effects of $P+R$. Decreasing congestion in city centres could stimulate car drivers again to use their car in the city, since accessibility will have increased (Noel, 1988). P+R could then make driving more attractive. Another study found that Park \& Ride can generate extra car trips, divert motorists from other business centres and abstract patronage from other public transport services (Atkins 1998). This would then contribute to car use around the city centre. Also, cars drivers travelling via $P+R$ facilities to the city centre may make some extra miles to reach the $P+R$ facility. The precise weight of these negative externalities is still debated (and will differ from place to place), just as the net direct benefits of $P+R$ on car traffic in the urban area as a whole. It 
is uncontested however that well-used $\mathrm{P}+\mathrm{R}$ sites directly reduce car movements in the central city centre.

Studies on Park and Ride tend to focus on quantitative data around the factors influencing users of $P+R$ sites (cf. Bos et al., 2004) or on the effects of $P+R$ schemes on urban car use (cf. Parkhurst, 2000). Rarer are studies which examine the construction and use of $P+R$ sites over a period of several years in the context of evolving city transport policies, and parking strategies in particular. We thus aim to complement existing studies by including the various (evolving) stakeholder perspectives on $\mathrm{P}+\mathrm{R}$. In addition to infrastructure, substantial 'orgware' and 'socioware' are involved in such passenger transport interchange systems such as $P+R$ : delivery agencies working together to provide land, car parking arrangements, public transport services, publicity and funding for all these. Travellers opting for $P+R$ must embrace a significant symboliccultural change which reframes the car as a means to access public transport, rather than a door-to-door personal transport system, resulting in a revision to what can be regarded as the dominant socio-technical configuration of road transport. In other words, our analysis complements existing studies by addressing the emergence of $P+R$ in a broader social context.

The following section turns to consider the rationale and experience of six cities in the Netherlands and the UK on $P+R$ (see maps of the cities in Figure 8.1). We describe the relevant stakeholder perspectives (micro level) and policies, occupation levels and prices (macro level). As each of the cities was developing its $P+R$ policy according to its own schedule in time, in each we focus on the phase in which the significant part of $P+R$ capacity was being developed and delivered. We are less concerned with periods of policy stasis or incremental change.

\subsection{P+R IN AMSTERDAM}

\section{Introduction}

Amsterdam is the capital and largest city of the Netherlands. At January $1^{\text {st }}, 2006$, Amsterdam had 743,027 inhabitants, while more than 1 million inhabitants lived in the urban area of Amsterdam. The city has been built on and around canals, mainly during the $17^{\text {th }}$ century and this means that most of the city centre is formed by small streets where circulation of cars is difficult and where parking is just at the edge of canal banks. Since then, Amsterdam has gradually expanded into what is now known as Amsterdam Metropolitan Area, comprising Sloterdijk, Amsterdam Arena, Amstel station and the "Zuidas". The city is located in the western part of the Netherlands and is close to other cities like Rotterdam, The Hague and Utrecht. The region comprising these cities is called "Randstad" and it is home to more than 6 millions inhabitants.

The city is accessible by various highways, which nevertheless are usually subject to traffic jams and queues on a daily basis and especially during peak hours. This high traffic congestion is mainly due to the high number of commuters travelling towards Amsterdam each day for business purposes.

Many of the economic activities are present within the city centre, but during the past few decades more and more businesses have opened in the Amsterdam Metropolitan Area, such as West-poort, Zuid-Oost and Zuid-as. Amsterdam has nine train stations and the major one is the Central Station with about 280,000 travellers each day. Amsterdam has a good tram and underground public transport system that gives the opportunity to many people to easily reach most of the city centre. Finally more than 600,000 privately owned bikes make the traffic situation in Amsterdam a lot livelier. 


\section{City government perspective}

Throughout the 1990s Amsterdam's city government aimed at preserving accessibility of the city, while increasing liveability (dIVV, 2001b). It launched a new policy plan in 1994: the VIP-plan (i.e. "Verkeers en Inrichtingplan" or Transport and Spatial Plan). In this plan the authorities framed two issues as most salient problems: the high level of on-street parking, and the congestion on city corridors. Associated to this, they proposed two main policy solutions: a) reducing levels of on-street parking places by offering underground parking space (and raising street parking prices); b) decreasing congestion in the city centre by using traffic management system, and providing a low-priced parking alternative at the border of the city centre: a P+R 'transferium'. In the latter facility motorists would transfer to train or metro. The government combined the transferium with the new development of business area Zuid-oost and a football stadium, and furthermore subsidy from the national government had become available for $P+R$ initiatives. These factors helped in turning attitudes in the city council towards this plan positively.

After 1996 the policy frame reaffirmed in the "Nota Verkeer en Parkeren (Memorandum on transport and parking policies)" in 1999 and "Nota Parkeren is manoeuvreren" (Parking is manoeuvring) in 2001. Both policy documents focused on creating underground / private parking facilities so that the loss of on-street parking should be equal to the parking places available in underground/private parking facilities. Furthermore these documents focused on extending and increasing parking taxes ("fiscalisering"). Attitudes towards this measure were positive ('we can conclude that that pricing is a powerful strategy to attain mobility goals' (dIVV, 2001b) ). This was partly because it was financially self-supportive. A gradual, moderate increase of parking prices in the city centre was explicitly chosen to avoid unwanted effects on the local economy or social acceptance (in case of high increase), and too little effect on decrease of unnecessary car use (in case of low increase). The tariff for a parking license was proportional to these on-street parking tariffs (ibid, p.21). By 1999 a concrete goal was set to decrease car use in the city centre by $25 \%$ by 2005 , in comparison to 1991 (SAC, 1999).

There are signs of a reframing of the policy perspective to $P+R$ between 1999 and 2001. In 1999 Park-and-Ride initiatives were of 'a matter of importance' (SAC, 1999, section 4.3). They were mentioned in the reports, but generally treated as an additional initiative to parking polices, and not embedded in an overall plan to restructure the parking system in and around the city. After 1999, however, they were increasingly mentioned as 'an indispensable element of the accessibility of the city' (dIVV, 2001, p. 26). Since the first P+R site in Amsterdam, ArenA, was seen as relatively successful, attitudes towards opening more sites tuned positive. 

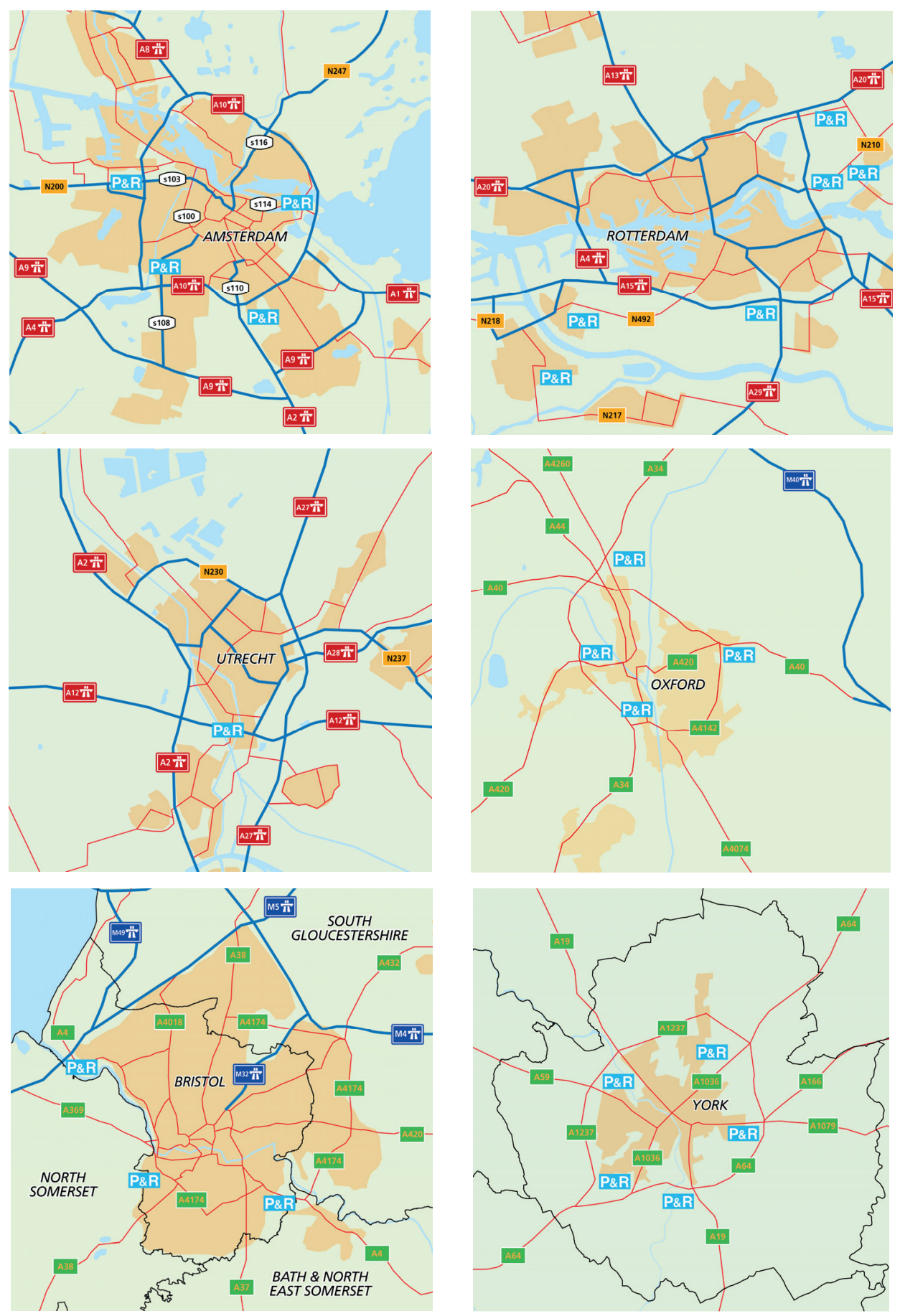

Figure 8.1: Geographical overview of the P+R sites in the six cities by 2005. (Copyright (C) 1995 - 2010 ESRI Data \& Maps, Europe) 
There are signs of a second reframing of the policy perspective by 2005, with respect to air quality. Until 2005, policy reports mention that $P+R$ sites are not solely meant to reduce congestion problems but also to improve the environmental and air conditions in and around the city (ibid, p. 24). However, nothing of this is reflected in transport policy aims or considerations. Only by January 2005 had this changed, when new European norms on air quality (especially 'small particles') forced city governments to seriously take emissions into account. Air quality indications are now becoming part of the policy discussion and influence initiatives. In the beginning of 2006 an air quality action plan was presented, which gave renewed importance to $P+R$.

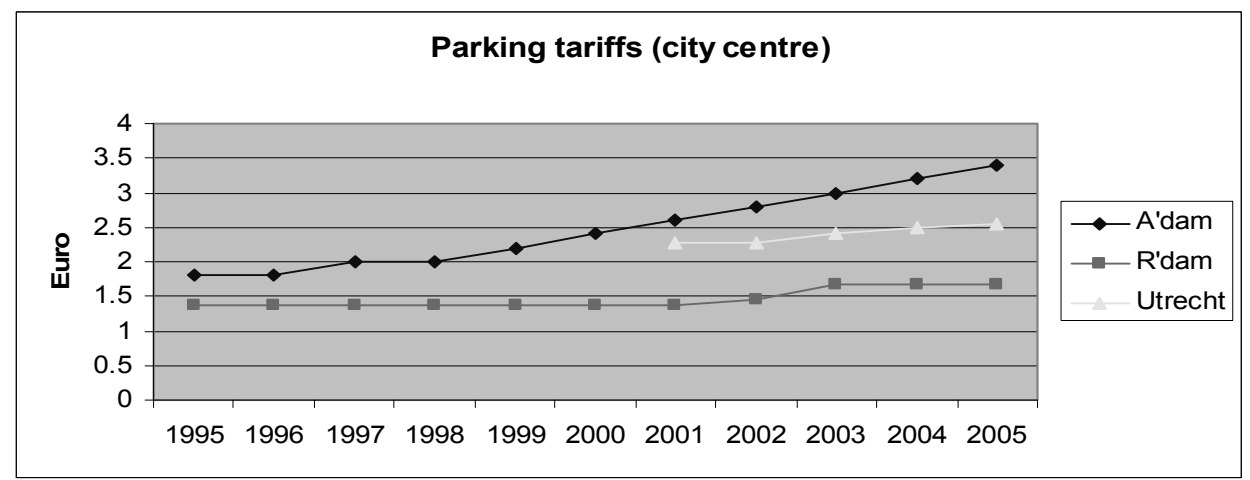

Figure 8.2: Parking tariffs in Amsterdam, Rotterdam and Utrecht (1995-2005). Tariffs in Rotterdam are averages (since they vary between streets and times of the day).

\section{Traveller perspective}

According to research from a branch organisation, a large share of people travelling in the Netherlands had the car framed as the only option for their journey by the beginning of the $90 \mathrm{~s}$ (around 50\%). Another quarter did consider both the use of the car and the public transport (this is the 'choosing traveller', the 'keuzereiziger'), though for many of those the car was the preferred option (OV9292, 2003). There are no indications that Amsterdam deviated much from this. This means that around $75 \%$ of the travellers preferred to drive 'as-far-as-they-could' towards their destination, and accepted the parking price.

The same study hints at a change of perspective of quite some travellers between 1991 and 2002. The amount of 'keuzereizigers' increased, from 26\% in 1991 to $45 \%$ in 2002 (OV9292, 2003). Thus, for $45 \%$ of the people public transport at least became an option for their trip, in addition to the $20 \%$ who uses public transportation any way.

Commuters also changed their behaviour more clearly due to policy initiatives. Initially (i.e. up to 1997) the extended introduction of parking taxes repelled parking in the city centre (dIVV, 2001b), and the total number of car kilometre in the city centre decreased between 1995 and 1997 (with 9 percent points). Commuters fled to other areas, longing for parking at a lower price or free. After further extension of the areas with tariffs however, parking in the city centre increased again (after 1998). Apparently visitors accepted the parking taxes, got used to it, and started to drive-as far-as they-could again, and paid for their parking (dIVV, 2001bb). 
Some motorists opted for P+R. A survey found an overall satisfaction score of the Arena facility was 7.5 in 1997 and 7.6 in $1999^{35}$. In the light of all travellers to Amsterdam, only a small minority chose for $P+R$ use: of about $0.2 \%$ (by 2005). Around $70 \%$ drove the whole trip by car, whereas about $30 \%$ used public transportation.

\section{Policies}

From 1993 to 1998 the city government extended the areas where parking was charged. It rose sharply from 8000 to 110.000 places in that period. Free parking was now limited to outer areas of Amsterdam. Further, parking tariffs in the city centre moderately increased between 1995 and 2005, during eight of the ten years (see Figure 8.2 ). Parking supply in the city centre was roughly held stable between 1993 and 2004, at about 28,500 spaces within the inner ring (SAC, 2008). In 2001 an 'Integral Dynamic Parking Indication System' was launched, easing the search for free parking places. All in all, regime restricting policies were moderately strong.

Policies to promote the $\mathrm{P}+\mathrm{R}$ niche were moderate in Amsterdam. In addition to the transferium Arena in 1996, the government opened two new P+R facilities in 2001: Olympisch stadion plein and Sloterdijk. By 2001 there were 1000 spots available (500 at Arena, and 250 each at others). A forth site, Zeeburg, opened in 2005. All of these linked to train, metro and (later) bikes, whereas no bus-based sites were introduced. The frequency and reliability of the public transport service from the sites was seen as attractive (although not very attractive), while facilities at or near the sites for users (shops, cafés, making waiting more attractive) scored poorly. No special collaborative efforts were applied to stimulate the use of $P+R$ over the decade (such as collaboration with companies or shops).

In the 1995 to 2005 period the city slightly improved the metro, tram and bus systems, most notably with extensions of tram lines (e.g. Gein to West). In the metro system ring line number 50 was added. Detailed accounts of these public transport innovations are beyond the scope of this research.

\section{Occupation levels}

The average parking pressure in 2004 was $80 \%$ (which was fairly stable after 1998). The total number of car-km travelled in the city centre decreased between 1995 and 1997 (by 9 percent points), due to the introduction of the new parking tariffs. After further extension of the areas with parking charges, parking acts in the city centre increased again (after 1998). In 2001 the city government estimated however that without parking taxes car use within the city ring would have been $13 \%$ higher than at that moment (dIVV, 2001b). The goal to reduce car use in the city centre by $25 \%$ was reached by 2005 . The share of visitors using public transportation grew to $30 \%$. The number of $P+R$ users is shown in Figure 8.3. Motorists opting for $P+R$ grew from 80 in 1996 to 240 in 2000, to 450 in 2005. About one third of these users was heading for a local destination (dIVV, 2001aa); two third continued their journey to the city centre by train or metro. Thus, only about $0.2 \%$ of car travellers were intercepted from a trip to the city centre, about 300 car trips each day (by 2005). In other words, the restricting central parking regime pushed most people into public transportation (for the whole trip), and few into P+R use.

\footnotetext{
${ }^{35}$ This is fairly high, but we acknowledge that assessing the opinion of actual users gives a biased view on the opinion of car travellers in general: it does not measure all the dissatisfaction of non-users, or drivers that tried once but did not return.
} 


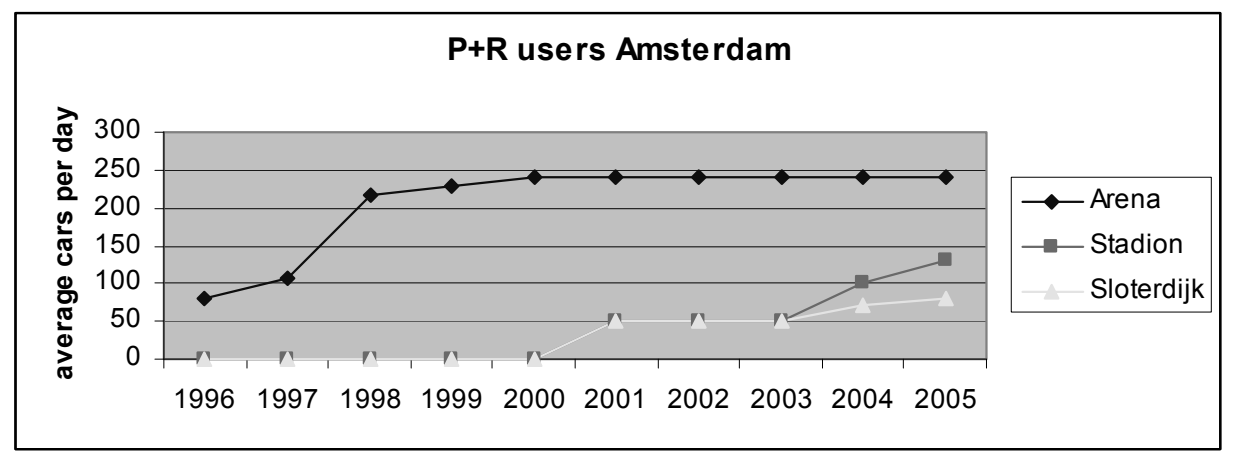

Figure 8.3: Daily use of the $P+R$ sites in Amsterdam (dIVV, 2001aa)

\subsection{P+R IN ROTTERDAM}

\section{Introduction}

Rotterdam is, in terms of population, the second largest municipality in the Netherlands, with 596,407 inhabitants (2005). In contrast to Amsterdam, Rotterdam has a modern and spacious road network, most of it put in place after severe damage during the Second World War. The port of Rotterdam is the largest in Europe and one of the busiest in the world, creating a zone of intense economic activity extending from the city centre to the North Sea coast. These activities comprise and attract high levels of traffic movements, both of goods and people.

\section{City government perspective}

City government's transport policy after 1995 consisted of plans to improve both accessibility and liveability of the city, making way for economic growth (Gemeente-Rotterdam, 1993). In an update of the plan in 2002 these aims were reaffirmed, while containing a new ambition for 'mobility networks': a pattern of well connected hubs, offering travellers a range of choices among modalities: car, metro, tram, bus, train and bike. Throughout the whole period, parking supply was not critical, and there was a common understanding that Rotterdam had provided sufficient numbers of parking places throughout the city, both on street and in garage, delivering relative low 'seeker kilometres'.

In the 1980s Rotterdam's city government had developed two types of $P+R$ sites: those with a local function and those with a regional function. The first type was built solely as parking lots near public transport stations (especially metro stations) for local users. The second type contains (larger) sites attuned to car drivers from the region that visit the city centre (also linked to metro and train stations). In the beginning of the 1990s the authority re-stressed the role and operation of P+R sites in their transport policy (Gemeente-Rotterdam, 1993). The sites would be upgraded to provide a more attractive opportunity for commuters.

Around 2000, striking reframing occurred in the government reports related to the attitude towards (road) traffic growth. As on national at policymakers in Rotterdam shifted from an aim to decrease car traffic growth, to an acceptance of the growth. The central idea became 'mobility is o.k.', and 'let the citizen choose' (Gemeente-Rotterdam, 2003). In other words Rotterdam allowed growth of parking places in the city, within the limit of what was called 'the environmental liveability of local neighbourhoods'. This approach continued between 2000 and 2005. 


\section{Traveller perspective}

Rotterdam resembles the national trends of a majority of people travelling to or from the city have the car framed as the preferred option for their journey (OV9292, 2003). In Rotterdam motorists face a spacious principle road network and ample parking spaces in the city centre. Accordingly, car driver will less likely be attracted to $P+R$. On the other hand, from those who do use the $P+R$ sites, 80 to $90 \%$ are satisfied or very satisfied with the $P+R$ site with respect to safety and comfort, as an evaluation at the Alexander site shows ${ }^{36}$.

Car commuters were affected by parking restrictions though. Confronted with extended introduction parking fees, many commuters initially chose a new parking location, at places where parking fees were still non-existent or low. This created a shift of parking pressure to an adjacent neighbourhood. After some time (and some complaints), the city government introduced fees in the adjacent neighbourhood, and the same reaction would recur. However, after a few years, people accepted the high tariffs in larger city centre area, and started to park again closer to their destination.

\section{Policies}

After 1995 a few additional garages were built, bringing the total to sixteen by 2005 . The area where parking was charged extended after 1995, phase by phase, from the centre further to adjacent neighbourhoods. The level of the fee that was introduced in a street was proportional to the parking pressure in that street. As Figure 8.2 shows, parking tariffs were fairly stable between 1995 and 2005. The city government collected the revenues in a parking fund, to be used for improvement of parking facilities. In 1994 a parking indication system was launched ( 0.9 million euros, for $75 \%$ drawn draw from the fund). In 2005 a major update of the system was made operational. The system guides car travellers to nearest parking lots in the city centre (reducing 'seeker' kilometres).

All in all, regime restricting policies were weak in Rotterdam.

After 1995 a number of (larger) P+R sites were more explicitly indicated at the ring road and attuned to car drivers from the region that visit the city centre: Alexander (A20), Kralingse Zoom (A16), Slinge (A15), Hoogvliet (A16) and Spijkenisse. These are connected to the underground and therefore provide fast and reliable rides to the city centre; more reliable than bus connections, which are often troubled by road congestion.

Most of these $P+R$ schemes were free to use, except for the one in Schiedam Centrum. In Alexander it is free provided that the commuters pay for the public transport ticket (since 2004 this arrangement is made). All in all, policies to promote the $P+R$ niche were moderately strong in Rotterdam.

\section{Occupation levels}

The net effect of the practices of road users resulted in a mild increase in road traffic between 1995 and 2005, although the area inside the inner city cordon was an exception, where demand in 2005 was back at the 1995 level (Gemeente-Rotterdam, 2005). Parking pressure decreased on average because of the introduction of parking fees, and overall sufficient parking supply. The total number of users of public transportation (i.e. bus, tram and metro) in Rotterdam decreased from 172 million in 1995 to 160 million in 2005 (source RET).

\footnotetext{
${ }^{36}$ As in the case of Amsterdam, we acknowledge that studying actual users gives a biased view on the car traveler in general, since it does not measure all the dissatisfaction of non-users, or drivers that tried once but did not return.
} 
The occupancy rates of the P+R sites Alexander, Kralingse Zoom, Slinge and Hoogvliet were $73 \%$, $110 \%{ }^{37}, 60 \%$, and $78 \%$ respectively (in 2006). This accounts for more than 2500 vehicles daily on average for the six regional sites in total (Gemeente-Rotterdam, 2007). Figure 8.4 shows the fluctuation between 1998 and 2003 for the six sites. The facilities were used by various groups: commuters, shoppers and tourists, of which commuters were the largest share. Local users, which were not a target group, made up 5 to 15\% (Mingardo, 2008). Another untargeted group are outbound travellers. Alexander is a special case in this respect: $60 \%$ of the parkers work in Amsterdam, Utrecht or The Hague. On other sites this is however not the case.

Mingardo (2008) studied the way $P+R$ users previously travelled. He found that at most sites $33 \%$ of the current users previously travelled by public transport or by bike. This means that one third of the current users does not decrease car use to the city centre. All in all we see that total daily car reduction in the city centre does not equal the $2500 \mathrm{P}+\mathrm{R}$ users as shown in figure 8.3, but is around 1500 cars (versus around 300 in Amsterdam) ${ }^{38}$.

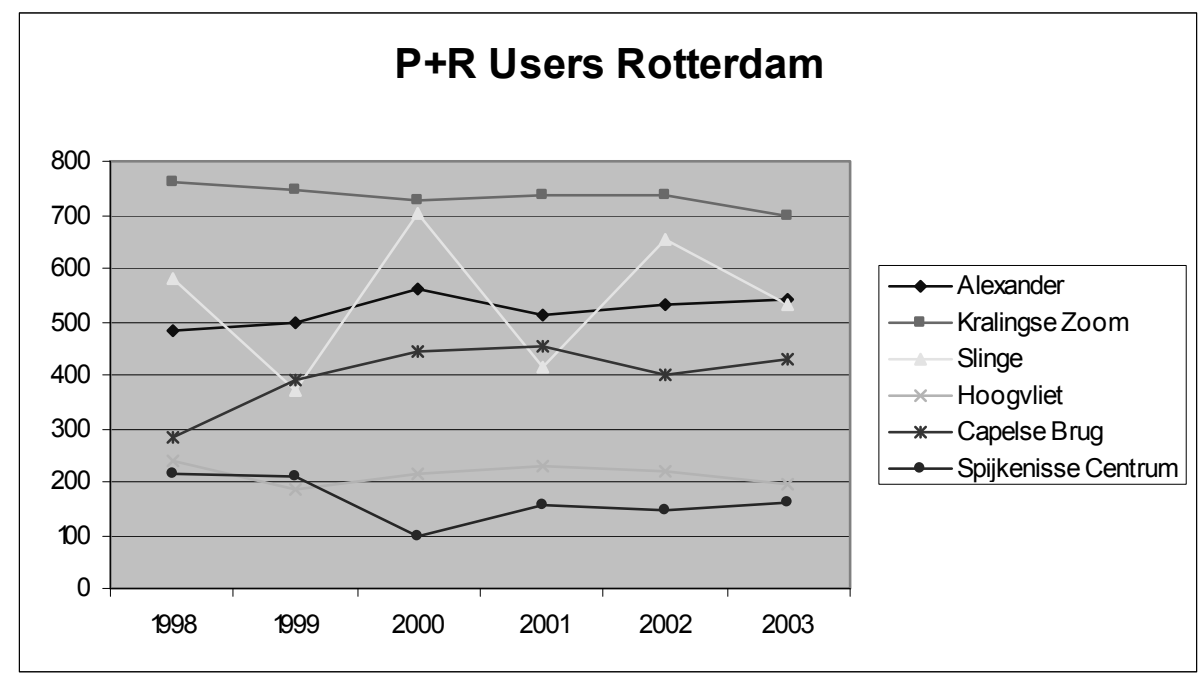

Figure 8.4: Trend of $P+R$ users in Rotterdam

\subsection{P+R IN UTRECHT}

\section{Introduction}

Utrecht is, in terms of population, the fourth largest city in the Netherlands. It is situated in the centre of a national web of infrastructure. Every day almost 100.000 cars enter the town, while 45.000 cars drive out (Gemeente-Utrecht, 2003b). The central train station transfers more passengers than Schiphol airport. The number of inhabitant has grown in the last decade, due to development of new area westward, from 234.000 in 2000 up to 275.000 in 2005. Traffic

\footnotetext{
${ }^{37}$ This means the parking lot was full, with additional cars outside the marked spots.

${ }^{38}$ The total number of daily car parkers in the city centre is estimated 50 to 100 thousand, while $P+R$ intercepts around 1500 car travellers to the city centre, which is about $2 \%$.
} 
movements have grown accordingly, and will continue to grow, according to the National Traffic-and Transport Plan 2001-2020.

\section{City government perspective}

Managing parking in the city is challenging. The city government records that 'Utrecht has a parking problem, meaning that demand for parking spots is higher than supply' (GemeenteUtrecht, 2003a, p.7). The prime objectives for the city's transport policy are maintaining or increasing accessibility and liveability. These should however respect the freedom of the car driver: [we aim to] meet the demand for car mobility of our citizens: 'car mobility is okay' (Gemeente-Utrecht, 2003b, p.10). After 2003 there is a slight refining, towards intensification of steering parking policy (ibid). Practically this meant the (proposed) use of price differentiation in influencing parking demand in different areas.

An increase of the number of parking places, also in the center, is regarded as one of the solutions for congestion problems (ibid, pg 17). At the least, current car accessibility should be maintained. Being able to park near the destination, either house, shop or work, is a high good' (pg. 23). A system of various $P+R$ sites around the city is studied in this period, and is seen as a solution for the farther future. It is not seen as a solution for the citizens of Utrecht, but for others: 'commuters and visitors of the inner-city are collected as much as possible at the city edge and transported to the centre by means of a smooth public transport connection' (pg.20).

\section{Traveller perspective}

Motorists to Utrecht were not attracted to the $\mathrm{P}+\mathrm{R}$ facility: only a few dozen chose to park their car there. There were various reasons why car drivers favoured parking in the centre. One is that there were still areas near the town centre where one could park for free. Another part is that finding a parking spot in the city centre was made easier, through an automatic indication system.

Commuters did change their behaviour slightly due to policy initiatives. The extended introduction of parking taxes urged commuters to park in adjacent areas, where parking was still free. They seemed to be happy walking 10 minutes when they could park for free. Due to further extension of the areas with charges, this became more and more difficult, though in Utrecht there are still areas with free parking in walking distance of the city centre.

\section{Policies}

Firstly, from 1996 onwards the city centre was made less attractive for car-use. By re-directing the drive directions, the centre became unsuitable to drive through. You could reach almost any street by car, but only via many de-tours. This was learned from Groningen. Secondly, from 2000 onwards PRIS was operational: an automatic indication system, guiding car drivers to parking lots with free spaces. Further, in 2003 the government launched a plan of building seven new garages just outside the inner-city (canals), but well within the ring road (Gemeente-Utrecht, 2003b). These garages added to the 12 existing garages in 2003, which provided 2400 places in total (in the first shell outside the inner-city there are another 6000). Developing garages takes time, usually a few years. The government expected the first three garages to be ready by 2004, 2005 and 2006 respectively, increasing the number of parking space with around 1000 places. (These garages were partly intended to remove (236) resident street parking to resident garages, but by 2003 it was not fully clear how these street places would be removed.) All in all an increase of at least 750 parking places within the ring road would be accomplished.

Alongside building new garages, areas of paid parking were extended between 1995 and 2005. It started with the quarters near the inner-city, especially the east side: buiten-wittevrouwenveld, and wittevrouwenveld. The government usually waits with applying this measure in an area till 
the parking pressure has risen above a certain level. Therefore not all areas in the first shell around the inner-city have paid parking yet.

Parking tariffs in the city centre were mildly increased, see Figure 8.2: between 2001 and 2005 the rise was around $13 \%$, to 2 euro 56 for an hour. This was just in between the price in Amsterdam (3 euro 40) and Rotterdam (1 euro 68). All in all, regime restricting policies in Utrecht were weak.

Together with the developments in the city centre, policymakers studied options to promote parking outside the city centre. In 1998 a P+R experiment started at Galgenwaard, called 'Shopping-Express'. On moments of shopping peak hours (only Thursday night and Saturday) the parking lot of the football stadium was used, and a bus shuttle drove up and down the city centre for a low price. In 2000, when the national government offered a subsidy, P+R Westraven was built at the south ring. It included 750 places, and was connected by (existing) quick-tram. Following disappointing use of this site, some years without action followed. Discussions and studies on the future of $P+R$ emerged. More recently, local government policy has departed from the principles of using $P+R$ to intercept traffic by stimulating use of the car park by firms located in the neighbourhood of the site, instead of preserving its use for transport to the city centre. As a result, it is not surprising that the facility did not decrease car use in the city centre.

All in all, policies to promote the $P+R$ niche were weak in Utrecht.

In 1996 a free bus lane became operational. It was like a 'tram on tires'. This was a great improvement for the quality of bus trips in the city, and supported bus use. The original plan of a tram in the city was rejected. Detailed accounts of this and other innovations in public transport are beyond the scope of this research.

\section{Occupation levels}

From 2000 till 2005 P+R Westraven was extremely little used: a few dozen of cars a day (apart from exceptions of large expositions in the Jaarbeurs, or shopping peak hours). It did not attract commuters during the working week. It did not decrease car pressure in the city centre.

\subsection{P+R IN OXFORD}

\section{Introduction}

Oxford is a medium-sized $(135,000)$ historic city located in central England in a geographical context constrained by river flood plains and heritage preservation designations, notably an encircling greenbelt. Significant industrial development mainly related to the motor industry occurred in the $20^{\text {th }}$ Century which resulted in large increases in jobs and population in a few decades and, combined with housing provision constraints, led to growing in-commuting.

\section{City council perspective}

Oxford City Council adopted bus-based P+R at the beginning of the 1970s as part of 'balanced' or 'integrated' transport strategy. At a time of growing public concern about the acceptability and affordability of urban highway construction to provide for free-flow traffic the council accepted the need for car traffic restraint for the first time.

It expected $\mathrm{P}+\mathrm{R}$ to contribute to curbing the rising local environmental consequences of car use, traffic congestion, and declining conditions for pedestrians. Therefore, it developed bus $P+R$, with new shuttle bus services, as a relatively cheap and pragmatic policy to adopt.

Oxford's P+R scheme was the only one to survive from the 1970s, and was itself not without critics on grounds of low patronage and financial viability. Over the subsequent 30 years the scheme would, however, be expanded to 5 sites offering a total of approximately 5,000 spaces. 


\section{Traveller perspective}

By 1993, a motorist approaching Oxford was offered 3,000 P+R spaces in four sites around Oxford. Frequent (10-30 minute headway) bus services were provided to each, with very basic car park facilities and buses in order to maintain financial viability. However, the alternative option for the motorist without reserved parking was paying parking costs much higher than in similar-sized towns, and uncertainty about how long it would take to find a free spot. In this context the basic facilities were judged as acceptable by users, and around $10 \%$ of inbound motorists opted for P+R use by the early 1990s (Parkhurst and Stokes, 1994). A decade later, with the $P+R$ scheme expanded in capacity, further restrictions and higher charges introduced in the city centre, and higher quality facilities offered, $P+R$ was carrying about $10 \%$ of all trips (although conventional public buses remained for more important in terms of total demand).

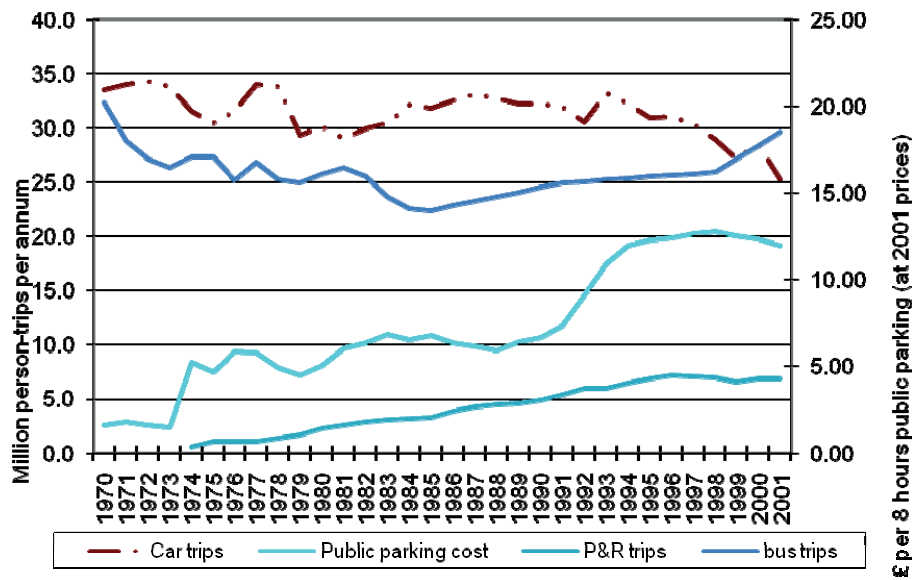

Figure 8.5: Key traffic trends in Oxford

Policies

A key factor of the Oxford policy was to link strong regime restricting (push) elements and with pull elements by increasing off-street parking charges (Figure 8.5), particularly for long stays and using the revenues to support $P+R$ operations. Another effective push policy was that Oxford City Council required property developers to contribute to funds for $P+R$ capacity rather than providing private off-street capacity in individual developments. A further potentially powerful policy was to limit the provision of public parking in the city centre (Parkhurst, 1993). However, this policy was only moderately restraining on traffic levels as a growing share of city centre motorists were either passing through the centre or had access to private, off-street parking. Also, an increased share of shorter stays, due to higher charges in public parking spaces, limited the reductions in overall traffic levels.

\section{Occupation levels}

By 1992 the total amount of parking for the city centre including $P+R$ had increased, although that available to the public in the central area had fallen. Off-street parking was reduced by around $10 \%$ but most of the on-street capacity was eliminated, so that an overall availability of more than 10,000 spaces in 1966 was reduced to less than 4,000 (Parkhurst 1993). However, private off-street parking capacity nearly doubled in the same period to more than 10,000 spaces despite restrictive development control policy, apparently as a result of long-standing offstreet parking 'rights' being used more intensively. 
These changes in parking provision were associated with a $20 \%$ decline in car traffic and an increase in bus use at the end of the 1990s (Figure 8.5). A key factor here was a re-invigorated traffic restraint policy which focussed on restricting through traffic in several central streets. $P+R$ use was in fact stable in this latter period whilst central parking charges actually fell in realterms.

\subsection{P+R IN YORK}

\section{Introduction}

York is also a historic city of around 135,000 inhabitants which like Oxford saw significant transport-industry related growth, but in this case in the $19^{\text {th }}$ Century, linked to railway operations and rail vehicle manufacturing, and confectionary. However unlike Oxford, which is embedded in the southeast economic core, York has a relatively rural location, as a central place serving a large hinterland.

\section{City council perspective}

York is regarded as one of the most successful examples of wide-area 'retrofit' pedestrianisation in the UK. Whilst congestion remains a relevant issue, the city council has managed the worst effects of car use on the city centre economy relatively effectively. Combined with the rural origins of many of the frequent users of the city centre and planned strategic growth, the highest priority for $\mathrm{P}+\mathrm{R}$ policy has been to contribute to economic objectives, with a medium contribution to reducing congestion and a small contribution to improving air quality(YCC, 2006b).

Following the implementation of a partial reorganisation of English local government in certain areas, York City Council was established as a unitary authority with control over the territory immediately beyond the perimeter of urban area. This reduced the number of local authorities involved in the delivery of short-range $P+R$ from 2 to 1.

In this context York City Council has pursued one of the most aggressive P+R policies in the UK, delivering 5 sites in less than 15 years (1991-2005), with a one-third expansion in capacity in the final five years of this period, to a total of around 3,500 spaces. Whilst operating costs were covered from user fares in recent years, significant capital costs for new sites were designated: $P+R$ expansion was in fact the largest item in the Council's transport capital spend from 2001/02 to 2005/06: $f 8.5$ billion of a total $f 28$ billion. Local planners have envisioned a particular innovation for $P+R$ sites by operating them as rural bus termination points, with passengers transferring for the final journey leg, to increase the efficiency of rural bus operations, although this is yet to be implemented.

\section{Traveller perspective}

By 2003/4 P+R patronage in York had grown to around 2 million return trips per year and towards the end of the decade was approaching 3 million. The ample supply of $P+R$ sites made it an attractive option for car travellers. For citizens aged over 60 parking and shuttle bus were even provided free, due to the introduction nationally of free bus travel for this age group.

\section{Policies}

Parking supply policy places a cap on off-street public car parking in the city centre at 2002 levels $(5,100$ spaces)(YCC, 2006b). As in Oxford a parking regime based on length of stay restrictions and tariffs which favour short and medium stays has been effective in reducing demand for commuter parking. Some parking capacity has also been transferred from city centre to periphery, although overall capacity has grown significantly. 
$P+R$ policies have sought to make the $P+R$ sites and shuttle services high-quality and financially attractive. The buses operate up to a ten-minute frequency and travel is relatively low cost, with discounts for frequent users and free travel for children accompanying adults.

\section{Occupation levels}

During the five years from 2000 when $P+R$ capacity increased by a third, there was a modal shift away from private cars for accessing the city centre of approaching $10 \%$ overall, but $30 \%$ in the morning peak. These changes are associated with a 3\% reduction in car traffic at peak times, but a similar level of traffic growth over the typical days, as travellers respond to the parking regime. Demand for city centre parking fell overall by 30\% 2000-2005(YCC, 2006a). Hence, a 10\% reduction in council-controlled off-street parking supply to a total of 3,500 spaces as a result of redevelopment has not resulted in scarcity of demand but parking revenues fell. Reductions in parking revenue for the authority have continued ( $10 \%$ or $f 3$ million in the period $2006 / 7$ 2008/9)(YCC, 2009).

\subsection{P+R IN BRISTOL}

\section{Introduction}

Along with Nottingham, Bristol was one of the pioneers of bus $P+R$ as a solution for medium-size cities in England. The Bristol urban area has a population of 520,000 . Rail-based $P+R$ is typically more suited to this scale of city as rail services, requiring segregated corridors, generally achieve higher priority. In the case of Bristol, though, suburban rail services are limited, with both train schedules and station car parking management being oriented towards serving regional and national movements. Bristol is the largest city in southwest England, characterised by hilly terrain and a city centre which like Rotterdam suffered wartime destruction and was redeveloped with shopping precincts and an extensive road system including urban motorways in the post-war period. A combination of physical, economic and institutional factors has resulted in Bristol arguably becoming the most car dependent of the ten largest urban areas in Britain, with the lowest traffic speeds outside London and a public transport modal share of less than $15 \%$.

From 1974 to 1996 planning and transport for the whole Greater Bristol area was the responsibility of the subregional Avon County Council (Avon). From 1996, following local government reorganisation, Avon was divided into four single-tier 'unitary' authorities. Most of the urban area was designated as Bristol City, although around a quarter of the city's population in the northern suburbs was allocated for electoral and demographic reasons to a different unitary (South Gloucestershire).

\section{City council perspective}

Over three decades Avon and then Bristol City Council (BCC) led unsuccessful attempts to reintroduce light rail and adopt city centre road pricing, projects which had the highest priority. $P+R$ was introduced as part of a package of shorter-term measures including intermittent bus priorities on the highways. Avon introduced the first permanent site (Bath Road) in 1993 on the southeast side of the city (1,300 spaces). A second was planned under Avon and opened in 1997 beyond the city boundary to the southwest at Long Ashton (1,500 spaces). BCC provided a third, Portway, in 2002 to the northwest. The bus service to the last of the sites is also targeted as a 'walk to bus' service to those residential areas it passes through.

The primary objective of policy was reducing peak-hour congestion, although secondary accessibility, road safety and air quality benefits were also intended (WoEP, 2006). To date attempts to establish a site to the northeast of the city to serve one of the busiest radial approaches to the city centre have not been successful due to site identification issues, with the 
most suitable site options being beyond the BCC boundary, and controlled by South Gloucestershire Council, which has had a different vision of $P+R$ form and function. The reorganisation left $B C C$ with no formal powers to influence transport-related matters beyond boundaries unsuitable for strategic transport management. It does, however, form joint policy through voluntary cooperation within the 'West of England Partnership'; a structure which also offers BCC limited influence on neighbouring authorities.

\section{Traveller perspective}

Demand for $P+R$ has generally emerged since sites have been provided. The majority of this demand is from travellers who perceive their alternative travel option to be drive-by-car to the city centre. However, approaching half of users at the Bath Road site and a third at the Long Ashton site were found from surveys in the 1990s to have transferred from public transport, and to see those services as their alternative options. Around a half of users to the Bath Road site were also travelling from origins within $10 \mathrm{~km}$ (BCC, 1996; BCC/NSC, 1997). The site is located adjacent to dense suburbs and on the corridor between Bristol and the neighbouring city of Bath, just $10 \mathrm{~km}$ to the southeast. Such modal shifts and short-range trips to $P+R$ are understand in a context of high rail fares, peak-hour crowding on trains and also non- $P+R$ bus fares which are higher than $P+R$ fares.

\section{Policies}

$P+R$ provision has been linked to a parking policy to transfer long-stay parking from the city centre to $P+R(B C C, 2001)$ using deterrent tariff structures for public parking and development control measures for private parking. In practice, however, the policy has faced two key constraints. First, BCC only controls around half of the public off-street parking. Second, the city centre faces significant economic competition from a large out-of-centre shopping mall (Cribbs Causeway), located on the edge of the Bristol urban area with 7,000 free, unrestricted parking spaces. Its presence is acknowledged as having a significant competitive impact on parking policy (WOEP 2006): concern about economic competition resulted in BCC supporting plans to develop a new shopping centre, Cabot Square, in the city centre, which opened in 2008 with 2,600 additional charged parking spaces, representing a $25 \%$ increase in city centre supply. Following the economic downturn the car park has significant excess capacity, which is being aggressively marketed by the private sector operator.

\section{Occupation levels}

The policy intention to transfer long-stay parking to the periphery of the city has had some success, although a large minority of users would have otherwise used public transport and total parking capacity in the city centre has risen, whilst the share controlled by BCC has fallen. The local policy target for traffic flow to Bristol city centre is for 'zero growth'. A $10 \%$ reduction inflow in fact developed over the four years to 2007-8, although this was partially reversed in 2008-9 (WoEP, 2008). The changes at least in part reflect the reconstruction and then opening of Cabot Square, involving road and parking closures.

\subsection{CO-EVOLUTION OF DEMAND AND SUPPLY FOR PARKING}

In this section we first compare the implementation of $P+R$ in the six cities. Then we turn to consider the extent to which the introduction of $P+R$ affected the dominant regime of urban car use, addressing how supply and demand for urban parking co-evolve.

Table 8.1 summarises the way in which push and pull policies were deployed in the six cities examined and the impact we found on city centre traffic. 
Table 8.1: Outcomes of deployment of parking policies in the six cities

\begin{tabular}{|l|l|l|l|}
\hline City & $\begin{array}{l}\text { Regime restricting } \\
\text { Policies (push) }\end{array}$ & $\begin{array}{l}\text { Niche promoting } \\
\text { Policies (pull) }\end{array}$ & $\begin{array}{l}\text { Combined } \\
\text { pressure on city } \\
\text { traffic }\end{array}$ \\
\hline Amsterdam & Strong & Moderate & Medium-High \\
\hline Bristol & Weak & Moderate & Medium-Low \\
\hline Oxford & Strong & Moderate & Medium-High \\
\hline Rotterdam & Weak & Strong & Medium \\
\hline Utrecht & Weak & Weak & Low \\
\hline York & Moderate & Strong & Medium-High \\
\hline
\end{tabular}

Since none of the cities combined strong regime restricting (push) policies with strong niche promoting (pull) policies, we suggest that none of the cities had maximized the potential to transfer parking to P+R. Nevertheless, Amsterdam, Oxford and York were the cities in which the strongest pressure was applied on city centre traffic. In the case of the first two, particularly strong penalties on city centre parking were the key features, and in the case of York, a particularly attractive $P+R$ offer. Rotterdam emerged as an intermediate case, where limited disincentives for city centre parking to some extent counteracted the strength of the public transport offer. Finally, in the case of Bristol and Utrecht, the policy rhetoric was insufficiently translated into delivery, with weak push and pull signals, except perhaps for a moderate niche promoting policies in Bristol.

The comparison explains well the outcome of the $P+R$ (push and pull) policies to the pressure on city centre traffic, but reaching general conclusions on traffic reduction is more problematic. After all the relation of $P+R$ use to actual reductions in traffic is not a straightforward relationship, but depends partly on factors such as the economic activity context and effectiveness of other traffic management measures, such as restrictions on through traffic and promotion of public transport in general. Hence, the cities with the greatest reduction in traffic - Amsterdam and Oxford - achieved this more through increasing modal shift from car to conventional public transport rather than $P+R$ use. York was notable in that $P+R$ does seem to have been a specific factor resulting in traffic reduction in the peak period, but this was accompanied with traffic growth overall as car owners took advantage of available short-stay car-parking in the interpeak.

Hence, we find that $P+R$ at least had an important symbolic role to the development of traffic restraint frames, building consensus around the idea that alternatives for car dependent travellers are being provided. It was often presented as a tool of 'integrated' transport planning in that it facilitates combination of different modes. Nevertheless, in each of the six cities $P+R$ was developed parallel to upgrades of parking supply for the city centre. To different extents in the six case-studies then, we find echoes of Kauffman's (2000) conclusion that: promoting the use of public transport by improving it, whilst simultaneously constructing new car parks for commuters in the city centre, is mutually incompatible.

Examination of our six case-studies did not indicate a particularly strong 'national character' to the interpretation and adoption of $P+R$ as a niche traffic management innovation, even if there were clear superficial differences, such as the exclusive use of bus transport in the UK and the reliance on rail in the Netherlands. 


\section{Co-evolution}

Despite the city specific contexts, there is a pattern we come across in most of the six cities: from no parking measures, through parking regulation and control, to various activities of tuning the combination of private and public transport. With our two-layered model of chapter 2, we stylize the subsequent steps in the underlying process, see Figure 8.6.

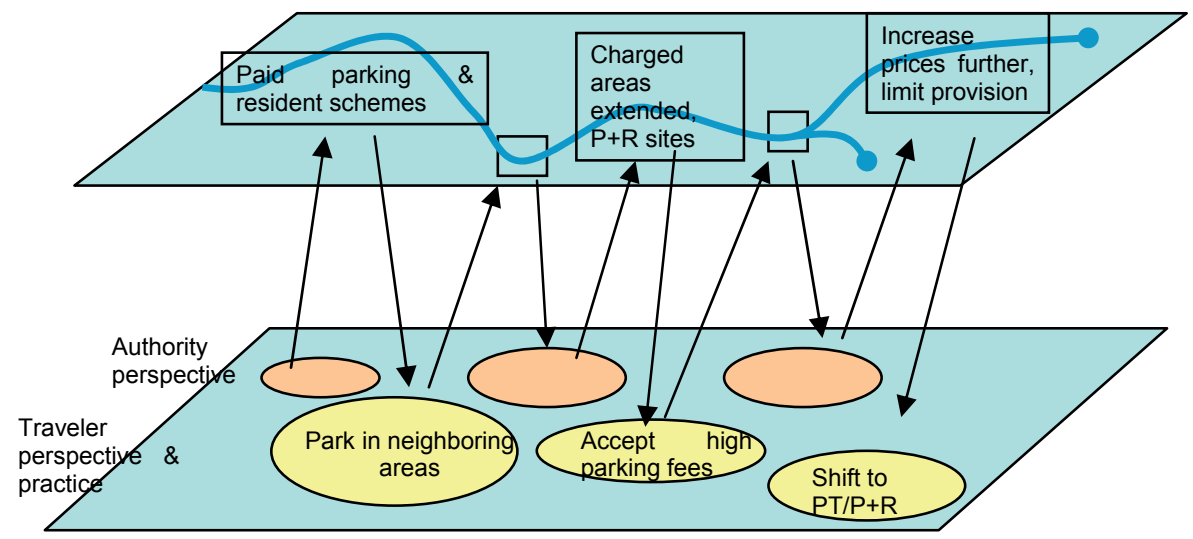

Figure 8.6: Stylized process underlying urban car parking innovation

All of the six city authorities started to regulate and control parking supply at some point in time, involving a ban on parking in some central streets, whereas in surrounding streets paid parking and residential parking schemes were gradually introduced. Typically, parking intensity (demand) shifted to areas just outside the paid parking zones, and people walked further to their end-destinations. Triggered by complaints about these practices, often from residential areas, city authorities extended parking restrictions and paid parking zones, and developed $P+R$ facilities as a niche solution (supply). In most cities, the initial $P+R$ usage did not accumulate significantly by itself: most car motorist ignored the $P+R$ site(s) and accepted the higher fees for parking in or near the centre. This condition put city councils at a crossroads. Some authorities saw this as proof that $\mathrm{P}+\mathrm{R}$ was not a good solution for transport issues, and should not get too much attention (especially since they could be detrimental to the revenues from parking). Correspondingly, there was little support for strong regime restricting policies and $P+R$ promotion in those cities. Car travellers accepted the (moderate) parking fees grudgingly and continued to park in the city centre, leaving the $P+R$ niche with insignificant modal share (Utrecht, Bristol, Rotterdam). Other cities authorities seized the presence of $P+R$ sites as an opportunity to make regime restriction and niche promotion policies increasingly stronger, arguing that the facilities provided an affordable alternative to car drivers. Here, car drivers became more reluctant to parking in the city centre, and a significant share shifted to public transportation and or P+R (Oxford, Amsterdam, York).

The highlighted process (see Figure 8.6) is a pathway of innovation of urban car parking, which is an outcome of interactions of the city councils' regulation, infrastructures (supply) and the daily practices of travellers (demand), in which we found three types of traveller groups (see section 8.2). It is a sequence of introducing a new policy with partially unforeseen outcomes, followed by another new policy introduction. More than a sole outcome, the pathway also forms the landscape or context which constrains and enables future practices and reactions.

This co-evolutionary process is essentially a socially enacted process of actors with different perspectives and interests. Our approach has been less successful in highlighting the social and 
political dynamics around the city authority. More than being a single decision maker, the local authority is composed of departments (economy, transport, environment etc.) as well as the city council, who are lobbied by stakeholders and sensitive to their own constituencies and professional groups. In our analysis we have left out such dynamics, and just addressed the policies and regulation that passed the city council. In future research this part of our framework needs to be elaborated. Also, actor learning mechanisms should be further elaborated. For both these issues, we see the two-layered framework as a good starting point.

\subsection{CONCLUSION}

In this chapter we have considered the introduction of $P+R$ facilities of six cities as an emerging niche alongside the dominant regime in urban parking, which has been 'parking in the city centre' for decades.

We found that each of the cities had a distinctive policy frame and mode of implementation. In none of cities more than a modest share of urban travellers and commuter was attracted by $P+R$. Analysis of the impact of $P+R$ on the urban parking regime showed that three cities (two British, one Dutch) had implemented $P+R$ with push (regime restriction) and pull (niche promoting) factors of sufficient potency to result in partial transformation away from the dominant parking regime. This shows that possibilities of local authorities to shape the practices of car drivers are small. 



\section{Chapter 9}

SCENARIOS OF CO-EVOLUTIONARY TRAJECTORIES 


\section{Scenarios of co-evolutionary trajectories}

In this chapter we explore future scenarios of car engine technology with support of a simulation model. Whereas chapter four to eight provided historic-analytic approaches to our two cases, we now turn to the question: what could happen? We develop plausible but simplified descriptions of two possible trajectories. These descriptions involve both technological and economic aspects as well as the formation of social connotation. To consider the complex and uncertain dynamics between the latter and the former phenomena, we benefit from a simulation model analysis. Therefore we formalize the two-layered innovation framework (see section 2.4), and make it 'tailored' to the case of car engine innovation. We deliver a model, simulating the co-evolution of demand and supply, giving rise to various possible trajectories. We formalize stakeholder perspectives, based on the empirics of chapter 4,5 and 6 . The main duty of the model is to support the analysis of the role of social connotation in innovation dynamics.

This chapter has four sections. In section 1 we review the diffusion modelling literature, covering the early epidemic modelling approach of Bass, up to the recent co-evolutionary approach. In section 2 we describe the simulation model. In section 3, the model is applied, both in retrospect, and to explore the future, and draws lessons on the role of social connotation. Section 5 presents scenarios for the diffusion of cleaner car engines. Section 5 draws conclusions and discusses the novelties of our analysis and challenges for future research.

\subsection{FROM EPIDEMIC MODELLING TOWARDS A CO-EVOLUTIONARY APPROACH}

Much has been written about innovation diffusion. The focus is on aggregate patterns. Rogers (1983) mentions five characteristics of an innovation, as perceived by potential adopters, which help to explain their difference in rate of adoption: (1) relative advantage, (2) compatibility, (3) complexity, (4) triability, and (5) observability. He offers a taxonomy of adopters based on when they adopt but does not offer a dynamic model of innovation diffusion in terms of endogenous and exogenous mechanisms.

For explaining dynamic patterns we have three types of models. The first, well-known, and widely applied model is the epidemic model pioneered by Bass (1969). It builds on the premise that what limits the speed of usage is the lack of information available about the new technology, how to use it and what it does. Information diffusion is governed by social contacts and marketing. Epidemic models have been widely applied in curve-fitting exercises (Bass 1986; Mahajan et al. 1990). Supply factors and changes in the environment are usually neglected, or incorporated in a crude way ${ }^{39}$. Mahajan et al. (1990) identify nine crude assumptions, three of which are:

- Total market potential of a new product (= final number of adopters) stays constant in time.

- Diffusion of an innovation is independent of all other innovations.

- The nature of an innovation does not change over time

Although Mahajan et al. and others (for example Lee et al. 2006) mention studies that overcome several assumptions, the models remain one sided in explaining the driving forces of innovation diffusion processes (still spread of information). Other relevant feedback effects, such as progressive improvement of the product (affecting adopter attitudes), remain neglected.

${ }^{39}$ Nevertheless, starting from Metcalfe (1981), models of diffusion have been proposed incorporating the production capacity growth rate, such as for instance by Bruno Amable (1992), Batten (1987), and Leoncini (2001). 
The second type of model is rational choice models, or threshold models (David, 1969; Kemp, 1998). In this type of model economic micro theory is applied based on the assumption of rational behaviour: any actor is expected to adopt an innovation the moment it becomes economic to do so. Supply aspects such as the techno-economic characteristics of an innovation can be incorporated in this type of model (as is being done in Ireland and Stoneman 1982). Learning and social and institutional aspects are typically poorly integrated. The model is mostly applied to the diffusion of production technologies, often using firm size as critical variate (David 1969; Davies 1979). Bigger companies are expected to adopt earlier because of economies of scale advantages or available capabilities. Bonus (1973) applies a threshold analysis to the diffusion of household durables (cameras, TV sets, automobiles), using income as the critical stimulus.

There has emerged a third type of diffusion models in which technological change is endogenized, called evolutionary or 'non-equilibrium' models (in the tradition of Nelson and Winter, 1982). Evolutionary approaches have sought to improve rational choice models by including learning of agents whilst maintaining an economic focus (Silverberg, 1991). The creation of technology and its adoption are seen as mutual dependent. Supply depends on demand and vice versa. Suppliers learn form users and benefit from scale economies, which allow them to sell the improved product at a lower price. Silverberg notes that this black spot of many diffusion studies, decoupling diffusion from further development, dates back to Schumpeter's linear model of progression from invention to innovation to diffusion. He states that realistic concepts should include feedback from diffusion of an innovation towards the profitability, relative competitiveness and market shares of the potential developers. The same holds for feedback from diffusion to price changes and towards perceived utility for potential adopters, we argue.

In their application evolutionary models have been focussing on firms and industries and to process innovations related to production efficiency. Windrum \& Birchenhall (2005) however, move ahead by presenting a multi-agent framework that explicitly models consumers and firms. In their model the nature and direction of technological innovation is determined by the interaction of heterogeneous consumer preferences and heterogeneous firm knowledge bases at the micro level. Since the two populations exercise a strong selective force on each other, we can speak of a co-evolutionary model. The authors investigate the possibility of technological succession by introducing a 'technological shock', which is a discrete step towards offering a new feature to the existing set of (service) characteristics. The merit of their approach is the identification of technology as set of characteristics, which makes it a variable, multi-faceted, mediating device between evolving consumers and firms. The approach does not include social meaning of a technology and imitation of adoption.

Although existing diffusion models have shown their value in simulating innovation at firm level (technological innovation, learning), market and sector level (competition and diffusion, structural change), and the macro level (growth, long waves and international trade), the models are as yet less applied to consumer products in a changing social context. Popularity or social connotation of products, especially new emerging environmental products, may change alongside technological innovation. A chief example is hybrid-electric vehicles entering the car market since 2000. Owners see their vehicle as 'socially responsible', as 'the right vehicle for society' (Heffner, Turrentine et al., 2006). Progression of such connotation will influence the further innovation and diffusion process of the technology, affecting both the consumer and the producer side. There are currently no models available that incorporate this interaction of such social and technological aspects.

In this chapter we aim to extend the co-evolutionary approach to innovation diffusion in a changing social context. To this end, state-of-the-art evolutionary modelling is combined with the literature of social construction of technology (SCOT; Bijker 1995). This results in an agentbased model to analyse the interaction between consumer demand and industry supply as a co- 
evolutionary process. We formalize agents' perspectives and behaviour and implement their subjection to feedback mechanisms from micro-to-micro, as well as macro-to-micro, as conceptualized in chapter 2 and described in chapter 6 . More precise, we formalize the framestructure that an actor group applies as the set of weights that an actor group applies in evaluating adoption, or investment and launch. An adopter's frame includes attributes of functionality, but also of social connotation. The attribution of meaning influences decisions of peer consumers, something that is well-established in marketing but has been neglected in innovation diffusion analysis. The interplay of demand and supply through various feedback loops give rise to trajectories. A model analysis of these paths of innovation is instrumental to understand the role of social connotation in innovation dynamics.

\subsection{A FORMAL MODEL OF CAR ENGINE INNOVATION}

In this section we describe the simulation model concisely. For a more detailed description (including equations and parameters) we refer to Appendix J.

\subsubsection{Model overview}

The model assumes a limited number of possible innovation trajectories: one related to internal combustion engine (ICE), and one to electric/ hybrid-electric ((H)EV) technology. We have two populations of agents: a large group of potential consumers (1000), and a small group of potential suppliers (10 firms). A prospective consumer considers buying a vehicle. It may adopt a vehicle type, or postpone its decision. After adopting a vehicle type, an agent is out of market for 15 time steps (re-purchase period). Then it is receptive again to buy a new vehicle type. Suppliers sell vehicles, invest in R\&D, and assess their business opportunity in the two technologies.

Agents are conceptualized by three components: (1) a frame-structure, (2) an evaluation of options, and (3) a decision (e.g. adoption by users; investing in R\&D or launching products by developers). The two agent groups, users and suppliers, are heterogeneous, and individual agent characteristics are considered (such as preferences and technological capabilities).

In accordance to the conceptual framework the model has two layers. The micro level contains the characteristics and decisions of agents. The macro level contains aggregate variables, such as total adoption levels, total investment levels, prices, and social connotations, see Figure 2.1 and 2.2 in chapter 2.

Regulators are considered exogenous in the model, for simplicity. We assume an exogenous regulatory system in place that requires gradual reduction of emissions. We assume that these requirements can be met with both technologies.

\subsubsection{User frame and supplier frame}

The user frame accentuates certain attributes of the car (engine). Each attribute goes with a certain 'weight' or emphasis. The following attributes are taken into account, see Figure 9.1: 
1) Price $(P)$ of the innovation or 'cost of adoption'

2) Perceived functionality (PF): the direct utility a potential adopter perceives, in comparison to the current situation. The utility depends on techno-economic characteristics of the innovation and functional needs of the individual user

3) Social connotation (SC) of an innovation, as defined by cultural peers.

4) Environmental impact (EI) of an innovation, with regard to ecological and social impact.

\section{Typic al user frame-structure}

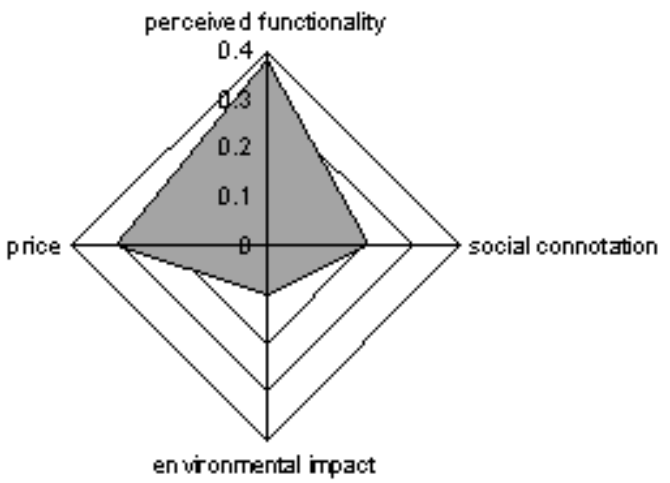

Figure 9.1: Typical user frame-structure

The frame consists of four weights of the 4 factors: w1 to w4. This actor frame is the basis for the appreciation of the innovation (i), which leads to a certain level of 'receptiveness' $(R)$ in the following way:

$R_{i}=\left(+w_{1} * P F_{i}+w_{2} * S C_{i}+w 3 * E I_{i}\right)-w_{4} * P_{i}$

In other word, psychological and cultural factors of meaning and framing are combined with economic variables such as cost of adoption (indirect utility) and perceived functionality (direct utility). Especially automobiles are acknowledged to provide more than just transportation. They have a symbolic meaning that goes beyond functionality. Receptiveness is an extended/enriched type of utility. Each potential user is characterized by an individual level of receptiveness.

In chapter 4 we have analyzed consumer frames of car engines in more detail. In that analysis we found three types of consumer groups (frames), and also found frame-structures changing in the course of market development. Nevertheless, in this version of model, for brevity and simplicity, we assume that frame-structures are static, and we have chosen an average of the frames we found for 2000 and 2005. Also, we have simplified the number of consumer group from 3 to 2 groups. The sets of weights we estimate for the two groups (see Table 9.1) are based on that analysis.

Table 9.1: Two weights sets representing two consumer groups

\begin{tabular}{|l|l|l|}
\hline & Frame group 1 (900x) & Frame group 2 (100x) \\
\hline Weight 1 & 0.75 & 0.4 \\
\hline Weight 2 & 0.3 & 0.3 \\
\hline Weight 3 & 0.1 & 0.5 \\
\hline Weight 4 & 0.2 & 0.2 \\
\hline
\end{tabular}

A supplier's frame on the other hand is about the business case or business opportunity of a car engine, which is assessed by weigh up expected benefits and expected cost of launching a new 
vehicle. Supplying firms differ in their precise strength and weakness of capabilities for innovation (cf. the literature on 'core capabilities'), which will drive their expected cost for launching a new product technology. Silverberg (1991) denotes the importance of production quantity for the developing firm, in order to get beyond break-even point. As long as production investments in a new product-technology have no profitable outlook, a firm will wait with launching the product.

Alongside decisions on launching new products, firms also invest in research and development, to enhance their technological capabilities. In our model their future expectations of demand in the two respective technologies (reflected in their R\&D investments), are driven by (1) the number of successful launching competitors (endogenous in the model), and also (2) the (current) level of positive social connotation of a technology (endogenous in the model) ${ }^{40}$. The two components have equal weights.

\subsubsection{Implementing the feedback loops}

The innovations evolve over time, as does the social environment (connotations). As a consequence of both, agents' attitudes towards the innovation(s) are changing. Mechanisms of change describe how various factors relate to each other. Five feedback-loops that have been identified in literature are implemented in the model. They are described one after each other below, and visualized in Figure 9.2.

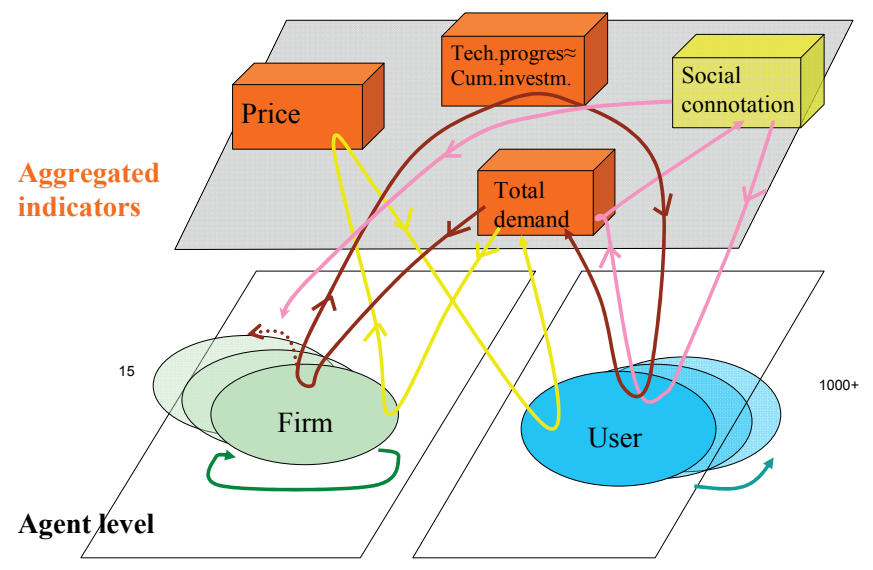

Figure 9.2: Five feedback-loops: increasing returns-to-scale (yellow), learning-by-doing (green), imitation of use (blue), learning-from-the-market (brown), and formation of symbolic meaning (pink).

\section{Increasing returns-to-scale and learning- by-doing}

The increasing returns-to-scale mechanism consists of the following sequence: cost per unit fall as firms take advantage of economies of scale, allowing them to profitably sell products at lower prices, which stimulates sales and further scale economies. Costs also fall because of learningby-doing (workers getting better at what they do). In our model, learning by doing is imple-

\footnotetext{
${ }^{40}$ We assume that the social connotation of the technologies affects the regulatory pressure for the two technologies (e.g purchase subsidies, tax benefits). Therefore the social connotation is an important driver for the firm R\&D investments.
} 
mented through decreasing variable costs over time. This accounts for the producers' accumulated experience over time, or by their cumulative output ${ }^{41}$. Increasing returns-to-scale is implemented through price setting of firms, who divide their fixed and variable cost over their (expected) production volume. When their production volume rises, price will decrease ${ }^{42}$.

\section{Learning-from-the-market}

Besides learning-by-doing, there is also learning-from-the-market. Learning-from-the-market refers on the one hand to user feedback helping suppliers to improve their products, and on the other hand to better ways of using the innovation by the consumers (Rosenberg, 1982). Increase of use gives developers insight in customer preferences, which are obviously heterogeneous. This helps to direct their investments in new product launches, serving a greater range of customers. Because of learning-from-the-market we are likely to see greater (perceived) product quality and greater product variety both of which will increase perceived functionality from customers. This will lead to further increase of adoption of the innovation.

This mechanism is implemented as follows. As a first component, capabilities of (all) firms rise when the numbers of consumers rise (even if a firm has not launched a product in that technology). Firms thus learn (directly, i.e. without own R\&D) from the use of products of rivals, which is referred to by some as emulative learning (Windrum and Birchenhall 1998). Second, increasing number of launching competitors (due to rising consumer sales) will drive up R\&D investment levels of all firms, which will increase their technological capabilities. As a third and final component, R\&D investments will increase user perceived functionality. This is modelled simply as follows: perceived functionality of an innovation increases with total increasing investment in an innovation. These model assumptions thus reflect the mechanism that user feedback eventually leads to better products.

\section{Formation of symbolic meaning of products}

Whereas the previous mechanism identified the increase in utilitarian functionality, this subsequent mechanism addresses socio-cultural values that are connected to the product.

The symbolic meaning and appreciation of the product becomes (among others) manifest in stories of market actors (Rosa and Spanjol 2005). When making a speech on a car engine, agents use adjectives or adverbs. By telling stories to each other, social connotation spreads and thus affects receptiveness. Though symbolic meaning and appreciation of a product is a pluralistic phenomenon, ultimately the set of adjectives and adverts is net positive (adding perceived value to the product), or negative. It the case of a car engine, people may use terms as 'revolutionary', 'super', 'promising', 'high-tech', 'you want to be seen in this', or in contrast terms as 'bulky', 'weak' or 'dull'.

In our model the social formation of meaning involves two conflicting stories: a positive one and a negative one. Agents may incline to one of the two stories. This is implemented by assuming different trends for spread the stories: (after market launch) the number of users inclined to the positive connotation of a product may grow steadily in time, up to $80 \%$ of the population, while the negative connotation stays small. This is an example of dominance of the idea 'you need to have this'. Similarly, strong growth trends can be assumed for negative stories. Each of the

\footnotetext{
${ }^{41}$ In an ideal case, the decrease of price would be linked only to specific producers (namely those that have launched), but this was too complex for the current model. Here, the price decrease counts for all producers. Since firms only differ on the level of technological competences, the company with highest technological capabilities (lowest investment cost) will set the market price.

${ }^{42}$ We assume that the market price of the innovation is the lowest price at which at least one company can still make a profit. Fixed cost account for investment in R\&D, product engineering and production facilities. The variable cost counts for material and labour of one product.
} 
patterns can be chosen as input to the model, to explore scenarios. (By the way, being inclined to a positive story does not mean that an agent in all cases adopts. It is one of five factors in the formation of 'receptiveness'.)

\section{Imitation of use}

For consumer products there is a tendency of potential adopters to imitate peers (e.g. Rogers, 1983). We treat imitation as a bandwagon effect ${ }^{43}$ within their social group (which is the group with whom they share the same frame). In a bandwagon process individuals do not make the final decision to adopt or reject, but they are receptive to social pressure (from others that have already adopted), that spreads through the population (Abrahamson and Rosenkopf, 1993). The distribution of receptiveness is heterogeneous however, so that differences in individual benefits to the innovation result in a higher or lower receptiveness.

A more detailed account of the model can be found in appendix J More than existing models, this model should suitable to analyse the role of changing social connotation of a product within the co-evolution of demand and supply.

\subsection{MODELLING RESULTS}

In this section we present simulation results of the model described in section 2, using a simple numeric simulation model. We simulate the co-evolution of supply and demand for electric engine cars and diesel engine cars as competing products. The five feedback-loops, which underlie co-evolution of demand and supply, are incorporated.

The model outputs show how two innovation trajectories may co-exist in the sector, as a result of diversity in preferences (i.e. framing) of different consumer groups. We have calibrated the model for the first half of the model run by mimicking what we know about the diffusion of electric and diesel engine passenger cars from 1990 until $2010^{44}$. A model analysis is provided in Appendix K This analysis suggests that the model is valid for an order-of-magnitude analysis of cause and effect relationships of social connotation with technical and economic factors such as investments, prices, technological progression and adoption.

We present two runs. In the first run we assume an increasing share of the consumer population included in a positive social connotation for $(H) E V s$ in the longer run. At the same time, a negative connotation of ICE technology becomes dominant.

In the second run we assume again a positive connotation for $(\mathrm{H}) \mathrm{EV}$, but now we assume that ICE innovations will also predominantly acquire a positive social connotation, see Table 9.1.

Table 9.1: input values for the two model runs

\begin{tabular}{|l|l|l|l|l|}
\hline Parameter & \multicolumn{2}{l|}{ RUN 1 } & RUN 2 \\
\hline & ICE new & (H)EV & ICE new & (H)EV \\
\hline InfP: Positive Connotation & 0.1 & 0.75 & 0.75 & 0.75 \\
\hline InfN: Negative Connotation & 0.75 & 0.1 & 0.1 & 0.1 \\
\hline
\end{tabular}

\footnotetext{
${ }^{43}$ An alternative way of incorporating imitation would be to place agents in a spatial structure, where they imitate neighbours.

${ }^{44}$ We match the first half of the model and the period of 1990-2010 in the following way. Some research suggests that the average re-purchase time of new cars is 6.3 yearsBoyd, T. (2006). Report on Demographic and Consumption Behaviors of USMS Members. Londonderry NH, USMS., and in the model we choose 15 steps as the re-purchase period. Therefore, 50 modelling steps represent about 22 years.
} 
Obviously, there is much more to tell about other possible runs and lessons or propositions we can draw from this model. Nevertheless for the sake of this chapter we will only address the role of social connotation, which we can understand better through the examination of these two runs already.

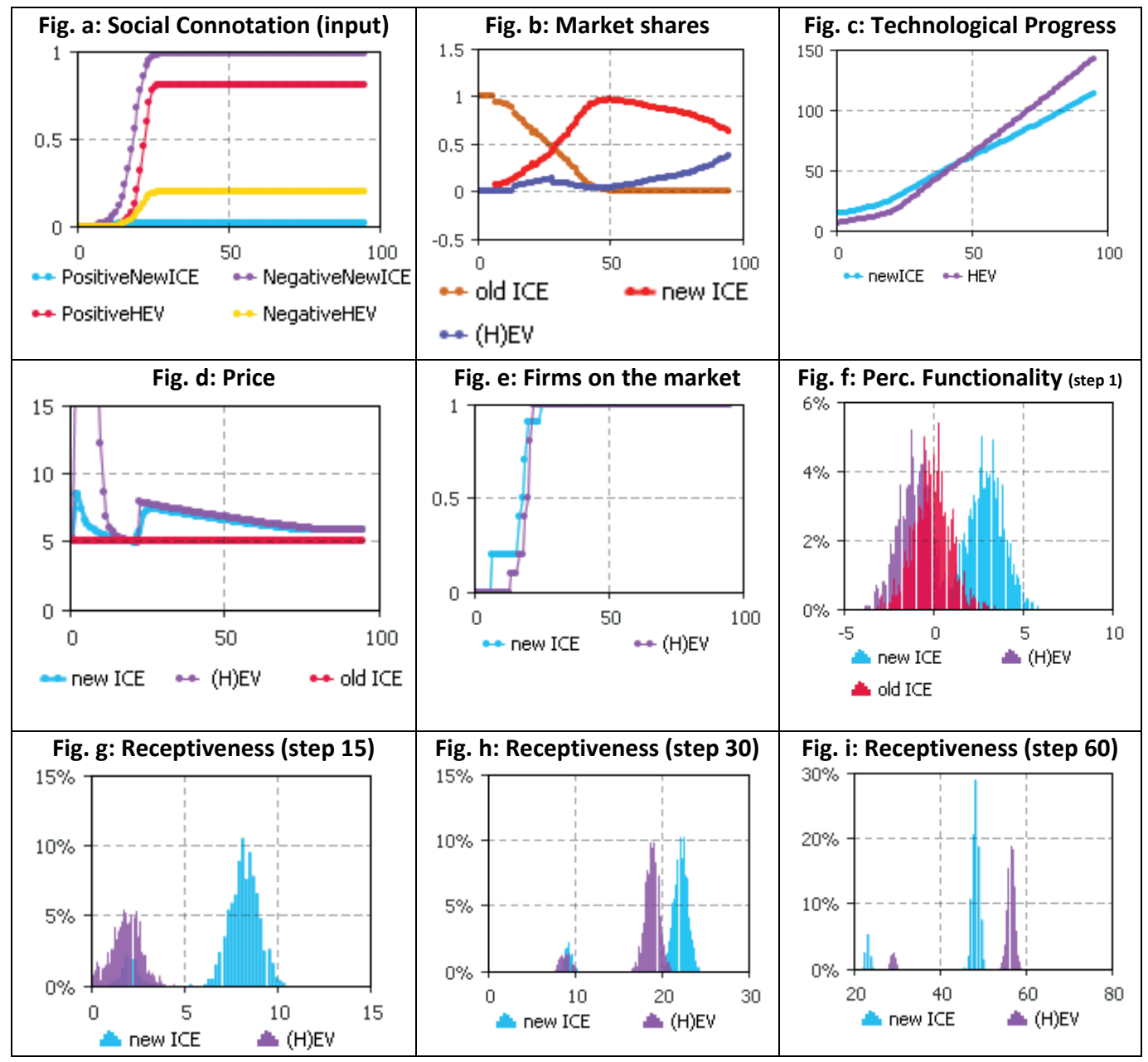

Figure 9.3: Model output Run 1. In this run the input is: only HEV acquires a positive Social Connotation, whereas ICE a negative.

For both runs the first half of the run is very similar. It shows new diesel engines being launched in the early 1990s, and electric and hybrid-electric engines in the second half of the 1990s. Also, the new diesel systems have diffused towards $100 \%$ with respect the non-direct-injected diesel engines by about 2010. Further, the diffusion of electric vehicles stagnates after initial launches due to perceived superiority of diesel technology at that time. In the second half of the model period, the model runs really diverse. 
In Run 1 (see Figure 9.3a to i) we choose social connotation of HEV to become strongly positive and ICE strongly negative (Figure 9.3a). We observe that the market share of (H)EV steadily rises after step 50 (Figure 9.3b). In the other graphs we find explanations for this. For instance, the

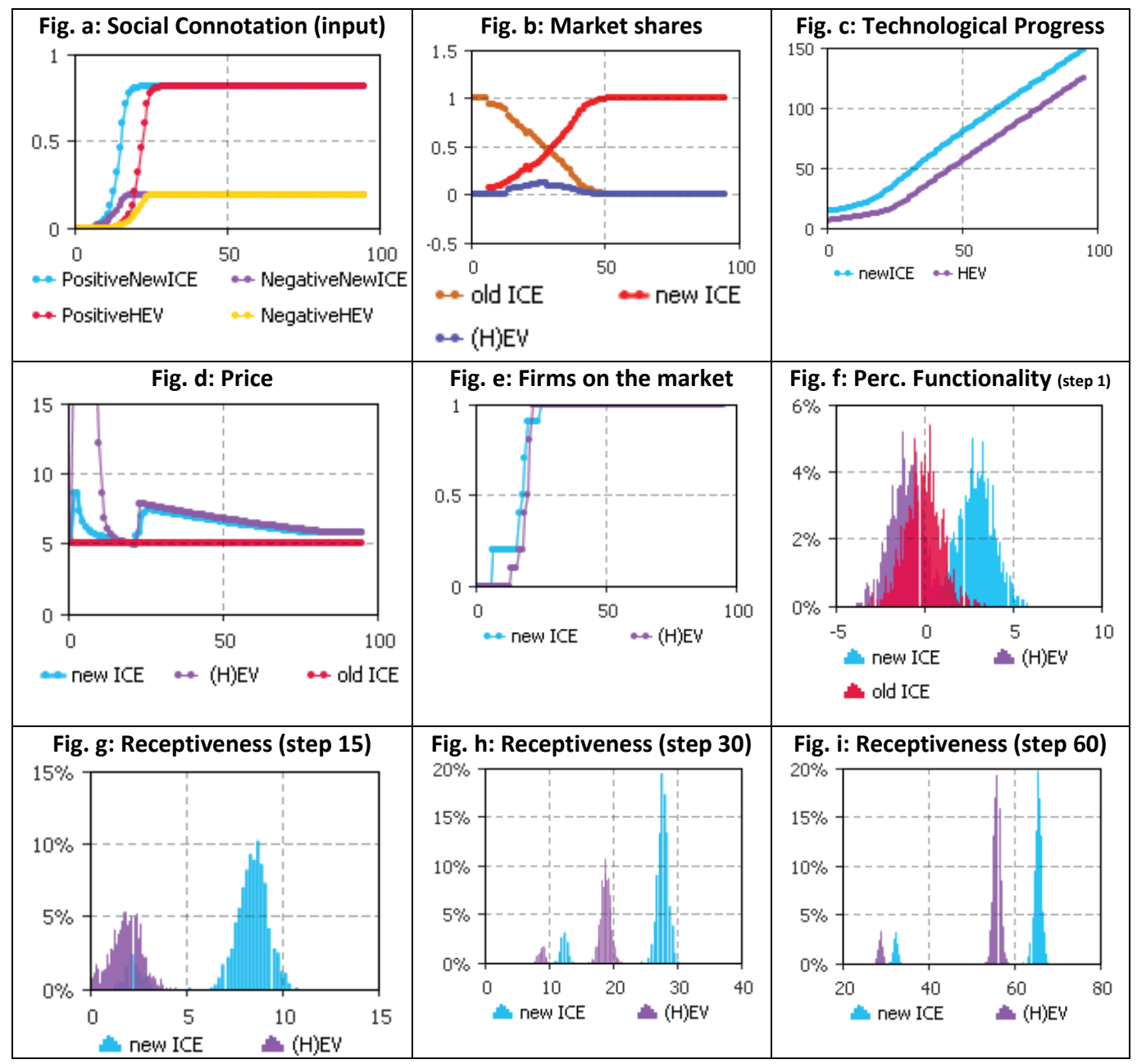

Figure 9.4: Model output Run 2. In this run the input is: both HEV and ICE acquire a positive Social Connotation.

state of $(\mathrm{H}) \mathrm{EV}$ technology is progressing at a steeper rate than ICE (Figure 9.3c). It overtakes ICE at about step 40. As a consequence, for the majority of consumers receptiveness for HEV overtakes receptiveness for ICE at about step 40. For the green consumer group that has happened earlier (about step 30).

In Run 2 (see Figure 9.4a to i) we choose social connotation of both (H)EV and ICE to become predominantly positive (Figure 9.4a). Here we find the market share of $(\mathrm{H}) \mathrm{EV}$ remaining marginal in the longer run (Figure 9.4b). The state of ICE technology remains superior to (H)EV (Figure 9.4c). Consumer receptiveness of ICE remain higher than for $(\mathrm{H}) \mathrm{EV}$, even for the green market niche. 
In both runs we find similar price trends. We find the price decreasing because of rising firm capabilities through R\&D investments and (after launch also) economies-of-scale, which can be observed in practice. However, we also find that the price rises again when more suppliers launch vehicles on the market, whereas the market niche is not growing in terms of consumers. At a first glance this is strange (prices usually decease in a diffusion process, especially when competition rises), but a closer look suggest that it is caused by a jump in the perceived quality of the product, due to a series of launch investments of firms. In order words, it is not the same product of which the price rises, but it is a new generation of the technology. In practice we also found new generations of DI injection diesels engines (or plug-in hybrids for that matter), which have initially higher prices (together with their higher perceived functionality). Although we can understand why the price trend in the model may jump (at moment of much investments and technological progression), this price trend is somewhat problematic and needs reconsideration in future applications of the model. Still, for the analysis of the role of social connotation, this discontinuity in the price trend does not seem to be significant (for example the figure of the market shares shows just a slight unevenness on the moment the price jumps).

Another issue is the relative importance of various learning mechanisms. In the current model firms learn in various ways (through R\&D, market sales (use), from each other), but the output graphs show that their technological capabilities mostly grow form R\&D investments, whereas learning from user levels is a minor effect. (That is the reason why in run 2 the Technological Progress graphs remain parallel, despite the wider use of ICE.) In general the relative strength of learning mechanisms and other feedback effects is significant for the model results, whereas practical information to support the choices is hardly available, and therefore it is fairly hard to check weather these are reasonable assumptions.

\section{Lessons learned}

We draw a few lessons on the role of social connotation in the innovation dynamics from these model runs:

- Initially the role of social connotation for new technologies is rather weak, since the connotation is poorly defined (right after launch). They only slightly impact R\&D portfolios, and at the demand side few consumers adhere to a connotation yet.

- When more consumers adhere to some social connotation of the new products, a positive connotative will mean an increase in receptiveness for the respective consumer groups (even though for consumers social connotation remains less important than perceived functionality).

- More significantly, a rise in positive social connotation will trigger more R\&D investments in the new technology and after some time trigger more product launches. (For a negative social connotation this is the reverse effect.)

- At longer last, when technological capabilities for the new technology have grown to similar levels as those of the established technology, the social connotation provides the competitive edge, and adoption levels surpass those of technology with inferior social connotation, driving even more technological refinements.

\subsection{SCENARIOS FOR ELECTRIC ENGINE CARS AND DIESEL CARS}

In this section we present plausible but simplified descriptions of two possible sociotechnological trajectories. They are narrative scenarios, based on expert knowledge, combined with the insights from the quantitative model simulations. We develop two scenarios, based on two alternative assumptions on the uncertain formation of social connotation in the future. 
Before presenting the scenario's we concisely describe the developments between 1990 and 2010.

\subsubsection{Recent history}

Two innovation trajectories can be distinguished for the case of cleaner vehicles after 1990: the conventional diesel and gasoline internal combustion engine (ICE) trajectory and a trajectory of electric propulsion (EP) ${ }^{45}$. Two important innovations in ICE are Direct (fuel) Injection (DI) systems and variable valve-timing (VVT) is another. In the EP trajectory we find innovations such as improved batteries (i.e. lithium-ion batteries), regenerative braking and plug-in technology. In the last fifteen years, DI systems diffusion has been quick. Diffusion in electric vehicle innovations on the other hand has been slow. The only success so far is the hybrid-electric Prius car which has sold of 1.7 million units worldwide since 1997 (see Table 9.2 for a comparison on sales units in the Netherlands).

Table 9.2: Yearly sales of diesel cars (units), battery electric vehicles and hybrid electric vehicles in the Netherlands 1995-2006 (Sources: own calculations based on Avere (2008), Bovag (2008), Beise \& Rennings (2005))

\begin{tabular}{|l|l|l|l|l|}
\hline & BEV & HEV & DI Diesel & Old Diesel \\
\hline 1995 & & 0 & 8500 & 76500 \\
\hline 1996 & 60 & 0 & 28800 & 61200 \\
\hline 1997 & 10 & 0 & 33250 & 61750 \\
\hline 1998 & 15 & 0 & 48000 & 52000 \\
\hline 1999 & 13 & 0 & 66000 & 54000 \\
\hline 2000 & 12 & 0 & 86400 & 33600 \\
\hline 2001 & 0 & 50 & 93600 & 26400 \\
\hline 2002 & 0 & 63 & 93500 & 16500 \\
\hline 2003 & 25 & 17 & 92650 & 16350 \\
\hline 2004 & 7 & 1062 & 102000 & 18000 \\
\hline 2005 & 0 & 2800 & 104550 & 18450 \\
\hline 2006 & 0 & 2800 & 116450 & 20550 \\
\hline
\end{tabular}

Behind these diffusion patterns is a complex phenomenon. The fast diffusion of DI systems and slow diffusion of electric vehicle technologies can be described and explained with the help of the two-layered, co-evolutionary model. Electric propulsion requires new capabilities at the supply side and positive appraisal from consumers. We observed that while electric vehicles got improved, consumers still decided for an improved ICE vehicle. This slowed down both the development and diffusion of electric vehicle technology. Up until today electric vehicles have suffered from two unfavourable characteristics: low autonomy (kilometres per battery charge) and high battery costs. Alongside these techno-economic mechanisms (which have been studied relatively well) a social mechanism played a role and interacted. Concerns about the climate

${ }^{45}$ We discard developments in hydrogen technology here. 
enhanced awareness of impact of technologies. Social meaning and image of new engine types is however not an 'instant delivery' phenomenon, but unfolds over time and level of use. As a consequence, suppliers were initially reluctant to invest (much) in alternative models and capabilities, until they observed changes in actual market launches of competitors, and also in the effects of positive connotation of EP on tax incentives (etc.) for EP. Only then more firms gave priority to building up EP capabilities. Up to this day, sales levels of EP have been modest. In this perspective the future trajectories will be the outcome of the co-evolutionary process: suppliers creating capabilities in electric vehicles and ICE in parallel, affected by socio-regulatory pressures, offering both electric vehicles and new ICEs; consumers assessing HEVs on their fuel economy (higher for non-highway drives), prices (higher), their image as a car (green, trendy), engine capacity (sufficient, not spectacular), range (similar), engine noise (absent), and in the future the possibility of renting batteries and changing them during a long trip. With help of the model runs we can give more structure to this analysis, and explore various diffusion scenarios.

\subsubsection{Two scenarios}

Scenario 1: Social popularity triggers functionality boost

In scenario 1 we assume an increasing share of the consumer population adhere to a positive social connotation for $(\mathrm{H})$ EVs: up to $75 \%$ in the longer run, whereas a majority become negatives about ICEs.

1-5 years - This scenario foresees only a small growth in adoption of $(\mathrm{H}) \mathrm{EV}$ in the next five years, limited to a group of green consumers. Other than the latter consumers are hardly interested in buying $(H) E V$ since they perceive price/performance levels of $(H) E V$ as yet as inferior. Nevertheless, average receptiveness of consumers for $(\mathrm{H}) \mathrm{EV}$ is increasing, and coming closer towards those of ICEs. This rise is both driven by increasing perceived functionality, but also through increasing positive social connotation of $(\mathrm{H}) \mathrm{EV}$ owing to growing concerns about global warming and higher prices for fuel. These stimulate praise for fuel efficient vehicles, which benefits electric engines, which are efficient to drive. Moreover, electric vehicles benefit from cultural icons (such as Hollywood stars) buying them, giving electric propulsion a positive image (something we are observing at the moment). The positive social connotation provides support for regulatory measures (most notably national tax exemption schemes) that favour battery and hybrid-electric vehicles. These stimulations affect firms' R\&D portfolios, which now devote more resources to EP than to ICE.

5-10 years - After five years, rising average receptiveness of $(\mathrm{H}) \mathrm{EV}$ s has not led to massive adoption yet, because it was still inferior to that of ICE. Soon after 2015 however, ongoing investments in electric engine technologies bring perceived price/functionality levels at the same level as $(\mathrm{H}) \mathrm{EV}$. New generations of $(\mathrm{H}) \mathrm{EV}$ s include Li-ion batteries and Direct Drive in wheel technology. A variety of models with electric engines appears on the market, some minimizing fuel use (plug-in hybrids), others boosting performance. Renting schemes for batteries emerge, making refueling of electric vehicles possible in a few minutes. Continued policy support of (H)EVs brings prices equal to diesels.

Near 2020 the sector passes a bifurcation point, after which adoption of (H)EVs increases steadily. A second consumer group, those for whom price is the most prominent attribute, increasingly chooses for electric propulsion. Around 2025 their sales have increased to $25-35 \%$.

\section{Scenario 2: ICE strikes back}

In scenario 2 we assume that the social connotation of both (H)EV and ICE becomes more predominantly positive. 
1-5 years - Scenario 2 foresees a small growth in adoption of $(H) E V$ in the next five years, similar to scenario 1, limited to a group green consumer, and those who benefit from support schemes for EP. Average receptiveness of consumers for $(H) E V$ is growing, due to some refinements in EP technology. However, at the same time, diesels are increasingly equipped with particle filters and within 5 years also increasingly with NOx filters. Firms are successful in presenting these diesels as clean, proven technology, at a relative low price. Because of this, national and EU policymakers start treating filtered diesels as environmentally equivalent to hybrids (partly as defensive support for the European automotive industry).

5-10 years - Without special support from tax authorities, hybrid engines stay somewhat more expensive than diesels, in equivalent vehicles. (Especially) European automotive firms expect higher profitability from diesel in comparison to hybrids, and focus R\&D on the first. Increased availability of ( $2^{\text {nd }}$ generation) biodiesel is anticipated. Receptiveness of hybrids stays lower than diesels for a large majority of consumers. In this scenario the growth of $(H) E V$ stagnates and tends to fall back. By 2020, hybrids have stayed a niche market only, smaller than five percent.

\subsection{DISCUSSION AND CONCLUSION}

In this chapter we explore future scenarios of car engine technology with support of a simulation model. In addition to previous evolutionary models, this model is instrumental to analyse technological innovation in a changing social context.

We suggest and offer how an agent-based analysis of innovation diffusion can be formalized, which offers a micro- underpinning of macro patterns, which incorporates feedback loops from macro to micro. The formal model is analytically novel by taking explicit account of actor frames. By attaching weights to various product attributes, different groups of consumers interpret the same product differently: they attach different meaning and value to it. A frame includes attributes of functionality, but also of social connotation and others. Mediated by various feedback loops, demand and supply co-evolve. Attention is being given to the (changing) technoeconomic characteristics of the innovation (as an important supply feature), competition between various product offerings, and to processes of taste formation (as an important demand feature). With the model as a supporting tool it becomes possible to explore various possible futures, scenarios, depending on what mechanism plays a salient role, and the strength thereof.

We presented two scenarios, based on two assumptions regarding progress of social connotation. For that matter, we do not suggest that formation of social connotation is the most essential mechanism, but that it is a relevant factor with high uncertainly. Performing our history-friendly simulation analysis, we found that the trend in social connotation impact the innovation process in the following way:

- Initially the role of social connotation for new technologies is rather weak, since the connotation is poorly defined (right after launch). They only slightly impact R\&D portfolios, and at the demand side few consumers adhere to a connotation yet.

- When more consumers adhere to some social connotation of the new products, a positive connotation will mean an increase in receptiveness for the respective consumer groups (even though for consumers social connotation is not the most important attribute; generally less important than perceived functionality).

- More significantly, a rise in positive social connotation will trigger more R\&D investments in the new technology, and after some time more product launches. (For a negative social connotation this is the reverse effect.)

- At longer last, when technological capabilities for the new technology have grown to similar levels as the established technology, the social connotation provides the competitive edge, 
and adoption levels surpass those of technology with inferior social connotation, driving even more technological refinements.

In this chapter the model has been applied empirically to the case of clean vehicles, where we examine the diffusion of improved internal combustion engine vehicles and the diffusion of (hybrid) electric vehicles, as part of an integrated analysis in which the diffusion of one vehicle is at the expense of the diffusion of the other vehicle.

We have developed two narrative scenarios. In the first scenario the social connotation of (H)EV technology becomes predominantly positive, whereas ICE predominantly negative. Here we find a gradual increase of the state-of-the-art of electric propulsion, within 10 years surpassing the state-of-the-art of ICE. After the initial adoption of electric propulsion in a limited group of green consumers, wider adoption occurs after 2020.

In the second scenario new ICE versions acquire a similar positive connotation as (H)EV. Here, the state-of-the-art of ICE remains ahead of $(\mathrm{H}) \mathrm{EV}$, and after some adoption of electric models, even some green consumers shift back to refined versions of ICE.

In the scenario analysis in this paper we have grouped HEV and BEV technology, which is slightly problematic regarding the differences of the products, especially the different requirements of an infrastructure. For instance, for BEV the availability of an extensive plug-in infrastructure is essential, for HEV it is not, whereas for plug-in hybrids this is fairly important. Nevertheless, the necessary technological competences to develop BEV and HEV overlap to a large extent (and both deviate from ICE competences), and this was the rationale for grouping them in this chapter.

The model can be applied in principle to any diffusion process both retrospectively and prospectively. It cannot be used for prediction (because diffusion is not a deterministic process and because we lack data on certain variables) but can be used for exploration on the basis of proxy data. Especially micro level data (time series of agents' attitudes and frames for evaluation) is rather difficult to obtain. It is also hard to determine the relative strength of the various feedback loops. These should probably be assessed outside the modelling analysis. Perhaps expert opinion can be used for this. Implementing the model with expert opinion in an open fashion allows for the creation of models closer real world observations. The strength of such a modelling approach is then that it combines the structure and scientific underpinning of analytical modelling with the richness of participatory methods so as to address real complex issues of societal change in a consistent and meaningful way. We recommend this as a topic for future research. 

Chapter 10

POLICY OPTIONS FOR SUSTAINABLE CAR MOBILITY 


\section{Policy options for sustainable car mobility}

In the previous chapters we have addressed innovation in car mobility in a co-evolutionary perspective. In this perspective we highlighted the dynamic interplay of demand and supply. We have seen that this complex process is shaped by policies and policymakers in various ways. In this chapter we analyze what our co-evolutionary approach learns about the role of policy in the innovation process in the two cases.

As referred to in chapter 1, policymakers at local, national and international levels have been challenged firmly to deal with the societal impact of car mobility. Despite that some transport policies have been successful in the last 20 to 30 years (safety, nitrogen oxides etc.), still some effects have remained critical or have even grown. Congestion levels and greenhouse gas emissions are the main examples of this. It raises the question how policies around these two issues can be improved. For our two cases, $P+R$ and (hybrid-) electric vehicles, which may contribute to mitigation of the two issues, this delivers two more specific questions: what does the co-evolutionary analysis learn about:

1.. the extent to which policies in the past decades have supported innovation in these two outer-regime niches, and

2. how innovation at these niche trajectories can be supported in the future?

This chapter has three sections. In section 1 we review the main policy instruments considered in the literature on environmental policy and innovation policy, including the contribution of the (co-)evolutionary perspective to this field. The focus of our discussion is on the innovation effects of policy instruments. Then we address the two questions for each of our case studies. We analyze which policy instruments have been applied in the two cases in the last 15 years, and we asses their impacts. Then we sketch some policy options to simulate low-carbon car engines, and use of $P+R$ in cities respectively.

\subsection{POLICY FOR GREEN INNOVATION: FROM STATIC TO EVOLUTIONARY INSTRUMENTS}

There are two main perspectives on environmental and innovation policy in the literature, the welfare perspective and an evolutionary perspective. Of these two the first one is best worked out. It says that policy intervention is warranted in the case of market failure, when allocation via markets leads to a non-optimal allocation of resources. Examples of market failures are: negative externalities (such as environmental pollution causing social costs from private activities and profits) and public good problems (when goods are non-rival in use and when there are difficulties of excluding others from free use). In the welfare perspective policy should intervene up to the point where marginal costs start to equate marginal benefits, being the point at which welfare is maximised.

Environmental policy studies suggest various instruments to spur and shape innovation, and from a welfare perspective these are most notably:

- Pollution taxes and emission trading. A widespread view among economists holds that this economic instrument is most effective to spur innovation, addressing financial incentives. For example, Milliman and Prince (1989) suggest that incentive-based instruments are most effective, finding that emission taxes and auctioned permits are better facilitators of technological change than regulation and free permits. This is called into question however by other theoretical studies (e.g. Fischer et al., 2003).

- Standards and regulation. This type of instruments sets specific target outcomes, such as emission limits and product bans. There is ample evidence of regulations that spurred innovation, but also ample evidence that it did not (Kemp, 1997). In some cases it triggered a 
modernization of the industry, in terms of improved productivity (Ashford et al., 1985) and efficiency (Dieleman and Hoo, 1993).

The conflicting results suggest that there is not one instrument best in all circumstances - the choice should depend on the circumstances and give due attention to the design (specific characteristics) of the instruments. Relevant circumstances are: technological opportunities for dealing with environmental problems, market entry barriers for newcomers, openness to change, willingness to experiment, knowledge infrastructure. Attention should also be given to non-cost drivers of innovation, such as societal and business expectations and political factors (Foxon and Kemp, 2006). Other possible instruments for promoting eco-innovation are:

- Investment subsidies. Subsidies for green investments are a much used instrument. Various studies suggest that sole subsidies have only limited impact on the development of innovations new to the world, since the behavioral effect of the innovator (either firms or users) was low. However, a combination of investment subsidies with environmental taxes may be effective for diffusion of a cleaner technology, provided that a substitute technology is available.

- $\quad$ R\&D programmes and subsidies. This instrument deals with subsidies for development of cleaner technologies. Studies suggest that this instrument does trigger research that would not have been performed otherwise but also generates windfall profits for some innovators (those who would have done the R\&D anyhow). It is not clear to what extent the programmes affect established or future market products.

- Covenants or voluntary agreements. According to Klok (1989) the effectiveness of covenants is typically small, since it leaves firms to rely more on autonomous technological change and market evolution, than on the covenant.

In our case studies, we have addressed dynamic processes of co-evolution, where outer-regime niches emerged next to the regime. In this perspective it is not just a question of 'does an instrument spur innovation', but also: 'does an instrument spur innovation to improve the existing regime (the lower quadrants of Figure 1.5, reprinted as 10.1) or does it spur an alternative trajectory' (the top quadrants of Figure 10.1)? Such a key question has not been investigated systematically by research and is given only scant attention by policy makers, since the traditional welfare perspective operates mostly in a technology-blind manner. 


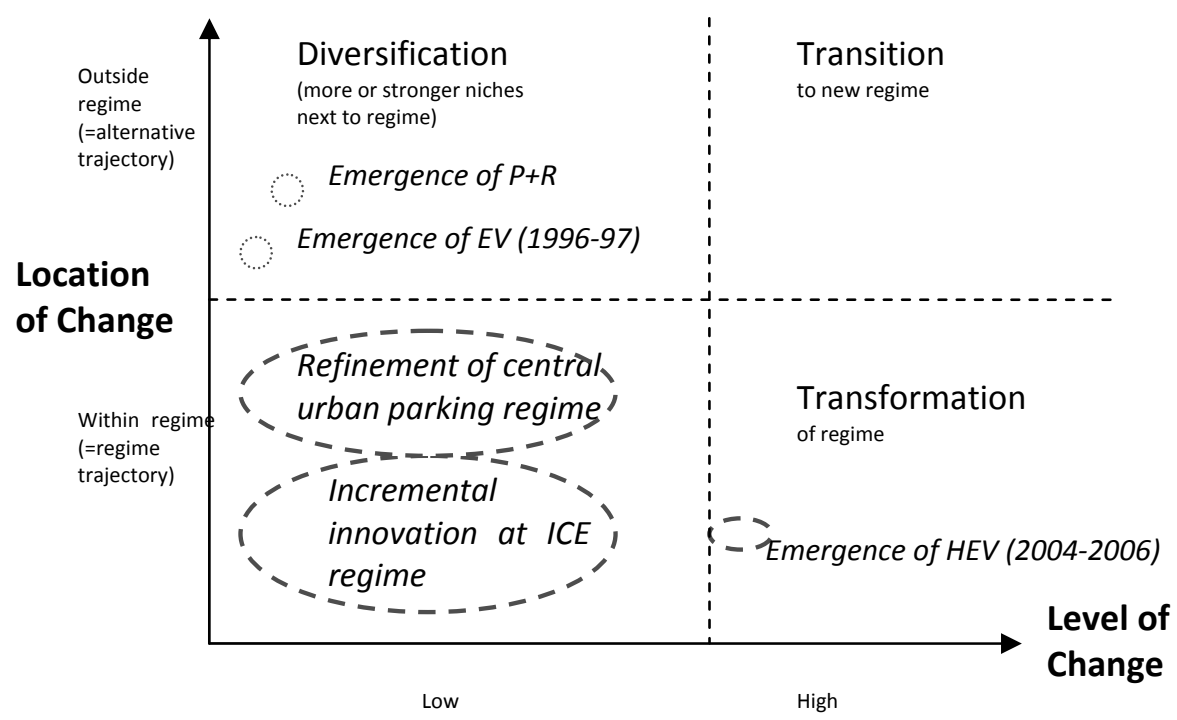

Figure 10.1: Typology of innovation trajectories (combining notions of Abernathy \& Clark (1985) and Geels and Kemp (2007), see also Figure 1.5.

It should not come as a surprise that the common response of industry to environmental pressures has been the adoption of existing technologies and incremental innovation (the bottom-left quadrant in Figure 10.1), as opposed to alternative innovation trajectories (the top left and top right quadrants) (Kemp, 1997; Foxon and Kemp, 2006). When policymakers seek more fundamental shifts from unsustainable regimes to more sustainable ones, the traditional instruments are less appropriate, since the isolated application of a classical instrument hardly supports the outer-regime niches (or, in the case of sole R\&D subsidies for the niche, will have little impact on the regime). Therefore, in those cases the coherency of a set of policy instruments is what matters rather than the type of instrument chosen (Kemp 1997).

In the same line of inquiry, Rip and Kemp (1998) notice that environmental innovation policies should not just lay down functional requirements (to products and processes), but governments should modulate the innovation dynamics, oriented towards the strategic interactions among market actors. This involves: facilitating communication, broadening the scope of inquiry, providing resources for research that is unlikely to yield short term results, and stimulating cooperative activities in a novelty seeking business environment (p.391). One such approach is strategic niche management, "the creation and management of protected spaces (niches) for promising technologies by means of experimentation with the aim of learning about the performance, effects, economic viability and social desirability of the technology and to use this knowledge to inform private and public (support and control) policies that are needed for the further development and rate of application of new technologies and technology systems" (Kemp et al., 2000) ${ }^{46}$. These insights have inspired the approach of transition management which is broader in scope, focuses on system changes and system innovation, and advocates evolving adaptive portfolios of alternative niches (e.g. Rotmans et al., 2001). More recently, the concept of time strategies has been put forward which focuses on the political preparation and

${ }^{46}$ See Kemp et al. (1998, 2001), Hoogma et al. (2002) and Schot and Geels (2008). 
utilisation of time windows of opportunities in unstable phases of technological competition (e.g. Nill and Zundel, 2001).

These approaches suggest that policies should be concerned not only with providing incentives and setting limits but also with providing orientation, stimulating mutual learning, fostering socio-technical alignment, making sure that a wide variety of options is explored, dealing with conflicting claims by technology actors and with learning about the effects of their policies. Since the policies concern the dynamics of variation, selection and retention, they are referred to as evolutionary policy. This is a second perspective on innovation policy and an alternative to the welfare perspective.

\section{Evolutionary policy}

The evolutionary perspective on policy concerns itself with shaping interactions-between firms and other actors in markets and policy arenas-to desirable outcomes. It builds upon evolutionary theories of innovation and change (Nelson and Winter, Potts, Hodgson) where the term evolutionary may refer to gradual change or to the evolutionary mechanism of variation, selection and retention (inheritance). Nill and Kemp (2009) and Van den Bergh and Kallis (2009) have coined the term "evolutionary policy" for an policy approach that is concerned with the dynamics of variation, selection and retention, which is mindful of (the sources of) lock-in, and sets out to learn about new paths in a forward-looking, adaptive manner.

These novel evolutionary policy models have provided principles to support a shift to niche trajectories, but these principles have been quite abstract. In the next sections we analyze whether we can identify elements of evolutionary steering in the historic policies in our two case studies, and secondly, what this policy model can practically contribute to future policies in the two cases. This leaves us with two questions: (1) to what extent have policies in the past supported innovation in the two outer-regime niches, and (2) how can innovation at niche trajectories be supported in the future in our two cases?

\subsection{POLICY OPTIONS FOR MITIGATING (TOTAL) $\mathrm{CO}_{2}$ EMISSIONS OF CAR USE}

\section{Policy analysis}

Environmental policymakers consider and have considered various instruments and technologies to mitigate the (total) $\mathrm{CO}_{2}$ emissions of car use. Over the last two decades technological solutions have received most attention, and electric vehicles, hydrogen vehicles, hybrids (whether or not plugged-in), clean and small diesel and gasoline vehicles have all been in the spotlights as possible low emission vehicles (LUVs) and ultra low emission vehicles (ULEVs). There has been considerable debate on which technology is most promising. This is a politicized debate, influenced by technological uncertainty, vested economic interests and ecological objectives, also between various member states in Europe (Jacob et al., 2005).

As a first instrument of environmental innovation, emission regulation was adopted around 1985 at a European level. The initial emission requirements for various pollutants that were set were gradually tightened (these are the Euro 1, 2, 3, 4 and 5 standards, see chapter 6 ). In the last two decades, these have resulted in a steady reduction of exhaust gas emissions of new vehicles, through refinement of engine technology. The gains in eco-efficiency have, however, not been sufficient yet to compensate for the rapid growth of vehicle volumes, bringing about the rise of total greenhouse gas emissions of road transport.

The gradual tightening of these standards over time continues to be a major stimulus for the development of cleaner propulsion technology. So far, however, more stringent emission requirements could always be met by refining conventional IC engine technology and introducing or improving exhaust after-treatment systems. Recent studies show that the potential for 
the further improvement of existing Otto and diesel engines, catalyst technology and powertrain control systems is still large and will probably be sufficient to meet near future emission standards in the next five to eight years. This means it will not be necessary for manufacturers to introduce hybrid or hydrogen propulsion technology in this period from the viewpoint of meeting future emission standards.

The second environmental policy instrument on the issue of $\mathrm{CO}_{2}$ is a voluntary agreement or covenant between the $\mathrm{EU}$ and the automotive industry. The two parties signed agreements for a reduction of the average $\mathrm{CO}_{2}$ emission of new passenger cars in 1998 , from around $180 \mathrm{~g} / \mathrm{km}$ to $140 \mathrm{~g} / \mathrm{km}$ by $2008 / 2009$ (i.e. a $22 \%$ reduction compared to 1995 ). The main contribution to achieving this goal was expected to come from the widespread introduction of direct-injection diesel and direct-injection gasoline engines. A vision of the role of hybrid and hydrogen technology was not given by the partners. A recent review of the effectiveness of the covenant showed that between 1995 and $1999 \mathrm{CO}_{2}$ emissions of new cars decreased by $5.6 \%$. At the end of 2006, the manufacturers appeared to be behind schedule and unlikely to meet the 2008 targets. In June 2007, the EU decided to change the voluntary agreement to a compulsory requirement for 2010: a $\mathrm{CO}_{2}$ emission of $130 \mathrm{~g} / \mathrm{km}^{47}$. We conclude that emission requirements and the voluntary agreement have resulted in the decrease of emissions per vehicle of about 1 to 2 percent a year. However, development of ultra-low emission vehicle (ULEV) technology, which seems to be necessary to decrease total $\mathrm{CO}_{2}$ emissions, is currently not stimulated by this policy instrument.

The European level direct support for ULEVs comprises mainly R\&D subsidies for electric and hydrogen vehicles. This is the third type of policy instrument that we identify in the sector's recent history. The R\&D programs sometimes include demonstration projects. In the 1990s some funding was provided for demonstration programmes, such as ZEUS, in which eight cities jointly operated several hundreds of electric vehicles, as well as vehicles running on biogas and natural gas (Hoogma et al., 2002). A few European countries supported electric vehicles at a national level, mostly through demonstration experiments. Most remarkable were the French state electrical utility EDF ordering in total close to $2000 \mathrm{EVs}$, amongst other in the La Rochelle experiment. Other experimenting countries were Germany (Rugen Island), Switserland (Mendriso), and Norway (Think!).

Whereas direct support for electric vehicles in the 1990s was only slightly encouraged by the European Union (EU), the high expectations around hydrogen technology around the year 2000 triggered more thorough initiatives. The European level support of hydrogen technology for vehicles is embedded in the wider field of hydrogen and fuel cell (FC) technology, including transportation-, stationary- and portable applications. The EU provides basic funds for R\&D, supporting identified European Research Areas (ERAs) in which large consortia of industry and $R \& D$ organizations team up their R\&D investments and activities for an extended period of time in 'Integrated Projects'. A High-Level Group for Hydrogen and Fuel Cell Technologies (HLG) was initiated in 2002 by Directorates-General Research and Energy and Transport. It established a basic proposal for a European hydrogen and FC roadmap in its report Hydrogen Energy and Fuel Cells $-A$ vision to our future. This commitment led to the creation of the Hydrogen and Fuel Cell Technology Platform (HFP) in 2004 in order to reach the targets stated in the HLG report.

Besides direct R\&D on (general) hydrogen and FC technology, the European Commission supports vehicle demonstration projects with hydrogen and fuel cell vehicles (FCVs). Currently, most experiments are in urban delivery or public transport. Many vehicles are involved in such projects. The Clean Urban Transport for Europe (CUTE) project is a demonstration project partly

\footnotetext{
${ }^{47}$ This requirement includes a $10 \mathrm{~g} / \mathrm{km}$ reduction for fuel, which brings the total emission of an average vehicle down to $120 \mathrm{~g} / \mathrm{km}$.
} 
financed by the EU, where FC buses and hydrogen infrastructure are demonstrated in nine European cities. A total of $27 \mathrm{FC}$ prototype buses have been delivered to the cities (three buses to each city) and are currently being demonstrated and tested in normal operations during a five-year period. These projects are effective in finding out the actual acceptance of FCVs among operators, passengers and vehicle developers and producers. They will play an important role in the preparations for the market launch.

Currently, no direct incentives on customer purchase of hydrogen vehicles exist at the European level. Such consumer tax exemption schemes are a fourth possible instrument in the sector. Such incentives for hydrogen vehicles neither exist at the national level. In most European countries national schemes of tax exemption (either VAT or road tax) have been implemented for cleaner vehicles, but threshold values for these exemptions have been broader than ULEV (in most countries 90 or $120 \mathrm{~g} / \mathrm{km}$ ), in order to include hybrid vehicles. As a result they have not exclusively triggered demand for electric or hydrogen vehicles, whereas their effect on hybrid has been modest. In most countries sales of hybrids have not exceeded 1 or 2 percent of annual sales. These tax exemption schemes are a fourth type of instrument of innovation policy that we identify in this sector.

We find that the four instruments in our case study have mostly lead to diffusion of existing technologies and incremental innovation, not to transformation or shift to alternative trajectories. This confirms the proposition of Foxon and Kemp (2006). The first instrument, the stepwise emission standard scheme (Euro 1 to 5 ) sustains firms focusing on only few years ahead. They do not provide an incentive to go beyond the standards. In chapter 5 we found that from a business perspective, it is not very attractive to invest much in a new, still immature technology. Those efforts will very likely lead to losses in the short term. Competition on the present market is fierce and it is (relatively) more attractive and necessary to invest in the incremental innovation of the existing technology. Firms that would invest large portions of their R\&D portfolio in future engines (for launches five to ten years ahead) draw from their engineering budgets of forthcoming engines, pruning their competitiveness in the next few years, and running the risk of being outcompeted. In other words, firms with a longer time focus are punished by the market. This is an important cause of the sailing ship effect that we found in chapter 6 . The emission scheme in place has not compensated for this market failure.

We found that the second instrument, the voluntary covenant, was only slightly effective. This too is in correspondence with earlier studies (Klok 1989). The progress that was made came from wider application of existing technology: direct injection systems. The fourth instrument, tax exemption schemes at the user side have been applied at national levels. This measure makes sense since we found in chapter 4 that (in The Netherlands) around $35 \%$ of the consumers of new cars buys the cheapest engine. Tax benefits for hybrid-electric vehicles have therefore stimulated their sales in various countries, though these have not exceeded market shares of a few percent. To what extent has this triggered car firms to develop more hybrid electric vehicles? This effect has not been substantial, regarding that by nine years after the market launch of Toyota's Prius, only two car firms, Honda and Toyota (including Lexus), have hybrid models on the European market. Although the tax benefit also counted for electric vehicles, it has not triggered established car firms to launch electric models. There is only one firm offering electric vehicles in most European markets, the Norwegian Think, which is a new market entrant.

The third instrument applied, R\&D subsidy programmes, is especially interesting for our question of regime shift, since it includes direct promotion of the niche and includes some elements of an evolutionary steering approach. The European polices on electric and hydrogen vehicle technology, such as support of R\&D via HFP and vehicle demonstration projects have enhanced the niches of electric and hydrogen vehicle technology. They contributed to improved versions of electric and hydrogen vehicles, and provided experiences with actual usage of these 
vehicles in practical settings, which otherwise probably would not have been performed. However, these propulsion technologies have not yet reached the necessary maturity for broader market applications. In chapter 5 we found that the average contemporary willingness of car firms to develop hydrogen vehicles is between uncertain and slightly low. A large majority of the seven firms perceive their own technological capabilities and organizational learning capabilities to develop hydrogen vehicles as weak or uncertain. Therefore, this R\&D instrument has not yet resulted in positive willingness of car firms to launch market vehicles, and it's not clear whether it has made market application more likely than before. After all, the development of electric and hydrogen technology took place alongside refinement and learning on ICE technology. The various technological trajectories are as moving targets and interact with each other, mostly in a competitive relation. The isolated character of the R\&D subsidies, disconnected from the ICE regime, is a disadvantage of this measure.

Some of the European R\&D programmes include the establishment of a European platform or demonstration projects, often including provision of local infrastructure. From an evolutionary steering perspective these are important additions to the R\&D subsidy instrument. Demonstration projects foster interaction between users, producers and infrastructure in early stage, which provides rich lessons learned. In the same vein, the establishment of a platform is important because it structures the communication between various stakeholders in the sector: firms, research centers, universities, regulators, NGO's, consumer groups. It stimulates the acknowledgement of each others perception of the issue and possibly the emergence of a shared problem perception. The platform can address the issue of niche-regime competition collaboratively. Of course, as with any specific technology policy there is a danger of regulatory capture. Policy makers have to be mindful about this. Much lobbying work is undertaken by various organisations to influence the perceived desirability of various technologies, including their potential. Ultimately, the objective is to shape expectations of policy makers. Decision makers must, consequently, develop an independent position and critically assess attempts to shape the perceived desirability of various technologies. They also must not fall prey to hypedisillusionment cycles, resulting in too massive support of not yet ripe options and the withdrawal of support when positive results do not quickly materialise. Policy should promote a portfolio of options and should create an element of continuity in support policies. As Verbong and others write:

"Experiences in the 1990s and in other countries (Denmark, Germany) showed that regulatory stability and long term support were crucial for successful development of renewable technologies (Jacobsson and Lauber, 2006). Policy analysts and consultants recognised these characteristics as key components for renewable energy policy, but these lessons were not internalised, as policy actions in the early 2000s demonstrate (frequent policy changes that created instability and uncertainty). Policy makers did not provide long-term guarantees and too rapidly abandoned innovations when setbacks occurred. They cut off protection measures too soon, and introduced market pressures when innovations had not yet stabilised. So, the lessons from the 1990s were either forgotten or not implemented (for political or financial reasons)" (Verbong et al., 2008, p. 570-571).

In summary, we state that the four instruments that have been applied have not contributed much to regime transformation or transition. We found two elements though, sectoral platforms and demonstration projects, useful approaches for addressing niche-regime dynamics and for working toward regime shifts. 


\section{Policy advice}

Regarding the fairly certain future growth of vehicle numbers both in Europe and worldwide, a large decrease of $\mathrm{CO}_{2}$ emissions per vehicle would inevitably be required in order to reach the (stated aim in Europe of) reduction of total $\mathrm{CO}_{2}$ emissions (EEA, 2004). This requires substantial transformation of vehicle technology or even transition (lower right or upper right quadrant respectively in Figure 1.5). How can the niche of such ultra low emission vehicles (ULEVs) effectively be stimulated?

From an evolutionary path-creation perspective, to escape lock-in the European Union should try and modulate the niche-regime dynamics, and shape the strategic interactions among the market actors. More concrete, the EU could strengthen and develop the role of the hydrogen platform (one niche technology) into a low-carbon car platform (relating to niches and regime technologies). This platform could be instrumental in determining a portfolio of various propulsion technologies, and be involved in monitoring the potentials of the technologies. It could be instrumental in disseminating lessons learned in demonstration projects through evaluation and monitoring reports. These reports should address technical as well social/behavioral issues, in order to exploit the socio-technical co-construction potential to the full (Elzen, 2004). Experience from different projects should be combined. The platform could have an important advisory role in the allocation of EU R\&D budgets and future emission requirements. These regulations should be adaptive to ongoing developments, whereas the goal of curbing total emissions of the sector should be steady. To prevent a tunnel vision and stimulate learning over a wide range of issues, the platform should be a diverse group ranging from industry representatives, consumer organizations, policymakers, research organizations and NGOs. It is important that they include a variety of expertise and interests, including experts on transition processes.

The platform should discuss the future of the compulsory requirement that have recently been introduced: the required level $130 \mathrm{~g} / \mathrm{km}$ as a fleet average for 2010. It needs to assess and agree an average future level of $\mathrm{g} / \mathrm{km}$ that would be sufficient to arrive at lower total $\mathrm{CO} 2$ levels of the car sector, probably around $65 \mathrm{~g} / \mathrm{km}$. It should discuss how this averaged level may be moved down stepwise. Such average levels are technically challenging, and car firms will probably contest that such a slide is unrealistic, as they have done in the past. Independent assessment therefore is needed. The platform is the right place to address the feedbacks in niche-regime interactions, which constitute the major complexities and reason why emissions are indeed difficult to mitigate. One point for discussion is the proportions in R\&D portfolios of incremental technology versus ULEV technology. Traditional stepwise schemes (such as Euro 1 to 5) do not encourage firms to look more than a few years ahead. To counteract this effect additional policy options need to be explored: ways to put incentives to R\&D expenditures more directly. For instance, rules on R\&D expenditures could not only stimulate competence building on ULEVs, but could concurrently slow down the incremental innovation of the existing technology. An example would be to require firms to reserve at least $50 \%$ of their R\&D budgets in ULEV technology. Fairness over the various car firms and their competition could be achieved through the use of a percentage of R\&D expenditures. Since much technological innovation has also recently shifted to suppliers, these (first-tier) suppliers may need to be included in the platform and in such regulation. In order not to be short-sighted and bet on one technology, the requirement should be defined for 'very low emission' propulsion technology instead of a specific technology such as hydrogen or EVs. An alternative solution is to create a large R\&D fund to which companies can submit proposals.

Another option for discussion in the EU platform would be to adopt California's ZEV mandate, which requires minimum sales levels of low-emission vehicles, and combine it with (existing) $R \& D$ subsidies. The ZEV mandate already supported R\&D on ULEVs indirectly (Frenken et al., 2004; Van den Hoed, 2004), but the coherent combination of it with R\&D subsidies, demonstra- 
tion projects and emission regulation, could provide a strong stimulation for escaping lock-in from the ICE trajectory.

All in all, with regard to increasing vehicle numbers in Europe (and even more worldwide), the stated aim to decrease of $\mathrm{CO} 2$ emissions of the vehicle fleet as a whole will almost certainly need radical measures. For such a complex issue, we can not simply conclude: develop a regulation that allows, for instance, only $65 \mathrm{~g} / \mathrm{km}$. To acknowledge the complexity, we stated that a sectoral platform is a suitable way to provide communication between the relevant stakeholders, and address the feedbacks in niche-regime interactions, which are a major reason of why emission levels are indeed difficult to mitigate. We have provided a few suggestions for the platform to seek ways to shift the balance of R\&D budgets from incremental to more radical environmental innovation. It is important that the platform houses different types of expertise and interests. Instead of one platform, different platforms could be created for various options. Here the Dutch transition approach with the seven transition platforms for sustainable energy is of interest ${ }^{48}$. The platforms serve as vehicles for learning and action for innovative solutions identified by business and experts (micro co-generation, battery electric vehicles, energy producing greenhouses, and others). Through the platforms the interest in society (business) in innovative change is mobilised. Strategic issues are considered via the Coordination-body Dutch Energy Transition created in 2008. The Coordination-body is responsible for developing an overall vision for the energy supply (electricity and heat) in the Netherlands and to formulate a strategic agenda based on inputs of the platforms.

The whole approach is set up as a vehicle for socio-technical change and policy change in a coordinated manner. The transition approach seeks to encourage industry to work on lowcarbon innovations including those that are not yet ready for the market, and to assist in the development of those innovations (Kemp, 2009). Generic policies are combined with technology-specific policies. This (national) approach could be a prototype for a European platform of car propulsion technology.

\subsection{POLICY OPTIONS FOR MITIGATING URBAN CAR USE AND PARKING}

\section{Policy analysis}

The role of policy in the second case study is at least as complex as the previous case, even though urban car use and parking is a local issue rather than a global one. For $\mathrm{P}+\mathrm{R}$, policymakers are both the regulator and (usually) the developer of the facilities, giving them a double role. Various policy instruments have been applied in the urban parking sector (as we saw in chapter 8). The first instrument is parking restrictions: banning parking from certain streets, and also time restriction on the length of stay. This regulatory instrument is typically applied in the early phase of a city's parking policy, as a first step to mitigate congestion in some streets.

The second type of instrument is pricing strategies. This economic instrument puts a price (or tax) on parking in streets which are most congested, as a negative incentive. The third type of instrument is investment subsidies. Investment subsidies have both been applied to support the regime of central parking and for the $P+R$ niche. Through investments in new (often expensive, underground) garages in the city centers and in parking indication systems at the ring road, the central parking regime was refined. In addition, local governments have invested in $P+R$ sites.

We found that the rationale behind parking policy instruments is not at all evident. In larger cities, typically rival policy frames exist: a frame where parking policy is a tool to attract customers, striving for greater parking accommodation and alternatively a frame of parking

${ }^{48}$ Based on Kemp (2009). 
restriction to reduce car traffic (congestion) and to enhance quality of life in the urban area. Related to the first frame is another motivation, generally less publicly articulated, which is the raising of revenue for local authorities from charging for parking on the highway or from investments in off-street parking capacity. From our survey in chapter 7 with respect to $P+R$, we found most evidence for the first frame, since economic effects (e.g. effects on local shops, parking revenues) and market pressures (e.g. preferences from car drivers) are salient drivers for city governments whether or not to engage in $\mathrm{P}+\mathrm{R}$ development, not environmental considerations. In practice, parking policy tends to reflect a compromise between these frames, delivered through the twin instruments of regulations which limit who can park and for how long and pricing structures which may seek to favour parking acts of different duration.

It is understandable that economic effects are important for local authorities, since they typically have high financial dependence on nationally-raised taxes allocated by the central governments, which retain a strong influence over how allocated funds are ultimately spent. In the context of this financial regime parking revenues offer the prospect of a significant revenue stream which can be allocated to transport or non-transport budgets against locally-determined motivations and justifications. In Amsterdam parking revenues make up $25 \%$ of total local tax revenues.

In our analysis of the emergence of Park-and-Ride in chapter 8 the role of policies was an important concern. Most of the six cities have introduced the three instruments in the chronological order as we just described them, and currently apply a combination of the three. However, the cities apply the instruments to a different extent, resulting in a differing pressure to curb the dominant regime of central parking, as well as a different promotion of the $P+R$ niche.

Since none of the cities combined strong regime restriction with strong $P+R$ niche investment, none of the cities has maximized the potential to transfer parking to $P+R$. Nevertheless, Amsterdam, Oxford and York were the cities with the strongest pressure on city centre traffic. In the case of the first two, particularly strong parking restrictions and pricing on city centre parking were the key features, and in the case of York, a particularly attractive $P+R$ offer. In Amsterdam this resulted in $25 \%$ less car use in the (core) city centre, though without much use of $P+R$. In Oxford it yielded an interception ratio by $P+R$ of $10 \%$ (by 1993). The case of Amsterdam shows that even strong parking restriction and taxes can not automatically result in strong increase of $P+R$ usage. In Amsterdam travellers favoured use of public transport over $P+R$ use. In Oxford too car travellers shifted to bus use after 1993, with no major change in $P+R$ use.

We found that neither Rotterdam nor Utrecht nor Bristol has applied strong parking restrictions and taxing in the research period. Rotterdam emerged as an intermediate case, where limited disincentives for city centre parking to some extent counteracted the strength of the public transport offer. In the case of Bristol and Utrecht, the policy rhetoric was insufficiently translated into delivery, with weak regime restrictions and weak niche promotion. Neither of the cities has shown great positive impacts of $P+R$ use, in terms of depressurizing urban car use and congestion.

In summary, few cities aspired to stimulate a regime shift to low-traffic centres, and hardly treated the niche and regime as competing and moving targets. In most of the six cities we found an overall increase in parking supply for the city centre, even if the regime was curbed though parking restrictions and pricing. At the same, all cities refined central parking through investments in parking indication systems. In addition, cities invested in P+R sites, but mostly as isolated projects. To different extents in the six case-studies then, we find echoes of Kauffman's (2000) conclusion that: promoting the use of public transport by improving it, whilst simultaneously constructing new car parks for commuters in the city centre, is mutually incompatible. As a result, we found parking policy instruments were effective for incremental refinement of the central parking regime, temporarily solving congestion issues. When traffic levels grew in time, 
new measures were necessary. The application of the instruments did not lead to low-traffic city centres.

\section{Policy advice}

How can city planners aiming for low-traffic city centres exploit $P+R$ most effectively? The complexity of the issue does not allow distilling a set of necessary and sufficient conditions for a city government policy in order to achieve successful, city-centre traffic reducing $P+R$ facilities. A city government can not control the subtle practices of travellers, and these stay a source of some uncertainty. Further, the local government cannot decide upon these issues purely on its own and needs to participate with local stakeholders to achieve enough support for their policies. The co-evolutionary analysis has highlighted though some of the niche-regime dynamics, and these provide some hints to alternative policy options from an evolutionary steering perspective. Similar as in the first case study, we suggest that an urban transport platform is a suitable way for learning and to encourage coordination between the relevant stakeholders. The platform should be a diverse group ranging from local shops and businesses, citizens, tourist organizations, local government, NGO's (especially on air quality), private parking firms, parking experts, public transport organizations etc. They could jointly sketch various possible futures of urban transport with special attention to the role of cars. Collectively they should discuss and address the niche-regime interactions, including the relative attractiveness of central parking, $P+R$ use and use of public transport, which are a major reason of why congestion issues are indeed difficult to mitigate. The broad range of transport organizations makes the platform an excellent place to promote and design ways of inter-modality: the smooth linking of various transport modes.

Our analysis did provide a few guidelines to how the urban transport platform can exploit $P+R$ best to stimulate a shift of the urban car use regime towards low-traffic city centres. It should discuss and design the various policy instruments concertedly. Two elements seem essential here, even though each needs to be tailored for local issues:

- the central parking regime needs to be curbed through strong parking restrictions and high pricing; central parking tariffs need to be considerably higher then tariffs at $P+R$ sites.

- $\quad$ high-quality and smooth $P+R$ facilities need to be available at all major inbound roads.

The second without the first is ineffective, as the cases of Rotterdam and Bristol show, confirming older studies. If both are absent, the case of Utrecht confirms that $P+R$ use will be minimal. Finally, experiences in Oxford and studies of Bos and Molin (2006) suggest that, in order to reduce car traffic in the city centre, both initiatives are necessary, though the case of Amsterdam shows that they are not certainly sufficient to create expanding use of $P+R$ facilities. Investing in $P+R$, whilst simultaneously constructing new car parks for commuters in the city centre, is mutually incompatible. Stabilizing or even decreasing central parking availability is challenging for city governments, giving the opposition from shop owners and possibly car owners. However, in order to reduce problems related to car use in city centres it seems unavoidable. Otherwise, $\mathrm{P}+\mathrm{R}$ will likely be nothing more than 'some additional parking space'.

Finally, with regard to the economic risks that local governments perceive (chapter 7$)$, national governments are advised to support city governments financially for $P+R$ development. Analysis of the three Dutch cases (chapter 8 ) has confirmed that national subsidies are an important enabler for local government to develop $P+R$. Also, the parking policies should not be viewed an end in themselves but be undertaken within a wider perspective of sustainable mobility which seeks to fulfil individual mobility needs in a more sustainable way. 


\subsection{CONCLUSION}

In this chapter we have analyzed the role of policy in our two cases from a co-evolutionary perspective. We found that policy instruments were mostly applied in a technology-blind manner, leading mostly to adoption of existing technologies and incremental innovation. We have suggested options for evolutionary policy to promote the niche innovation in our two case studies, as these may mitigate the $\mathrm{CO}_{2}$ and congestion issues with greater drive. As a red line through the policy advice in both cases we find the suggestion to try and modulate innovation dynamics through a sectoral platform, which:

- $\quad$ engages in niche-regime coordination: coordinate regime policies with bottom-up (niche) initiatives. Experience from local experiments should be shared for policy making at the (supra-)national level and there should be strategic experimentation for system innovation, two things that have happened only incidentally in the past. There should be more and better coordination between top-level and local policies. National strategies should be coordinated with international policies because go-it-alone initiatives can be harmful unless there are clear first-mover advantages.

- deals with existing path-dependencies but in doing so avoids getting locked into suboptimal solutions. This calls for anticipation of outcomes and the use of markets for coordination and context control instead of planning. A second way of circumventing lock-ins is by exploring different configurations through support of a portfolio of niches, instead of supporting just one alternative. 

Chapter 11

CONCLUSION 


\section{Conclusion}

This chapter addresses the five research questions that were formulated in section 1.4. Questions 1 and 2 relate to the theoretic side of this thesis, while questions 3 and 4 relates to the methodology, and question 5 to the policy side

\subsection{QUESTION 1: HOW TO COMBINE SCOT AND EVOLUTIONARY ECONOMICS?}

How can the objectivist approach of evolutionary economics (EE) with its attention to prices and markets be combined with the constructivist approach of SCOT (social construction of technology) with its attention to frames and actor groups?

In Chapter 2 we have combined evolutionary economic concepts with SCOT through a micromacro framework. At the micro level, the innovation is described through the eyes of stakeholders, whereas at macro level aggregated indicators such as total sales and prices are incorporated. We hold (groups of) actors as the basic element of analysis, stepping into their shoes, mapping their mental framing and attitudes. Further, we incorporate feedback loops between the levels, and we extended the notion of feedback effects through scale and learning with the effect of consumer taste formation, including social connotation.

Though in the field of sociological and historic studies it is unconventional to combine a micro and a macro approach in one framework (Lorenz, 2006), our analysis revealed that there are crucial feedbacks between the two. In economics it is more common. A seminal contribution is Thomas Schelling's Micro-motives and Macro-behaviour. Macro level characteristics are the aggregate of individual practices and decisions, but also individual practices and decisions are shaped by aggregate characteristics. This highlights the relevance of an integrated analysis of the micro and the aggregate level as wells as the feedbacks between the two.

In the economic tradition the micro level usually refers to the firm level. The neo-Schumpeterian tradition within evolutionary economics has, much more than mainstream economics, also incorporated direct and indirect institutions in the economic analysis, in terms of research and imitation heuristics and companies operating within or outside a technological paradigm. Nevertheless, the studies are based on the assumption of an objective innovation, neglecting the various social meanings a technology or product may have to different social groups. The social dynamics during technological change are overlooked, especially at the consumer side.

Geels (2005) has already combined elements of SCOT and of EE to a certain extent. In his case studies he incorporates the views of stakeholders frequently. However, in the conceptual threeleveled niche, regime and landscape model (MLP) the actor perspectives have remained somewhat problematic: they may be at any of the three levels. In the TIS approach there is little attention for the role of stakeholder perspectives. Our micro-macro framework provides an alternative model for socio-technical change in which the position and perspective of actors is more evident (at the micro level), and their role is incorporated in the feedback effects. The MLP and TIS approach are however stronger in highlighting structures of relations between actor groups (through formal and informal rules) and sub-regimes, whereas SCOT is stronger in highlighting the social and political dynamics (lobbying, power plays) during technological change.

We have worked out the micro-macro framework through an explanatory case study in chapter $6(\mathrm{HEV})$ and chapter $8(\mathrm{P}+\mathrm{R})$, and through a simulation analysis in chapter $9(\mathrm{HEV})$. We found that the micro-macro distinction is a useful way to integrate objectified and subjectivist knowledge elements in a systematic way. The case studies provided rich and explanatory descriptions of socio-technical and economic change in our two cases. The extensive attention for stakeholder 
perspectives, based on elements of SCOT, was instrumental to improve understanding of the role of stakeholders. The simulation analysis has incorporated stakeholder perspectives too (of firms and consumers), and has highlighted some dynamics that can not easily be traced by noncomputer methods or told in words.

The applicability of the two-levelled framework is bounded by the high demand for both micro and aggregated level data. Further, the understanding of the complex dynamics of feedback mechanisms remain a source of some uncertainty, since we had difficulties to identify the relative strength of feedback loops in practical cases. This issue is an important direction for future research.

\subsection{QUESTION 2: IS A CO-EVOLUTIONARY APPROACH REASONABLE AND RELEVANT FOR STUDYING THE EMERGENCE OF (H)EVS AND P+R?}

(H)EVs and $\mathrm{P}+\mathrm{R}$ are both consumer products or practice, and in both cases a combination of 'hardware' (technology and/or infrastructure) and 'socio-ware' (stakeholder perspectives and institutional factors) is likely important, as we stated in Chapter 1. Co-evolutionary approaches have emerged in EE to include more the dynamics of social institutions, and therefore, we expected it to be relevant. Still, as Saviotti (2005) notices, the current understanding of coevolving institutions and technologies is poor. In our framework we have elaborated coevolution as co-evolution of demand and supply. We have sought to highlight more than previous approaches the key processes underlying the coevolving components. We now turn to the three sub-questions of research question 2 :

\section{... regarding the diffusion dynamics it highlights?}

The case study on $(\mathrm{H}) \mathrm{EV}$ s has highlighted that a variety of technological solutions has appeared at the market (where some have been launched as market vehicles, and others as concept cars at motor shows). At firm level most firms have selected only a few technologies for further development. At the consumer side, we have found a variety of (three) consumer frames of car engines. Aggregate sales level trends have illustrated which engines have mostly been selected. Other studies have addressed the emergence of $(H) E V$, but mostly with a narrower focus. Some (Pilkington et al., 2002; Hekkert and Van den Hoed, 2004; Oltra and Saint Jean, 2009b) focused only on firms, while ignoring consumers. Others (Haan et al., 2006) focused on consumers, whilst disregarding car firms. Our two-leveled, co-evolutionary approach integrates consumers and firms, and competition between technologies. Therefore, this approach helps to highlight dynamics between consumers (and demand structures) and suppliers (and supply structures). In chapter 6 we have discussed feedback mechanisms underlying the two coevolving components in an historic case study. It proved possible to identify empirically the feedback loops, in an approximate manner. In chapter 9 we investigated the interaction between techno-economic and social mechanisms through a simulation method, something that has hardly been explored systematically before. The co-evolutionary analyses in chapter 6 and 9 have therefore contributed understanding of demand-supply interaction in the car propulsion sector with respect to previous studies. All in all, we find that the co-evolutionary approach is very relevant to study the emergence and diffusion of $(\mathrm{H}) \mathrm{EV}$.

$P+R$ is quite a different case. Here we have addressed the diffusion of use of the facilities at the local level in a number of cities. We have highlighted the process of progressive innovation of urban car parking as an outcome of interactions of the city councils' policy, infrastructures and the daily practices of travellers (chapter 8 ). By offering parking at various locations and prices, city governments and parking companies create a variation of parking supply. Of the possible options to park, some are selected to a higher extent, to the exclusion of others. Heterogeneity 
of travellers translates into a heterogeneity or variety of parking demand, in which we found three types of traveller groups. City governments select foci for their innovation and development efforts. They built new garages, develop parking indication systems, improve bus or metro lines, or develop P+R.

Few other studies have addressed the emergence of $P+R$, and these tend to focus on quantitative data around the factors influencing users of $P+R$ sites (cf. Bos et al., 2004) or on effects of $P+R$ schemes on urban car use (cf. Parkhurst, 2000). In our study we have analyzed the evolving stakeholder perspectives, and how they interact with aggregate trends (regulation, infrastructures, prices). We suggest that the two-layered co-evolutionary framework is more than previous approaches, instrumental to highlight the key systemic processes, i.e. the interaction of the city councils' policy and the daily practices of travellers, which shape the diffusion of use of $P+R$.

Our approach has been less successful in highlighting the social and political dynamics in and around the city authority. More than being a single decision maker, the local authority is composed of departments (economy, transport, environment etc.) as well as the city council, who are lobbied by stakeholders and sensitive to their own constituencies and professional groups. In our analysis we have left out such dynamics, and just addressed the policies and regulation that passed the city council. In future research this part of our framework needs to be elaborated. Also, the character of learning and economies-of-scale at local governments should be further elaborated. For both these issues, we see the co-evolutionary framework as a good starting point.

... regarding what it learns about path dependence and path creation (i.e. niche-regime dynamics)?

Other studies (Kemp et al., 1998; Garud and Karnoe, 2001) have already stressed that despite the 'burden' of history new paths may get created through forward-looking choices. By strategic choices of agents, entrepreneurs, consumers or policymakers may stimulate creation of and momentum at new innovation paths. In our study our two case studies provide further elaboration on this issue.

In the $(\mathrm{H})$ EV case we have identified a strong ICE regime and indicated various sources of lock-in (Chapter 6). Moreover, we have described how an (H)EV trajectory has emerged, first as BEV, later as HEV. Especially Toyota and CARB have played a prominent role on this. In chapter 10 we illustrated how European emission regulation provided little incentives for firms to focus on longer term and more radical innovation for the reduction of greenhouse gases. Learning and scale economies for incremental innovation (at the regime) have as a result been much larger than for non-ICE technologies (in outer-regime niches). We have discussed policy options that may deal with niche and regime as two moving targets, and which can therefore be more effective in promoting the niche, if aspired.

In the $P+R$ case we found initially a strong established regime of urban car use and central parking in all of the six cities (chapter 8 ). We have described how each city invested in the $P+R$ niche in its own way. Few cities aspired to stimulate a regime shift to low-traffic centres, and hardly treated the niche and regime as competing and moving targets. In most of the six cities we found an overall increase in parking supply for the city centre, even if the regime was curbed though parking restrictions and pricing. At the same time, all cities refined central parking through investments in parking indication systems. In addition, cities invested in P+R sites, but mostly as isolated projects. We have discussed policy options which can be more effective in promoting the niche, if aspired.

With this analysis we offer a third way to analyze niche-regime dynamics:

1. Geels (2005) describes developments at the regime and the niche for a number of cases in successive sub-periods, and then points at a number of patterns (fit-stretch, niche accumu- 
lation, etc.). Geels and Schot (Geels and Schot, 2007) identified four transition pathways (transformation, de- \& re-alignment, technological substitution, and reconfiguration). This typology of pathways however neglects the many cases of niche-regime dynamics when transition does not occur.

2. Raven and Verbong (2007) describe developments in two distinct but interacting regimes (also in successive sub-periods), and then point to four types of relations between the two: competition, symbiosis, integration and spill-over.

3. In our analysis we described niche-regime interaction through a discussion of four key underlying feedback mechanisms, which constitute co-evolution of demand and supply, and deliver niche and regime innovation trajectories, with four possible futures: reproduction of the regime (and incremental innovation), technological transformation, diversification, and socio-technical transition.

In summary, we suggest that the exposition of underlying processes of learning and scale economies and taste formation, shaped by the regulatory context, has shed fresh light on nicheregime dynamics as moving targets.

... regarding the incorporation of both aggregate and agent-based elements so as to give a micro-underpinning of macro patterns with feedback loops from macro to micro?

With respect to established economic co-evolutionary approaches we have extended attention for stakeholder perspectives at the micro level, based on concepts of SCOT. In this way heterogeneity at the user side and producer side can be incorporated more explicitly. It delivers a few important novelties to the study of innovation and diffusion. First, the two-layered, agentbased approach allows a micro-underpinning of macro patterns which incorporates feedback loops from macro to micro (such as done in the emerging field of social simulation, see Squazzoni (2008). Various innovation and diffusion studies have hinted at the importance of different systemic or feedback effects, such as increasing returns to scale, learning economies, imitation of use etc. In such complex issues as innovation diffusion in changing social contexts there is often not just one or two salient factors, but there are a number of mechanisms that are salient for the innovation dynamics. In chapter 6 we have suggested four key mechanisms (and three key stakeholders) being significant during the emergence of $(\mathrm{H}) \mathrm{EV}$. In chapter 9 we have incorporated these mechanisms in a simulation analysis. For instance we considered the interaction between (macro level) social connotation, in which micro level consumers may become inclined, and how this affects firm R\&D levels and technological progression. This simulation analysis is not all-encompassing in the sense that the model is a 'truth machine', perfectly replicating the social systems and predicting the future. It should be seen as a simplified but integrated model which can nevertheless provide useful insight in the principle dynamics of complex issues or sectors. One of the tough issues is to assess the relative speed of the various feedback loops. These should probably be assessed outside the modelling analysis (for instance through stakeholder participation), and reconsidered for each case. This is an important issue for future research.

All we all we suggest that the incorporation of both aggregate and agent-based elements has illuminated the role of social institutions and demand structures (three consumer groups) more than established economic co-evolutionary approaches, such as Windrum and Birchenhall (2005). On the other hand, the latter approach is richer in terms of price-quality strategies and recombination of innovation. 


\subsection{QUESTION 3: CAN WE MEASURE USER FRAMES AND SOCIAL CONNOTATIONS OF INNOVATIONS} AND INCORPORATE THE RESULTS IN COMPUTER SIMULATIONS AND IN HISTORIC-ANALYTICAL ANALYSES OF SOCIO-TECHNICAL CHANGE?

Mapping or measuring user frames and social connotation is not easy, since they are not directly observable. Though frame analysis has a long history in political sciences (Rein and Schon, 1977; Schon and Rein, 1994), communication sciences (lyengar, 1991; Reese et al., 2001), and more recently sociology of technology (Bijker 1995), currently no fully fledged, standard methodology exists to analyse frames (König, 2008). In this thesis we have mapped user frames through discourse analysis (chapter 4). We have developed a way to track the attributes that storytellers use, and how they evaluate the various attributes. We used this method to analyze market stories of one regime technology (diesel, incremental innovation) and two niche markets (electric and hybrid-electric engines), and we found clear differences in the way these innovation are framed.

As one of the frame attributes we tracked the adjectives and adverbs that were used when speaking about the engine whilst not referring to functional aspects, and this is what we labeled as 'social connotation'. In this way we could compare the attention for functional attributes and social connotation, and compare framing of different innovations and their evolution over time. The analysis served as an input of the consumer perspective for the explanatory historic analytic case study (chapter 6) with a two-levelled framework. We first addressed the two layers separately (section 6.2 and 6.3). Then we addressed feedbacks processes within and between the layers (section 6.4). In these descriptions trends of objectified at the upper level, were combined with interpretations of stakeholders (of these trends), their subsequent response, and in return the impact on the aggregate trends. In chapter 9 we formalized this analysis in a simulation model. Accordingly this model also combined subjective notions of stakeholders with objective aggregate trends.

For $\mathrm{P}+\mathrm{R}$ we started with analyzing the innovation though the eyes of local policymakers (chapter 7). We have benefitted from a recent PhD-study on the attitude of the travelers towards $P+R$ (Bos, 2004), and therefore did not include a separate chapter on the view of traveler. In chapter 8 we added objective knowledge elements. For each of the three Dutch cities we first addressed the two layers separately (section 8.2 to 8.7 ). Then we addressed feedbacks processes between the layers (section 8.8).

The frame analysis (chapter 4) also served as an input for the computer simulation. In the simulation model we wanted to incorporate the effect of conflicting frames between consumer groups. Our discourse analysis method is less suited for identifying different consumer groups. For this we made a detour, analyzing actual car engines sales data, in combination with interviews of car salesmen. Through integration of the results of the various methods, conflicting frames of consumer groups were sketched, and these served as an input for the simulation model.

In this thesis we thus combined a number of methods. As we discussed in chapter 3, authors have argued that combining methods has advantages (Rotmans 2001; Yin 1994). In our cases we can recognize these advantages. For example, objectivistic analyses of electric vehicles easily overlook the role of consumers. They often conclude that most drivers drive less than $100 \mathrm{~km} \mathrm{a}$ day, so will be happy with an EV with a range of $120 \mathrm{~km}$. A closer look at the consumer viewpoint, as in the subjectivist approach of chapter 4, suggests that consumers do not make such a narrow trade-off. They have got used to the convenience of a 500 or $800 \mathrm{~km}$. Moreover, many consumers choose their vehicle or engine for the most critical trip of the year: their summer holidays. If that requires a strong engine and long range, they are happy to drive with an 
oversized and over-ranged vehicle for the rest of the year. In other words, we need subjectivist approaches to incorporate such effects in the broader analysis.

As we also discussed in chapter 3 , combining methods has difficulties. There is an issue of whether the methods do not have the same bias, i.e. whether the methods are really orthogonal, very different. In our study we have applied various methods, sometimes for the different objects of study (chapter 4 on consumers, chapter 5 on firms), but also on the same phenomenon (both chapter 6 and chapter 9 on the emergence of (hybrid-) electric cars). In the latter case we have applied an explanatory case study and a simulation method respectively. These are very distinct methods, the first being richer in its descriptions, the latter being more abstract and suitable for dynamic analysis. Though it is difficult to prove that these approaches have do not share biases, the distinct character of both methods provided a complementary strength. Moreover, we applied the model to develop scenarios. Scenario analysis is distinctive for its quality to deal with uncertainties in the phenomenon of study. Our scenario analysis, although brief, was useful for exploring uncertainties in the role of social connotation of engines in the emergence of new engines. The analysis was however only model-based. For future research we recommend a participatory scenario analysis, which can provide additional richness from stakeholder perspectives and their interactions. Such an analysis can provide scenarios of car mobility in a collaborative and participating setting with relevant stakeholders and scientist from relevant fields. The practicalities for such a project are however challenging.

\subsection{QUESTION 4: DOES THE INCORPORATION OF COMPETING TECHNOLOGIES IN A DIFFUSION MODEL LEAD TO DIFFERENT RESULTS?}

The simulation model developed in chapter 9 pays attention to dynamic competition between two or more products or technologies. Most diffusion models do not pay attention to competition. They study diffusion independent from all other innovation(s) (Mahajan et al. 1990).

Incorporating competing technologies has the principal advantage that for most new technologies the competition with established technologies, i.e. niche-regime dynamics, is key. For our two cases, $(H) E V$ s and $P+R$, this was certainly the case.

In contrast to diffusion models, some evolutionary innovation models have addressed competition between technologies (i.e. Arthur, 1989; Pistorius and Utterback, 1997), though typically in an abstract way. Recently, Windrum and Birchenhall (2005) have model development competition of product designs through the interaction of heterogeneous consumer preferences and heterogeneous firm knowledge bases. Their framework is rich in terms of price-quality strategies and recombination of innovation.

We have developed an agent-based model tailored to the case of car engine technologies. In our model we have incorporated R\&D and progression of the technologies (because of R\&D and dynamic learning and scale economies). Suppliers' R\&D decisions and product offerings during diffusion are modelled. Further, the model is a hybrid model by combining endogenous mechanisms with exogenous mechanisms. The endogenous mechanisms are: epidemic learning and consumer taste formation (at the consumer side), learning economies and scale economies (at the supply side). This methodology can be applied in principle to any diffusion process both retrospectively and prospectively. It cannot be used for prediction (because diffusion is not a deterministic process and because we lack data on certain variables) but can be used for exploration on the basis of proxy data.

We found that the agent-based methodology was especially instrumental to incorporate competing technologies, since they can easily acknowledge the character of knowledge as being cumulative, entail spill-over to other firms, and being a combination of R\&D investments (dollars) and tacit learning. 
Limits to our methodology are the requirement for a significant amount of micro level data (time series of agents' attitudes and frames for evaluation), which is for many cases rather difficult to obtain. Also, it is hard to determine the relative speed of the various feedback loops in each case. These should probably be assessed outside the modelling analysis, where probably expert opinion can be of great value.

\subsection{Question 5: What is THE VAlUE OF A CO-EVOlUtionary CONCEPTUALIZATION OF} INNOVATION DYNAMICS FOR POLICY?

Does it lead to different policy implications than the technology-blind economic welfare perspective and those of the innovation system perspective?

In chapter 10 we have analyzed the role of policy in our two cases from a co-evolutionary perspective. We found that policy instruments were mostly applied in a technology-blind manner which fits with the neoclassical welfare perspective, and found four types of instruments in the case of $(\mathrm{H}) \mathrm{EV}$ s and three in the case of $\mathrm{P}+\mathrm{R}$. Though they were applied simultaneously, they were not designed and introduced in coherence at a certain moment, but were typically introduced at different points in time to address a (relatively) separate issue or problem.

With help of the co-evolutionary analyses of the two cases (chapter 6 and 8), highlighting the niche- regime dynamics, we found that the classic policy instruments that were applied in Europe, have mostly supported adoption of existing technologies and incremental innovation of the established regime, and not supported shifts to alternative outer-regime niches (EV and $\mathrm{P}+\mathrm{R})$.

Whereas the economic welfare perspective is useful to assess which instruments spur innovation to a higher or slower extent, the co-evolutionary approach is instrumental to highlight also where the innovation is located and supported: at the regime or at outer-regime niches. By providing insight in underlying processes of niche-regime dynamics, the approach provides clues on how to promote regime shifts (as we have done in chapter 10).

The more institutional, system-based perspective of Innovation Systems (IS) on the other hand is richer than the welfare perspective through incorporation of social and institutional factors during an innovation process. However, most national, regional and sectoral IS studies take little account of innovation dynamics and feedbacks. TIS studies are an exception to this, and incorporate more and more evolutionary elements, and can thus be instrumental for evolutionary steering approaches too, as the co-evolutionary approach can. However, in TIS studies there is more focus on the niche, and less on the niche-regime dynamics, which makes the TIS approach less suitable to inform niche-regime (or multi-level) coordination, compared to the coevolutionary perspective. 


\section{References}

Abernathy, W. and K. Clark (1985). "Innovation: mapping the winds of creative destruction." Research Policy 14: 3-22.

Abernathy, W. and J. Utterback (1978). "Patterns of industrial innovation." Technological Review 50: 41-47.

Abrahamson, E. and L. Rosenkopf (1993). "Institutional and Competitive Bandwagons: using mathematical modeling as a tool to explore innovation diffusion." Academy of Management Review 18(3): 487-517.

Adams, J. (2005). Hypermobility: a challenge to governance. New Modes of Governance: Developing an Integrated Policy Approach to Science, Technology, Risk and the Environment. C. Lyall and J. Tait. Aldershot, Ashgate.

Arndt, J. (1967). "Role of product-related conversations in the diffusion of a new product." Journal of Marketing Research IV: 291-5.

Arthur, W. B. (1989). "Competing technologies, increasing returns, and lock-in by historical events." The Economic Journal 99: 116-131.

Ashford, N. A., C. Ayers and R. Stone (1985). "Using Regulation to Change the Market for Innovation." Harvard Environmental Law Review 9: 419-466.

Avadikyan, A. and P. Larrue (2003). The Partnership for a New Generation of Vehicles and the US DoE Transportation Fuel Cells Programme. The Economic Dynamics of Fuel Cell Technologies. A. Avadikyan. Heidelberg, Springer-verlag: 133-58.

Avere (2008). EVs Today, www.avere.org (visited september 2008). 2008.

Bass, F. M. (1969). "A New Product Growth Model for Consumer Durables." Management Science 15: 215-227.

Bass, F. M. (1986). The adoption of a marketing model. Innovation Diffusion of New Product Acceptance. V. Mahajan and Y. Wind. Cambridge, MA, Ballinger Publishing Company.

BCC (1996). A4 Bath Road, Bristol 1996 User Survey. Bristol, Bristol City Council.

BCC/NSC (1997). Long Ashton Park \& Ride 1997 User Survey, Bristol City Council/North Somerset Council.

Beise, M. and K. Rennings (2005). "Lead markets and regulation: a framework for analyzing the international diffusion of environmental innovations." Ecological Economics 52(1): 5-17.

Berggren, C., T. Magnusson and D. Sushandoyo (2009). "Hybrids, diesel or both? The forgotten technological competition for sustainable solutions in the global automotive industry." International Journal of Automotive Technology and Management 9(2): 148 - 173.

Bhaskar, R. (1994). Plato Etc. London, Verso.

Bijker, W. (1995). Of Bicycles, Bakelites and Bulbs: Toward a Theory of Sociotechnical Change. Cambridge, MIT Press.

Bijker, W., T. Hughes and T. Pinch, Eds. (1987). The Social Construction of Technological Systems: New Directions in the Sociology and History of Technology. Cambridge, MA, MIT Press.

Bonus, H. (1973). "Quasi-Engel Curves, Diffusion, and the Ownership of Major Consumer Durables." Journal of Political Economy 81: 655-677.

Bos, I. (2004). Changing Seats: a behavioral analysis of P\&R use. TRAIL. Delft, TU Delft. PhD.

Bos, I. and E. Molin. (2006). "Is there a 'Stick' Bonus? A Stated Choice Model for P\&R." Retrieved November 6th, 2008, from www.ejtir.tbm.tudelft.nl.

Bos, I., R. Van der Heijden, E. Molin and H. Timmermans (2004). "The choice of Park and Ride Facilities: an analysis using a context-dependent hierachical choice experiment." Environment and Planning A 36: 1673-1686.

Bovag-Rai (2005). (Brand)stof tot nadenken - 25 vragen en antwoorden over brandstof en voertuigtechniek. Amsterdam, Stichting BOVAG-RAI Mobiliteit. 
Bovag. (2008). "Auto Registraties." Retrieved 2008.

Boyd, T. (2006). Report on Demographic and Consumption Behaviors of USMS Members. Londonderry NH, USMS.

Breschi, S. and F. Malerba (1997). Sectoral Innovation Systems: Technological Regimes, Schumpeterian Dynamics, and Spatial Boundaries. Systems of Innovation - Technologies, Institutions and Organizations. C. Edquist. London, UK, Pinter: 130-156.

Burke, A., K. Kurani and E. J. Kenney (2000). Study on the Secondary Benefits of the ZEV Mandate. Paper UCD-ITS-RR-00-07, Institute of Transportation Studies, UC Davis.

Cairns, M. R. (1997). "The development of Park and Ride in Scotland." Journal of Transport Geography 6(4): 295-307.

Carlsson, B., S. Jacobsson, M. Holmen and A. Rickne (2002). "Innovation Systems: Analytical and Methodological Issues." Research Policy 31(2): 233-245.

Carlsson, B. and R. Stankiewicz (1991). "On the nature, function, and composition of Technological Systems." Journal of Evolutionary Economics 1(2): 93-118.

Center for Electric Vehicles (2006). Chronological Development of Hybrid Electric Vehicles, Japan Automobile Research Institute.

CNW (2006). Hybrid Motivators. Report \#135Q. C. M. Research. Bandon, CNW Market Research.

Cohen, S., A. Di Minin, Y. Motoyama and C. Palmberg (2009). "The Persistence of Home Bias in R\&D in Wireless Telecom and Automobiles." Review of Policy Research 26(1-2): 55 - 76.

Correlje, A. and G. Verbong (2004). The transition from coal to gas: radical change of the Dutch gas system. System innovation and the transition to sustainability: theory, evidence and policy. B. Elzen, F. Geels and K. Green. Cheltenham, Edward Elgar: 114-136.

Cowan, R. and S. Hulten (1996). "Escaping Lock-in: the case of the electric vehicle." Technology Forecasting and Social Change 53(1): 61-80.

CROW (2004). Overstappunten - Ervaringen met Park and Ride in Nederland. Brochure 10: van parkeerbeheer naar mobiliteitsmanagement. CROW. Ede, CROW \& MU-Consult.

Daimler-Chrysler (2003). Energy for the Future. Stuttgart, Germany, Daimler Chrysler Communications.

David, P. A. (1969). A Contribution to the Theory of Diffusion. Stanford Research Memorandum 71, Stanford Centre for Research in Economic Growth.

Davies, S. (1979). The Diffusion of Process Innovations. Cambridge, Cambridge University Press.

De Ridder, W., J. Turnpenny, M. Nilsson and A. Von Raggamby (2007). "A Framework for Tool Selection and Use in Integrated Assessment for Sustainable Development." Journal of Environmental Assessment Policy and Management 9(4): 423-441.

DeCicco, J., F. An and M. Ross (2001). Technical Options for Improving the Fuel Economy of U.S. Cars and Light Trucks by 2010-2015, ACEEE.

Dieleman, H. and S. d. Hoo (1993). PRISMA: the Development of a Preventative, Multi Media Strategy for Government and Industry. Environmental Strategies for Industry: International Perspectives on Research Needs and Policy Implications. K. Fischer and J. Schot. Washington DC, Island Press: 245-275.

dIVV (2001a). Eindevaluatie P+R Transferium Arena. Amsterdam, dienst Infrastructuur, Verkeer en Vervoer, Gemeente Amsterdam.

dIVV (2001b). Parkeren is manoeuvreren. Nota Parkeerbeleid. Amsterdam, Dienst Infrastructuur Verkeer \& Vervoer, Gemeente Amsterdam.

Dosi, G. (1982). "Technological paradigms and technological trajectories: a suggested interpretation of the determinants and directions of technical change." Research Policy 6: 147-62.

Douglas, M. and B. Isherwood (1979). The World of Goods. New York, Basic Books.

Dresner, T. and P. Barkan (2005). A review and classification of Variable Valve Timing Mechanisms. 100 Years of Engine Developments. D. J. Holt. Warrendale, PA, Society of Automotive Engineers (SAE). 
EEA (2004). Ten key transport and environment issues for policy-makers. EEA report. E. E. Agency. Luxenbourg, European Environment Agency.

Elzen, B. (2004). Taking the socio-technical seriously. Transition to Sustainability - Theory, Evidence and Policy. B. Elzen, F. Geels and K. Green. Cheltenham, Edward Elgar.

Emirbayer, M. (1997). "Manifesto for a Relational Sociology." American Journal of Sociology 103(2): 281-317.

Entman, R. M. (1993). "Frames: Toward clarification of a fractured paradigm." Journal of Communication 43(4): 51-58.

Fazio, R. H. (1989). On the power and functionality of attitudes: the role of attitude accessibility. Attitude, Structure and Function. A. R. Pratkanis, J. Breckler and A. G. Greenwald. Hillsdale, $\mathrm{NJ}$, Lawrence Erlbaum Associates.

Feick, L. and L. Price (1987). "The market maven: A diffuser of marketplace information." Journal of Marketing 51: 83-97.

Fischer, C., I. W. Parry and W. A. Pizer (2003). "Instrument Choice for Environmental Protection when Technological Innovation is Endogenous." Journal of Environmental Economics and Management 45: 523-545.

Fischetti, M. (2002). "Why not a 40-MPG SUV." Technology Review November: 41-46.

Foxon, T. and R. Kemp (2006). Innovation impacts of environmental policies. The International Handbook On Environmental Technology Management. D. e. a. Marinova. Cheltenham, UK, Edward Elgar.

Freeman, C. (1987). Technology, policy, and economic performance: lessons from Japan. London, UK, Pinter.

Freeman, C. and C. Perez (1988). Structural crises of adjustment, business cycles and investment behavior. Technical Change and Economic Theory. G. Dosi, C. Freeman, R. R. Nelson, G. Silverberg and L. Soete. London, Uk, Pinter: 38-66.

Frenken, K., M. P. Hekkert and P. Godfroij (2004). "R\&D portfolios in environmentally friendly automotive propulsion: variety, competition and policy implications." Technological Forecasting \& Social Change 71: 485-507.

Funk, K. and A. Rabl (1999). "Electric versus conventional vehicles: social costs and benefits in France." Transportation Research Part D 4: 397-411.

Garud, R. and P. Karnoe (2001). Path Dependency and Creation. Mahwah, NJ, Lawrence Erlbaum Associates.

Garud, R. and P. Karnoe (2003). "Bricolage versus breakthrough: distributed and embedded agency in technology entrepreneurship." Research Policy 32(2): 277-300.

Geels, F. (2005). Technological Transitions and System Innovations: a co-evolutionary and sociotechnical analysis. Cheltenham, UK, Edward Elgar.

Geels, F. and R. Kemp (2007). "Dynamics in socio-technical systems: Typology of change processes and contrasting case studies." Technology in Society 29(4).

Geels, F. and J. Schot (2007). "Typology of sociotechnical transition pathways." Research Policy 36(3): 399-417.

Gemeente-Rotterdam (1993). Verkeers- en Vervoersplan Rotterdam (VVPR). Rotterdam, Gemeente Rotterdam.

Gemeente-Rotterdam (2003). Verkeers- en Vervoersplan Rotterdam (VVPR) 2002-2020. Rotterdam, Gemeente Rotterdam.

Gemeente-Rotterdam (2005). Effectmonitor VVPR 2004. Rotterdam, dS+V, afd. Verkeer \& Vervoer, Gemeente Rotterdam.

Gemeente-Rotterdam (2007). Effectmonitor VVPR 2006. Rotterdam, dS+V, afd. Verkeer \& Vervoer, Gemeente Rotterdam.

Gemeente-Utrecht (2003a). Onderzoek naar andere parkeervergunningssystemen. 
Gemeente-Utrecht (2003b). Parkeren: een kwestie van kiezen. Parkeernota. Utrecht, Gemeente Utrecht.

Genus, A. and A. Coles (2008). "Rethinking the multi-level perspective of technological transitions " Research Policy 37(9): 1436-1445.

Gerard, D., P. Fischbeck and H. Mathews (2006). Diesel and hybrids don't mix: perceptions of the interested public and actual driving behavior of new car owners. C. f. t. S. I. o. Regulation, Carnegie Mellon University.

Giddens, A. (1984). The constitution of society. Outline of the theory of structuration. Cambridge, Polity Press.

Griliches, Z. (1990). "Patent statistics as economic indicators: a survey." Journal of Economic literature 28(4): 1661-1707.

Grosskurth, J. (2008). Regional Sustainability: Tools for Integrated Governance. ICIS. Maastricht, Maastricht University. PhD.

Haan, P. d., A. Peters and M. Mueller (2006). "Comparison of Buyers of Hybrid and Conventional Internal Combustion Engine Automobiles: Characteristics, Preferences, and Previously Owned Vehicles." Transportation Research Record: Journal of the Transportation Research Board 1983: 106-113.

Haan, P. d., A. Peters and A. W. Scholz (2007). "Reducing energy consumption in road transport through hybrid vehicles: investigation of rebound effects, and possible effects of tax rebates." Journal of Cleaner Production 15: 1076-1084.

Hallahan, K. (1999). "Seven Models of Framing: Implication for Public Relations." Journal of Public Relations Research 11(3): 205-42.

Hannibal, W. and K. Meyer (2000). Patentrecherche und Uberblick zu variablen Ventilsteuerungen. Essen, Markische Fachhochschule Iserlohn, Ingenieurburo Bockmann Hannibal.

Hare, M. and P. Deadman (2004). "Further towards a taxonomy of agent-based simulation models in environmental management." Mathematics and computers in simulation 64: 25-40.

Heath, A. P. and D. Scott (1998). "the self-concept and image congruence hypothesis." European Journal of Marketing 32(11/12): 1110-1123.

Heffner, R. R., K. Kurani and T. S. Turrentine (2005). Effects of Vehicle Image in Gasoline-Hybrid Electric Vehicles. Davis, CA, ITS, UC Davis.

Heffner, R. R., K. Kurani and T. S. Turrentine (2007). "Symbolism in California's early market for hybrid electric vehicles." Transportation Research Part D 12: 396-413.

Heffner, R. R., T. S. Turrentine and K. Kurani (2006). A Primer on Automobile Semiotics. ITS Working Paper 06-01. Davis, ITS, UC Davis.

Hekkert, M. P., R. Suurs, S. Negro, S. Kuhlmann and R. Smits (2006). "Functions of Innovation Systems: A new approach for analysing technological change." Technology Forecasting and Social Change In Press.

Hekkert, M. P., R. Suurs, S. Negro, S. Kuhlmann and R. Smits (2007). "Functions of Innovation Systems: A new approach for analysing technological change." Technology Forecasting and Social Change 74(413-432).

Hekkert, M. P. and R. Van den Hoed (2004). "Competing technologies and the struggle towards a new dominant design: the emergence of the hybrid vehicle at the expense of the fuel cell vehicle?" Greener Management International September.

Holt, D. J. (2005). 100 Years of Engine Developments. Warrendale, USA, Society of Automotive Engineers.

Hoogma, R., R. Kemp, J. Schot and B. Truffer (2002). Experimenting for Sustainable Transport. London, New York, SPON Press.

Hughes, T. P. (1983). Networks of Power: Electrification in Western Society, 1880-1930. Baltimore, MD, John Hopkins University Press. 
Ireland, N. and P. Stoneman (1982). "The Role of Supply Factors in the Diffusion of New Process Innovations." Economic Journal.

Iyengar, S. (1991). Is Anyone Responsible? How Television Frames Political Issues. Chicago, University of Chicago Press.

Jacob, K., M. Beise, J. Blazejczak and M. Janicke (2005). Lead markets for environmental innovations, Zentrum für Europäische Wirtschaftsforschung (ZEW) / Springer.

Jacobides, M. G. and S. G. Winter (2005). "The co-evolution of capabilities and transaction costs: explaining the institutional structure of production." Strategic Management Journal 26: 395-413.

Jacobsson, S. and V. Lauber (2006). "The politics and policy of energy system transformation explaining the German diffusion of renewable energy technology." Energy Policy 34(3): 256-76.

Jager, W. (2000). Modelling consumer behaviour. Faculty of Social Sciences. Groningen, University of Groningen. PhD.

Janssen, M. and B. d. Vries (1998). "The Battle of Perspectives: a multi-agent model with adaptive responses to climate change." Ecological Economics 26: 43-65.

Karishu, H. and Y. Tanokura (2007). "U.S. Auto Makers Fighting back with Plug-in Hybrid." Nikkei Electronics(January 29): 65-72.

Kaufmann, V. (2000). "Modal Practices: From the rationales behind car \& public transport use to coherent transport policies. Case studies in France \& Switzerland." World Transport Policy \& Practice 6(4).

Kemp, R. (1997). Environmental Policy and Technical Change. Cheltenham, UK, Edward Elgar.

Kemp, R. (1998). "The Diffusion of Biological Waste-Water Treatment Plants in the Dutch Food and Beverage." Environmental and Resource Economics 12(1): 113-136.

Kemp, R. (2005). Zero Emission Vehicle Mandate in California. Misguided Policy or Example of Enlightened Leadership? Time Strategies, Innovation and Environmental Policy. C. Sartorius and S. Zundel. Cheltenham, UK, Edward Elgar.

Kemp, R. (2009). The Dutch Energy Transition Approach. 2nd International Wuppertal Colloquium on "Sustainable Growth, Resource Productivity and Sustainable Industrial Policy - Recent Findings, New Approaches for Strategies and Policies, University of Wuppertal, Schumpeter School of Business and Economics.

Kemp, R. and S. Pontoglio (2008). The innovation effects of environmental policy instruments - a typical case of the blind men and the elephant. DIME Workshop on Empirical Analyses of Environmental Innovations, Fraunhofer Institute for Systems and Innovation Research (ISI), Karlsruhe.

Kemp, R., A. Rip and J. Schot (2001). Constructing transition paths through the management of niches. Path Dependence and Creation. R. Garud, Karnoe, P. Mahwah, NJ, Lawrence Erlbaum: 269-299.

Kemp, R., J. Schot and R. Hoogma (1998). "Regime shifts to sustainability through processes of niche formation: The approach of strategic niche management." Technology Analysis \& Strategic Management 10(2): 175-198.

Kemp, R., B. Truffer and S. Harms (2000). Strategic niche management for sustainable mobility. Social Costs and Sustainable Mobility. Strategies and Experiences in Europe and the United States. K. Rennings, O. Hohmeier and R. Ottinger. Heidelberg, Physical Verlag. 167-187.

Klok, P. J. (1989). Covenanten als instrument van milieubeleid. Enschede, Twente University. PhD.

König, T. (2008). "Frame Analysis: Theoretical Preliminaries." Frame Analysis Retrieved July 1st, 2008, from http://www.ccsr.ac.uk/methods/publications/frameanalysis/index.html.

Kubic, M. (2006). Consumer Views on Transportation and Energy (Third Edition). Technical Report NREL/TP. Colorado, National Renewable Energy Laboratory. 
Kuhn, T. S. (1962). The structure of scientific revolutions. Chicago, University of Chicago Press.

Lave, L. and H. MacLean (2002). "An environmental-economic evaluation of hybrid electric vehicles: Toyota's Prius vs. its conventional internal combustion engine Corolla." Transportation Research Part D: Transport and Environment 7(2): 155-162.

Lee, J., Y. Cho, J.-D. Lee and C.-Y. Lee (2006). "Forecasting future demand for large-screen television sets using conjoint analysis with diffusion model." Technological Forecasting \& Social Change 73(4): 362-376.

Lehna, M. (2004). Hybrids Vehicles - problems, solutions, experience, future prospects. European Electric Drive Transportation Conference \& Exibition, Estoril, Portugal.

Leonard-Barton, D. (1992). "Core capabilities and Core rigidities, a paradox in managing new product development." Strategic Management Journal 13(5): 111-125.

Leonard-Barton, D. (1995). Wellspring of Knowledge: Building and sustaining the Sources of Innovation. Boston, MA, Harvard Business School Press.

Lie, M. and K. H. Sørensen (1996). Making technology our own?: domesticating technology into everyday life. Oslo, Stockholm, Scandinavian University Press.

Lorenz, C. (2006). De constructie van het verleden - een inleiding in de theorie van de geschiedenis. Amsterdam, Boom.

Lundvall, B. A. (1988). Innovation as an interactive process: from user-producer interaction to the national system of innovation. Technical Change and Economic Theory. G. Dosi, Freeman, C., Nelson, R.R., Silverberg, G., and Soete, L. London, Pinter.

Lundvall, B. A. (1992). National Systems of Innovation - towards a Theory of Innovation and Interactive Learning. London, UK, Pinter.

Lynn, G., M. Mazzuca, J. Marone and A. Paulson (1998). "Learning is the critical success factor in developing truly new products." Research Technology Management 41(3): 45-51.

Magnusson, T. and C. Berggren (2001). "Environmental innovation in auto developmentmanaging technological uncertainty within strict time limits." International Journal of Vehicle Design 26(2/3): 101-115.

Mahajan, V., E. Muller and F. M. Bass (1990). "New Product Diffusion Models in Marketing: A Review and Direction for Research." Journal of Marketing 54(January): 1-26.

Malim, T. and A. Birch (1998). Introductory Psychology. London, Macmillan Press.

Martens, P. (2006). Integrated Assessment Models. More Puzzle-solving for Policy, Maastricht, ICIS.

Milliman, S. and R. Prince (1989). "Firm incentives to promote technological change in pollution control." Journal of Environmental Economics and Management 17: 247-265.

Mingardo, G. (2008). Effecten van Park \& Ride in Rotterdam. Rotterdam, European Institute for Comparative Urban Research (EURICUR), Erasmus University Rotterdam.

Mingers, J. and J. Brocklesby (1997). "Multimethodology: towards a Framework for Mixing Methodologies." Omega 25(5): 489-509.

Molot, M. (2008). The race to develop fuel cells: Possible lessons of the Canadian experience for developing countries. Making Choices about Hydrogen: Transport Issues for Developing Countries. L. K. Mytelka and G. Boyle, Tokyo: UNU Press and Ottawa: IDRC Press.

Montalvo, C. (2002). Environmental Policy and Technological Innovation. Cheltenham, UK, Edward Elgar.

Montalvo, C. (2006). "What triggers change and innovation?" Technovation 26(2006): 312-323.

Moss, S., C. Pahl-Wostl and T. Downing (2001). "Agent-based integrated assessment modelling: the example of climate change." Integrated Assessment 2(1): 17-30.

MU-Consult (2000). EvaluatieTransferia - eindrapport. Amersfoort.

Mukoyama, T. (2006). "Rosenberg's "learning by using" and technology diffusion." Journal of Economic Behavior \& Organization 61(1): 123-144.

MVW (2006). Verkeersongevallen in Nederland. Rotterdam, Ministerie van Verkeer \& Waterstaat / Rijkswaterstaat. 
Mytelka, L. K. (2008). Hydrogen fuel cells and alternatives in the transport sector: A framework for analysis. Making Choices about Hydrogen: Transport Issues for Developing Countries. L. K. Mytelka and G. Boyle. Maastricht, Netherlands, Tokyo: UNU Press and Ottawa: IDRC Press.

Negro, S. (2007). Dynamics of Technological Innovation Systems - The Case of Biomass Energy. Utrecht, Utrecht University. PhD.

Nelson, R. R. (1992). "National Systems of innovation: A Retrospective on a Study." Industrial and Corporate Change(2): 347-374.

Nelson, R. R. (1994). "The Co-evolution of Technology, Industrial Structure, and Supporting Institutions." Industrial and Corporate Change 3(1): 47-63.

Nelson, R. R. and S. Winter (1982). An Evolutionary Theory of Economic Change. Cambridge, MA, Harvard University Press.

Nill, J. and R. Kemp (2009). "Evolutionary approaches for sustainable innovation policies: From niche to paradigm?" Research Policy 38(4).

Nill, J. and S. Zundel (2001). "Die Rolle von Vielfalt für Zeitstrategien ökologischer Innovationspolitik." Zeitschrift für angewandte Umweltforschung 13: 148-157.

Noel, E. C. (1988). "Park-and-ride: alive, well, and expanding in the United States." Journal of Urban Planning and Development 114(1): 2-13.

Norgaard, R. B. (1984). "Coevolutionary development potential." Land Economics 60: 160-173.

Norgaard, R. B. (1994). Development betrayed: the end of progress and a coevolutionary revisioning of the future. London, NewYork, Routledge.

Notten, P. W. F. v. (2005). Writing on the Wall, Maastricht University. PhD.

OECD (2006). Decoupling the Environmental Impacts of Transport from Economic Growth. Paris, OECD PUBLICATIONS.

OECD (2007). Managing Urban Traffic Congestion. Paris, OECD Publications.

Oltra, V. and M. Saint Jean (2009a). "Sectoral systems of environmental innovation: an application to the French automotive industry." Technological Forecasting \& Social Change 76: 567-583.

Oltra, V. and M. Saint Jean (2009b). "Variety of technological trajectories in low emission vehicles (LEVs): a patent data analysis." Journal of Cleaner Production 17(2): 201-213

Orsato, R. (2009). Sustainability Strategies, Pelgrave MacMillan and INSEAD Business Press.

Oudshoorn, N. and T. Pinch (2003). How users matter: The co-construction of users and technology. Cambridge, MA, MIT Press.

OV9292 (2003). 9292 gaat autorit vergelijken met openbaar-vervoerreis. REISwijzer (OV'R 9292). 1: 4-5.

Parkhurst, G. (1993). A Comparison of Policies Aimed at Controlling Car Use in the Historic Cities of Oxford and York. PTRC Summer Annual Meeting, University of Manchester Institute of Science \& Technology, PTRC, London.

Parkhurst, G. (2000). "Influence of bus based park and ride facilities on users' car traffic." Transport Policy 7(2): 159-172.

Parkhurst, G. and J. Richardson (2002). "Modal integration of bus and car in UK local transport policy: the case for strategic environmental assessment." Journal of Transport Geography 10: 195-206.

Parkhurst, G. and G. Stokes (1994). Park and Ride in Oxford and York: Report of Surveys. Working paper 797. Oxford, Transport Studies Unit.

Pilkington, A. and R. Dyerson (2006). "Innovation in disruptive regulatory environments: a patent study of electric vehicle technology development." European Journal of Innovation Management 9(1): 79-91.

Pilkington, A., R. Dyerson and O. Tissier (2002). "The electric vehicle: Patent data as indicators of technological development." World Patent Information 24: 5-12. 
Pistorius, C. W. I. and J. M. Utterback (1997). "Multi-mode interaction among technologies." Research Policy 26: 67-84.

Prahalad, C. and G. Hamel (1990). "The Core Competence of the Corporation." Harvard Business Review May/June: 79-91.

Quandt, C. O. (1995). "Manufacturing the electric vehicle: a window of technological opportunity for Southern California." Environment and Planning A 27: 835-862.

Raven, P. H. and G. Verbong (2007). "Multi-Regime Interactions in the Dutch Energy Sector. The Case of Combined Heat and Power in the Netherlands 1970-2000." Technology Analysis \& Strategic Management 19(4): 491-507.

Reese, S., O. H. Gandy and A. E. Grant (2001). Framing Public Life: Perspectives on Media and our Understanding of the Social World. Mahwah, NJ, Lawrence Erlbaum Associates.

Rein, M. and D. A. Schon (1977). Problem setting in policy research. Using social research in policy making. C. Weiss. Lexington, MA, Lexington Books.

Rip, A. and R. Kemp (1998). Technological Change. Human Choice and Climate Change. S. Rayner, Malone, E.L. Columbus, OH, Battelle Press. 2: 327-399.

Roe, E. (1998). Taking Complexity Seriously: Policy Analysis, Triangulation and Sustainable Development. Boston/ Dordrecht, Kluwer Academic Publishers.

Rogers, E. M. (1983). Diffusion of Innovations. New York, The Free Press.

Rosa, J. A. and J. Spanjol (2005). "Micro-level Product-Market Dynamics: Shared Knowledge and Its Relationship to Market Development." Journal of the Academy of Marketing Science 33(2): 197-216.

Rosenkopf, L. and M. L. Tushman (1998). "The coevolution of community networks and technology: lessons from the flight simulation industry." Industrial and Corporate Change 7: 311-346.

Rothman, D. (2006). Scenarios: structured thinking about the future. More Puzzle-solving for Policy: Integrated Assessment from theory to practice. P. Valkering, B. Amelung, R. v. d. Brugge and J. Rotmans. Maastricht, ICIS.

Rotmans, J. (2001a). IA-scenarios and IA-models: A cross fertilisation. Puzzle-solving for Policy: a provisional handbook for Integrated Assessment. M. B. A. Van Asselt, J. Rotmans and S. Greeuw. Maastricht, ICIS.

Rotmans, J. (2001b). Integrated Assessment: a bird's eye view. Puzzle-solving for policy: a provisional handbook for Integrated Assessment. M. Asselt, J. Rotmans and S. Greeuw. Maastricht, ICIS.

Rotmans, J., R. Kemp and M. B. A. v. Asselt (2001). "More evolution than revolution: transition management in public policy." Foresight 3 (1): 15-32.

Rotmans, J. and B. d. Vries (1997). Perspectives on Global Change: the TARGETS approach. Cambridge, Cambridge University Press.

SAC (1999). Nota Verkeer en Parkeren Binnenstad. Amsterdam, Stadsdeel Amsterdam-Centrum (SAC).

SAC (2008). Schriftelijke vragen en antwoorden. Amsterdam, Stadsdeel Amsterdam-Centrum (SAC).

Safarzynska, K. and J. C. J. M. Van den Bergh (2010). "Demand-supply coevolution with multiple increasing returns: policy analysis for unlocking and system transitions." Technological Forecasting \& Social Change 77: 297-317.

Saviotti, P. P. (2005). On the Co-evolution of Technologies and Institutions. Towards Environmental Innovation Systems. M. Weber and J. Hemmelskamp. Berlin, Springer.

Saxenian, A. (1991). "The origins and dynamics of production networks in Silicon Valley." Research Policy 20(5): 423-437.

SBD (2009). Bevölkerung nach dem Gebietsstand. www.destatis.de. S. B. Deutschland, Statistisches Bundesamt Deutschland. 
Scheufele, D. (1999). "Framing as a Theory of Media Effects." Journal of Communication 49(4): 103-22.

Schon, D. A. and M. Rein (1994). Frame reflection: Toward the resolution of intractable policy controversies. NY, Basic Books.

Schot, J. (1998). "The usefulness of evolutionary models for explaining innovation. The case of the Netherlands in the nineteenth century." History of Technology 14: 173-200.

Schot, J. and F. Geels (2008). "Strategic niche management and sustainable innovation journeys: theory, findings, research agenda, and policy." Technology Analysis \& Strategic Management 20(5): 537 - 554.

Schrank, D. and T. Lomax (2007). THE 2007 URBAN MOBILITY REPORT, Texas Transportation Institute.

Schumpeter, J. A. (1934). The theory of economic development: An inquiry into profits, capital, credit, interest, and the business cycle. Cambridge, MA, Harvard University Press (reprint 1912).

Schumpeter, J. A. (1935). "The analysis of economic change." The Review of Economics and Statistics May.

Scott, W. A., D. Osgood and C. Peterson (1979). Cognitive Structure: Theory and Measurement of Individual Differences. Washington DC, V.H. Winston.

Shove, E. and G. P. Walker (2007). "CAUTION! Transitions ahead: politics, practice, and sustainable transition management " Environment and Planning A 39: 763-770.

Silverberg, G. (1991). Adoption and Diffusion of Technology as a Collective Evolutionary Process. Diffusion of technologies and social behavior. N. Nakicenovic, Grubler, A. Berlin, SpringerVerlag: $x x-y y$.

Smith, M. R. and L. Marx, Eds. (1994). Does Technology Drive History? Cambridge, MA, MIT Press.

Squazzoni, F. (2008). "The micro-macro link in social simulation." Sociologica 1.

Steg, L., C. Vlek and G. Slotegraaf (2001). "Instrumental-reasoned and symbolic-affective motives for using a motor car." Transportation research part F-Traffic Psychology and Behavior 4: 151-169.

Stienstra, S. (2004). Parkeren in Europees Perspectief. Van parkeerbeheer naar mobiliteitsmanagement. CROW. Ede, CROW.

Tachimoto, S., T. Hayashi and Y. Kawabata (2005). "Conditions for the Diffusion of Hybrid Vehicles." Nikkei Automotive Technology(7): 138-157.

Tanokura, Y. and H. Karishu (2006). "Hybrid Vehicles Flourish in the United States." Nikkei Electronics(January 30): 69-74.

Tansey, J., J. Carmichel, R. VanWynsberghe and J. Robinson (2002). "The future is not what it used to be: participatory integrated assessment in the Gorgia Basin." Global Environmental Change 12(2): 97-104.

TCT (2005). Parking policies and the effect on economy and mobility - COST action 342. Report on COST. T. C. o. Transport. Brussels, European Union.

Teske, J. and J. J. Chanaron (2007). "Hybrid vehicles: a temporary step." International Journal of Automotive Technology and Management 7(4): 268 - 288.

Toyota Motor Corporation (2003). Toyota Hybrid System THS II. Tokyo, Toyota Motor Corporation.

UNEP (2002). Global Environmental Outlook 3. London, Earthscan.

Valkering, P. (2009). Toddling 'long the River Meuse. ICIS. Maastricht, Maastricht University. PhD.

Van Asselt, M. B. A. (2000). Perspectives on uncertainty and risk: The prima approach to decision support. Dordrecht, Kluwer Academic Publishers.

Van Asselt, M. B. A., J. Rotmans and D. Rothman (2005). Scenario Innovation: Experiences from a European Experimental Garden, Taylor and Francis. 
Van den Bergh, J. C. J. M., A. Faber, A. Idenburg and F. Oosterhuis (2006). "Survival of the greenest: evolutionary economics and policies for energy innovation." Environmental Sciences 3(1): 57-71.

Van den Bergh, J. C. J. M. and G. Kallis (2009). Evolutionary Policy. Papers on Economics and Evolution. M. J. Evolutionary Economics Group. Jena, MPI.

Van den Bergh, J. C. J. M. and S. Stagl (2003). "Coevolution of economic behaviour and institutions: towards a theory of institutional change " Journal of Evolutionary Economics 13: 289-317.

Van den Hoed, R. (2004). Driving Fuel Cell Vehicles: How Established Industries React to Radical Technologies. Design, Engineering and Production. Delft, Delft University of Technology. PhD-thesis.

Van den Hoed, R. (2005). "Commitment to fuel cell technology?: How to interpret carmakers' efforts in this radical technology." Journal of Power Sources 141(2): 265-271.

Van der Veen, A. and J. Rotmans (2001). "Dutch perspectives on "Agents, Regions and Land Use Change"." Environmental Modeling and Assessment 6(2): 83-86.

Verbong, G., F. Geels and R. Raven (2008). "Multi-niche analysis of dynamics and policies in Dutch renewable energy innovation journeys (1970-2006): hype-cycles, closed networks and technology-focused learning." Technology Analysis \& Strategic Management 20 (5): $555-573$.

Vigar, G. (2001). "Reappraising UK transport policy 1950-99: the myth of 'mono-modality' and the nature of 'paradigm shifts'." Planning Perspectives 16: 269-291.

Von Hippel, E. (1988). The Sources of Innovation. Oxford, Oxford University Press.

Von Hippel, E. and M. J. Tyre (1995). "How learning-by-doing is done: problem identification in novel process equipment." Research Policy 24: 1-12.

Ward, W. H. (1967). "The sailing ship effect." Bulletin of Institute of Physics and The Physical Society 18: 169.

Weick, K. (1995). Sensemaking in Organizations. Thousand Oaks, CA, Sage.

WHO (1999). Health Costs due to Road Traffic-related Air Pollution. An impact Assessment Project of Austria, France and Switzerland. Bern, World Health Organization.

Wikipedia (2006). European emission standards.

Windrum, P. and C. Birchenhall (2005). "Structural change in the presence of network externalities: a co-evolutionary model of technological successions." Journal of Evolutionary Economics 12(2): 123-148.

WoEP (2006). Final Joint Local Transport Plan 2006/7-2010/11. Bristol, West of England Partnership.

WoEP (2008). Joint Progress Review 2008. Bristol, West of England Partnership.

Yarime, M. (2007). "Promoting Green Innovation or Prolonging the Existing Technology: Regulation and Technological Change in the Chlor-Alkali Industry in Japan and Europe." Journal of Industrial Ecology 11(4): 117-139.

Yarime, M., H. Shiroyama and Y. Kuroki (2008). The Strategies of the Japanese Auto Industry in Developing Hybrid and Fuel Cell Vehicles. Making Choices about Hydrogen: Transport Issues for Developing Countries. L. K. Mytelka and G. Boyle, IDRC Press (Ottawa) and United Nations University Press (Tokyo).

YCC (2006a). Local Transport Plan 2001-2006 Delivery Report. Committee Report 25/7/06. York, City of York.

YCC (2006b). Local Transport Plan 2006-2011. York, City of York.

YCC (2009). Car Parking In York. Committee Report 8/9/09. York, City of York.

Yin, R. K. (1994). Case Study Research: design and methods. Thousand Oaks, London, New Delhi, Sage Publications. 


\section{Appendix A: Method of analysis of stories}

For each of the accounts, we analyze the 'story' around an innovation in the following way. We assess the three aspects of stories as defined by Rosa and Spanjol (2005): complexity, ordinality, and subjectiveevaluative centrality. In addition, we make the appraisal of the various attributes explicit (if evaluated at all). To make appraisal operational, qualitative descriptions seem most appropriate. Quantification may be possible however, on a 'quick and dirty' way. In the case the statement around the attribute contains a subjective evaluation we apply five scales: the (attribute of the) innovation is seen as a large improvement, improvement, comparable, decline or large decline with respect the existing product. The scales are graded with $+2,+1,0,-1$ and -2 . All subjectively evaluated attributes in all accounts (in a year) are examined. The number of times an attribute is mentioned (with that grade) can be taken as a weight factor. For example, if we assume that attributes of an innovation are evaluated 12 times: seven are seen as decline, three as large decline, and two as an improvement. Appraisal can then be quantified to:

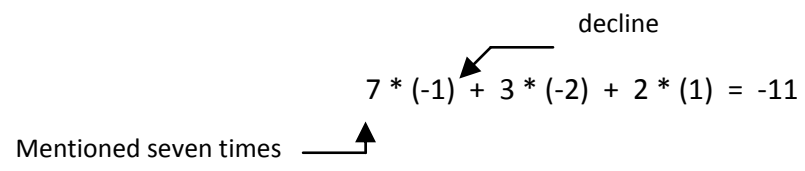

The method is 'dirty' since it doesn't account well for priority of attributes in the user frame. It can well be that a large decline of the range a car is an insurmountable factor for many users. In reality it can then not be compensated with high improvement of the environmental impact (or other attributes), while in the 'quick and dirty' method it can. While this method is therefore certainly not very accurate, it does indicate roughly what the appraisal of the innovation is.

During the analysis, it turned out that a number of types of accounts can be distinguished. Some are based on user experience; others are informative observations of the car engine sector, sometimes with future expectations. Some accounts are part of policy discussions of announcements; others are related to product launches or research announcements of producers. The percentage of accounts that are based on user (i.e. as a driver) and producer experiences is also an important indicator, since it indicates to what extent judgments are based on stories of others, or on actual experiences with the innovation. Therefore it will be taken into account as a fifth aspect of market stories. 


\section{Appendix B: Definition of attributes}

All attributes that are brought up in stories may be grouped in three groups:

- 'True engine attributes': attributes that strictly relate to the electromotor or IC engine, or the combination. These are in bold.

- Vehicle propulsion attributes: attributes relate (directly) to the use of an engine in a vehicle. These are in italics.

- Socio-interface attributes: attributes broadly relate to the use of an engine in a vehicle, for user, producer or society. These are in the regular font style.

\begin{tabular}{|c|c|c|c|}
\hline Attribute & Definition & Ordinal? & Conventional? \\
\hline Engine volume & $\begin{array}{l}\text { Labels remarks on the size of the combustion chamber; } \\
\text { usually indicated with number of liters, e.g. } 2.0 \text { liter }\end{array}$ & Yes & Yes \\
\hline Engine structure & $\begin{array}{l}\text { This is the label for all remarks on valves, turbo's, common } \\
\text { rail, injection systems, combinations of electromotors \& ICE's, } \\
\text { etc. Also remarks on batteries are put under this label }\end{array}$ & $\begin{array}{c}\text { Not } \\
\text { Ordinal }\end{array}$ & Yes \\
\hline Engine capacity & $\begin{array}{l}\text { Label for when amount of pk (horsepowers) or KW is } \\
\text { mentioned }\end{array}$ & Yes & Yes \\
\hline Acceleration & $\begin{array}{l}\text { Labels indication of how fast the vehicle speeds up, either } \\
\text { qualitatively or quantitatively (e.g. } 0 \text { to } 100 \text { time) }\end{array}$ & Yes & Yes \\
\hline Noise level & Relates to the level of noise/sound the engine produces & Yes & Yes \\
\hline Price (of engine) & $\begin{array}{l}\text { This labels remarks on the (purchase) price of the engine, not } \\
\text { the vehicle. This may be both quantitatively or qualitative }\end{array}$ & Yes & Yes \\
\hline $\begin{array}{l}\text { Fuel (or energy) } \\
\text { efficiency }\end{array}$ & $\begin{array}{l}\text { Fuel efficiency or output ('rendement' in Dutch) of a type of } \\
\text { engine (e.g. 'diesel is more fuel efficient than gasoline') }\end{array}$ & Yes & Yes \\
\hline Fuel (or energy) use & Fuel use of a specific vehicle & Yes & Yes \\
\hline $\begin{array}{l}\text { Environmental } \\
\text { impact }\end{array}$ & $\begin{array}{l}\text { Labels general remarks on environmental friendliness, e.g. } \\
\text { 'this engine is better for the environment' }\end{array}$ & Yes & Yes \\
\hline Social connotation & $\begin{array}{l}\text { This is the label for adjectives or adverbs before (or behind or } \\
\text { around) 'engine'; e.g. sportive, modern, revolutionairy, } \\
\text { powerful, super, boring - engine }\end{array}$ & $\begin{array}{c}\text { Not } \\
\text { Ordinal }\end{array}$ & Yes \\
\hline Engine weight & $\begin{array}{l}\text { When the speaker refers to the weight of the engine (not } \\
\text { vehicle) quantitatively (usually kg) or qualitatively }\end{array}$ & Yes & Yes \\
\hline Maximum speed & Maximum or top speed of the vehicle & Yes & Yes \\
\hline Performance & $\begin{array}{l}\text { The label is used when the storyteller uses phrases like 'this } \\
\text { vehicle performs...' }\end{array}$ & Yes & Yes \\
\hline Torque & When speaker explicitly refers to number of $\mathrm{Nm}$ & Yes & Yes \\
\hline Range & $\begin{array}{l}\text { When the maximum number of kilometers (that can be } \\
\text { driven without refuelling) is indicated }\end{array}$ & Yes & Yes \\
\hline Production cost & $\begin{array}{l}\text { Indicates (usually general) remarks on the cost to produce an } \\
\text { engine (not to be confused with 'price') }\end{array}$ & Yes & Yes \\
\hline
\end{tabular}


Appendices

\begin{tabular}{|c|c|c|c|}
\hline Attribute & Definition & Ordinal? & Conventional? \\
\hline Drivability & $\begin{array}{l}\text { Labels remarks on the easiness and comfortability of DRIVING } \\
\text { the vehicle - ONLY as far as the speaker relates this to the } \\
\text { engine (and e.g. not to the transmissions). Not to be confused } \\
\text { with performance. }\end{array}$ & Yes & Yes \\
\hline Tax on engine & $\begin{array}{l}\text { Lables remarks on the tax that needs to be paid, or is } \\
\text { discounted from the price, thus a benefit. May be quantita- } \\
\text { tive. }\end{array}$ & Yes & No \\
\hline Emission level & $\begin{array}{l}\text { When the speaker refers to emission of gases in general, or } \\
\text { to emission level in regulation (Euro 3, } 4 \text { etc.)('this engine } \\
\text { meets euro 5') }\end{array}$ & Yes & Yes \\
\hline SO2 emission & When SO2 emission is explicitly mentioned & Yes & No \\
\hline NO emissions & When NO emission is explicitly mentioned & Yes & No \\
\hline CO2 emissions & When $\mathrm{CO} 2$ emission is explicitly mentioned & Yes & No \\
\hline NOx emissions & When NOx emission is explicitly mentioned & Yes & No \\
\hline Particle emission & When emission of soot or particles is explicitly mentioned & Yes & No \\
\hline HC emissions & When $\mathrm{HC}$ emission is explicitly mentioned & Yes & No \\
\hline $\begin{array}{l}\text { Maintenance level } \\
\text { (necessary) }\end{array}$ & $\begin{array}{l}\text { Labels remarks on the amount of maintenance that is } \\
\text { required when using the engine }\end{array}$ & $\begin{array}{l}\text { Yes, low } \\
\text { precision }\end{array}$ & No \\
\hline Refuel time & Labels remarks on the time it takes to refuel the vehicle & Yes & No \\
\hline Way of refuelling & Labels remarks on how the vehicle needs to be refuelled & $\begin{array}{c}\text { Not } \\
\text { Ordinal }\end{array}$ & No \\
\hline $\begin{array}{l}\text { Engine dimensions } \\
\text { (size) }\end{array}$ & $\begin{array}{l}\text { Labels remarks on the physical dimensions of the engine as a } \\
\text { whole; not to be confused with engine volume (see above) }\end{array}$ & Yes & No \\
\hline Profitability & $\begin{array}{l}\text { Labels remarks on how profitable it is to develop and produce } \\
\text { and sell an engine }\end{array}$ & Yes & Yes \\
\hline Operation cost & $\begin{array}{l}\text { Refers to cost of use of the engine (usually combining fuel } \\
\text { cost with maintenance, and or new batteries) }\end{array}$ & Yes & Yes \\
\hline Number of passengers & $\begin{array}{l}\text { Labels remarks on the number of passengers - ONLY in the } \\
\text { case this is related (by the speaker) to engine volume or size } \\
\text { (e.g. if the amount of batteries on board resulted in less } \\
\text { passenger seats) }\end{array}$ & Yes & No \\
\hline $\begin{array}{l}\text { Re-use of braking } \\
\text { energy }\end{array}$ & $\begin{array}{l}\text { Labels remarks on whether the propulsion systems re-uses } \\
\text { braking energy, to re-load batteries }\end{array}$ & $\begin{array}{l}\text { Yes, } \\
\text { binary }\end{array}$ & No \\
\hline Way of heating & $\begin{array}{l}\text { Labels remarks on the way of heating in the cabin - ONLY if } \\
\text { this is related (by the speaker) to the engine. E.g. 'Since the } \\
\text { engine produces to less heat, an extra electric heater is } \\
\text { necessary in the cabin' }\end{array}$ & $\begin{array}{c}\text { Not } \\
\text { Ordinal }\end{array}$ & No \\
\hline Choice of propulsion & $\begin{array}{l}\text { Labels remarks on how the engine 'chooses' to drive on } \\
\text { electromotor or ICE; the driver may have control on this as } \\
\text { well }\end{array}$ & $\begin{array}{c}\text { Not } \\
\text { Ordinal }\end{array}$ & No \\
\hline
\end{tabular}




\begin{tabular}{|c|c|c|c|}
\hline Attribute & Definition & Ordinal? & Conventional? \\
\hline Automatic start/stop & $\begin{array}{l}\text { Labels remarks on whether the propulsion systems } \\
\text { automaticly stops when vehicle speed is zero }\end{array}$ & $\begin{array}{l}\text { Yes, } \\
\text { binary }\end{array}$ & No \\
\hline Aerodynamic styling & $\begin{array}{l}\text { Labels remarks on aerodynamic styling of the vehicle - ONLY } \\
\text { if this is related to the engine. E.g. to save engine power and } \\
\text { fuel, the vehicle is shaped faily sharp, which will not be } \\
\text { appreciated by many. }\end{array}$ & $\begin{array}{c}\text { Not } \\
\text { Ordinal }\end{array}$ & No \\
\hline Engine visualization & $\begin{array}{l}\text { Labels remarks on visualization of the engine process in the } \\
\text { cabin }\end{array}$ & Yes & No \\
\hline Zero emission range & $\begin{array}{l}\text { Refers to the range (usually in } \mathrm{km} \text { ) that the vehicle runs on } \\
\text { electricty, thus (locally) emission free }\end{array}$ & Yes & No \\
\hline $\begin{array}{l}\text { Product availability } \\
\text { /variety }\end{array}$ & $\begin{array}{l}\text { Labels remarks on the number of models that are available of } \\
\text { the specific innovation, or also remarks on delivery time }\end{array}$ & Yes & No \\
\hline Fuel price & $\begin{array}{l}\text { Marks comments on fuel price, when related to evaluation of } \\
\text { an engine }\end{array}$ & Yes & No \\
\hline Vibration level & $\begin{array}{l}\text { Labels remarks on vibaration level in (parts of) the vehicle, as } \\
\text { a rult of the engine }\end{array}$ & Yes & No \\
\hline Tax certainty & $\begin{array}{l}\text { Marks comments on the possibility that tax levels may soon } \\
\text { or later change }\end{array}$ & Yes & No \\
\hline Parking cost & $\begin{array}{l}\text { Labels remarks on the parking cost (in a city), ONLY when this } \\
\text { differs from the normal level because of the engine type (e.g. } \\
\text { hybrid engines may have free parking in some cities) }\end{array}$ & Yes & No \\
\hline Life time batteries & Remarks on when batteries need replacement & Yes & No \\
\hline $\begin{array}{l}\text { Danger of } \\
\text { electricfication }\end{array}$ & $\begin{array}{l}\text { Marks comments on the danger for emergency services when } \\
\text { assisting vehicles with a certain engine type }\end{array}$ & Yes & No \\
\hline Max trailer weight & $\begin{array}{l}\text { Labels remarks on the maximum trailer weight that a vehicle } \\
\text { with a certain engine can bear }\end{array}$ & Yes & No \\
\hline Turning circle & $\begin{array}{l}\text { Refers to the turning circle of a vehicle ONLY if the is related } \\
\text { (by the speaker) to the type of engine (for example when the } \\
\text { size of the engine caused a large decrease of the turning } \\
\text { circle of a vehicle) }\end{array}$ & Yes & No \\
\hline Refuel locations & The number of places where the engine can be refuelled & Yes & No \\
\hline Dirty whether speed & The maximum speed in case of heavy rain fall & Yes & No \\
\hline Durability & Refers to general remarks on how long a product lasts & Yes & Yes \\
\hline
\end{tabular}




\section{Appendix C: Example of all HEV stories in 1996}

There were 7 newspaper accounts on hybrid-electric vehicle in 1996, and we found the following attributes:

\begin{tabular}{|l|l|l|l|}
\hline Attribute & Precision & Appraisal* & $\begin{array}{l}\text { Total } \\
\text { freq. }\end{array}$ \\
\hline Price & High & Improvement (1) vs. n.e. (1) & 2 \\
\hline Environmental impact & Low & large improvement (1); improvement (5) & 6 \\
\hline Engine structure & Not Ordinal & improvement (1) vs. n.e.(6) & 7 \\
\hline Maximum speed & High & n.e. (2) comparable (1) & 3 \\
\hline Fuel efficiency /use & High & large improvement (1) improvement (1) n.e. (1) & 3 \\
\hline Engine weight & High & n.e.(2) decline (1) & 3 \\
\hline Number of passengers & High & n.e.(2) & 2 \\
\hline Character & Not Ordinal & improvement (1) & 1 \\
\hline Tax & Low & improvement (1) & 1 \\
\hline Way of refueling & $\mathrm{Not} \mathrm{Ordinal}$ & Comparable (1) & 1 \\
\hline Choice of propulsion & $\mathrm{Not}$ ordinal & improvement (1) Comparable (1) & 2 \\
\hline Operation cost & Low & large improvement (1) & 1 \\
\hline Engine volume & $\mathrm{H}(2)$ & n.e. (2) & 2 \\
\hline Engine capacity & $\mathrm{H}(2)$ & n.e. (2) & 2 \\
\hline Durability & L(1) & improvement (1) & 1 \\
\hline Acceleration & $\mathrm{H}(1)$ & n.e. (1) & 1 \\
\hline Range) & $\mathrm{H}(2)$ & n.e. (1) comparable (1) & 2 \\
\hline Torque & $\mathrm{H}(1)$ & decline (1) & 1 \\
\hline Noise & $\mathrm{L}(1)$ & n.e. (1) & 3 \\
\hline
\end{tabular}

* When appraisals are conflicting between accounts, the term 'vs.' is used. When attributes are not evaluated, this is indicated with n.e.

Further analysis reveals:

1 Complexity: 19 attributes

2 Average number of attributes used per account: $42 / 7=6$

3 Ordinality: 4 attributes not ordinal $(15 / 19=79 \%)$

4 Overall appraisal: applying the formula of Appendix $A$ the overall appraisal of the hybrid-electric vehicle in 1996 was: $3 x(+2)+12 x(+1)+2 x(-1)+0 x(-2)=+16$.

5 Subjective-evaluation: in $50 \%$ of the cases that an attribute was mentioned, it was subjectively evaluated.

6 Frequency: it shows that engine structure is the most frequent mentioned attribute: in seven of seven accounts. Environmental impact is second, with six out of seven.

7 User or producer experience: the analysis showed that none of the seven accounts was based on actual user or producer experience. 


\section{Appendix D: Analysis of engine choice}

Customers of new vehicles can choose their preferred type (and size) of engine out of a range of alternatives. For example, as Figure 1 below shows, Ford Focus consumers could choose between four gasoline engines and three diesel engines in 2007 . 3.3\% of them choose for the smallest gasoline, $1400 \mathrm{cc}$, and $81.8 \%$ choose for the smallest diesel, 1600cc. Car salesmen have explained that these consumers typically buy the cheapest engine in the range. We did this same analysis for the $\mathbf{3 0}$ most sold vehicles in the Netherlands. For all these models we found that on average $34.8 \%$ choose for the cheapest and lightest engine in 2007 . The average number significantly differs between brands, models and fuel. Typically, the larger models of the premium brands with gasoline engines have the lowest percentage of this group (e.g. Audi A6, Mercedes Sclass), whereas consumers of smaller vehicles or diesel engines have a higher preference for the cheapest version.
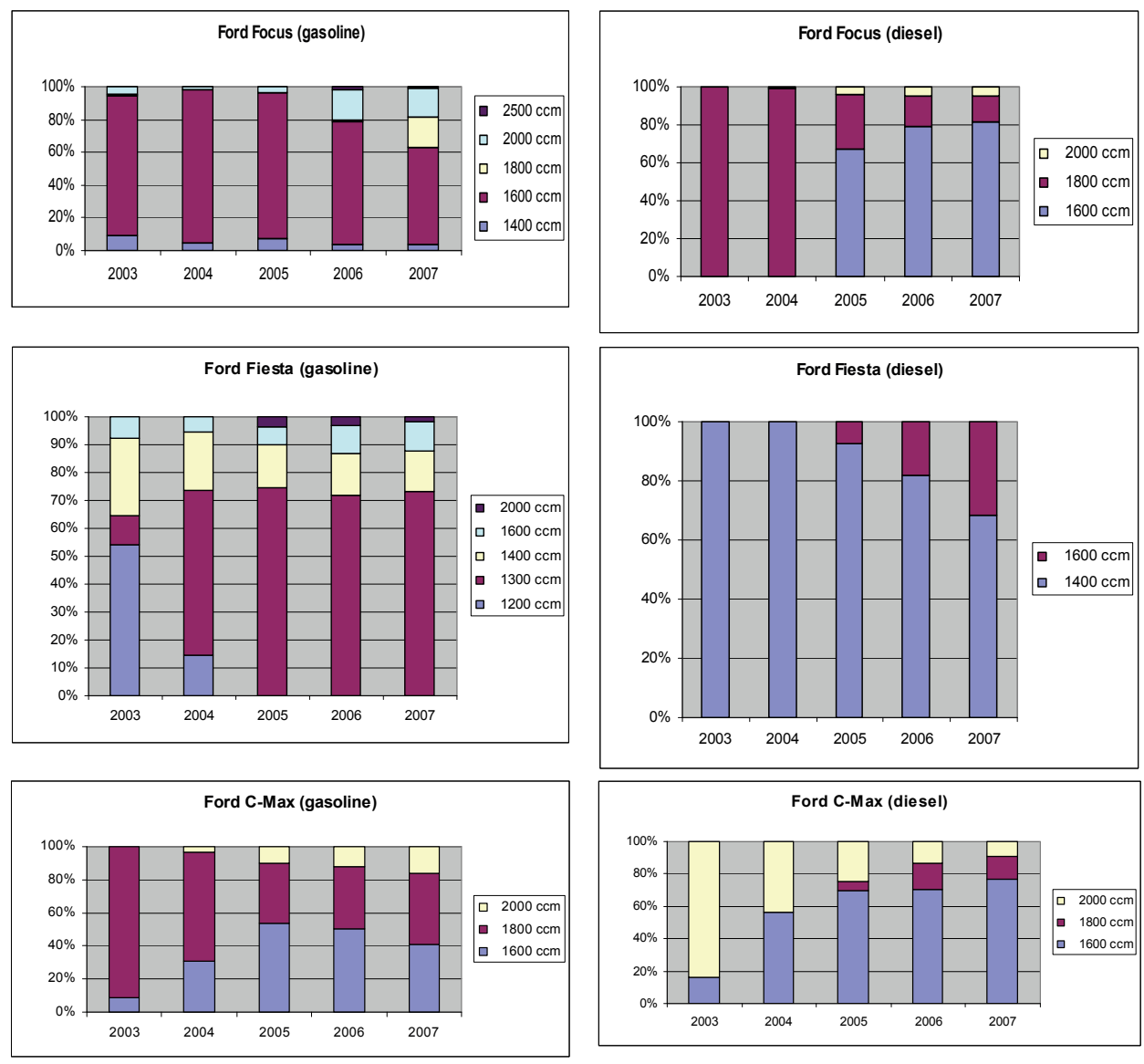

Figure D.1: Sales figures for three Ford models (source: Ford Nederland / RDC). 
Trend of A-segment

In the last few years consumer choices for various car sizes were fairly stable, though there is some tendency towards smaller models (see Table D.1 and Figure D.2 below for trends in the Netherlands). Smallest cars segment $A$ and $B$ increased a few percentages, while $C \& D$ decreased 10 percentage points in eight years. However, segment J/K, medium and large MPVs, increased from 5 to 18 percents. These consumers likely came from segments $C$ and $D$.

Table D.1: Trends in market segments (Examples: $A=$ Fiat Panda, $B=$ Peugeot 206, $C=$ Volkswagen Golf, $D=$ Audi $A 4, E=$ Volvo V70, $\mathrm{J} / K=$ Renault Scenic, Chrysler Voyager)

Trends in sales per market segment NL

\begin{tabular}{lccccc} 
Segments & $\mathbf{1 9 9 8}$ & $\mathbf{2 0 0 0}$ & $\mathbf{2 0 0 2}$ & $\mathbf{2 0 0 4}$ & $\mathbf{2 0 0 6}$ \\
\hline A & 9 & 11 & 10 & 10 & 13 \\
B & 19 & 20 & 22 & 21 & 22 \\
C & 30 & 26 & 23 & 22 & 18 \\
D & 27 & 21 & 20 & 17 & 16 \\
E & 6 & 5 & 13 & 19 & 3 \\
J/K & 5 & 11 & 7 & 7 & 18 \\
Others & 4 & 6 & & & 10 \\
\hline
\end{tabular}

Despite the soft trend to smaller vehicles, average vehicle mass increased with around 10 percent in this period, compensating part of the weight decrease.

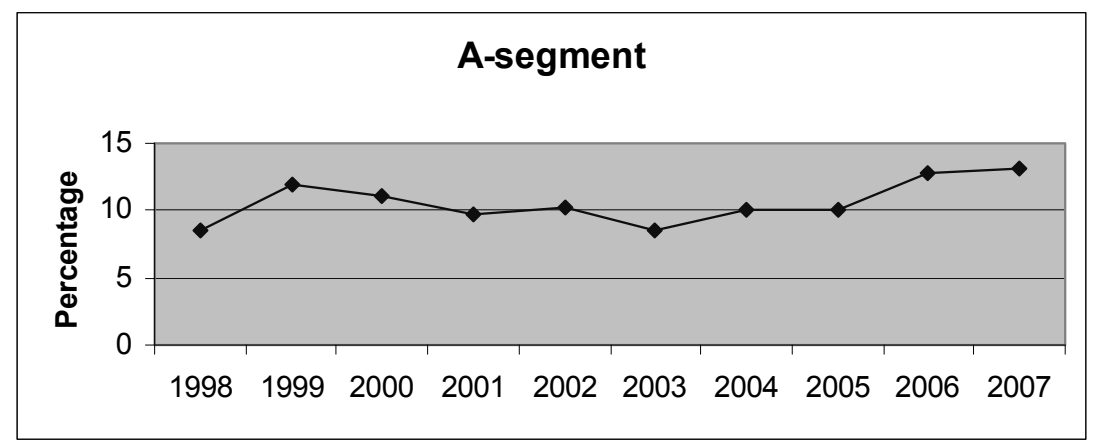

Figure D.2: Trend in size of segment $A$ 


\section{Appendix E: Stakeholder consultation}

This appendix provides the details on the consultation of the stakeholders for both the $P+R$ case and the car engine case. It describes which stakeholders where involved in the interviews and questionnaires, what their role in the organization is, and how they were contacted.

\section{E1: Questionnaire survey respondents (all spring-summer 2005)}

For the Park-and-Ride case (Chapter 7) we contacted city authorities with the request of completing a questionnaire on Park-and-Ride. In most cases we were put through to the traffic and transport department. Sometimes were we advised to contact a specific person that they chose (by email or telephone), and sometimes it was distributed further internally outside our influence. Almost all respondents have indicated their position on the questionnaire form (though not all). In southern Europe and France some people complained about the difficulty of the English language of the questionnaires, and this affected response rates negatively in these areas. In total 45 questionnaires were completed and returned (see Table E1), whereas about 80 were sent out. The questionnaire is printed below in appendix $F$.

Table E1: Respondents for the questionnaire surveys in chapter 5 and 7

\begin{tabular}{|c|c|c|c|}
\hline Case & Organization & Respondent & Position \\
\hline \multirow{7}{*}{$\begin{array}{l}\text { Car engine } \\
\text { (Chap. 5) }\end{array}$} & Renault & Fabien Boudjemaa & Team Leader \\
\hline & Peugeot & Mr. Bruné & Engineer (alternative energies) \\
\hline & Saab & Tommy Lindholm & Project leader (Engineering) \\
\hline & Audi & René van Doorn & chief engineer \\
\hline & Honda & Thomas Brachmann & - \\
\hline & Nissan & Yukimasa Ban & Engineer \\
\hline & Daimler/Chrysler & anonymous & - \\
\hline \multirow{12}{*}{$\begin{array}{l}\mathrm{P}+\mathrm{R} \text { (Chap. } \\
\text { 7) }\end{array}$} & Madrid & Mayte Sánchez & Cabinet Adviser \\
\hline & Luxemburg & Hoffmann Paul & head of staff service de la circulation \\
\hline & Sheffield & David Budd & Transport Planner \\
\hline & Bern & Juerg Staehli & Projektleiter, Verkerhrsplanung Bern \\
\hline & Berlin & Joachim Krey & $\begin{array}{l}\text { head of the group implementation of transport } \\
\text { policy }\end{array}$ \\
\hline & Edinburg & Chris Day & $\begin{array}{l}\text { Professional Officer at City Development, } \\
\text { Transport, Parking Operations }\end{array}$ \\
\hline & Sofia & Mariana Krasteva & head expert \\
\hline & Florence & Anonymous & sent to: Deputy Mayor of Urban Traffic Plan \\
\hline & Belgrade & Zoran Tasic & Assistant in the traffic department \\
\hline & Torino & BIAGIO BURDIZZO & TOP MANAGER - TURIN CITY COUNCIL \\
\hline & Rotterdam & Judith Boelhouwers & Urban planner/ traffic \& transport dep. \\
\hline & Bratislava & Vladimir Mikus & head of dept. for transport planning and traffic control \\
\hline
\end{tabular}




\begin{tabular}{|c|c|c|c|}
\hline Case & Organization & Respondent & Position \\
\hline & Warshau & Stanisław Jedliński & main specialist \\
\hline & Bergen & Rune Herdlevær & Senior Executive Officer \\
\hline & Muncih & Elisabeth Zorn & officer for transport planning \\
\hline & Luzern & Simone Fedderke & project manager in transportation planning \\
\hline & Prague & Jaroslav Mach & Prague City Hall \\
\hline & Helsinki & Tuomas Rajajärvi & Director, City Planning Department \\
\hline & Oxford & Graham Smith & Business Manager for Transport \& Parking \\
\hline & Tallinn & ENO SAAR & head of transport department \\
\hline & Birmingham & CHRIS HAYNES & POLICY MANAGER, TRANSPORTATION \\
\hline & Dortmund & Burckhard Kahrmann & Leader of workgroup "public transport" \\
\hline & Gothenburg & Hans Magnusson & Parking manager \\
\hline & Stuttgart & Ulrich Steimer & Mayor's Office, Department of Engineering \\
\hline & Zurich & christoph suter & transportation engineer; traffic planning division \\
\hline & Vienna & Roman Riedel & \\
\hline & Leeds & Louise Holliday & Transport Planner (Policy) \\
\hline & Gent & Peter de Gra. & Chef Mobiliteit en Transport \\
\hline & Genève & Jean-Yves Go. & Managing director \\
\hline & Bochum & Anonymous & Head department of Traffic \\
\hline & Hamburg & Mr. Franke & Directorate ... \\
\hline & Copenhagen & Brian Hansen & Transport planner \\
\hline & Riga & Anonymous & Traffic and Transport Affairs Committee \\
\hline & The Hague & Jeroen Golstein & Beleidsmedewerker \\
\hline & Eindhoven & Jacques Splin. & Head department of Traffic \\
\hline & Oslo & Knut Galta & engineer \\
\hline & Lodz & Mr. Marek Ci. & Operation manager \\
\hline & Belfast & Tom McCourt & Deputy div. \\
\hline & Glasgow & Patti MacLeo. & Transport ... \\
\hline & Nottingham & Mark Garlick & Senior Public... \\
\hline & Plymouth & Alex Huke & Public Transp. \\
\hline & Southampton & Pete Brunski & Principal transport planning (policy) \\
\hline & Wolverhampton & Lydia Barnst. & Head Transport strategy \\
\hline & London & Simon Williams & Senior Business manager \\
\hline
\end{tabular}


We can be confident that respondents were sufficiently knowledgeable about the city's policies and initiatives on $\mathrm{P}+\mathrm{R}$ for two reasons. First, the city organizations helped in finding an appropriate person to complete the questionnaire after our request for information 'concerning barriers and drivers to the adoption of Park \& Ride facilities in your city' in the cover letter of the questionnaire. Second, from the respondents who indicated their position we find that a majority works at senior level in the traffic and transport department (team leader, head of a group), whereas a minority is junior policy employee.

We assume both these types of respondents to have voiced the vision of their organization. In various statements in the questionnaire we use the phrase 'in our city', and there is no reason to presume that these transport professionals would not be able to indicate the field of influence around $P+R$ in their city, especially since many are at senior level. Nevertheless, the respondent's assessment of various pressures on the city government will be slightly colored by the personal opinion on $\mathrm{P}+\mathrm{R}$ or position in the organization. In our analysis we neglect these personal biases, and assume that the respondent perfectly voiced the view of the city government and the considerations behind current policies. We realize that this is a fairly strong assumption.

As mentioned in chapter 3 we have used an existing questionnaire format that has proved to be valid in an earlier innovation study (Montalvo 2002, 2003). Consequently, we also inherited a jargon that was not always very familiar in our respondent community of transport planners, such as 'market place' and 'organizational capabilities', see question 4 and 8 in the questionnaire. Also, the distinction between 'community pressure' and 'signals from the market place' (question 4 and 5) may have been slightly confusing. In our analysis we have interpreted the 'signals (demand) from the market place' as the 'demand of car motorist for $\mathrm{P}+\mathrm{R}$ ', and 'community pressure' as 'signals from local NGO's or citizens groups'. Our assumption that respondent have unvaryingly understood our questions may be a strong assumption for a few questions, such as the above mentioned cases. In a future version of this questionnaire (as we are doing in a new survey in spring 2010), we have for instance amended 'the market place' into 'car motorists'.

For the car engine case (chapter 5) respondents were contacted at the Electric and Hydrogen Vehicle Symposium (EVS 21) in Monaco in the spring of 2005. At this type of symposiums company engineers present the latest developments of their firm with regard to electric and hydrogen technology. Some people we contacted completed the questionnaires at the spot, some asked to transfer it to a colleague and return it later. A number of requests were later rejected by email, referring to the confidential nature of the information. Seven questionnaires were returned completed (see Table E1). Not all respondents have indicated their position in the organization, but the majority is, as observed in Table E1, at senior engineering level. Therefore, we can be confident that respondents were sufficiently knowledgeable about the firm's strategy on hydrogen. (The questionnaire is printed below in Appendix. F.)

We assume these people to have voiced the vision of their organization. Regarding the seniority of most respondents and the way we have asked the question ('for your organization') this is plausible. Nevertheless, the response may be slightly biased for two reasons. Apart from the personal bias (as in the case of $P+R$ ), there may be strategic PR considerations involved. At this point it is very difficult to assess to what extent this has played a role for the respondents. The way we validated the questionnaire survey was by interpreting the data in the light of (a few) stakeholder interviews that had been performed beforehand (see section 5.3 and section E2 of this Appendix). Therefore we can be fairly confident about the responses to the survey questions.

\section{E2: Stakeholder interviews}

For the Park-and-Ride case (chapter 7 and 8) we contacted city authorities with the request of doing an interview on Park-and-Ride in their city. In most cases we were put through to the traffic and transport department, and the secretary of the department typically asked her head to whom the questionnaire would be sent. In most cases the choice fell on a senior employee. It was fairly easy to plan a meeting with a senior policy officer in the traffic and transport department who was willing to elaborate on the city transport policy. We applied a semi-structured interview format; see section E3 in this appendix.

For the car engine case (chapter 5) we applied a similar strategy and contacted a few car firms in Germany and France with the request of doing an interview on hybrid and hydrogen car technology. We were typically 
put through to senior engineers, and it was often hard to actually get a reply of the particular person and, when prepared to an interview, to make an appointment in their busy calendars. Some people who were contacted did not want to participate in an interview (e.g. Volkswagen), typically because of strategic sensitivity of the information. Nevertheless, the three interviewees were fairly open about the conflict of interest between their business and environmental concerns. Also, their level of seniority suggests that we can be confident that respondents were sufficiently knowledgeable about the firm's strategy on hydrogen. We applied a semi-structured interview format; see section E4 in this appendix. This interview format gave the opportunity to continue to ask for elaboration and examples, and confront the interviewee with other information (e.g. data on market trends or patent information). Therefore, we find this interview method to be slightly less vulnerable for personal bias of the interviewee and strategic or PR considerations of the organization in comparison to the questionnaire survey, and the responses were very useful for interpreting the survey outcomes in chapter 5.

For chapter 4 we interviewed car salesmen at car dealer of three different brands (Peugeot, Audi, and Opel). In these interviews we provided them with the data of national sales figures of different engine types (20032007, see Appendix D), and we asked them whether they could explain why consumers choose for the various types of engines.

Table E2: Respondents for our interview surveys in chapter 4, 5, 7 and 8

\begin{tabular}{|c|c|c|c|c|}
\hline Case & Organization & Interviewee & Position & Date \\
\hline \multirow{7}{*}{$\begin{array}{l}\text { Car } \\
\text { engine } \\
\text { (Chap. } 5 \\
\text { and 4) }\end{array}$} & $\begin{array}{l}\text { Peugeot-Citroen } \\
\text { (Parijs) }\end{array}$ & Dénis Depuis & $\begin{array}{l}\text { senior research } \\
\text { engineer }\end{array}$ & Summer 2004 \\
\hline & $\begin{array}{l}\text { Audi } \\
\text { (Ingolstadt) }\end{array}$ & Ingrid Paulus & $\begin{array}{l}\text { head of transport \& } \\
\text { environment }\end{array}$ & Summer 2004 \\
\hline & $\begin{array}{l}\text { DAF Trucks } \\
\text { (Eindhoven) }\end{array}$ & Peter van der Heijden & manager performance & Summer 2004 \\
\hline & $\begin{array}{l}\text { Peugeot-dealer } \\
\text { (Maastricht) }\end{array}$ & Mr. Van der Cluijs & Salesman & $\begin{array}{l}\text { Spring } 2005 \text {, } \\
\text { Spring } 2009\end{array}$ \\
\hline & $\begin{array}{l}\text { Opel-dealer } \\
\text { (Maastricht) }\end{array}$ & Frank Geurts & Salesman & $\begin{array}{l}\text { Spring } 2005 \text {, } \\
\text { Spring } 2009\end{array}$ \\
\hline & $\begin{array}{l}\text { Audi-dealer } \\
\text { (Maastricht) }\end{array}$ & Jean Lucassen & Salesman & $\begin{array}{l}\text { Spring 2005, } \\
\text { Spring } 2009\end{array}$ \\
\hline & $\begin{array}{l}\text { Ford Nederland bv. } \\
\text { (Amsterdam) }\end{array}$ & Roland Roordink & $\begin{array}{l}\text { Sales \& Marketing } \\
\text { department }\end{array}$ & Spring 2009 \\
\hline \multirow{7}{*}{$\begin{array}{l}\text { P+R } \\
\text { (Chap. } 7 \\
\text { and 8) }\end{array}$} & \multirow{2}{*}{$\begin{array}{l}\text { Amsterdam City } \\
\text { Government }\end{array}$} & Rick Batelaan & Senior policy advisor & Spring 2008 \\
\hline & & Frans Heijnis & Policy Advisor Traffic & Spring 2007 \\
\hline & \multirow{2}{*}{$\begin{array}{l}\text { Rotterdam City Govern- } \\
\text { ment }\end{array}$} & Judith Boelhouwers & Policy advisor $\mathrm{P}+\mathrm{R}$ & \multirow{2}{*}{$\begin{array}{l}\text { Spring } 2007 \\
\text { Spring } 2008\end{array}$} \\
\hline & & Eric Arnold & Policy advisor $\mathrm{P}+\mathrm{R}$ & \\
\hline & \multirow[t]{2}{*}{ Utrecht City Government } & Niek Tijhuis & $\begin{array}{l}\text { Head of Traffic } \\
\text { department (including } \\
P+R \text { ) }\end{array}$ & Spring 2007 \\
\hline & & Harry Servaas & Policy advisor & Spring 2008 \\
\hline & $\begin{array}{l}\text { Maastricht City govern- } \\
\text { ment }\end{array}$ & John Aarts & $\begin{array}{l}\text { city alderman for } \\
\text { transport }\end{array}$ & Summer 2004 \\
\hline
\end{tabular}




\section{E3 Format for interview at city government $(P+R)$}

Focus: $P+R$ \& parking policy in the periods that $P+R$ was introduced (mainly between 1995 \& 2005) Tone: we try to understand how things have been going, not to value whether the right choices have been made.

A. What has been your city government's policy regarding $P+R$, after the middle of the 1990s?

- If necessary continue to ask about the relation with general parking policy, congestion, public transportation policy, air quality concerns.

- If necessary continue to ask about: (1) policy aim / strategy, and (2) policy initiatives

B. Were there within the city government (and or within the city council) conflicting insights / opinions towards $\mathrm{P}+\mathrm{R}$ and parking policy in general? If yes, which?

C. How did the city government acquire information or (expert) knowledge around the introduction and development of $\mathrm{P}+\mathrm{R}$ ? (If necessary, continue to ask about contacts with other cities, platforms etc.)

D. What were outcomes of the actual policies (around $\mathrm{P}+\mathrm{R}$ ) in your city?

E. Has there been a change in traveller patterns (especially travels towards and from the city centre) in the period that $P+R$ was introduced? Do the changes relate to the introduction of $P+R$ ?

\section{E4 Format for interview at car (or truck) manufacturer}

A (Attitude)

- What do you see as the advantages/gains/benefits of your (company's) engagement in the adoption (or development) of < hydrogen vehicles $>$ ?

- What do you see as the disadvantages/drawbacks of your (company's) engagement in the adoption (or development) of < hydrogen vehicles >

- If necessary: Is there anything else, either positive or negative, that you associate with in the adoption (or development) of < hydrogen vehicles $>$ for your company?

- What could be the effect on the environment derived from the adoption?

B (Social pressures)

- $\quad$ Are there any people, organisations or institutions who you think want/push you / your company to engage in the adoption (or development) of $<<$ hydrogen vehicles $>>$ ?

- $\quad$ Are there any people or institutions that you think oppose that your company adopt (or develop) $<$ hydrogen vehicles $>$ ?

- Does anybody else come to mind when you think about your company adopting (or developing) $<<$ hydrogen vehicles $>>$ ?

- Do you have any examples of policy instrument or measures put in place to encourage adoption or development of $<<$ hydrogen vehicles $>>$ ?

- If necessary: Do you have any examples of barriers/difficulties made by people/institutions to the development/uptake of $<<$ hydrogen vehicles $>>$ ? 
C (Control of innovation)

- What kind of skills or abilities do you think you /your company needs to adopt (or develop) $<<$ hydrogen vehicles $>>$ ?

- If necessary ask further about:

- What experience, information, additional resources in terms of time/money, do you think your company needs to engage < hydrogen vehicles $>$ ?

- $\quad$ Are there any particular circumstances/opportunities you think your company relies on for developing hydrogen vehicles?

- $\quad$ Are there any constraints you think are stopping your company from developing hydrogen vehicles? 


\title{
Appendix F: Questionnaires
}

\author{
F1 Questionnaire 'Park and Ride facilities in the City 49
}

\section{Section I: General information}

City's name:

European Member State within which you are based:

Respondent name:

Position:

Date:

The size of your city population is: <500k $\square \quad 500 \mathrm{k}-1 \mathrm{M} \square \quad \square 1 \mathrm{M} \square \quad$ >2M

Section 2: P+R information

1. To what extent is your city presently engaged in developing $\mathrm{P}+\mathrm{R}$ facilities?

2. To what extent does your city have existing plans to develop $P+R$ facilities?

3. Regarding the environmental effects generated by the usage of our cars in the city centre, the relevance of $P+R$ is:

4. In general it can be said that the signals (demand) that we perceive from the market place (for example: citizens, suppliers and other cities) tell us that we should develop and offer $\mathrm{P}+\mathrm{R}$ facilities are:

5. In general, the pressure from the community (local NGO's, mass-media, shops \& businesses, etc.) that this city faces to develop and offer $\mathrm{P}+\mathrm{R}$ facilities are:

6. There are several regulatory institutions (e.g. the EU and national authorities) pushing us to develop and offer $\mathrm{P}+\mathrm{R}$ facilities.

\footnotetext{
${ }^{49}$ The original questionnaire was much longer and was part a European FP6 project. We have left out many detailed questions that were not included in our analysis.
} 


\begin{tabular}{|c|c|c|}
\hline & $\begin{array}{l}\text { We find that the level of state of the art knowledge } \\
\text { available in the marketplace for our city to engage in the } \\
\text { development and implementation of } P+R \text { facilities is: }\end{array}$ & At the moment \\
\hline 8. & $\begin{array}{l}\text { Our city government has the necessary organizational } \\
\text { capabilities to reshape our organizational structures to } \\
\text { develop and implement } P+R \text { facilities in our city. }\end{array}$ & At the moment \\
\hline 9. & $\begin{array}{l}\text { Our city finds the performance of strategic alliances (with } \\
\text { companies, organisations or other cities) to develop } P+R \\
\text { facilities: }\end{array}$ & At the moment \\
\hline 10. & $\begin{array}{l}\text { Establishing networks of collaboration to acquire know- } \\
\text { how to develop and implement } P+R \text { facilities for our city } \\
\text { is: }\end{array}$ & At the moment \\
\hline 11. & $\begin{array}{l}\text { For our city the venture of development of } P+R \text { facilities } \\
\text { would imply economically }\end{array}$ & At the moment \\
\hline 12. & $\begin{array}{l}\text { 'Increasing the prices to park' is one of the measures of } \\
\text { my city to decrease car-use in our city-centre: }\end{array}$ & \\
\hline 13. & $\begin{array}{l}\text { Current parking price in the centre for } 1 \text { hour is: } \\
\qquad<2 \text { euro } \square<2.51 \text { euro } \square<3.1 \text { euro } \square>3 .\end{array}$ & \\
\hline 14. & $\begin{array}{l}P+R \text { facilities are one of the measures my city imple- } \\
\text { ments to decrease car-use in our city-centre. }\end{array}$ & \\
\hline 15. & $\begin{array}{l}\text { 'Expanding parking capacity in the city centre' is one of } \\
\text { the measures of my city to solve parking problems: }\end{array}$ & \\
\hline 16. & $\begin{array}{l}\text { 'Expanding capacity of the roads to the centre' is one of } \\
\text { the measures of my city to solve congestion. }\end{array}$ & \\
\hline 17. & $\begin{array}{l}\text { 'Decreasing the number of vehicles in our centre' is } \\
\text { chosen as a policy aim to increase the quality of the city } \\
\text { centre environment: }\end{array}$ & \\
\hline 18. & $\begin{array}{l}\text { The effectiveness of 'limiting or decreasing places to park } \\
\text { in the city centre' as a measure to decrease car-use in } \\
\text { our city-centre is. }\end{array}$ & \\
\hline 19. & $\begin{array}{l}\text { 'Increasing the prices to park' would be a good measure } \\
\text { my city could implement to decrease car-use in our city- } \\
\text { centre }\end{array}$ & \\
\hline 20. & $\begin{array}{l}\text { P\&R-facilities would be a good measure of my city to } \\
\text { decrease car-use in our city-center. }\end{array}$ & \\
\hline 21. & $\begin{array}{l}\text { I believe that other available technologies / practices are } \\
\text { more effective. (to increase environmental quality of the } \\
\text { city centre): } \\
\text { a. ...namely: }\end{array}$ & \\
\hline
\end{tabular}

This concludes the survey. Thank you for your time. 


\section{F2 : Questionnaire 'Hydrogen fuel cell car's0}

\section{Section I: General information}

Organisation's name:

European Member State within which you are based:

Respondent name:

Position:

Date:

\section{Section 2: Hydrogen car information}

\begin{tabular}{|l|l|}
\hline 1. $\begin{array}{l}\text { To what extent is your firm presently engaged in develop- } \\
\text { ing a fuel cell car? }\end{array}$ & \\
\hline 2. $\quad \begin{array}{l}\text { To what extent does your firm have existing plans to } \\
\text { develop a fuel cell car? }\end{array}$ & At the moment \\
\hline 3. $\quad \begin{array}{l}\text { The environmental effects generated by the usage of our } \\
\text { current cars models are likely to be: }\end{array}$ & At the moment \\
\hline 4. $\begin{array}{l}\text { In general it can be said that the signals (demand) that we } \\
\text { perceive from the market place (for example customers, } \\
\text { suppliers and competitors) tell us that we should develop } \\
\text { and sell a fuel cell car are: }\end{array}$ & At the moment \\
\hline $\begin{array}{l}\text { In general, the pressure from the community (local and } \\
\text { global NGO's, mass-media, unions, etc.) that this firm } \\
\text { faces to develop and sell a fuel cell car is : }\end{array}$ & At the moment \\
\hline There are several regulatory institutions (e.g. the EU and \\
national authorities) pushing us to develop and sell a fuel \\
cell car.
\end{tabular}

${ }^{50}$ The original questionnaire was much longer and was part a European FP6 project. We have left out many detailed questions that were not included in our analysis. 


\begin{tabular}{|c|c|c|}
\hline 9. & $\begin{array}{l}\text { Our firm finds the performance of strategic alliances (with } \\
\text { suppliers, customers or competitors) to develop a fuel cell } \\
\text { car: }\end{array}$ & At the moment \\
\hline 10. & $\begin{array}{l}\text { Establishing networks of collaboration to acquire know- } \\
\text { how to develop a fuel cell car for our firm is: }\end{array}$ & At the moment \\
\hline 11. & $\begin{array}{l}\text { For our firm the venture of development of a fuel cell car } \\
\text { seems to imply economically }\end{array}$ & At the moment \\
\hline 12. & $\begin{array}{l}\text { After evaluating the outcomes, pressures and capabilities } \\
\text { to develop a fuel cell car what is the likelihood that your } \\
\text { city engages in the development of this new product? }\end{array}$ & $\begin{array}{l}\text { At the moment } \\
\text { In the next } 5 \text { to } 10\end{array}$ \\
\hline
\end{tabular}

This concludes the survey. Thank you for your time. 


\section{Appendix G: Diffusion of VVT and DI after 1990}

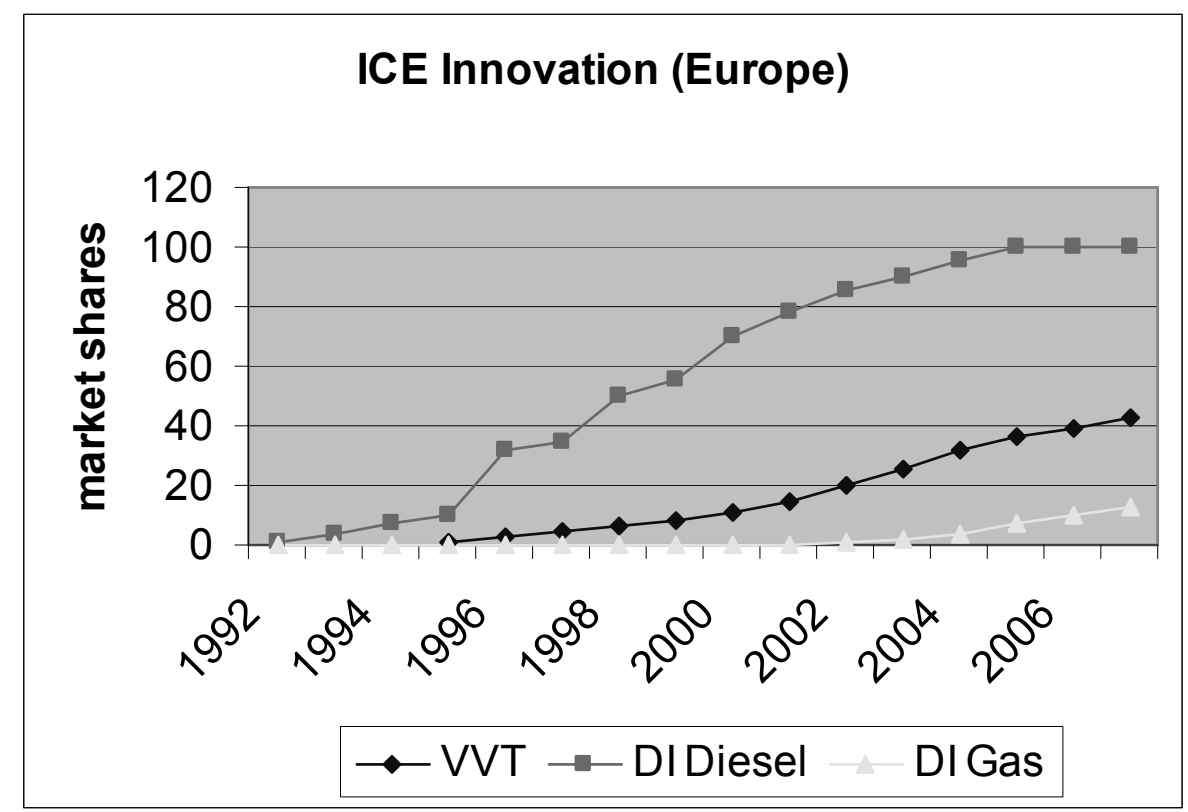

Source: own calculations, based on data provided by Bosch and Delphi 


\section{Appendix H: Individual firm strategic activities}

\begin{tabular}{|c|c|c|c|}
\hline Honda & $\begin{array}{l}\text { R\&D focus on gasoline. Pioneer in } \\
\text { variable valve timing (VTEC). First } \\
\text { launch in } 1989 \text { Honda Civic } \\
\text { (Europe), gradually appeared in } \\
\text { other vehicles (CRx, 1990; Accord \& } \\
\text { Civic mid-90s. New generation of } \\
\text { VVT around 2000. In } 1999 \text { concept } \\
\text { of VVT combined with (gasoline) } \\
\text { direct injection. } \\
\text { Diesel DI first borrowed from Rover } \\
\text { (1995), by } 2004 \text { first own launch: I- } \\
\text { CDTI. Second generation diesel (in } \\
\text { 2008) combines DI with VVT: i-DTEC }\end{array}$ & $\begin{array}{l}\text { Launched Honda EV } \\
\text { plus by } 1996 \text {. Sold } \\
\text { around hundred } \\
\text { annually. } \\
\text { Shift of focus away } \\
\text { from BEV in } 1996 \\
\text { (after relaxation of } \\
\text { ZEV), towards HEV } \\
\text { and fuel cells. }\end{array}$ & $\begin{array}{l}\text { Followed Toyota with launch } \\
\text { of Honda Insight in } 1998 . \\
\text { Honda has had three hybrid } \\
\text { models now (Accord, Civic, } \\
\text { Insight), though sales } \\
\text { numbers are } 50-80 \% \text { lower } \\
\text { than Toyota. }\end{array}$ \\
\hline $\begin{array}{l}\text { Daimler- } \\
\text { Chrysler }\end{array}$ & $\begin{array}{l}\text { VVT launched on various production } \\
\text { vehicles (1990, 1993, 1999). After } \\
1997 \text { focus on common rail DI, first } \\
\text { launch in 1998. Common rail (CDI) } \\
\text { soon became standard for diesels. }\end{array}$ & $\begin{array}{l}\text { Launch of the Chrysler } \\
\text { EPIC in } 1997 . \text { Sold only } \\
\text { a few hundred yearly } \\
\text { up to } 1999 . \\
\text { After relaxation of ZEV } \\
\text { mandate (1996) } \\
\text { research focus shift } \\
\text { towards fuel cell } \\
\text { technology }\end{array}$ & $\begin{array}{l}\text { Until } 2004 \text { skeptical about } \\
\text { hybrids. In } 2006 \text { research } \\
\text { collaboration was } \\
\text { established with GM and } \\
\text { BMW. Chrysler will follow } \\
\text { the launch of GM SUV with } \\
\text { launch of Dodge Durango by } \\
\text { 2008. Mercedes has shown } \\
\text { prototypes of S-class hybrid } \\
\text { (already in 2005). Launch } \\
\text { data? }\end{array}$ \\
\hline Ford & $\begin{array}{l}\text { Slow follower of engine innovation. } \\
\text { First launch of VVT (called variable } \\
\text { cam timing) by } 1998 \text { (Ford Sigma). } \\
\text { Bought diesel TDCi from PSA in } \\
\text { 2002. Soon applied for all diesel } \\
\text { models. }\end{array}$ & $\begin{array}{l}\text { Ford launched the } \\
\text { Ranger in 1998, and } \\
\text { sold a few hundred } \\
\text { vehicles annually. } \\
\text { After relaxation of ZEV } \\
\text { mandate (1996) } \\
\text { research focus shift } \\
\text { already towards fuel } \\
\text { cell technology. }\end{array}$ & $\begin{array}{l}\text { Until } 2004 \text { skeptical about } \\
\text { hybrids. Groups-member } \\
\text { Volvo experimented with } \\
\text { hybrid (Desiree concept in } \\
\text { 1999) This knowledge was } \\
\text { later used in Ford Escape } \\
\text { (launch in 2004). Sales are } \\
\text { under targets. }\end{array}$ \\
\hline Fiat & $\begin{array}{l}\text { Launch of VVT system was early (in } \\
\text { Twin Spark engine 1980s), applied in } \\
\text { Alfa Romeo models. Later only in } \\
\text { some sporty version of Fiat. } \\
\text { Launch gasoline DI in } 2000 \text { (in Alpha } \\
\text { Romeo, dubbed JTS), soon became } \\
\text { standard. } \\
\text { Co-pioneered (with VW) on diesel DI } \\
\text { systems: first launch in } 1987 \\
\text { (Croma). Pioneering launch of } \\
\text { common-rail in } 1997 \text { (Alfa 156). By } \\
2002 \text { all diesels had Di/common rail } \\
\text { (called JDI). }\end{array}$ & $\begin{array}{l}\text { Experimented with } \\
\text { Panda electric already } \\
\text { in } 1992 . \text { Sales were } \\
\text { very low. In } 1998 \text { Fiat } \\
\text { tried again and } \\
\text { launched the Seicento } \\
\text { Electra. There were } \\
\text { only } 294 \text { produced, } \\
\text { unto 2002, when the } \\
\text { production stopped. }\end{array}$ & $\begin{array}{l}\text { Presented batch of Multipla } \\
\text { hybrid in } 2000 \text {. No launch, } \\
\text { due to low expected sales. } \\
\text { Reluctant on business } \\
\text { opportunities for current } \\
\text { launch. }\end{array}$ \\
\hline PSA & $\begin{array}{l}\text { Launch of VVT only in } 2005 \text { (called } \\
\text { CVVT: Continuous-VVT. Launched }\end{array}$ & $\begin{array}{l}\text { Was initially serious } \\
\text { about EVs: by } 1993\end{array}$ & $\begin{array}{l}\text { PSA is skeptical about full } \\
\text { hybrids. Only prototype of }\end{array}$ \\
\hline
\end{tabular}




\begin{tabular}{|c|c|c|c|}
\hline & $\begin{array}{l}\text { gasoline DI engine in } 1999 \text { (under } \\
\text { license of Mitsubishi). Succeeded by } \\
\text { in- house developed HPi engine in } \\
2000 \text { (for 406/C5). } \\
\text { Launched DI diesel in } 1998 \text { (for 406), } \\
\text { called HDi. Soon adopted in more } \\
\text { diesels; by } 2002 \text { all diesels were } \\
\text { HDi. }\end{array}$ & $\begin{array}{l}\text { Peugeot aimed at } \\
\text { producing } 50.000(!) \\
\text { electrics in } 1998 . \\
\text { Several versions were } \\
\text { launched. Disap- } \\
\text { pointments followed } \\
\text { when sales were only } \\
\text { around } 2.000 \text { annually } \\
\text { (even though these } \\
\text { were highest in the } \\
\text { sector). }\end{array}$ & $\begin{array}{l}\text { Citroen Berlingo. Launch of } \\
\text { mild hybrid: Citroen C } 3 \text { with } \\
\text { start \& stop since } 2005 \text {. }\end{array}$ \\
\hline VW-Audi & $\begin{array}{l}\text { Pioneered with diesel direct } \\
\text { injection in } 1989 \text { (Audi } 100 \text { TDI). } \\
\text { Gradually adopted in more engines; } \\
\text { by } 1996 \text { all diesel had DI. } \\
\text { VVT launched on various (gasoline) } \\
\text { production vehicles, 1996, } 1999 . \\
\text { Pioneer in DI for gasoline engines in } \\
2000 \text { (Lupo), which they dubbed FSI. } \\
\text { Gradually available for all model } \\
\text { classes (A4 2001, Golf 2002, etc.). }\end{array}$ & $\begin{array}{l}\text { Launch of VW } \\
\text { CityStromer in } 1995 . \\
\text { Only } 150 \text { vehicles } \\
\text { were sold. }\end{array}$ & $\begin{array}{l}\text { Pioneered with Audi-duo in } \\
1997 \text { (plug-in HEV). Sold only } \\
60 \text { vehicles. Disappoint- } \\
\text { ments created skepticism on } \\
\text { market potential of hybrids. } \\
\text { After } 2005 \text { R\&D increased } \\
\text { (with Posche) and hybrid } \\
\text { versions of VW Touareg, } \\
\text { Audi Q7 and Posche Cayenne } \\
\text { are studied, but no launch } \\
\text { data announced. }\end{array}$ \\
\hline Nissan & $\begin{array}{l}\text { Production launch of VVT (known as } \\
\text { VVL) in } 1997 \text { (Primera and others). } \\
\text { Second generation in } 2001 .\end{array}$ & $\begin{array}{l}\text { Nissan launched the } \\
\text { electric Altra by } 1998, \\
\text { but only sold around } \\
50 \text { vehicles annually. }\end{array}$ & $\begin{array}{l}\text { Nissan announced an Altima } \\
\text { hybrid for } 2007 \text {, with } \\
\text { technology bought from } \\
\text { Toyota. With in-house } \\
\text { technology launch } \\
\text { announced for } 2010 \text {. }\end{array}$ \\
\hline Renault & $\begin{array}{l}\text { Adopted DI on some diesels in } 1998 \\
\text { (from Bosch), dubbed dTi or dCi. By } \\
2002 \text { all diesels had DI. } \\
\text { Pioneered with DI on gasoline in } \\
1999 \text { (Megane coupe, later Laguna). } \\
\text { Not widely adopted yet. } \\
\text { Adopted VVT in } 1999 \text { in one model. }\end{array}$ & $\begin{array}{l}\text { Was initially serious } \\
\text { about EVs: Renault } \\
\text { planned in } 1993 \text { to } \\
\text { produce } 4000 \text { electrics } \\
\text { in } 1995 \text {. Disappoint- } \\
\text { ment when actual } \\
\text { sales of Clio and } \\
\text { Express were only a } \\
\text { few hundred annually. }\end{array}$ & $\begin{array}{l}\text { Renault is still skeptical } \\
\text { about full hybrids, and has } \\
\text { not announced any } \\
\text { launches. }\end{array}$ \\
\hline Mitsubishi & $\begin{array}{l}\text { Pioneered with direct injection in } \\
\text { gasoline market in } 1997 \text { (Charisma). } \\
\text { Adopted VVT in some by } 1992 \text { and } \\
1994 .\end{array}$ & & \\
\hline
\end{tabular}




\section{Appendix I: Statistical Details}

This appendix provides the details of the statical analysis in chapter 7. Table J.1 present a summary of the various model combination we found through a backward regressiosn procedure with dependent variable i2 (current behavior). The model numbers refer to the following combinations of predictors (see chapter 3 for definitions):

1. Model 1: Strategic alliances (al), Market pressure (mp), Economic risk (er), Environmental relevance (evr2), Regulatory pressure (rp), Technological capability (tc1), Networks of collaboration (nk), I Learning capability (I), Community pressure (cp)

2. Model 2: $\mathrm{mp}$, er, evr2, rp, tc1, $\mathrm{nk}, \mathrm{l}, \mathrm{cp}$

3. Model 3: mp, er, evr2, tc1, nk, l, cp

4. Model 4: $\mathrm{mp}, \mathrm{er}, \mathrm{evr} 2, \mathrm{tc} 1, \mathrm{l}, \mathrm{cp}$

5. Model 5: $\mathrm{mp}, \mathrm{er}, \mathrm{evr} 2, \mathrm{l}, \mathrm{cp}$

6. Model 6: $\mathrm{mp}, \mathrm{er}$, evr2, I

7. Model 7: $\mathrm{mp}, \mathrm{er}, \mathrm{I}$

Table J1: Model summary

\begin{tabular}{|l|c|c|c|c|c|c|}
\hline Model & $\begin{array}{c}\text { Number of } \\
\text { (indep.) } \\
\text { variables }\end{array}$ & $\mathrm{R}$ & R Square & $\begin{array}{c}\text { Adjusted R } \\
\text { Square }\end{array}$ & $\begin{array}{c}\text { Std. Error of } \\
\text { the Estimate }\end{array}$ & $\begin{array}{c}\text { Significance } \\
(\mathrm{p}<0.01)\end{array}$ \\
\hline 1 & 9 & 0.644 & 0.415 & 0.227 & 0.895 & 0.053 \\
2 & 8 & 0.644 & 0.415 & 0.254 & 0.879 & 0.030 \\
3 & 7 & 0.643 & 0.414 & 0.277 & 0.865 & 0.016 \\
5 & 6 & 0.637 & 0.406 & 0.291 & 0.857 & 0.009 \\
6 & 5 & 0.630 & 0.397 & 0.303 & 0.849 & 0.005 \\
7 & 4 & 0.626 & 0.392 & 0.318 & 0.840 & 0.002 \\
\hline
\end{tabular}

Table J.2 provides correlation between the predicators for model 7.

Table J2: Correlations for model 7

\begin{tabular}{|ll|c|c|c|}
\hline & & $\begin{array}{c}\text { mp Market } \\
\text { pressure }\end{array}$ & $\begin{array}{c}\text { I Learning } \\
\text { capability }\end{array}$ & $\begin{array}{c}\text { er Economic } \\
\text { risk }\end{array}$ \\
\hline mp Market pressure & Pearson Correlation & 1 & .148 & -.128 \\
& Sig. (2-tailed) & & .374 & .430 \\
& $\mathrm{~N}$ & 40 & 38 & 40 \\
I Learning capability & Pearson Correlation & .148 & 1 & .084 \\
& Sig. (2-tailed) & .374 & & .607 \\
& $\mathrm{~N}$ & 38 & 40 & 40 \\
er Economic risk & Pearson Correlation & -.128 & .084 & 1 \\
& Sig. (2-tailed) & .430 & .607 & \\
& $\mathrm{~N}$ & 40 & 40 & 43 \\
\hline
\end{tabular}

Table J.3 provides details of the coefficients of the various models. 
Table J3: Linear regression coefficients for dependent variable i2 (current behavior)

\begin{tabular}{|c|c|c|c|c|c|c|}
\hline \multicolumn{2}{|r|}{ Model } & \multicolumn{2}{|c|}{$\begin{array}{l}\text { Unstandardized } \\
\text { Coefficients }\end{array}$} & \multirow{2}{*}{$\begin{array}{c}\text { Standardized } \\
\text { Coefficients } \\
\text { Beta } \\
\end{array}$} & \multirow{2}{*}{$\begin{array}{l}\mathbf{t} \\
\mathrm{B}\end{array}$} & \multirow{2}{*}{$\begin{array}{l}\text { Sig. } \\
\text { Std. } \\
\text { Error }\end{array}$} \\
\hline & & B & $\begin{array}{l}\text { Std. } \\
\text { Error }\end{array}$ & & & \\
\hline \multirow[t]{10}{*}{1} & (Constant) & .712 & 1.037 & & .687 & .498 \\
\hline & evr2 Environment. Relevance & -.082 & .115 & -.112 & -.711 & .483 \\
\hline & mp Market pressure & .207 & .123 & .303 & 1.689 & .102 \\
\hline & $\mathrm{cp}$ Community pressure & .082 & .151 & .115 & .542 & .592 \\
\hline & rp Regulatory pressure & .026 & .121 & .043 & .219 & .828 \\
\hline & tc1 Technological capability & .130 & .156 & .165 & .836 & .410 \\
\hline & I Learning capability & .223 & .150 & .310 & 1.484 & .149 \\
\hline & nk Networks of collaboration & -.096 & .174 & -.101 & -.554 & .584 \\
\hline & er Economic risk & .238 & .105 & .342 & 2.277 & .031 \\
\hline & al Strategic alliances & -.009 & .133 & -.014 & -.069 & .946 \\
\hline \multirow[t]{9}{*}{2} & (Constant) & .715 & 1.019 & & .701 & .489 \\
\hline & evr2 Environmental Relevance & -.081 & .113 & -.112 & -.722 & .476 \\
\hline & $\mathrm{mp}$ Market pressure & .209 & .118 & .305 & 1.770 & .087 \\
\hline & cp Community pressure & .081 & .147 & .113 & .547 & .589 \\
\hline & rp Regulatory pressure & .027 & .119 & .043 & .226 & .823 \\
\hline & tc1_Technological capability & .130 & .153 & .164 & .848 & .403 \\
\hline & I Learning capability & .218 & .132 & .303 & 1.655 & .109 \\
\hline & nk Networks of collaboration & -.101 & .156 & -.106 & -.646 & .523 \\
\hline & er Economic risk & .239 & .102 & .343 & 2.329 & .027 \\
\hline \multirow[t]{8}{*}{3} & (Constant) & .712 & 1.003 & & .710 & .483 \\
\hline & evr2 Environmental Relevance & -.076 & .109 & -.105 & -.702 & .488 \\
\hline & mp Market pressure & .208 & .116 & .303 & 1.790 & .084 \\
\hline & cp Community pressure & .098 & .125 & .137 & .782 & .440 \\
\hline & tc1_Technological capability & .124 & .148 & .156 & .834 & .411 \\
\hline & I Learning capability & .223 & .128 & .311 & 1.746 & .091 \\
\hline & nk Networks of collaboration & -.095 & .151 & -.100 & -.626 & .536 \\
\hline & er Economic risk & .237 & .100 & .340 & 2.356 & .025 \\
\hline \multirow[t]{7}{*}{4} & (Constant) & .512 & .941 & & .544 & .590 \\
\hline & evr2 Environmental Relevance & -.080 & .107 & -.110 & -.742 & .464 \\
\hline & mp Market pressure & .201 & .114 & .294 & 1.757 & .089 \\
\hline & $\mathrm{cp}$ Community pressure & .086 & .122 & .121 & .707 & .485 \\
\hline & tc1_Technological capability & .095 & .139 & .119 & 679 & .502 \\
\hline & I Learning capability & .216 & .126 & .301 & 1.718 & .096 \\
\hline & er Economic risk & .235 & .099 & .338 & 2.366 & .024 \\
\hline \multirow[t]{4}{*}{5} & (Constant) & .819 & .819 & & 1.000 & .325 \\
\hline & evr2 Environmental Relevance & -.066 & .105 & -.091 & -.631 & .532 \\
\hline & $\mathrm{mp}$ Market pressure & .200 & .113 & .292 & 1.765 & .087 \\
\hline & $\mathrm{cp}$ Community pressure & .065 & .117 & .091 & .555 & .583 \\
\hline
\end{tabular}




\begin{tabular}{|c|c|c|c|c|c|c|}
\hline & Model & $\begin{array}{r}\text { Unstanc } \\
\text { Coeffi }\end{array}$ & $\begin{array}{l}\text { ized } \\
\text { ts }\end{array}$ & $\begin{array}{c}\text { Standardized } \\
\text { Coefficients }\end{array}$ & $\mathbf{t}$ & Sig. \\
\hline & I Learning capability & .262 & .106 & .365 & 2.480 & .019 \\
\hline & er Economic risk & .226 & .098 & .325 & 2.313 & .027 \\
\hline 6 & (Constant) & .876 & .804 & & 1.090 & .284 \\
\hline & evr2 Environmental Relevance & -.071 & .103 & -.098 & -.692 & .494 \\
\hline & $\mathrm{mp}$ Market pressure & .234 & .095 & .341 & 2.460 & .019 \\
\hline & I Learning capability & .268 & .104 & .373 & 2.575 & .015 \\
\hline & er Economic risk & .229 & .096 & .329 & 2.375 & .023 \\
\hline 7 & (Constant) & .618 & .706 & & .875 & .388 \\
\hline & $\mathrm{mp}$ Market pressure & .232 & .094 & .339 & 2.466 & .019 \\
\hline & I Learning capability & .247 & .099 & .344 & 2.500 & .017 \\
\hline & er Economic risk & .234 & .095 & .336 & 2.451 & .020 \\
\hline
\end{tabular}




\section{Appendix J: Model description}

The model we used for the model runs in this paper consists of 1000 consumers, 10 firms and 3 technologies and a few exogenous factors. We aim to simulate developments after (approximately) 1990, so initialize for the 1990 situation.

\section{Agent rules}

\section{Consumers /users}

The principal characteristic of a consumer is receptiveness $\mathrm{R}$ for technology $\mathrm{i}$ :

$R_{i}=\left(w_{1} * P F_{i}+w_{2}\right.$ * $\left.S C_{i}-w_{3} * E I_{i}\right)-W_{4} * P_{i}$

With Perceived functionality (PF), Social connotation (SC), Environmental impact (EI), and Price (P) of an innovation, and four frame weights of the 4 factors: $w 1$ to $w 4$. There are two sets of weights representing two consumer groups (see Table K1 below). PF and P are endogenous; SC and El are exogenous in the model. Consumers:

- initially own a car with an ICE

- update their receptiveness for each technology [i] in every time step

- start to consider re-adoption after they have owned a vehicle for at least 10 (15) time steps (i.e. readoptionTime $=10$ ):

ownershipPeriod = counter - adoptionTime;

if (ownershipperiod $>=$ readoptionTime)

for (int $i=0 ; i<$ nrTech; $i++$ )

if (adoption [i] > 0)

adoption $[i]=0$;

with 'counter' as the number of the time step of the run, adoptionTime as the time step of the last purchase, adoption indicating whether the agent has adopted the product (1) or not (0).

- consider re-adoption of a vehicle with either an old ICE (i.e. the version at the start of the model), or a refined ICE, or a (hybrid-) electric version

- select the technology depending both the (micro level) relative receptiveness level for the three technologies), and the macro level peer pressures (within their consumer group or frame). This works as follows. A macro level (logistic) spread function determines the number of agents (i.e. a threshold) that adopts the technology in that time step (resembling the social imitation pressure for it). The agents on the micro level are ranked for each technology on the basis of their receptiveness for it. When an agent is ranked above the threshold of the time step, it adopts the product. When an agent is above the threshold for more than one product, it adopts the one for which it has the highest receptiveness. This is implemented as:

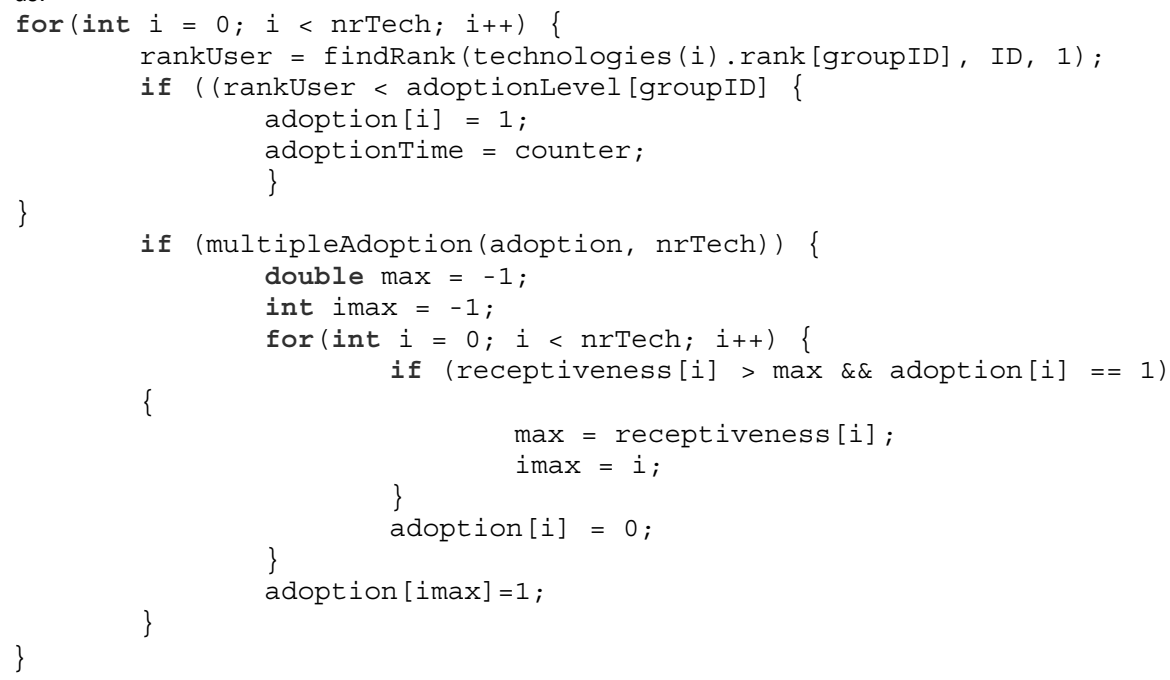


The total group of 1000 consumer consists of two sub-groups which are represented by two distinct sets of weights (frames). One group consists of 900 consumers and one of 100 consumers, and their respective frame-structure is as follows:

\begin{tabular}{|l|l|l|}
\hline & Frame group 1(900x) & Frame group 2 (100x) \\
\hline Weight 1 & 0.75 & 0.4 \\
\hline Weight 2 & 0.3 & 0.3 \\
\hline Weight 3 & 0.1 & 0.5 \\
\hline Weight 4 & 0.2 & 0.2 \\
\hline
\end{tabular}

Table K1: Two weights sets representing two consumer groups

In chapter 4 we have analyzed consumer frames of car engines in more detail. Our estimations are based on that analysis. In the analysis we found that frames change in the course of market development. Nevertheless, in this version of model, for brevity and simplicity, we assume that frames are static, and we have chosen an average of the frames we found for 2000 and 2005. Also, we have simplified the number of consumer group from 3 to 2 groups.

Consumers are initialized with a certain level of initial perceived functionality of the two technologies. We set their perceived functionality of (hybrid-) electric vehicles slightly lower than ICE by 1990, applying normal distributions over the group of consumers (with first the standard deviation, then the average):

perceivedFunctionality $[\mathrm{ICE}]=\operatorname{normal}(1,3)$;

perceivedFunctionality $[$ Electric $]=\operatorname{normal}(1,-1)$;

\section{Firms /developers}

The key characteristics of firms are Technological Capabilities (TC) for a technology, and perceived Business Opportunity (BO). Technological capabilities for a technology are initially uniformly distributed over the firms:

techCap $[i]=$ uniform_discr $(\operatorname{minTC}, \operatorname{maxTC})$;

with minTC a parameter indicating the lowest capability level of a firm of the group, and maxTC as the highest in the group (see values below in 'parameter values').

Firms consider launching new ICE versions and electric versions by assessing the business opportunity of the technology.

Business Opportunity (for developer d): BO = B - C

with $B$ as the benefits (that the developer expects after the investment):

benefit $[i]=$ techES * techPrice;

with techES the expected sales and techPrice as the price.

The cost for the developer $C_{d}$ is composed of two parts: fixed cost (resembling investments in R\&D, engineering and production facilities and launch marketing), and variable cost (from material and labor):

cost $[i]=$ techFR - techCap $[i]$ + launchInvest + (techES * techVC);

with techVC as the variable cost, techFr as the capabilities of the most advanced firm, and launchlnvest is the investments in production facilities and launch marketing.

Firms launch a product as soon as (expected) returns on investments are higher than $10 \%$.

$\mathrm{BO}[i]=(($ benefit $[i]$ - cost $[i]) /($ techFR - techCap $[i]+$ launchInvest $))$;

if $(\mathrm{BO}[\mathrm{i}]>$ targetROI)

launch $[i]=$ true;

with targetROI as the return on investments. 
Firms learn:

- from R\&D. The amount they invest in R\&D in a technology is driven by (a) the number of launching competitors (LD), (b) the (current) level of positive social connotation of a technology (SC), which also reflects the socio-regulatory expectation of a technology. The two components have equal weights:

InvestmentRD [i] = maxRD* $($ techLD + techSC $) / 2 ; \quad$ with $\operatorname{maxRD}$ as the maximum available R\&D budget for a firm in the time step

- Learning-by-doing: after launch, the variable cost of a technology decrease in time, $1 \%$ in each time step.

- $\quad$ Learning-from-the-market:

- Learning-from-Use (LFU): firm capabilities increase with the level use trough a logistic function (Mukoyama, 2006): learnFromUse [i] = techA * maxLFU * (1 - techA), with total marketshare of technology A as techA and max LFU as a maximum value.

- Emulative learning: firms reduce their lag in technological capabilities (w.r.t. most advanced firm) through learning from competitors in the market: by $5 \%$ from each launching firm:

emulativeLearn [i] = techFR - techCap[i] - ((techFR - tech Cap [i])* pow (0.95, nr_LaunchDev)) ;

with techFr as the capabilities of the most advanced firm, and nr_LaunchDev as the number of firms that have launched a market vehicles of that technology in the market.

So, firms capabilities for technology [i] increase through:

techCap [i] =+ (investmentRD[i] + learnByUse[i] + emulativeLearn[i])

Before and after (its) market launch, each company computes a (virtual) price at which it would still make a profit:

After launch:

price $[i]=$ (launchInvest $/$ techEI) + pm*techVC

Or before launch:

price $[i]=($ techFR - techCap $[i]+$ launchInvest $) /$ techEI + pm*techVC;

with techEl as the of expected interest for the technology [i] and techVC as the variable cost of the technology, and pm as the profit margin.

\section{Macro level rules}

Price

Price develops endogenously: Market price $p$ of the innovation (at launch) is set by the developer $d$ which can, at the relatively lowest price, still make a profit. In other words, it is the lowest price of these virtual firm prices:

Price $=$ MIN $\left(\right.$ price $\left._{d}\right)$

This means that the company with highest technological capabilities $T C$ will set the market price.

Aggregate technological progress

The firm with highest technological capabilities is regarded as the technological front:

for ( Developer d :) \{

$$
\text { if (d.techCap[ID] > front) }
$$

front $=$ d.techCap [ID];

This front moves because of R\&D investments of the firm in every time step, and also through learning from the market. Other firms catch up through emulative learning.

TechProgression (in a time step) = investmentRD[i] + learnByuse[i] + emulativeLearn [i]) 
The perceived functionality (PF) of all consumers increases with increasing technological progress of the technology. This is plausible since engineers and businessmen at firms try to overcome user-problems as they continue to develop an innovation, from what's already there. So in one time step:

$\mathrm{PF}=\mathrm{PF}$ (in previous step) + TechProgression;

\section{Launching developers}

The number of firms that have launched a market vehicle of that technology in the market is counted every time step (nr_LaunchDev). (For the micro decision to launch or not: see above.)

\section{Aggregate demand and sales}

The distributions of (consumer) receptiveness for each of the technologies are tracked. In each time step and for each technology the consumers are ranked on the basis of their receptiveness. A macro level (logistic) spread function determines the number of agents (i.e. a threshold) that adopts the technology in that time step (resembling the social imitation pressure for it):

newAdopters [i] = (1 - adoptionLevel[i]) * adoptionLevel[i] * infA;

adoptionLevel[i] +=newAdopters[i];

with infA being the level of infectiousness for adoption.

As we described above in the consumer paragraph, actual adoption will only happen if a consumer has owned a previous vehicle for at least 10 (or 15) time steps, and derived from a combination of the (micro level) receptiveness for the various technologies and the strength of the imitation bandwagon for the technologies.

Expected sales are derived from both the distribution of consumer receptiveness, and the number of other firms expected in the market. A consumer is considered as interested in (i.e. as a potential buyer of) the product when its perceived utility (that is receptiveness without the price term) is higher than certain threshold:

If $\left(\mathrm{w}_{1} * \mathrm{PF}_{\mathrm{i}}+\mathrm{w}_{2} * \mathrm{SC}_{\mathrm{i}}-\mathrm{w} 3 * \mathrm{EI}_{\mathrm{i}}\right)>$ AdoptionExp

expInterest ++ ;

By combining the size of the potential market, and the current firms who have launched on this market, the space for a new launching firm is computed and correspondingly a number of interested firms (i.e expected competition). We assume that the market is equally shared between the launching firms. Firms calculate expected sales for each product technology (which they use for computing their business potential) based on the expected consumer interest and expected competition.

expsales = expInterest / (launchDev + 1) ;

Learning-by-doing

After launch, the variable cost of a technology decreases in time (or production levels) by a progress ratio: varcost * = learnByDo;

\section{Social construction of connotation}

This mechanism is considered exogenous. It is such a socially shaped phenomenon that is does not make sense to link it to techno-economic variables (e.g. investments levels or prices). In the model it progresses with time. The start of the process for a technology is however endogenous, that is: it only starts when sales (and thus use) of the technology is $>0$. Therefore, at the start of the model run the initial value for new version of ICE and for electric propulsion is 0 , whereas for the contemporary version of ICE it is 1 . This means that social connotation is adding value to the product for the consumers which adhere to this connotation. The formation of social meaning for the new technologies is modelled as follows. Individual consumers become inclined to either the positive connotaion $(+1)$ or the negative connotation $(-1)$ through an epedemic spread function:

newPositivists $=(1$ - positivists - negativists $)$ * positivists * infP; newNegativists $=(1$ - positivists - negativists $)$ * negativists * infR; with infp and infR being the level of infectiousness for the two processes. These are the two variables with which the two scenarios in chapter 9 are developed: 


\begin{tabular}{|l|l|l|l|l|}
\hline & \multicolumn{2}{|l|}{ RUN 1 } & RUN2 & $(\mathrm{H})$ EV \\
\hline & ICE new & (H)EV & ICE new & 0.75 \\
\hline infP & 0.1 & 0.75 & 0.75 & 0.1 \\
\hline infN & 0.75 & 0.1 & 0.1 & \\
\hline
\end{tabular}

The connotations spread uniformly distributed over the user population:

while (counter < pro \&\& loop < 1000) \{

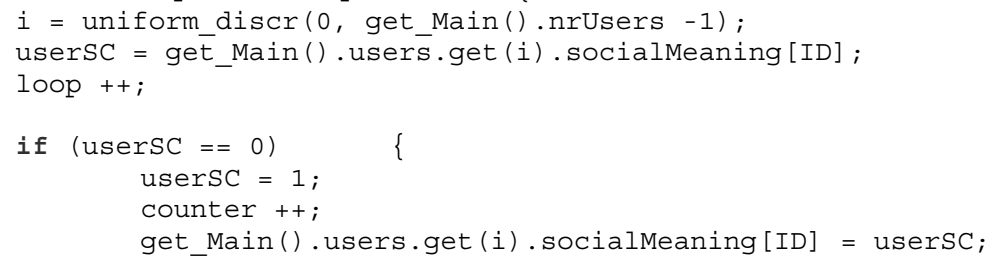

We assume that the social connotation of the technologies affects the regulatory pressure for the two technologies (e.g purchase subsidies, tax benefits). Therefore the social connotation is an important driver for the firm R\&D investments.

\begin{tabular}{|c|c|c|c|}
\hline Symbol & Description & Value & Remarks \\
\hline envImpact & $\begin{array}{l}\text { Environmental impact of } \\
\text { the technologies }\end{array}$ & $\begin{array}{l}{[\text { ICE new }]=4} \\
{[\text { Electric }]=1} \\
{[\text { ICE old }]=4}\end{array}$ & $\begin{array}{l}\text { This is an exogenous } \\
\text { parameter. We assume that } \\
\text { the actual emissions of } \\
\text { electric vehicle are } 4 \text { times } \\
\text { lower that ICE. Obviously, } \\
\text { this depends to a high } \\
\text { degree on the way } \\
\text { electricilty is generated. }\end{array}$ \\
\hline $\begin{array}{l}\text { (Initial) minTC } \\
\& \operatorname{maxTC}\end{array}$ & $\begin{array}{l}\text { Technological capabilities } \\
\text { for a technology are } \\
\text { initially uniformly } \\
\text { distributed over the firms, } \\
\text { these the boundary values }\end{array}$ & $\begin{array}{l}\text { For ICE new: } \\
\operatorname{minTC}=6 \text {; and } \operatorname{maxTC}= \\
14 ; \\
\text { For electric: } \operatorname{minTC}=0 ; \\
\text { and } \operatorname{maxTC}=6 ; \\
\text { For ICE old: } \\
\text { minTC = 15; and } \operatorname{maxTC}= \\
20 ;\end{array}$ & $\begin{array}{l}\text { We assume capabilities for } \\
\text { contemporary ICE } \\
\text { technology being greatest, } \\
\text { followed by calpabilities for } \\
\text { refined ICE, wheras } \\
\text { capabilities for (H)EV are } \\
\text { initially lowest. }\end{array}$ \\
\hline (Initial) PF & $\begin{array}{l}\text { Initial perceived } \\
\text { Functionality of the } \\
\text { technologies, which is a } \\
\text { normal distribution over } \\
\text { the group of consumers }\end{array}$ & $\begin{array}{l}\text { ICE (old and new): } \\
\text { Normal }(1,3) \text { (so } \\
\text { standard deviation } 1 \text { and } \\
\text { average } 3 \text { ) } \\
\text { (H)EV: } \\
\text { Normal }(1,-1)\end{array}$ & $\begin{array}{l}\text { Initially ICE old and new are } \\
\text { the same. The average of } \\
\text { perceived functionality of } \\
\text { (H)EV around is much lower } \\
\text { than ICE, therefore minus } 1 \\
\text { compared to } 3 \text {. }\end{array}$ \\
\hline $\max \mathrm{LFU}$ & $\begin{array}{l}\text { Maximum Learning-from- } \\
\text { Use }\end{array}$ & 1.2 & $\begin{array}{l}\text { Parameter that inidcates } \\
\text { the strenght of increasing } \\
\text { capabilities from increasing } \\
\text { use. We calibrated this in } \\
\text { comparison to learning } \\
\text { from R\&D investments. }\end{array}$ \\
\hline $\mathrm{PM}$ & $\begin{array}{l}\text { Profit margin applied on to } \\
\text { the variable cost in the } \\
\text { price computation. }\end{array}$ & 2.5 & \\
\hline learnByDo & Parameter that indicated & 0.99 & Ratios for industrial \\
\hline
\end{tabular}




\begin{tabular}{|c|c|c|c|}
\hline Symbol & Description & Value & Remarks \\
\hline & $\begin{array}{l}\text { the price decraese in each } \\
\text { time step }\end{array}$ & & $\begin{array}{l}\text { production are typically } \\
80 \% \text { (Ford model T was } \\
87 \% \text { ). This means: first if } \\
\text { first } 1000 \text { units cost } 100 \\
\text { dollars, the next } 100 \text { cost } 80 \\
\text { dollars. We apply however } \\
\text { the progress ratio in time } \\
\text { (not in production } \\
\text { quantity). We found that } \\
99 \% \text { in each time step } \\
\text { delivers a similar effect. }\end{array}$ \\
\hline EL & $\begin{array}{l}\text { Emulative learning from } \\
\text { each launching firm }\end{array}$ & $5 \%$ & $\begin{array}{l}\text { We assume that firms } \\
\text { reduce their lag in } \\
\text { technological capabilities } \\
\text { (w.r.t. most advanced firm) } \\
\text { through learning from } \\
\text { competitors in the market: } \\
\text { by } 5 \% \text { from each launching } \\
\text { firm }\end{array}$ \\
\hline launchInvest & $\begin{array}{l}\text { Investments relating to the } \\
\text { market launch of a } \\
\text { technology, such as } \\
\text { production facilities and } \\
\text { laucnh marketing }\end{array}$ & 0.3 & $\begin{array}{l}\text { We calibrated this relative } \\
\text { to } R \& D \text { investments }\end{array}$ \\
\hline $\mathrm{ROI}$ & Return on Invetsments & 0.1 & $\begin{array}{l}\text { This means that expected } \\
\text { returns should be } 10 \% \\
\text { higher than investments } \\
\text { before a firm starts } \\
\text { launching. }\end{array}$ \\
\hline $\operatorname{maxRD}$ & $\begin{array}{l}\text { the maximum available } \\
R \& D \text { budget for a firm in } \\
\text { the time step }\end{array}$ & 2 & $\begin{array}{l}\text { We calibrated this on the } \\
\text { progression of the } \\
\text { technology. }\end{array}$ \\
\hline varCost & $\begin{array}{l}\text { Variable cost of the } \\
\text { technology }\end{array}$ & $\begin{array}{l}2 \text { (initially, and will not } \\
\text { become smaller than } 1 \text { ) }\end{array}$ & $\begin{array}{l}\text { We chose the same value } \\
\text { for all technologies, to keep } \\
\text { this effect out of the } \\
\text { analysis. }\end{array}$ \\
\hline $\inf A$ & $\begin{array}{l}\text { Infectiousness level of } \\
\text { adoption }\end{array}$ & 0.8 & $\begin{array}{l}\text { This is the strengh of } \\
\text { imitation among consumers } \\
\text { (in their groups). We } \\
\text { calibrated this for the } \\
\text { spread of direct injected } \\
\text { diesel engines. }\end{array}$ \\
\hline $\begin{array}{l}\text { Re-adoption } \\
\text { period }\end{array}$ & Average Ownership period & 15 (time steps) & $\begin{array}{l}\text { This is a fairly random } \\
\text { choice, after which other } \\
\text { parameters were } \\
\text { calibrated. }\end{array}$ \\
\hline AdoptionExp & $\begin{array}{l}\text { A threshold value for a } \\
\text { consumer being counted } \\
\text { as 'interested' in the } \\
\text { technology }\end{array}$ & 2.5 & \\
\hline
\end{tabular}




\section{Appendix K: Model analysis}

\section{B1. Model Calibration}

We calibrate the model by mimicking the actual data of diffusion of new engines after 1990 in the first half of the model (broadly up to step 50). We match the first half of the model and the period of 1990-2010 in the following way. Some research suggests that the average re-purchase time of new cars is 6.3 years \{Boyd, 2006 \#152\}, and in the model we choose 15 steps as the re-purchase period. Therefore, 50 modeling steps represent about 22 years. Since we take the start of the model as 1990s, we have calibrated the model (through the initialization of relative firm capabilities and initial perceived functionality of consumers) in order to launch new diesel engines from the beginning of the 1990s onwards (that is after about 4 or 5 time steps), and electric and hybrid-electric versions from the mid-1990s onwards (i.e. after about 10 or 12 time steps).

Further we have calibrated the model so that diffusion of new diesel engines replace all old diesel engines at about 2010 (corresponding approximately to step 40 to 45), mainly by tuning the parameter of the logistic imitation function (InfA). This way we mimic the actual data of diffusion of new diesel engines on the world market, see Figure L1, and of (hybrid-) electric vehicles, which have gradually grown to a market share of about $3.5 \%$ worldwide by 2010 .
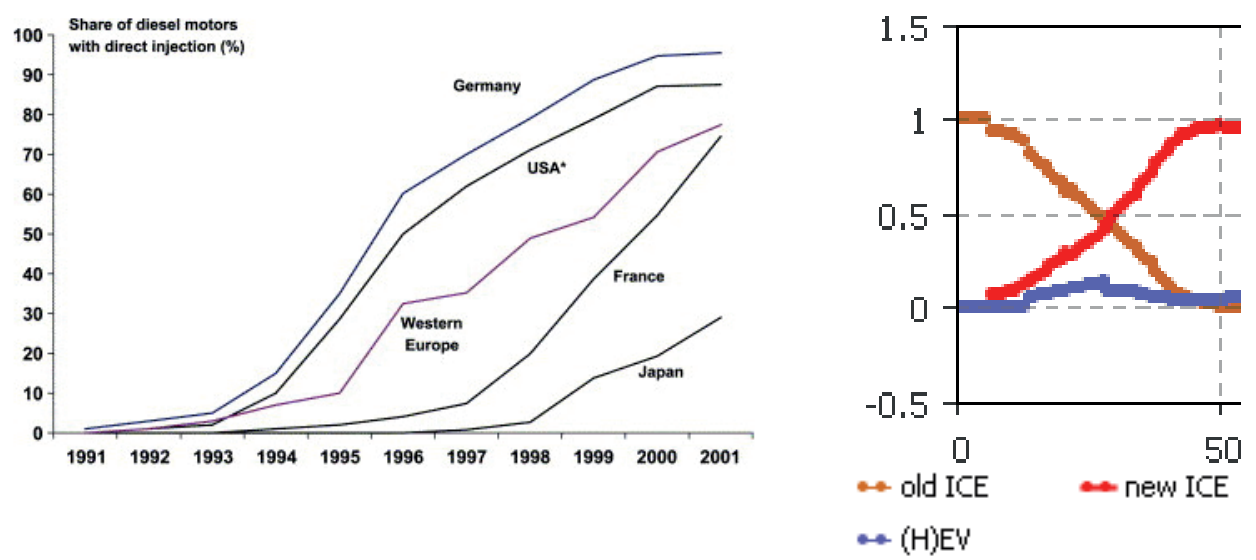

Figure L1a: Diffusion levels of Direct Injection systems (Source: Beise and Rennings, 2005). After 2001 diffusion levels have continued to rise and, on average, we estimate that by 2008-2010 all diesels have direct injection systems.

Figure L1b: Model output of Run 1 and 2.Tthe red line resembles diffusion of DI Diesel.

\section{B2 Sensitivity analysis}

In section 9.3 we have discussed the results of the model, where we focused on the role of social connotation for the development of market shares, by comparing two runs. Here we assess how other parameters may have a similar effect on market shares. We vary a few key parameters with +/- 25 to $50 \%$ and observe the impact on the output values, i.e. on the market share trends. As a starting point we take scenario run 1 (see Figure L2 left). 

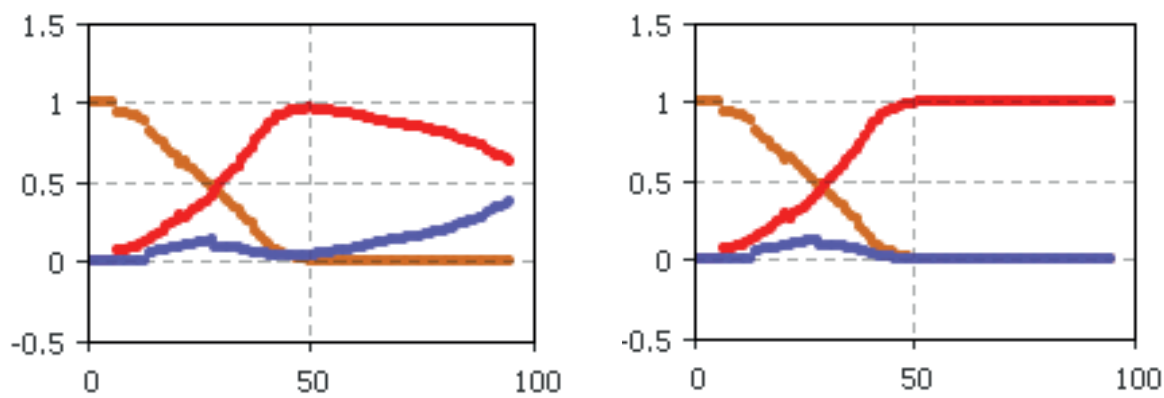

Figure L2: Market shares in the calibrated model in run 1 and 2

Consumer frame weights

Here we vary with the weight of Perceived Functionality in the frame of the 900 members of consumer group 1.

\section{$W(P F)=0.5($ instead of 0.75$)$}

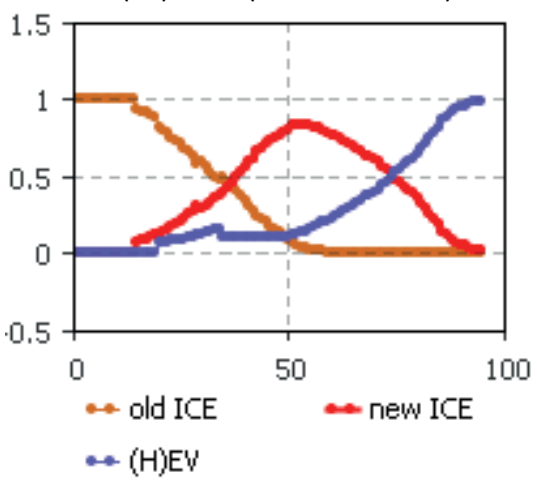

$W(P F)=1.0($ instead of 0.75$)$

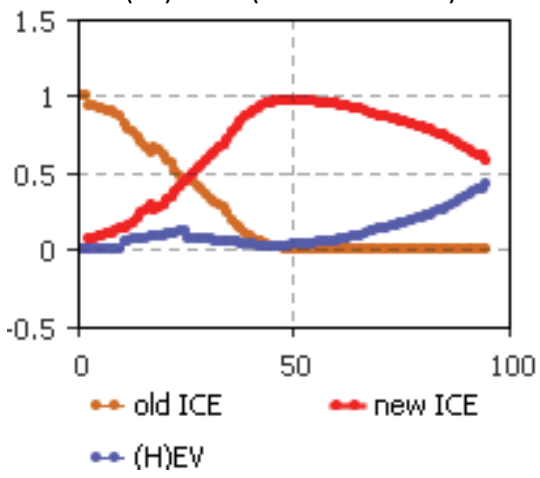

Figure L3: Market shares in the case of deviating values for weight of PF.

So, if functionality becomes significantly less important for the largest group of consumers (those who value functionality most), the market share of $(\mathrm{H}) \mathrm{EV}$ s will start rise much earlier and stronger (Figure L3, left). This makes sense, since inferior appreciation for the functionality of $(H) E V s$ is an important reason for why it takes so much time to diffusion: it takes time for firms to built up their capabilities. Alternatively (Figure L3, right), an even higher weight of perceived functionality does not have much effect.

\section{Readoption period}

Here we vary with the readoption period from 15 time steps to 10 and 20. 
readoption $=10($ not 15$)$

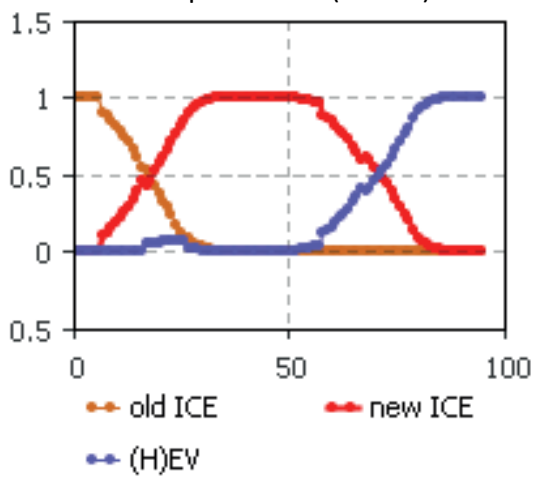

readoption $=20($ not 15$)$

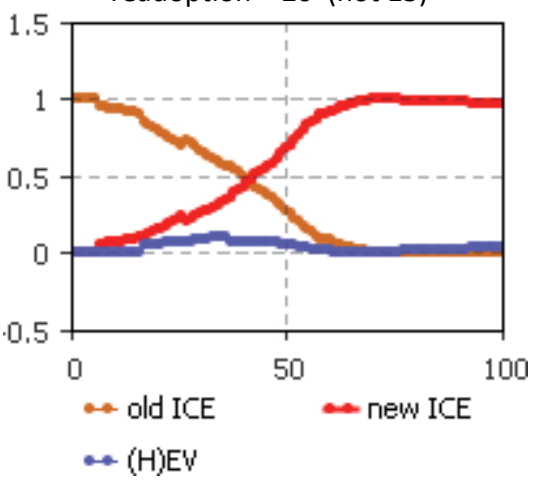

Figure L4: Market shares in the case of deviating values for readoption time.

We find that when consumer are faster in buying a new vehicle (readoption $=10$, Figure L4 left), the slope of diffusion of the innovation increases. However, it does not so much affect the relative investment levels of firms, and therefore $(\mathrm{H}) \mathrm{EV}$ still overtakes ICE in terms of perceived functionality around time step 50. Subsequently, the diffusion slopes of $(\mathrm{H}) \mathrm{EV}$ is steeper as well.

When consumers are slower in replacing their vehicle, we find the opposite effect. All in all, the model is fairly sensitive for variations in readoption time, which is reasonable regarding the actual market developments.

\section{Maximum $R \& D$ per step}

Here we vary with the maximum R\&D budget available at each firm from 2 to 3 and 1 .
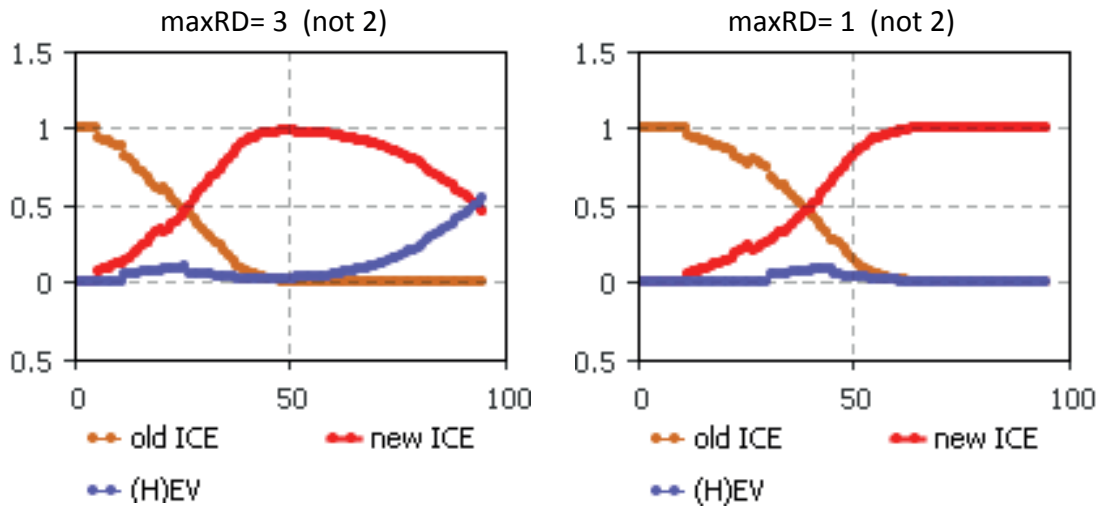

Figure L5: Market shares in the case of deviating values for maxRD.

When the maximum R\&D budget is 3 instead of 2 the market share of $(H) E V$ rises slightly stronger in the second phase of the run (see Figure L5 left). Total investments in (H)EV accumulate faster, and perceived functionality overtakes that of ICE at a slightly earlier moment, which makes the sensitivity reasonable. Alternatively, when the RD budget is 1 , we find precisely the opposite (Figure L5, right). The progression of $(\mathrm{H}) \mathrm{EV}$ is still on its way to overtake ICE, but the slope is lower here, and therefore it takes more time to pass ICE (and therefore adoption of $(\mathrm{H}) \mathrm{EV}$ only start growing after 100 time steps, outside the plot). 


\section{B3 Conclusion}

This model analysis shows that the model is similarly sensitive for many other parameters as it is for social connotation. Variations in these parameters deliver similar variations in the output (i.e. market shares) as the two runs in discussed in section 9.3. It is not surprising that indeed many factors play a role in innovation dynamics, as our conceptual model has proposed, and it is good to know that the model reflects that. The formation of social connotation is however one of the most uncertain, intangible factors in unfolding innovation trajectories; much more than, for instance, the average re-adoption time or the maximum R\&D level. Therefore, it was reasonable to base the two model runs and the respective scenarios on this variable of social connotation.

All in all, we find that the model gives a sufficient 'order-of-magnitude' indication of cause-and-effect relationships of social connotation with investments, prices, technological progression and adoption. The model should not be seen as a 'truth model', incorporation all the subtleties of explanatory case studies (such as in chapter 6), and the time dimension in the model should not be seen as a precise measure of when what will happen, especially not as predictions of the future. There is much more to tell about other possible runs, the salience of various variables and lessons or propositions we can draw from this model. We recommend other interesting applications of this model, such as the role of changing consumer frames, as a topic for future research. 



\section{Summary}

In the last 20 to 30 years people have travelled more often and further. Worldwide, more people have obtained access to car and air transport, and road traffic movements have grown strongly. In Europe, total passenger road kilometres doubled since 1980. Alongside the gains in freedom to travel there are some clear drawbacks of the steady increase of road traffic. Our society, in particular urban areas, has been burdened with the severe impact of congestion, harmful emissions, traffic accidents, noise, scarcity of fossil fuels, and fragmentation of landscapes.

Policymakers at local, national and international levels have been challenged firmly to deal with these negative effects of car mobility. Mobility issues are multi-faceted, since they include social, economic, ecological as well as technological aspects. Policy concerns are typically interconnected and cross several policy fields. Societal stakeholders have conflicting perceptions of the problem, whereas gains and burdens of transport activities are distributed unevenly over various societal groups. Furthermore, the outcomes of transport policies are often difficult to understand, let alone predict.

Nevertheless, transport policies have been partially successful in the last 20 to 30 years. The increase of safety levels and decrease of polluting gases (such as particulate matter and nitrogen oxides) can be attributed directly to transport-related policies. However, some effects have remained critical or have even grown. Congestion levels in urban areas are growing, and greenhouse gas emissions from road transportation are steadily growing as well. It raises the question how policies concerning these two issues can be improved. Two innovations may play a prominent role in the mitigation of greenhouse gas emissions and congestion levels, respectively: car engine technology and Park-and-Ride facilities $(P+R)^{51}$. Therefore it is relevant to study the emergence of these two innovations and the role of policy, since the deeper understanding of recent transport sectoral innovation dynamics may possibly enhance outcomes of transport policies.

In this thesis our aim is twofold. We aim to contribute to theories of innovation through the proposition of a co-evolutionary framework, and furthermore we aim to provide transport policy practitioners with additional insights in order to support policymaking in their sector, especially with respect to car engines and $P+R$.

Studies in various scientific disciplines and fields have addressed the emergence of new technology and innovation. Broadly there are three strands of literature. Although most economists treat innovation as just another investment opportunity, one strand originates from the Austrian economist Joseph Schumpeter (1883-1950), who bequeathed us with a scheme of technological change consisting of invention - the first practical demonstration of an idea; to innovation - the first commercial application of an invention to the market; to diffusion - the spread of the innovation into the market. In this tradition a new wave of economists revitalized evolutionary theorizing of innovation from the early 1980s onwards. Studies in this strand have explained the domination of a technology or practice in a sector as lock-in through path dependency. The models are, however, as yet less applied to consumer products in a changing social context. For consumer products symbolic meaning of products may play a significant role. Symbolic value is as a social connotation or meaning attributed to the product, and individual consumers will have a certain degree of inclusion in such a social construct. Though in itself a multi-dimensional phenomena, the construct may at a balance be positive or negative (even at

\footnotetext{
${ }^{51} \mathrm{P}+\mathrm{R}$ is a service provided by a city to motorists who can park their vehicle at the edge of a city (centre) and continue their journey by means of public transport.
} 
the same time for different groups of consumers), thus adding value in the eyes of a consumer, or reducing it. Progression of such connotation will affect the further development (supply side) and diffusion process (demand side) of the technology. There are currently few theories in this economic strand that incorporate this interaction of such social and technological aspects and as Pier Paolo Saviotti noticed, these dynamics are still poorly understood.

A second strand of innovation studies, innovation diffusion studies, is conceptually broader and originates from social geography, later adopted in marketing studies. The focus in most diffusion studies is on aggregate patterns, which are often found to be S-shaped. In the field of marketing the symbolic meaning or value that goods and innovations hold is well established, where it is typically distinguished from the functional value. The seminal work of Everett Rogers offers a typology of adopters based on when they adopt but does not offer a dynamic model of innovation diffusion in terms of endogenous and exogenous mechanisms.

A third strand of innovation literature originating from the sociology and history of technology, where authors have emphasized the social context in which technology is created and used. A key concept is the social construction of technology (SCOT, developed by Wiebe Bijker), where 'technology' is viewed not as an objective entity (as in economic and technical studies), but rather described 'through the eyes of social groups'. These authors demonstrated how various social interpretations of technology shape various directions of technological development.

Authors in the latter two strands have addressed the interaction of technology and social factors. Most recently Arie Rip and René Kemp elaborated on co-evolution of 'the social' and 'the technical', analysing the emergence, transformation and decay of socio-technical systems. Their 'multi-level' model of innovation distinguishes between the macro level of the sociotechnical landscape, the mesolevel regime, and the microlevel niche. Frank Geels added the key idea that radical innovations come about through interactions between processes at these three levels. That is: the breakthrough from niche to regime level occurs gradually, as a new technology 'branches' or 'penetrates' different application domains, before entering mainstream markets. These studies have highlighted more than previous studies the patterns in which established technologies are sometimes abandoned and overthrown by emerging niches. A number of scholars have argued that these studies have been less clear on why some niches are 'successful' in growing and even overtaking a regime, while other niches die. Interactions between niche and regime are claimed to be important, yet the interactions are not specified in terms of processes; feedback effects, such as scale and learning, and taste formation mechanisms are neglected. In this thesis we suggest a conceptual, co-evolutionary framework that highlights feedback effects and actor perspectives.

In chapter $\mathbf{2}$ we elaborate our co-evolutionary approach to innovation, building upon the integrating bridge of evolutionary economics and sociology of technology, initiated by Rip, Kemp and Geels. We develop a micro-macro model (more familiar to the economic tradition), thus deviating from the three-levelled niche, regime and landscape model. At the micro level, the innovation is described through the eyes of stakeholders, whereas at macro level aggregated indicators such as total sales and prices are incorporated. We hold (groups of) actors as the basic element of analysis, stepping into their shoes, mapping their mental framing and attitudes. A frame is the way in which the innovation is described or interpreted by an actor. Further, in our scheme we extend the notion of feedback effects through scale and learning with the effect of consumer taste formation, including social connotation. We discuss the advantages and disadvantages of this approach for the notion of co-evolution. We aim to contribute to evolutionary economic co-evolutionary studies (in the neo-Schumpeterian tradition), as well as to co-evolutionary approaches in the broader field of innovation studies.

Before we perform two explanatory case studies in the core of this thesis, applying our coevolutionary framework to the case of automotive engines and $P+R$, we amplify on our methodology (in chapter 3 ). Explanatory case studies are suitable for applying pre-defined 
frameworks to a new case, testing causalities and explanatory value. As an input to our explanatory case studies we analyze the frames of the key stakeholders, employing a range of other methods, most notably discourse analysis (chapter 4) and questionnaire surveys (chapter 5 and 7). In addition to the explanatory case studies we develop scenarios, supported by a simulation model analysis (chapter 9).

Such a combination of methods has a few advantages. The simultaneous use of various methods can improve the quality and adequacy of a study considerably, and conclusions are usually more convincing if they are based on several different sources of information. Combining methods can compensate for one-sidedness. In complex issues, one method easily results in only partial explanation of a phenomenon, as in the blind men and the elephant tale. Combining methods has difficulties too. Integration of outcomes and knowledge elements is difficult to validate scientifically, and methods may have a similar bias. Although a theory on the use of different methods is still in development, we will include evidence from a range of methods in our explanatory case study, to facilitate the understanding of the multifaceted phenomena of the emergence of hybrid-electric vehicles and $P+R$.

In chapter 4 we analyze how car users frame car engines. Car engines have been build on internal combustion (IC) technologies for more than hundred years now; however, in the last decade hybrid-electric engines have been successfully introduced. The coexistence of conventional and unconventional technologies raises the interesting question to what extent these different engine technologies are framed differently, and how they change over time. Studies of technological frames and mental models suggest that frames of established technologies are more obdurate. In this chapter we analyse technological frames of three types of car engines: the incremental innovation of the diesel engine, the unconventional electric and the hybridelectric engine, and furthermore we study how these frames have shifted during market evolution between 1990 and 2005. We find that engines are framed rather differently. Frames of conventional diesel engines emphasize engine capacity (measured in $\mathrm{kW}$ ), engine volume (measured in liters) and torque (measured in $\mathrm{Nm}$ ), whereas for hybrids fuel-efficiency is by far the most prominent attribute. Further we find that the frame of the conventional engine (diesel) is more stable than that of an unconventional engine (hybrid and full-electric), which confirms the obduracy hypothesis that is raised in earlier studies of technological frames.

In chapter $\mathbf{5}$ we analyze technological frames of car firms towards development of Ultra Low Emission Vehicles (ULEV). We examine the framing of firms by studying their belief systems and actual engagement. The central question is: Which underlying beliefs significantly drive the engagement in the development of ULEV technology? A second question concerns whether we can map out diversity between firms. We thus 'step into the shoes' of the car firms and analyse their social, business, technological and environmental considerations. In order to achieve enough focus, we will focus on hydrogen vehicle technology as an example of an ULEV. Scholars, industry strategists as well as policy makers acknowledge hydrogen as an important future energy carrier for transportation. The study reveals that different firms deal differently with hydrogen vehicle development. Broadly, three groups of firms were distinguished concerning their engagement level in ULEV: uncertain firms, unwilling firms and optimistic firms. It addition, it was found that the level of technological and organisational capabilities is highly correlated to the actual engagement of firms in hydrogen technology development: firm who consider their capabilities higher (lower), are stronger (weaker) engaged. Although firms differ in their engagement in hydrogen technology, we found no evidence from additional interviews that frame-structures of car firms towards hydrogen technology differ significantly, i.e. regarding the weights they attach to economic opportunity, environmental risk etc. All firms are part of the same global market, with fierce competition. All firms emphasize business opportunities, both immediate and future opportunities, when considering development of hydrogen technology. A main question for them is: do consumers expect and value cleaner engines? Secondary, their 
relative position regarding competitors is important. Further, social expectations and pressures for novel technologies, such as hydrogen, affect R\&D expenditures of firms to some extent, whereas emission regulation is a boundary condition that needs to be met.

In chapter 6 we describe and explain the emergence of electric engines in the automobile market after 1990. Hybrid-electric vehicles have experienced a significant rate of growth in the last 10 years. This is remarkable, since the automotive sector is typically averse to the more radical technological change of engines. The internal combustion engine has been around for more than 100 years after all. In this chapter we provide rich descriptions of how and why propulsion technologies were developed and adopted after 1990, tagging the two levels of the framework. First we focus on aggregate patterns (sales levels and technological progress), while in the next section we address the micro level perspectives of stakeholders (firms, consumers, and regulators). Subsequently, the previous sections are integrated into a co-evolutionary framework. We discuss the role of techno-economic mechanisms alongside social and regulatory mechanisms (including the social meaning of an engine). The co-evolutionary analysis is novel in the integrated conception of actor perspectives, feedback effects and competition between products. We find three sources of lock-in through path dependency: from demand, supply as well as the regulatory side. We find that automotive engines were locked into an established trajectory of internal combustion technology sector due to techno-economic mechanisms, which produced inertia despite some sustainability pressures. In the 1990s the creation of a new innovation path of electric engines initially stalled, since the vehicles were broadly regarded as expensive and unpractical due to little autonomy, various stakeholders were unsuccessful in marketing their electric or hybrid-electric vehicles in the 1990s, such as Peugeot/Citroen with various electric models, or Audi with their Duo in 1997. However, after 2000 it recurred through hybrid-electric engines, mostly triggered by efforts of Toyota to find a new market, and stimulated by the gradual social formation of a positive connotation of hybrid-electric technology.

In chapter 7 we study how $\mathrm{P}+\mathrm{R}$ is framed by policy makers through a questionnaire survey amongst 45 major cities in Europe. Traffic congestion and the quality of the air in city centres is a major concern for urban planners. In recent years Park and Ride $(P+R)$ facilities have been increasingly introduced by local authorities as an alternative for or addition to parking supply in the city centre. We study how deployment of $P+R$ is framed by policy makers in the broader transport policy. The chapter offers three things. First, we report on present adoption levels of $P+R$ in Europe. The survey outcomes reveal that $P+R$ is adopted fairly unevenly across Europe. We find that a quarter of the responding cities are extensively engaged on implementing $P+R$, whereas another quarter has little or no engagement. It raises the question, if congestion is a problem present in most major cities across Europe, why adoption is so uneven? Therefore, secondly, we map out diversity in framing of $P+R$ throughout European cities, by revealing current beliefs about $P+R$. We show how diversified policy-makers interpretation of $P+R$ is. Thirdly, we track the salient beliefs underlying the policy frames that determine $P+R$ implementation. Linear regression analysis suggests that economic implications of $P+R$, perceived demand for $P+R$, and organisational learning capabilities are the most important drivers for city governments whether or not to engage in $P+R$ development, explaining $40 \%$ of the variance in their actual engagement in $\mathrm{P}+\mathrm{R}$ deployment.

Chapter 8 explores the introduction of $P+R$ as a niche solution and its potential transformative impact on urban mobility in two of the densest European states, UK and the Netherlands, dealing with similar urban sustainability problems. We examine three examples of implementation from each state: Oxford, York, Bristol, Amsterdam, Rotterdam and Utrecht. Our explanatory case study addresses the two-layers of the co-evolutionary framework, by describing P+R from the perspective of the city government and that of urban travellers (micro level), and further through aggregated indicators such as total parking availability and prices (macro level). The 
framework is applied to examine how and why $P+R$ was developed in the six cities and whether the introduction of $P+R$ has contributed to transition towards low-traffic city centres. It is found that whilst in most cities there has been a shift in policy aims and implementation from providing more parking towards transfer of parking locations and influencing modal choice, no significant reduction in overall parking intensity as an outcome can be observed; $P+R$ has been largely used as a way to provide more parking capacity.

In chapter 9 we explore future scenarios of car engine technology with support of a simulation model. Whereas chapter four to eight were devoted to the recent history of our two cases, we now turn to the question: what could happen? We develop plausible but simplified descriptions of two possible trajectories. These descriptions involve both techno-economic aspects as well as the formation of social connotation. To consider the complex and uncertain dynamics between the latter and the former phenomena, we benefit from a simulation model analysis. Therefore we formalize the two-layered innovation framework (see section 2.4), and make it 'tailored' to the case of car engine innovation. We deliver a model, simulating the co-evolution of demand and supply, giving rise to various possible trajectories. We formalize stakeholder perspectives, based on the empirics of chapter 4,5 and 6 . The main duty of the model is to support the analysis of the role of social connotation in innovation dynamics. The model is applied, both in retrospect, and to explore the future, and draws lessons on the role of social connotation. In the model, actor behaviour is modelled explicitly on the basis of actor frames which shape the appraisal of technology options by potential adopters and by suppliers. The model is analytically novel by incorporating five feedback loops: interactive learning between suppliers and users, scale and learning economies, endogenous taste formation among consumers, and social learning (attribution of meaning). The model is applied to explore future diffusion scenarios of vehicle engines, though it starts with simulating recent historic trends (about 20 years), including the quick diffusion of direct fuel injection systems (for diesels) and slow diffusion of electric vehicles. It is shown that the success of hybrid electric vehicles critically depends on suppliers shifting towards HEV development and production (resulting in greater supply of refinement of (H)EV models) and on consumers valuing (hybrid-)electric vehicles more than environmentally improved diesel vehicles.

We have developed two narrative scenarios. In the first scenario the social connotation of (H)EV technology becomes predominantly positive, whereas ICE predominantly negative. Here we find a gradual increase of the state-of-the-art of electric propulsion, within 10 years surpassing the state-of-the-art of ICE. After the initial adoption of electric propulsion in a limited group of green consumers, wider adoption occurs after 2020.

In the second scenario new ICE versions acquire a similar positive connotation as (H)EV. Here, the state-of-the-art of ICE remains ahead of $(\mathrm{H}) \mathrm{EV}$, and after some adoption of electric models, even some green consumers shift back to refined versions of ICE.

In chapter $\mathbf{1 0}$ we analyze what our co-evolutionary approach learns about the role of policy in the innovation process in the two cases. There are two main perspectives on environmental and innovation policy in the literature, the welfare perspective and an evolutionary perspective. We argue that in our two case studies policy instruments were mostly applied from a welfare perspective. In this perspective the instruments aim to spur innovation but in a technology-blind manner, leading mostly to adoption of existing technologies and incremental innovation.

In a (co-) evolutionary perspective, which conceptualizes alternative technologies as outerregime niches, it is not just a question of 'does an instrument spur innovation', but also: 'does an instrument spur innovation to refine the existing regime or does it spur an alternative trajectory'? Such a key question has not been investigated systematically by research and is given only scant attention by policy makers.

We have suggested options for evolutionary policy to promote the niche innovations in our two case studies, as these may mitigate the $\mathrm{CO}_{2}$ and congestion issues with greater drive. As a red 
line through the policy advice in both cases we find the suggestion to try and modulate innovation dynamics through a sectoral platform, which:

- Engages in niche-regime coordination: coordinate regime policies with bottom-up (niche) initiatives. Experience from local experiments should be shared for policy making at the (supra-)national level and there should be strategic experimentation for system innovation, two things that have happened only incidentally in the past.

- Deals with existing path-dependencies but in doing so avoids getting locked into suboptimal solutions. This calls for anticipation of outcomes and the use of markets for coordination and context control instead of planning. A second way of circumventing lock-ins is by exploring different configurations through support of a portfolio of niches, instead of supporting just one alternative.

In chapter $\mathbf{1 1}$ we summarize the key findings by answering the five research questions: (1) How to combine SCOT and evolutionary economics?, (2) Is a co-evolutionary approach reasonable and relevant for studying the emergence of $(H) E V s$ and $P+R$ ? , (3) Can we measure user frames and social connotations of innovations and incorporate the results in computer simulations and in historic-analytical analyses of socio-technical change?, (4) Does the incorporation of competing technologies in a diffusion model lead to different results?, and (5) What is the value of a co-evolutionary conceptualization of innovation dynamics for policy? In summary we find that the main merit of our co-evolutionary, micro-macro approach lies in the integration of consumers and firms, and competition between technologies. Therefore, this approach helps to highlight dynamics between consumers (and demand structures) and suppliers (and supply structures). Other studies have addressed the development of $(H) E V$ or $P+R$, but typically with a narrower focus, focusing only on supply, while ignoring consumers and user, or vice versa.

Limits to our methodology are the requirement for a significant amount of micro level data (time series of actor frames and attitudes), which is for many cases rather difficult to obtain. Also, it is hard to determine the relative speed of the various feedback loops in each case. These should probably be assessed through expert opinion or participation of stakeholders.

Our approach has been less successful in highlighting the social and political dynamics within the city or (supra-) national authority and within car companies. More than being a single homogenous entity, the government authorities are composed of departments (economy, transport, environment etc.) as well as a city council or parliament, who are lobbied by stakeholders and sensitive to their own constituencies and professional groups. Within firms various departments (business development, environmental affairs, research etc.) may have conflicting opinions on the best strategy to go. In our analysis we have left out such dynamics, and just addressed the policies and regulation that passed the city council, or R\&D investment and product launches that we undertaken by car firms. In future research this part of our framework needs to be elaborated. Also, the character of learning and economies-of-scale at local governments should be further elaborated. For both these issues, we see the co-evolutionary framework as a good starting point. 


\section{Samenvatting}

In de afgelopen 20 à 30 jaar zijn mensen vaker en verder gaan reizen. Wereldwijd hebben meer mensen toegang tot weg- en luchttransport, en wegverkeersbewegingen zijn sterk toegenomen. In Europa is het totaal aantal passagierskilometers over de weg sinds 1980 meer dan verdubbeld. Naast de pracht van een toegenomen vrijheid om te reizen is er ook een schaduwkant aan het groeiende wegverkeer. Onze samenleving, in het bijzonder het leven in de stad, wordt flink belast met neveneffecten zoals files, schadelijke uitlaatgassen, verkeersongelukken, geluid, gebruik van schaarse fossiele brandstoffen en doorsnijding van het landschap.

Beleidsmakers op lokaal, nationaal, en internationaal niveau zijn sterk uitgedaagd om de neveneffecten van automobiliteit aan te pakken. Verkeersvraagstukken zijn vaak divers en hebben verschillende aspecten, zoals sociale, economische, ecologische en technische facetten. Verkeer- en vervoersbeleid raakt aan al die aspecten, en doorkruist daarmee vaak verschillende bereidterreinen. Verschillende groepen in de samenleving hebben een andere kijk op wat precies een probleem is, en de lusten en lasten van het toenemende verkeer zijn ongelijk over de verschilleden groepen verdeeld. Ook zijn de uitkomsten en effecten van verkeersbeleid vaak moeilijk te doorzien, laat staan te voorspellen.

Niettemin is transportbeleid in de afgelopen 20 à 30 jaar gedeeltelijk succesvol geweest. De daling van dodelijke ongevallen en van de uitstoot van vervuilende deeltjes en gassen (zoals fijn stof en stikstofoxiden) kunnen er direct aan worden toegeschreven. Toch zijn sommige negatieve neveneffecten van wegtransport kritiek gebleven of zelf verergerd. Het congestieniveau in stedelijke gebieden is gegroeid en de uitstoot van broeikasgassen evenzo. Dit doet de vraag rijzen hoe beleid rond deze twee zaken verbeterd kan worden. Twee innovaties in het bijzonder zouden hierin een rol kunnen spelen: respectievelijk automotortechniek en parkeeren-reis $(P+R)$ voorzieningen ${ }^{52}$. Daarom is het relevant om de opkomst van deze twee innovaties te bestuderen en de rol van beleid daarin: een beter begrip van de innovatie dynamica in de sector zou immers de uitkomsten van transport beleid kunnen verbeteren.

Het doel van dit proefschrift is tweeledig. We beogen een bijdrage aan innovatie theorie door het voordragen van een raamwerk voor co-evolutie van vraag en aanbod. Daarnaast beogen we een bijdrage aan transportbeleidprofessionals, vooral aan hen die te maken hebben met beleid rond de automotor en $\mathrm{P}+\mathrm{R}$.

Studies in verschillende wetenschappelijke disciplines en velden hebben een bijdrage geleverd aan theorie over innovatie en de opkomst van nieuwe techniek. Grofweg zijn er drie stromingen in de literatuur. Alhoewel de meeste economen innovatie eenvoudigweg behandelen als één van de investeringsmogelijkheden, is de eerste stroming ontstaan uit het werk van de Oostenrijkse econoom Joseph Schumpeter (1883-1950), die ons een schema over technische verandering heeft nagelaten wat achtereenvolgens bestaat uit: uitvinding - de eerste praktische demonstratie van een idee; uit innovatie - de eerste commerciële toepassing van een uitvinding; en uit diffusie - de verspreiding van de innovatie over de markt. In deze traditie hebben een nieuwe reeks economen zogenaamde evolutionaire theorieën een nieuwe impuls gegeven na 1980. Studies in deze stroming hebben de dominantie van een bepaalde techniek of werkwijze in een sector verklaard als technologische insluiting ('lock-in') door padafhankelijkheid. De modellen zijn echter op dit moment nog weinig toegepast op consumenten producten in een veranderende sociale context. Voor consumenten kan de symbolische waarde van een product

\footnotetext{
${ }^{52} \mathrm{P}+\mathrm{R}$ is een voorziening voor automobilisten waar ze hun auto kunnen parkeren aan de rand van de stad (of het stadscentrum) en hun reis kunnen vervolgen per openbaarvervoer of publieke fiets.
} 
een belangrijke rol spelen. Symbolische waarde is als een sociale betekenis toegekend aan een product, en individuele consumenten zullen in een bepaalde mate deelgenoot zijn van het sociale construct. Alhoewel het construct een multi-dimensionaal fenomeen is, zal het (per saldo) een positieve of negatieve klank hebben (mogelijk op het zelfde moment voor verschillende groepen consumenten) en dus waarde toevoegen aan de functionele waarde of verminderen in de ogen van consumenten. De formatie en reformatie van die sociale betekenis zal zowel de technische ontwikkeling (aanbod zijde) als het diffusie proces (vraag zijde) van de innovatie beïnvloeden. Op dit moment zijn er weinig theorieën in deze economische stroming die de interactie tussen sociale en technische aspecten meenemen en, zoals Pier Paolo Saviotti opmerkt, is het begrip van deze dynamica nog gebrekkig.

Een tweede stroming binnen innovatie studies, innovatie diffusie studies, is conceptueel breder en is voortgekomen uit de sociale geografie en later opgenomen in marketing studies. De focus van de meeste diffusie studies is op aggregate patronen, welke vaak S-vormig blijken te zijn. Symbolische waarde van producten is in deze stroming een gevestigde notie, welke veelal wordt onderscheiden van de functionele waarde. Het baanbrekende werk van Everett Rogers levert een typologie van innovatie adopters op basis van wanneer ze adopteren, maar levert geen dynamisch model van innovatie diffusie in termen van endogene en exogene mechanismen.

Een derde stroming in de innovatie literatuur komt voort uit de sociologie en geschiedenis van de techniek, waarin auteurs de sociale context waarin een techniek is ontworpen en wordt gebruikt hebben benadrukt. Een kernbegrip is de sociale constructie van techniek (SCOT van Wiebe Bijker), waarbij techniek niet wordt gezien als een objectieve entiteit (zoals in economische en technische studies), maar wordt beschreven 'door de ogen van maatschappelijke groepen'. Deze auteurs laten zien hoe verschillende sociale interpretaties van een techniek, richting geven aan verschillende paden van technische ontwikkeling van die techniek.

Auteurs in de laatste twee stromingen hebben ook de interactie van technische en sociale factoren behandeld. Meest recent hebben Arie Rip en Rene Kemp co-evolutie van 'het sociale' en 'het technische' uitgewerkt, en daarmee de opkomst, transformatie en het verval van sociotechnische systemen geanalyseerd. Hun 'multi-level' model van innovatie onderscheid het macro niveau van het socio-technische landschap, het regiem op meso niveau en niches op het micro niveau. Frank Geels heeft de notie toegevoegd dat radicale innovaties voortkomen uit interactie tussen processen op deze drie niveaus. Dat wil zeggen: de doorbraak van een niche tot een regiem geschied geleidelijk, wanneer een nieuwe techniek zich vertakt en doordringt in verschillende toepassingsdomeinen, voordat het op de mainstream markt komt. Deze studies hebben, meer dan eerdere studies, het licht geworpen op patronen waarin gevestigde technieken soms worden verlaten en overvleugeld worden door nieuwe (voormalige niche) technieken. Een aantal innovatie onderzoekers heeft echter betoogd dat deze studies minder duidelijk zijn over waarom sommige niches 'succesvol' zijn in het groeien en omverwerpen van het regiem, terwijl (vele) andere niches een stille dood sterven. Interacties tussen niche en regiem worden belangrijk genoemd, maar deze interacties zijn nog weinig uitgewerkt in termen van processen en terugkoppeleffecten, zoals schaalvoordelen, leerprocessen en smaakvormingsmechanismen van consumenten. In dit proefschrift bieden we een co-evolutionair raamwerk aan wat de nadruk legt op terugkoppeleffecten en actor perspectieven.

In hoofdstuk 2 werken we ons co-evolutionaire raamwerk uit, voortbouwend op de brug tussen evolutionaire economie en sociologie van de techniek welke Rip, Kemp en Geels begonnen zijn. We ontwikkelen een micro-macro model (meer gebruikelijk in de economie), en laten dus het niche, regiem en landschap model even links liggen. Op ons micro niveau wordt de innovatie beschreven door de ogen van belanghebbenden ('stakeholders'), terwijl op het macro niveau aggregate indicatoren zoals totale verkopen en prijzen worden meegenomen. We nemen (groepen van) actoren als het basis element van de analyse, stappen in hun schoenen (op het micro niveau) en brengen hun mentale voorstellingen ('frames') en attitudes van de innovatie in 
kaart. We zien een frame als de manier waarop de innovatie wordt geïnterpreteerd door een actor. Vervolgens breiden we de notie van terugkoppeleffecten door schaal- en leerprocessen uit met de smaakvorming van consumenten, inclusief de sociale betekenis van een product. We bediscussiëren de voor- en nadelen van deze benadering voor de notie van co-evolutie. We beogen hiermee een bijdrage aan de co-evolutionare studies in de evolutionaire economie (in de Neo-Schumpeteriaanse traditie), alsmede aan co-evolutionaire benaderingen in het bredere veld van innovatie studies.

Voordat we in de kern van dit proefschrift twee verklarende gevalstudies uitwerken, waarbij het co-evolutionaire raamwerk wordt toegepast op de casus automotor en $P+R$, etaleren we de onderzoeksmethodologie (hoofdstuk 3). Verklarende gevalstudies (explanatory casestudies) zijn geschikt voor het toepassen van vooraf gedefinieerde raamwerken op een nieuwe casus, waarbij causaliteiten en verklarende waarde worden getest. Als input voor de gevalstudies analyseren we de frames van de meest relevante belanghebbenden, waarbij we een aantal andere onderzoeksmethoden gebruiken, zoals discours analyse (hoofdstuk 4) en vragenlijstenonderzoek (hoofdstuk 5 en 7). Aansluitend aan de verklarende gevalstudies ontwikkelen we toekomst scenario's, ondersteund door een simulatiemodel analyse (hoofdstuk 9).

Zo een combinatie van methoden heeft een aantal voordelen. Het gebruik van verschillende methoden in samenhang kan de kwaliteit en adequaatheid van een onderzoek aanzienlijk vergroten, en conclusies zijn vaak overtuigender als ze gebaseerd zijn op een aantal verschillende bronnen. Het combineren van methoden kan compenseren voor eenzijdigheid. In complexe kwesties leidt een enkele methode gemakkelijk tot een deelverklaring van een fenomeen, zoals in de parabel van de blinde mannen en de olifant. Het combineren van methoden brengt ook moeilijkheden met zich mee. Integratie van uitkomsten en kenniselementen is moeilijk wetenschappelijk te valideren, en methoden kunnen een zelfde bias hebben. Alhoewel een theorie over het gezamenlijk gebruik van verschillende onderzoeksmethoden nog in ontwikkeling is, nemen we in dit proefschrift resultaten uit een aantal methoden mee (als input) in onze gevalstudies, ten dienste van het begrip van de veelzijdige fenomenen van de opkomst van (hybride-)elektrische voertuigen en $P+R$.

In hoofdstuk 4 analyseren we hoe gebruikers van auto's de automotor 'framen' (dat wil zeggen: mentaal voorstellen). Automotoren zijn al meer dan 100 jaar gebaseerd op interne verbrandingstechniek; echter, in het laatste decennium zijn hybride-elektrische motoren succesvol geïntroduceerd. Het naast elkaar bestaan van een conventionele en onconventionele techniek doet de interessante vraag rijzen in hoeverre deze (technisch) verschillende motoren ook verschillend worden geframed, en hoe dit door de tijd heen verandert. Studies over technologische frames suggereren dat frames van gevestigde technieken meer star zijn. In dit hoofdstuk analyseren we technologische frames van drie type automotoren: de incrementele innovatie van de dieselmotor, de onconventionele elektrische en hybride-elektrische motor, en vervolgens bestuderen we hoe deze frames veranderd zijn tussen 1990 en 2005 . We vinden uit de analyse dat de motoren nogal verschillend worden geframed. Frames van de conventionele dieselmotor benadrukken motorvermogen (uitgedrukt in $\mathrm{kW}$ ), motorvolume (uitgedrukt in liter) en motorkoppel (uitgedrukt in $\mathrm{Nm}$ ), terwijl bij hybride motoren brandstofverbruik ( $\mathrm{km}$ per liter) op afstand het meest voorname attribuut is. Verder suggereren onze bevindingen dat het frame van de conventionele motor (diesel) meer stabiel is door de tijd dan een onconventionele motor (hybride en elektrisch), wat de hypothese uit eerder onderzoek bevestigt.

In hoofdstuk $\mathbf{5}$ analyseren we technologische frames van autobedrijven in de ontwikkeling van ultra schone voertuigen (zogenaamde ultra low emission vehicles, ULEV). We bekijken de frames van bedrijven door hun systeem van overtuigingen te onderzoeken, alsmede hun (door henzelf gestelde) daadwerkelijke toewijding aan de ULEV ontwikkeling. De centrale vraag is: welke overtuigingen dragen significant bij aan de toewijding aan de ontwikkeling van ULEVs? Een tweede vraag is in hoeverre we diversiteit hierin tussen de bedrijven in kaart kunnen brengen. 
We stappen dus in de schoenen van autobedrijven en analyseren hun zakelijke ('business'), technische, sociale en milieu overtuigingen. Om voldoende focus te verkrijgen in de analyse, concentreren we ons in dit hoofdstuk op waterstoftechniek, als een voorbeeld van een ULEV. Veel wetenschappers, industrie strategen en beleidsmakers zien waterstof als een belangrijke toekomstige energiedrager in transport. Uit onze studie blijkt dat verschillende bedrijven verschillend omgaan met de ontwikkeling van waterstof voertuigen. Grofweg kunnen drie groepen onderscheiden worden op basis van hun toewijding aan ULEV ontwikkeling: onzekere bedrijven, onwillige bedrijven, en optimistische bedrijven. Verder suggereren onze resultaten dat technische en organisatorische competenties gecorreleerd zijn aan de toewijding aan de ontwikkeling van waterstof voertuigen: bedrijven die hun capaciteiten hoger (lager) inschatten, zijn sterker (zwakker) geëngageerd in de ontwikkeling. Alhoewel bedrijven verschillende afwegingen maken rond waterstof, vinden we geen verschillen in de framestructuur van autobedrijven, dat wil zeggen het gewicht wat ze hangen aan economische kansen en milieuoverwegingen, etc. Alle bedrijven zijn onderdeel van een globale markt met scherpe concurrentie, en allen benadrukken ze daarom business opportunities, zowel op dit moment als in de toekomst. Een belangrijke vraag voor hen is daarom: verwachten en waarderen consumenten schonere motoren? Ten tweede is hun relatieve positie ten opzichte van concurrenten belangrijk. Tenslotte beïnvloeden sociale verwachtingen en druk op nieuwe (schone) techniek, zoals waterstof, hun R\&D uitgaven enigszins, terwijl emissie regulering een randvoorwaarde is waar aan voldaan moet worden (nu en in de toekomst).

In hoofdstuk 6 beschrijven en verklaren we de opkomst van elektrische motoren op de automarkt na 1990. Hybride-elektrische voertuigen hebben een significante groei laten zien in de afgelopen tien jaar. Dit is opmerkelijk, aangezien de automobiel sector een karakteristieke aversie heeft tegen radicale technische verandering van motoren. De interne verbrandingsmotor is immers al bijna 100 jaar dominant. In dit hoofdstuk geven we een veelzijdige beschrijving van hoe en waarom aandrijftechnieken zijn ontwikkeld en verkocht na 1990, waarbij we de twee lagen van het co-evolutionaire raamwerk volgen. Eerst concentreren we ons op de aggregate patronen (zoals verkoopaantallen en technische voortgang), terwijl in de volgende sectie de perspectieven van de meest relevante belanghebbenden beschreven worden (bedrijven, consumenten, beleidsmakers). Vervolgens worden voorgaande secties geïntegreerd in een coevolutionair raamwerk. We bediscussiëren de rol van technisch-economische mechanismen naast die van sociale mechanismen (inclusief de sociale betekenis van een motor), en de rol van beleid daarin. De co-evolutionaire analyse is nieuw in de integrale voorstelling van actor perspectieven, terugkoppeleffecten en competitie tussen producten. De analyse suggereert dat automotoren zijn ingesloten in een traject van de interne verbrandingsmotor ('lock-in') door padafhankelijkheid wat oorzaken heeft aan zowel de aanbod zijde, vraagzijde en de zijde van de regulering. Door een interactie van de vraag- en aanbodzijde hebben technisch-economische mechanismen stabiliteit of traagheid geboden aan het traject van de interne verbrandingsmotor ondanks de groeiende maatschappelijke aandacht voor duurzamer geachte alternatieven. In de jaren '90 bleef een opkomend innovatietraject van elektrische motoren aanvankelijk steken, toen elektrische voertuigen veelal duur en onpraktisch (als gevolg van hun kleine bereik) gevonden werden. Verschillende bedrijven waren onsuccesvol in het op de markt brengen van hun elektrische en hybride-elektrische voertuigen, zoals Peugeot/Citroen met verschillende elektrische modellen na 1995 en Audi met hun Duo in 1997. Echter, na 2000 kwam het traject weer op in de vorm van hybride-elektrische voertuigen, vooral door activiteiten van Toyota wat op zoek ging naar nieuwe markten voor hun competenties rond elektrische motoren, en gestimuleerd door het geleidelijk ontstaan van positieve sociale betekenis van hybrideelektrische technologie.

In hoofdstuk 7 bestuderen we hoe P+R wordt geframed door beleidsmakers, door middel van een vragenlijst die door 45 grote steden in Europa is ingevuld. In de stad zijn verkeersdrukte en 
kwaliteit van de lucht belangrijke kwesties voor de ruimtelijke planning. In de afgelopen jaren zijn Parkeer-en-Reis $(P+R)$ voorzieningen in toenemende mate geïntroduceerd door lokale overheden als een alternatief voor of uitbreiding op het parkeeraanbod in het centrum. We onderzoeken hoe $P+R$ als beleidsoptie wordt geframed in het bredere transportbeleid. Het hoofdstuk levert drie zaken op. Als eerste rapporteren we over het huidige adoptieniveau van $P+R$ in Europa. De resultaten laten zien dat $P+R$ vrij ongelijkmatig over het continent verspreid is. Een kwart van de steden is uitvoerig bezig met de ontwikkeling van $P+R$, terwijl een ander kwart weinig of niets met $\mathrm{P}+\mathrm{R}$ doet. Dit doet de vraag rijzen: als congestie in vrijwel alle steden een probleem is, waarom is de adoptie van $P+R$ dan zo ongelijkmatig? Daarom, als tweede, schetsen we de diversiteit in de manier waarop $P+R$ geframed wordt, door de overtuigingen rond $P+R$ in de verschillende steden expliciet te maken. We laten zien hoe divers beleidsmakers $P+R$ interpreteren. Ten derde analyseren we of sommige overtuigingen voornamer zijn dan anderen bij het besluit om $P+R$ te ontwikkelen. Een lineaire regressie analyse suggereert dat de economische implicaties van $P+R$, gepercipieerde vraag voor $P+R$ en de vaardigheden om als organisatie te leren de meest voorname factoren zijn voor locale overheden om wel of niet betrokken te zijn bij de ontwikkeling van $P+R$, omdat deze drie factoren zo'n $40 \%$ van de variantie in daadwerkelijke betrokkenheid verklaren.

Hoofdstuk 8 bestudeert de introductie van P+R en haar potentiële transformerende impact op stedelijke mobiliteit in twee van de landen met de hoogste bevolkingsdichtheid in Europa, Nederland en het Verenigd Koninkrijk, die te maken hebben met vergelijkbare stedelijke duurzaamheidproblemen. We bekijken drie voorbeelden van $P+R$ implementatie uit ieder land: Oxford, York en Bristol, Amsterdam, Rotterdam en Utrecht. Onze verklarende gevalstudie volgt de twee lagen van het co-evolutionaire raamwerk door $P+R$ te beschrijven vanuit het perspectief van de stadsoverheid en dat van de reizigers (micro niveau), en vervolgens door aggregate indicatoren zoals totale beschikbaarheid van parkeerplaatsen en parkeertarieven (macro niveau). Het raamwerk wordt toegepast om te bestuderen hoe en waarom $P+R$ wordt ontwikkeld in de zes steden en of de introductie van $P+R$ heeft bijgedragen aan een transitie naar een centrum met een lage (auto)verkeersintensiteit. Onze bevindingen laten zien dat alhoewel er in de meeste steden een verschuiving is geweest in beleid van het voorzien in meer parkeerplaatsen naar het verplaatsen van parkeerlocaties en het beïnvloeden van modaliteitkeuzes, er geen significante verlaging is te zien in de algemene parkeerintensiteit; $P+R$ heeft vooral geleid tot een uitbreiding van het parkeeraanbod.

In hoofdstuk 9 exploreren we toekomst scenario's van automotortechniek, ondersteund door een simulatiemodel. Waar hoofdstuk 4 tot 8 zich richten op het recente verleden, richten we ons nu op de vraag: wat zou er kunnen gebeuren? We ontwikkelen plausibele maar gesimplificeerde beschrijvingen van twee mogelijke toekomsten. Deze beschrijvingen betreffen zowel technischeconomische aspecten alsmede de vorming van sociale betekenis van een techniek. Om rekening te houden met de complexe en onzekere dynamica tussen de twee type fenomenen, gebruiken we een simulatie analyse. Hiertoe formaliseren we het twee-lagen raamwerk en maken we het op maat voor de casus van de automotor. Dit levert een model wat de co-evolutie van vraag en aanbod simuleert met als uitkomst verschillende mogelijke trajecten. We formaliseren stakeholder perspectieven gebaseerd op de empiri uit hoofdstuk 4, 5 en 6 . De voornaamste rol van het model is de analyse van de rol van sociale betekenis in de innovatie dynamica. Hiervoor wordt het model toegepast, zowel retrospectief als met het oog op de toekomst, om lessen te trekken over de rol van sociale betekenis. In het model is het gedrag van actoren expliciet gemodelleerd op basis van de actor frames, welke de waardering van de technische opties kleuren, zowel voor potentiële consumenten als producenten. Het model is analytisch vernieuwend omdat het vijf terugkoppelmechanismen meeneemt: schaal- en leervoordelen, interactief leren tussen producten en consumenten, endogene smaakvorming van consumenten, en de formatie van sociale betekenis. Het model wordt toegepast om 
toekomstige diffusie scenario's van automotoren te schetsen, terwijl het begint met het simuleren van de recente historie (ongeveer 20 jaar), inclusief de snelle diffusie van directe inspuitsystemen (voor diesels) en de langzame diffusie van elektrische voertuigen. De analyse suggereert dat het succes van (hybride-)elektrische voertuigen vooral afhangt van de mate waarin producenten hun onderzoek- en ontwikkelingswerk hierop richten (resulterend in een groter en kwalitatief verbeterend aanbod van (hybride-)elektrische modellen) en op het aandeel consumenten dat (hybride-)elektrische modellen hoger waardeert dan schonere diesels.

We hebben twee narratieve scenario's ontwikkeld. In het eerste scenario wordt de sociale betekenis van $(\mathrm{H}) \mathrm{EV}$ technologie wijdverbreid positief, terwijl ICE negatief wordt. Hier vinden we de gestage voortgang van de state-of-the-art van elektrische aandrijftechniek, welke binnen tien jaar de state-of-the-art van ICE inhaalt. $\mathrm{Na}$ de initiële adoptie van (hybride-)elektrische voertuigen in een beperkte groep groene consumenten, vind er bredere adoptie plaats na 2020. In het tweede scenario verwerven nieuwe ICE versies een vergelijkbaar positieve sociale betekenis als (H)EV. Hier blijft de state-of-the-art van ICE die van (H)EV vooruit, en na de adoptie van enkele (hybride-)elektrische modellen, schuiven zelfs de groene consumenten terug naar vernieuwde ICE modellen.

In hoofdstuk 10 analyseren we wat onze co-evolutionaire benadering leert over de rol van beleid in het innovatie proces in de twee cases. Er zijn twee voorname perspectieven op milieuen innovatiebeleid in de literatuur: het welvaartperspectief en het evolutionaire perspectief. We beargumenteren dat in onze twee cases beleidsinstrumenten vooral zijn toegepast vanuit een welvaartperspectief. In dit perspectief beogen instrumenten innovatie te stimuleren op een techiek-blinde manier, wat vooral leidt tot de adoptie van bestaande technieken en incrementele innovatie. In een (co-)evolutionair perspectief worden onconventionele technieken gezien als niches buiten het regiem en is het niet alleen de vraag of een instrument innovatie stimuleert, maar ook of het instrument innovatie stimuleert in het bestaande regiem of in een alternatief niche traject. Zo een vraag is nog niet systematisch onderzocht en heeft slechts gebrekkig aandacht gekregen van beleidsmakers.

We schetsen mogelijkheden voor evolutionair beleid om niche innovatie in onze twee cases te stimuleren. Als een rode lijn door het beleidsadvies in beide cases zit de suggestie voor de vorming van een sector platform, wat de innovatie dynamica in de sector kan beïnvloeden door:

- $\quad$ zich te richten op niche-regiem interactie: het coördineren van regiem beleid met bottomup (niche) initiatieven.

- $\quad$ rekening te houden met bestaande padafhankelijkheden, maar daarbij voorkomen opnieuw ingesloten te worden in suboptimale oplossingen, bijvoorbeeld door de ondersteuning van een portfolio van niches.

In hoofdstuk 11 worden de voornaamste bevindingen samengevat door het beantwoorden van de vijf onderzoeksvragen: (1) hoe kan het evolutionair economische perspectief verrijkt worden met SCOT? (2) Is een co-evolutionaire benadering relevant voor het bestuderen van de opkomst van $(H) E V$ en $P+R$ ? (3) Kunnen we consumenten frames en de sociale betekenis van innovaties meten en meenemen in computer simulaties en in historisch verklarende gevalstudies van sociotechnische verandering? (4) Leid het meenemen van concurrerende technieken in een diffusie model tot andere resultaten? en (5) Wat is de waarde van een co-evolutionair raamwerk voor beleid? Samengevat vinden we dat de belangrijkste waarde van een co-evolutionaire, micromacro benadering ligt in de integratie van consumenten en producenten en competitie tussen technieken. Daardoor helpt deze benadering het licht te werpen op de dynamica tussen consumenten (of: vraagstructuren) en producten (of: aanbodstructuren). Andere studies hebben de ontwikkeling van (H)EV en P+R ook behandelt, maar typisch met een nauwere focus; dan wel op het aanbod gericht met verwaarlozing van consumenten, dan wel vice versa.

Begrenzingen van onze methodologie liggen in de noodzaak voor een behoorlijke hoeveelheid micro niveau data (zoals gegevens over de actor frames en attitudes, liefst als tijdreeksen), wat 
voor vele gevallen vrij lastig te verkrijgen is. Ook is het moeilijk om de relatieve sterkte tussen de terugkoppelmechanismen te bepalen in iedere casus. Deze moeten waarschijnlijk gevonden worden door het raadplegen van experts of door participatieve sessies met belanghebbenden.

Onze benadering is minder succesvol in het belichten van de sociale en politieke dynamica binnen de lokale of (supra-) nationale overheid en binnen een autobedrijf. Meer dan een enkelvoudige en homogene organisatie is een overheidsorganisatie opgebouwd uit departementen (economische zaken, transport, milieu, etc.) alsmede een wetgevende en controlerende gemeenteraad of parlement, en deze staan allemaal onder invloed van lobby activiteiten door belangengroepen, hun achterban of beroepsgebruiken. Ook in bedrijven kunnen er verschillen van visie zijn tussen departementen (marktontwikkeling, onderzoek, milieuzaken, etc.) over wat de beste strategie is. In onze analyses hebben we deze dynamica weggelaten en enkel gekeken naar het beleid wat door de gemeenteraad werd goedgekeurd, of naar het investering- en productbeleid wat een autobedrijf voerde. In toekomstig onderzoek moet dit deel van het raamwerk beter uitgewerkt worden. Ook zullen leerprocessen en schaalvoordelen bij een locale overheid beter uitgewerkt moeten worden. Voor deze beide zaken zien we het co-evolutionaire raamwerk als een geschikt startpunt. 



\section{Dankwoord}

Het uitvoeren van een promotieonderzoek kun je niet alleen. Zelfs al heb ik het grootste deel van de afgelopen vijf jaar alleen doorgebracht achter mijn bureau op de Lenculenstraat met boeken en artikelen en een computer, toch is onderzoekswerk ook samenwerken. Juist in die samenwerking met medeonderzoekers en mensen uit de praktijk van de mobiliteitssector heb ik geleerd over innovatie, over de waarde en de grenzen van theorieën, en over de waarde en de grenzen van mijn eigen denken en onderzoeksmethoden. Daarom wil ik de mensen met wie ik samen heb mogen werken hier graag bedanken.

In de eerste plaats wil ik mijn promotor René Kemp bedanken, die mij gedurende het hele traject begeleid heeft. Je hebt me veel vrijheid gegeven in het zoeken naar een eigen lijn in het brede palet aan benaderingen in de innovatie en diffusie studies en dat heb ik erg gewaardeerd. Je bent kritisch op de inhoud van het werk en dat is de kwaliteit ten goede gekomen, ook al is het niet altijd leuk om kritiek te krijgen. Bedankt voor de begeleiding en de samenwerking, die we hopen voort te zetten in het nieuwe project.

In de tweede plaats wil ik al mijn collega's bij ICIS bedanken voor de goede werksfeer en de academische omgeving. Ik ervaar de breedte aan onderzoeksonderwerpen, persoonlijke achtergronden en onderzoeksmethoden als heel stimulerend en verfrissend. $\mathrm{Er}$ is denk ik zelfs nog meer potentie voor kruisbestuivingen tussen onze onderzoeken. Het is mooi dat we niet alleen collega's zijn, maar het ook goed met elkaar kunnen vinden.

Voor de inhoudelijke samenwerking wil ik in het bijzonder Pieter bedanken, met wie ik vele uren 'in' C++ en Anylogic heb doorgebracht.

Er zijn veel mensen uit de praktijk van de transportsector die ik heb mogen interviewen, of waar ik op een andere manier informatie van heb ontvangen die essentieel was om mijn onderzoek uit te kunnen voeren. Roland Roordink (Ford Nederland), Ingrid Paulus (Audi Ingolstadt), Dénis Depuis (Peugeot Parijs), Rick Batelaan (gemeente Amsterdam), Eric Arnold (gemeente Rotterdam), Niek Tijhuis (gemeente Utrecht) en vele andere respondenten van vragenlijsten of geïnterviewden (zie Appendix E) wil ik graag bedanken voor hun kostbare tijd.

Ook zijn er collega-onderzoekers in Nederland en daarbuiten met wie ik delen van dit onderzoek heb uitgewerkt. Juist in deze samenwerking heb ik gemerkt hoe veelzijdig de werkelijkheid is en hoe eenzijdig mijn onderzoek dreigt te zijn. Ik wil Carlos Montalvo (TNO Delft), Graham Parkhurst (UWE Bristol), Masaru Yarime (UT Tokyo), Renato Orsato (INSEAD Fontainebleau), Flor Avelino en Bonno Pel (beide EUR Rotterdam), Jorrit Nijhuis (WUR Wageningen), Desirée Verbeek (KUB Tilburg) en Janneke van Bakel bedanken voor hun stimulerende samenwerking.

Tenslotte ben ik dankbaar voor het stabiele thuisfront wat ik in Paulien heb, en voor de gezondheid en helderheid van denken die ik in de afgelopen vijf jaar ontvangen heb. Hier voor dank ik Hem die mij, jaren terug, geweven heeft in de schoot van mijn moeder (Psalm 139), inclusief mijn hersenen. Met het oog op dit laatste, maar ook met het oog op de personen die hierboven genoemd zijn, is er geen reden om mijzelf aan het eind van dit onderzoek op de borst slaan. Wel om blij te zijn dat het nu echt is afgerond, hoera! 


\section{About the author}

Marc Dijk (1977, the Netherlands) was educated as an engineer in aerospace at Delft University of Technology. He wrote his master thesis during an internship at the product development department of Jaguar Cars in Coventry, England, in 2001, where he compared the product development organisations of Jaguar and Volvo Cars (Sweden). After a summer program at the University of California (Berkeley) he completed a master program on Science and Technology Studies at Maastricht University. Marc started working as a junior researcher at TNO in 2003 and since 2005 he has been working as a PhD student at Maastricht University.

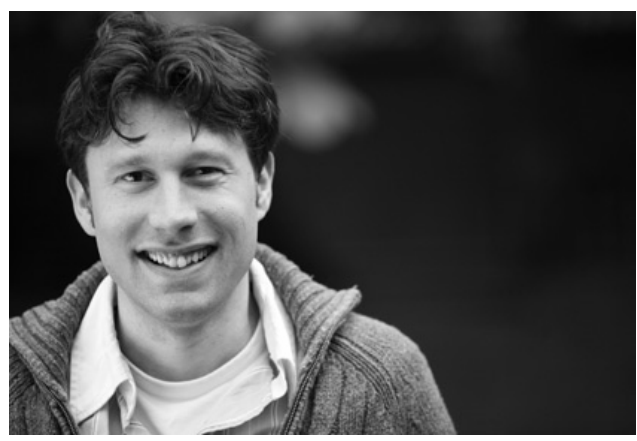

His research has focused on innovation in car mobility, combining a socio-technical and evolutionary economic perspective. His project was funded by the Knowledge network on System Innovation (KSI).

Next to his PhD project Marc was involved in the EU project Sustainability A-Test, which developed an overview of methods and tools to support policymakers working on sustainable development issues.

Furthermore he was responsible for education at the University College Maastricht, amongst others as a coordinator for a course on Integrated Assessment (Hands-on Sustainability Science) and as a tutor in the course Introduction to Sustainable Development. He also supervised various bachelor students in writing their theses.

Besides academic work Marc has worked for the last five years as a voluntary member of staff for the International Fellowship of Evangelical Students (IFES) in Maastricht. He organised a student conference on 'science and religion', introductory courses on Christianity (Alpha Course) and also advanced courses on reading the Bible. Marc is also a member of his church council. Since 2007 Marc is married to Paulien. They live in Maastricht and expect a child in July 2010. 